Universidad Politécnica de Valencia

Departamento de Ouímica

Instituto de Tecnología Química

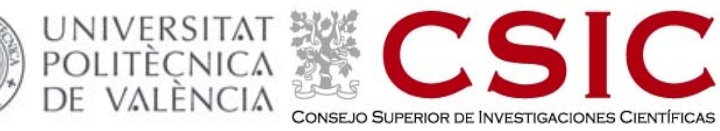

Hacia el desarrollo sostenible:

Líquidos lónicos como catalizadores para la transposición de Beckmann y reacciones

de formación de enlaces C-C

TESIS DOCTORAL

Presentada por: Raquel Montón Molina

Dirigida por: Dra. Sara Iborra Chornet 



\title{
Hacia el desarrollo sostenible: \\ Líquidos lónicos como catalizadores para la transposición de Beckmann y reacciones de formación de enlaces C-C
}

\section{MEMORIA}

\author{
Presentada por: \\ Raquel Montón Molina
}

Dirigida por:

Sara Iborra Chornet

DOCTORADO EN CIENCIA QUÍMICAS

Universidad Politécnica de Valencia

Departamento de Química Instituto de Tecnología Química

(UPV-CSIC) 



\section{INFORME FINAL}

Llegado el momento, solo resta agradecer, y puesto que no es algo a lo que una esté acostumbrada, me enfrento al problema de no saber qué decir... en todo caso y para que no se me olvide, diré MUCHÍSIMAS GRACIAS.

En primer lugar a Sara Iborra y a Avelino Corma por ser codirectores de este trabajo. Ella directa y explícitamente y él en la sombra pero de forma rotunda. Así mismo, he de agradecer por su apoyo, a Amparo Mifsud como gerente del ITO y a todos y cada uno de los investigadores del centro.

Muy especialmente agradezco el trabajo y la colaboración de Mercedes Boronat, Francesc Llabrés, C. Prestipino del ESRF en Grenoble, Teresa Blasco, Inés Lezcano, José Juan Calvino de la Universidad de Cádiz, Pablo Botella, María José Climent y María José Sabater.

A la gente de administración le he de agradecer que hayan sido intermediarias de todo proceso burocrático y que lo hayan hecho tan bien. Del mismo modo que a las chicas de caracterización y a los chicos de taller, porque en la mayoría de los casos, que nuestro trabajo esté bien hecho, pasa por que el de ellos esté bien y a tiempo.

Gracias a los que desde el principio han estado en los momentos de pitanza y refrigerio, dentro y fuera del italiano o en el coffee, pueden tener por seguro que guardo de esos momentos recuerdos imborrables.

En cuanto a todos los que habéis pasado por la primera planta durante mi larga estancia, que sepáis que, en este trabajo, habéis contribuido haciendo que mi día a día fuera divertido, diferente y siempre estimulante, por eso, no solo os doy las gracias si no que os debo una. También debéis saber que si hay algo que se echa de menos cuando dejas de ser ITO, no es el olor, ni la sala de gases, ni las colas en los ordenadores, lo que de verdad se echa de menos es a la gente, la que ha estado a tu lado, la que sabe de memoria tus gustos y tus debilidades / de hecho se saben hasta mi top ten de frases hechas!!!!) a Laurita, María, Raül, Carmen y Pablo mil gracias por haber estado siempre ahí (aunque estuvieramos enfadados).

Y una vez fuera, lo que me queda es un montón de gente a la que debo agradecer, empezando por mi idolatrado quinteto: "La estrella del Real” Jose San, "el elegante por detrás y por delante" Toni Cuen y "la joven pareja” Ana Lluch y Héctor "el chileno" porque cada uno de vosotros sois representantes absolutos de lo que se puede desear al pensar en un amigo y porque YOUR SMILES MAKE ME SMILE. 
A las chicas del San Peter por ser tan tolerantes con el tipo de amistad que les profeso, que soy un poco como el Guadiana, lo sé. Y a las chicas de Villar por estar en mi vida desde los principios.

A los del orfe, los de "siempre", los de "a veces" y los de "ahora" que seguro acabarán siendo de siempre, pues ellos hacen del ente, una realidad en la que solo importa la música y pasárselo bien. Y a los de Helcano por la amistad y la pasta.

A mi familia Erasmus: Patricia "la Zsa-zsá", Pedro Javier Rodríguez Cantó y Gemma Bret Palazülo "la chica de las manos de anuncio"... y a los que llegaron luego, Paquito, Anna y Jaime, simplemente porque me encantáis.

Debo también agradecer al grupo de trabajo en Alemania: Kai Peters "mi betreuyer", Prakash "el cuidador", Kinga "la polaca", Frank Heinemann "el de los cristales" y al profesor Sellmann esté donde esté, porque ellos fueron los que me introdujeron en el maravilloso mundo de la investigación científica.

Y finalmente a mi familia porque sin vosotros no sería lo que soy, y porque con vosotros me siento una auténtica mosquetera, somos todos para uno y uno para todos. 
"Los problemas más importantes y urgentes de la tecnología de hoy, no son tanto la satisfacción de las necesidades primarias o de los deseos arquetípicos, como la reparación de los males y daños forjados por la tecnología de ayer"

Dennis Gabor

1900-1979 



\section{Índice}

1.1.- Desarrollo Sostenible .............................................................................................. 1

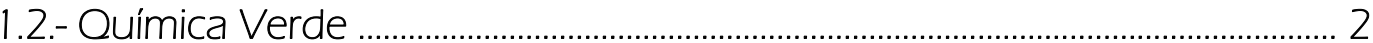

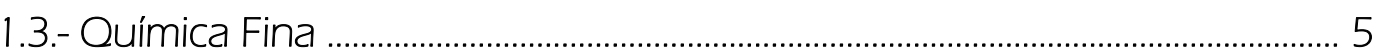

1.4- Catálisis, Catalizadores y Procesos ..................................................................... 7

1.5.- Otras alternativas catalíticas: Líquidos iónicos ...................................................... 9

1.5.1.- Breve desarrollo histórico ................................................................. 9

1.5.2.- Síntesis de Líquidos iónicos .............................................................. 15

1.5.2.1.- Reacciones de cuaternización ..................................... 15

1.5.2.2.- Reacciones de intercambio aniónico .............................18

- Con ácidos de Lewis

- Metátesis de aniones

1.5.3.- Síntesis "a la carta" de líquidos iónicos .......................................... 21

1.5.3.1.- Proceso general de síntesis de TSILS ......................... 22

- Cationes funcionalizados: Ejemplos y usos ........... 23

- Aniones funcionalizados ............................................ 24

- Líquidos iónicos bifuncionales .................................. 25

1.5.4.- Reciclado de LI ................................................................................... 26

1.5.5..- Propiedades Físico-Químicas de los LI ....................................... 27

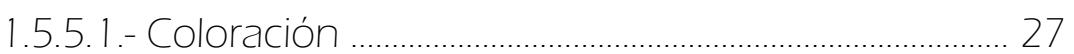

1.5.5.2.- Punto de Fusión ........................................................... 28

1.5.5.3.- Estabilidad térmica y Presión de vapor ..................... 30

1.5.5.4.- Densidad ................................................................. 30

1.5.5.5.- Viscosidad ........................................................................ 31

1.5.5.6.- Solubilidad, miscibilidad y solvatación ...................... 32

1.5.5.7.- Potencial electroquímico y conductividad .............. 33

1.5.5.8.- Toxicidad ...................................................................... 34

1.5.6.- Aplicaciones de los LI ............................................................................ 34

1.5.6.1- Líquidos iónicos en la industria ..................................... 34

1.5.6.2.- Otras aplicaciones de LI ................................................ 38

Líquidos iónicos en investigación .............................. 38

1.5.6.2.1.- Biocatálisis ..................................................... 38

1.5.6.2.2.- Sintesis de Polímeros ................................... 39

1.5.6.2.3.- Síntesis Inorgánica ........................................ 41

1.5.6.2.4- Síntesis Orgánica .......................................... 42 
CAPÍTULO II: Objetivos ............................................................................................. 55

CAPÍTULO III: Transposición de Beckmann con líquidos iónicos .......................... 57

3.1.- Introducción ........................................................................................................ 59

3. 1.1.- Transposición de Beckmann. Historia de un proceso .............. 59

3.1.2.- Mecanismo de la transposición de Beckmann de la ciclododecanona oxima .......................................................................... 64

3.2.- Obtención de $\omega$-laurolactama. Transposición de Beckmann ..................... 65

3.2.1.- Influencia del líquido iónico empleado .........................................65 65

3.2.2.- Estudios realizados por RMN ......................................................68

3.2.3.- Optimización de las condiciones de reacción ............................. 75

- Variación de la temperatura de reacción

- Variación de la concentración de oxima

3.2.4.- Reusos de los líquidos iónicos .................................................... 78

3.3.- Conclusiones ……………………………………………………………………………...... 79

CAPITULO IV: Síntesis y caracterización del material híbrido

Polioxometalato-Líquido iónico-Paladio (POM-IL-Pd) ................... 81

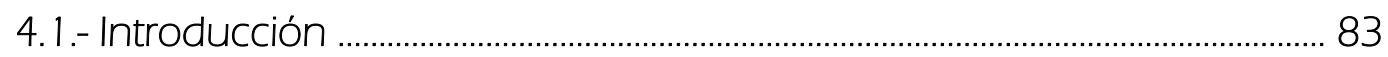

4.1.1.- Materiales híbridos orgánico-inorgánicos ..................................83 83

4.1.2.- Reacciones de acoplamiento Carbono-Carbono ....................... 86

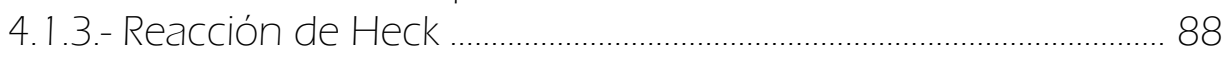

4.2.- Caracterización del material POM-IL-Pd ............................................................. 90

4.2.1.- Por microscopía electrónica .............................................................90 90

4.2.2.- Por espectroscopía de absorción de rayos X .............................. 93

4.3.- Estudio de la actividad catalítica del material POM-IL-Pd ..............................101

4.3.1.- Estudio de la influencia del disolvente

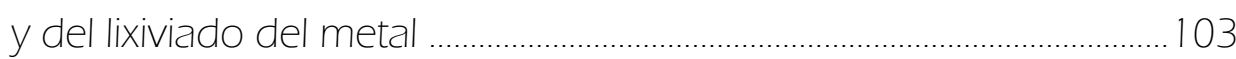

4.3.2.- Estudio de la estabilidad del catalizador .......................................106

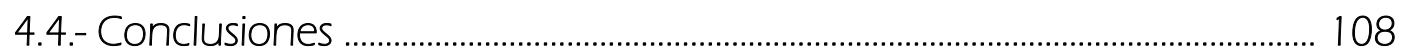

CAPÍTULO V: Líquidos iónicos con bifuncionalidad ácido-base como organocatalizadores en la reacción de Knoevenagel. Estudio de su aplicación en síntesis de cumarinas e iminocumarinas 
5.1.- Introducción .................................................................................................... 111

5.1.1.- Líquidos iónicos bifuncionales. Catálisis cooperativa ............ 113

5.2.- Resultados y discusiones ............................................................................... 118

5.2.1.- Estudio de la actividad catalítica .................................................. 118

5.2.2.- Estudio computacional del mecanismo de reacción ............ 124

5.2.3.- Estudio cinético de la reacción ................................................... 132

5.3.- Sintesis de cumarinas e iminocumarinas ......................................................... 138

5.3.1.- Introducción ..................................................................... 138

5.3.2.- Estudio de la actividad catalítica .......................................... 141

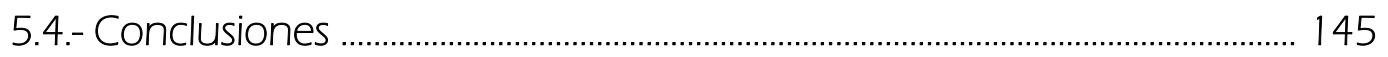

CAPÍTULO VI: Líquidos iónicos con bifuncionalidad ácido-base como organocatalizadores en la síntesis de trans-chalconas .............. 147

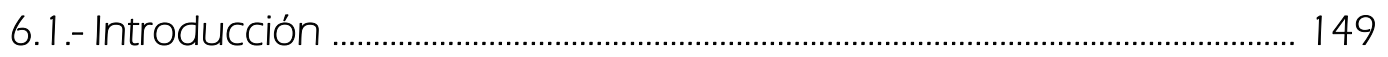

6.2.- Resultados y discusiones sobre la síntesis de trans-chalconas ................ 151

6.2.1.- Estudio de la actividad catalítica ............................................. 151

6.2.2.- Estudio del reuso del catalizador .............................................. 156

6.2.3.- Estudio computacional del mecanismo de reacción ............ 157

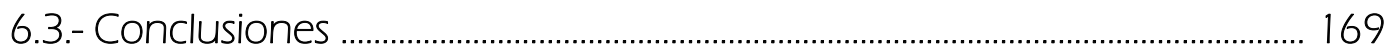

CAPÍTULO VII: Líquidos iónicos con bifuncionalidad ácido-base como organocatalizadores en adiciones de Michael y síntesis de 1,3-dinitroalcanos en un proceso multietapa

7.1.- Adición de Michael ........................................................................................................ 173

7.2.- Proceso multietapa ................................................................................................... 178

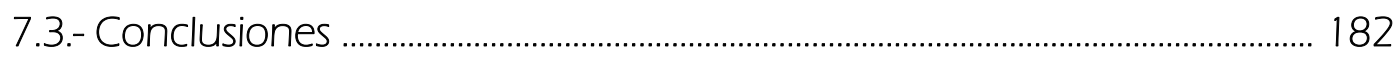

CAPÍTULO VIII: Procedimientos experimentales ...................................................... 185

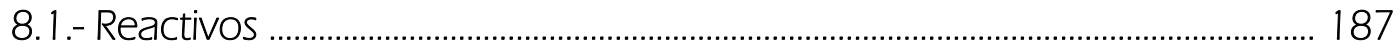

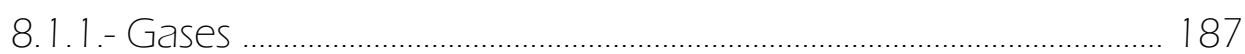

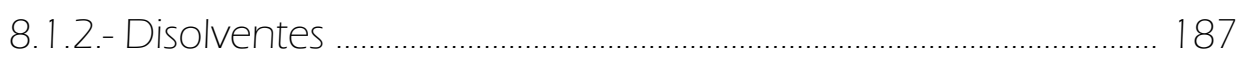

8.1.3.- Líquidos iónicos comerciales .......................................................... 188

8.1.4.- Reactivos ..................................................................................... 188 
8.2.- Técnicas de caracterización .................................................................................. 190

8.2.1.-Análisis químico ................................................................ 190

8.2.2.- Análisis termogravimétrico ............................................................. 191

8.2.3.- Espectroscopía de resonancia magnética nuclear (RMN) .... 192

8.2.4.- Espectroscopía infrarroja por transformada de Fourier

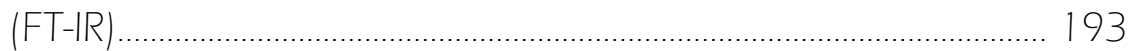

8.2.5.- Técnicas de microscopía electrónica de barrido (SEM) y de transmisión (TEM) .................................................................. 194

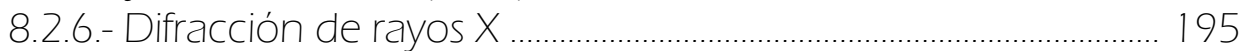

8.2.7.- Espectroscopía fotoelectrónica de absorción de rayos $X$ :

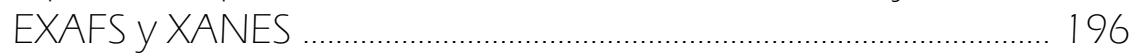

8.2.8.- Otras técnicas de caracterización ................................................... 197

8.3.- Técnicas de identificación y cuantificación de productos ........................... 198

8.4.- Estudios computacionales ....................................................................................... 198

8.5.- Preparación de catalizadores ............................................................................ 199

8.5.1.- Catalizadores derivados de sales de Keggin .............................. 199

8.5.1.1.- Sintesis de $\mathrm{H}_{5} \mathrm{PO}_{40} \mathrm{~V}_{2} \mathrm{MO}_{10} \cdot 27 \mathrm{H}_{2} \mathrm{O}$ (POM)

8.5.1.2.- Sintesis de $[\mathrm{bmim}]_{4} \mathrm{HPO}_{40} \mathrm{~V}_{2} \mathrm{MO}_{10}$ (POM-LI)

8.5. 1.3.- Sintesis de $\mathrm{Pd}_{0,5} \mathrm{H}_{4} \mathrm{PO}_{40} \mathrm{~V}_{2} \mathrm{MO}_{10}$ (POM-Pd)

8.5. 1.4.- Sintesis de $[\mathrm{bmim}]_{4} \mathrm{Pd}_{0,5} \mathrm{H}_{4} \mathrm{PO}_{40} \mathrm{~V}_{2} \mathrm{Mo}_{10}$ (POM-LI-Pd)

8.5.2.- Líquidos iónicos bifuncionales 203

8.5.2.1.- Sintesis de Tetrafluoroborato de

1-Piperidina-1-metil-piperidinio [Diamina-A]BF 4

8.5.2.2.- Sintesis de Tetrafluoroborato de

1-Piperidina-1-etil-piperidinio [Diamina-B]BF 4

8.5.2.3.- Síntesis de Tetrafluoroborato de

$\mathrm{N}$-Metilpiperidinio [N-Metilpiperidina] $\mathrm{BF}_{4}$

8.5.2.4.- Síntesis de Cloruro de

1-Piperidina-1-metil-piperidinio [Diamina-A]Cl

8.5.2.5.- Síntesis de Trifluorometanosulfonimidato de

1-Piperidina-1-metil-piperidinio [Diamina-A] $N\left(\mathrm{CF}_{3} \mathrm{SO}_{2}\right)_{2}$

8.5.2.6.- Síntesis de Tetrafluoroborato de

1-Piperidina-1-propil-piperidinio [Diamina-C] $\mathrm{BF}_{4}$

8.6.- Procedimientos generales de reacción

8.6. 1.- Transposición de Beckmann con L.I 205

8.6.1.1.- Sintesis de ciclododecanona oxima

8.6.1.2.- Reacción de transposición de Beckmann

A.- Procedimiento 
B.- Identificación de productos

8.6.1.3.- Experimentos in situen RMN de sólidos

8.6.2.- POM-IL-Pd 208

8.6.2.1.- Reacción test: Heck
A.- Procedimiento
B.- Identificación de productos

8.6.3.- Líquidos lónicos bifuncionales 209

8.6.3.1.- Reacción de Knoevenagel

A. 1.- Procedimiento general de reacción

de Knoevenagel

A.2.- Identificación de productos

B. 1.- Procedimiento de síntesis de

cumarinas e iminocumarinas

B.2.- Identificación de productos

8.6.3.2.- Reacción de acetalización

A.- Procedimiento

B.- Identificación de productos.

8.6.3.3.- Reacción de condensación aldólica

Síntesis de trans-chalconas

A.- Procedimiento

B.- Identificación de productos

8.6.3.4.- Adición de Michael

A.- Procedimiento

B.- Identificación de productos

8.6.3.5.- Reacciones multietapa

A.- Procedimiento

B.- Identificación de productos

Anexo I: Índice de figuras 223

Anexo II: Índice de tablas 228

Anexo III: Índice de Esquemas 233

Anexo IV: Abreviaturas y Acrónimos ................................................. 237

Anexo V: Cálculos 241

Resúmenes 239 

Capítulo l:
Introducción 

Durante las últimas décadas, la degradación ambiental se ha ido convirtiendo en un problema mundial. El desarrollo económico, tecnológico y social han puesto en jaque la preservación de la Tierra como lugar donde poder vivir, de modo que a partir de mediados de los años ochenta, la protección del medio ambiente ha pasado a ser un objetivo más del desarrollo, de no ser así, los excesos de contaminación y la sobreexplotación de recursos se convertirán, en un futuro, en la mayor barrera para el propio desarrollo.

\section{1}

\section{Desarrollo sostenible}

1987 es el año en que comienza a darse forma a lo que hoy en día conocemos como desarrollo sostenible. Se presenta en la Comisión Mundial sobre Medio Ambiente y Desarrollo el documento "Our Common Future" (Informe Bruntland) (WCED, 1987)1, en el que se plantea «un nuevo modelo de desarrollo que suponga el progreso humano sostenido no solamente en unos pocos lugares durante unos pocos años, sino para todo el planeta en un futuro lejano»> (WCED, 1987). Además en este documento se postula la que hoy consideramos primera definición de desarrollo

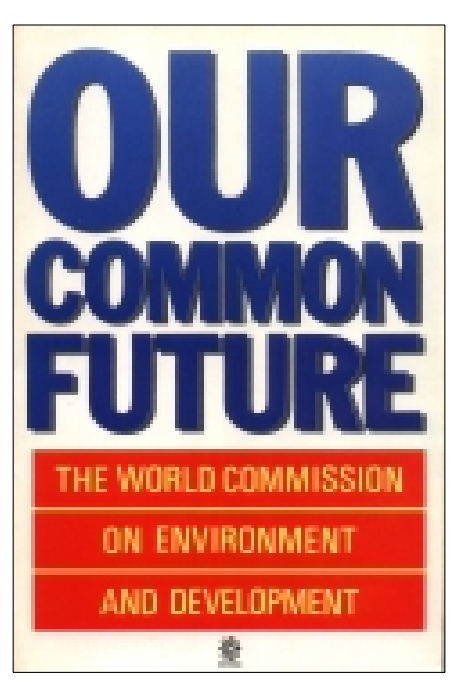
sostenible: «El desarrollo sostenible es aquel que satisface las necesidades actuales sin poner en peligro la capacidad de las generaciones futuras de satisfacer sus propias necesidades, lo que incorpora dos conceptos clave: el concepto de "necesidades", en particular las necesidades esenciales de los más pobres del mundo, a los que debe concederse la mayor prioridad, y la idea de limitaciones impuestas por el estado de la tecnología y la organización social sobre la capacidad del medio ambiente para satisfacer las necesidades presentes y futuras >.

La primera parte de la definición, aunque restringida, es hoy en día reconocida como definición canónica del desarrollo sostenible, pero es en la segunda parte, la de los dos conceptos clave y en particular el segundo concepto,

\footnotetext{
${ }^{1}$ World Commission on Environmental and Development. "Our Common Future". Oxford University Press. 1987.
} 
el que se ha considerado especialmente interesante en el ámbito científico, ya que cualquier tipo de desarrollo se entiende como un proceso de adaptación y aprendizaje, en el que el conocimiento debe tener un papel central. En el caso del desarrollo sostenible, la ciencia y la tecnología son decisivas para conseguir los requisitos que se establecen en las directrices de la sostenibilidad (término mediador aceptado tanto por teóricos desarrollistas como ambientalistas). De este modo, a partir de la Cumbre de Johannesburgo de 2002, se establece que la comunidad científica, además de continuar con su actividad identificadora de problemas ambientales y de recursos, debe establecer líneas de investigación que se acerquen, en la medida de lo posible, al desarrollo sostenible, ya que hasta el momento, el trabajo científico había estado mucho más direccionado hacia la parte del "desarrollo" que hacia la parte "ambiental" 2 .

El octavo principio de la Declaración de Río (Cumbre de Río) ${ }^{3}$ propone que "para conseguir el desarrollo sostenible y así una mayor calidad de vida para todo el mundo, los Estados deben reducir y poco a poco eliminar toda forma de producción que sea insostenible." Y el capítulo 35.2 de la Agenda 21, desarrollada en esa misma cumbre, concluye que "las ciencias en general son consideradas la única vía factible hacia la consecución del desarrollo sostenible."

Evidentemente, aunque la mención es general para todos los ámbitos científicos, la química tiene un papel muy importante en la sostenibilidad y en parte debe liderar la evolución hacia una civilización sostenible.

\section{2 \\ Química Verde}

La Química Verde se suele definir como la aplicación de la ciencia y la manufactura químicas de manera sustentable, segura, no contaminante, consumidora de cantidades mínimas de materia y energía y productora de poco o ningún material de desecho. Así pues, la química y la ingeniería química se pueden considerar verdes cuando modifican o rediseñan totalmente procesos y productos químicos, con el objetivo de minimizar los residuos y el uso o generación de materiales potencialmente peligrosos.

${ }^{2}$ Erias Rey A., Álvarez-Campana Gallo J.M. “Evaluación ambiental y desarrollo sostenible”. Ed. Pirámide. 2007.

${ }^{3}$ Report of the United Nations Conference on Environment and Development, Río de Janeiro, 1992. 
Si bien la definición de química verde parece bastante concisa, en realidad se trata de una disciplina que está en continua evolución, ya que congrega un gran número de subdisciplinas y conocimientos, que se aplican a la producción, el uso, el vertido y la disposición final de productos químicos, haciendo que se minimice el consumo de materiales, el daño ambiental, las sustancias tóxicas y ante todo la exposición de organismos vivos; además de buscar la rentabilidad económica. Se podría decir que la química verde es la forma más eficaz y menos costosa de la práctica química.

El término "química verde" fue propuesto originalmente por los profesores P. Anastas y J.C. Warner en el libro "Green chemistry: Theory and Practice" ${ }^{\prime \prime}$. En él se incluyen los doce principios de la química verde que son hoy por hoy la clave para conseguir la sostenibilidad simultánea en los ámbitos medioambiental, económico y social.

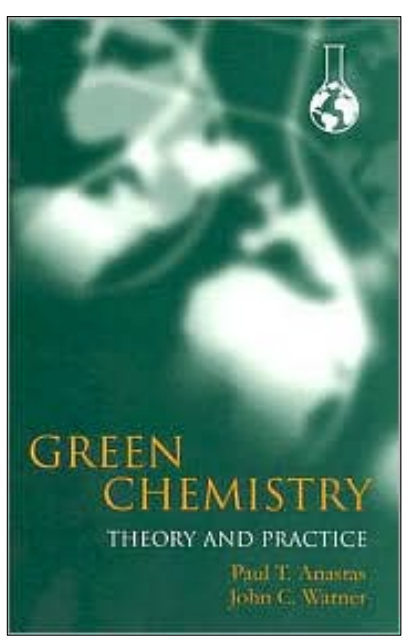

Posteriormente N. Winterton propuso “Doce Principios más sobre Química Verde" 5 con el propósito de introducir una aproximación cuantitativa que permitiera comparar las múltiples alternativas que se presentan para un proceso químico y determinar el potencial impacto medioambiental de cada una de ellas. En definitiva se trata de la evaluación sistemática y objetiva de los procesos, para así encontrar los más sostenibles.

Desde el punto de vista científico-social, la aplicación de la Química Verde se extiende día a día con la creación de organismos, redes, instituciones, revistas y programas educativos 6 . En 1993 se creó en E.E.U.U el “US Green Chemistry Program" dando pie a la celebración anual de la conferencia "Green Chemistry and Engineering Conference". Con el objetivo de promover la investigación, educación y expansión de la Química Verde se creó poco después el "Green Chemistry Institute"

Australia, Japón, Italia y Reino Unido, también han creado instituciones para el desarrollo de la química dentro del ámbito de la sostenibilidad. De hecho, en Italia, se generó un consorcio interuniversitario (INCA) con la Química

\footnotetext{
${ }^{4}$ Anastas P.T., Warner J.C. "Green Chemistry: Theory and Practice". Oxford University Press. New York, 1998.

${ }^{5}$ Winterton N., Green Chem., 2001, 3, G73-G75.

${ }^{6}$ Lancaster M."Green Chemistry: An introductory Text". 2002, 310.
} 
Verde como eje central de sus intereses; y la "Royal Society of Chemistry" (RSC) lanzó en 1999 la revista de investigación "Green Chemistry" que ha llegado a alcanzar índices de impacto superiores a los de la mayor parte de revistas de la RSC.

En España el interés por la Química Verde ha sido disperso y siempre ha estado vinculado a otros objetivos como la biotecnología medioambiental, el desarrollo de polímeros biodegradables o el desarrollo de nuevos catalizadores más selectivos, todo ello dentro del programa de Química Industrial o del de Tecnología Química.

De todos modos, las leyes de la Unión Europea (UE) para la protección del medio ambiente, están obligando a las empresas europeas a desarrollar procesos más respetuosos con el medio. La potenciación de los objetivos de la Química Sostenible por parte de la UE, viene marcada por la introducción continuada del concepto de desarrollo sostenible en todos los apartados considerados dentro del FP6 ("Six Framework Programme for Research and Technological Development").

El actual interés por la Química Verde refleja un cambio de rumbo desde la situación ambiental anterior, de "dominio y control" que implicaba un continuo tratamiento de residuos y un control bajo regulaciones, hacia la búsqueda de nuevas tecnologías mucho más limpias y económicamente rentables, basadas en la prevención. Con estas nuevas tendencias se pone de manifiesto el poder y la belleza que entraña la química, ya que es capaz de, a través de continuos y cuidados cambios, producir los productos que necesita la sociedad, pero salvaguardando el medio en el que se vive.

Es evidente que los beneficios económicos reportados por el desarrollo de la Química Verde son el sostén principal del propio desarrollo. Conforme se reducen los productos de desecho, el tratamiento de éstos así como su almacenamiento se hacen innecesarios y por tanto se reducen gastos. Evitar el uso de disolventes o reactivos intermedios aumenta la eficiencia material de los procesos $^{7}$ a la vez que los hace menos costosos y el empleo de catalizadores ofrece numerosos beneficios, entre otros un ahorro energético que indudablemente, tal y como están las cosas, es una gran contribución a la reducción de coste de los procesos industriales. 


\section{3}

\section{Química Fina}

Con el término Química Fina se designa a un tipo de producción muy especializada que genera compuestos de alto valor añadido, normalmente orgánicos, con estructuras complejas, polifuncionales, que suelen contener heteroátomos $(\mathrm{O}, \mathrm{S}, \mathrm{N}, \mathrm{P}$, etc.) y que se producen en volúmenes limitados 20-400 Tm/año. (Tabla 1.1)

La fabricación de productos de química fina y más concretamente de compuestos farmacéuticos y agroquímicos puede caracterizarse por8:

a Implicar síntesis largas con múltiples etapas (5-10 etapas según productos).

× Producir moléculas orgánicas con limitada estabilidad (isómeros, moléculas funcionarizadas).

x Generar productos de corta vida media (no suelen perdurar más de 20 años en mercado).

x Síntesis que se realizan en disolución, a presión ambiente y temperaturas bajas. Se suele trabajar en reactores discontinuos con volúmenes relativamente pequeños (500 L-10 m³).

ser necesaria una pureza extremadamente alta en los productos finales.

* El valor añadido de los productos finales

RESUMEN DE LAS PRINCIPALES CARACTERISTICAS

DE LA QUÍMICA FINA

- Moléculas

Complejas.

Con varios grupos funcionales.

Con estabilidad térmica limitada.

Con corto tiempo de desarrollo.

- Procesos

De varias etapas.

Con reacciones orgánicas

clásicas.

Con reactores en discontinuo.

Con reacciones en disolución.

- Catalizadores

Muy selectivos.

Activos a bajas temperaturas

Útiles para varios procesos.

De tecnología sencilla. es considerablemente alto, lo que en gran medida justifica los altos costes del proceso de producción.

* Generar grandes cantidades de productos de desecho, que deben ser tratados o reciclados siempre que sea posible. 


\begin{tabular}{lcc}
\hline & Productos de Química Fina & Productos a gran escala \\
\hline Producción anual $(\mathrm{Tm})$ & $10^{2}-10^{4}$ & $10^{4}-10^{5}$ \\
Precio $(\$ / \mathrm{kg})$ & $10-100$ & $1-10$ \\
Tiempo de I+D (años) & $0-6$ & $5-10$ \\
Ganancias (millones $\$$ ) & $1-100$ & $50-500$ \\
\hline
\end{tabular}

Tabla 1.1.- Comparativa entre Química Fina y a gran escala.

Uno de los conceptos surgidos a raíz de los principios de la Química Verde ha sido el factor $\mathrm{E}$, que relaciona la cantidad de material de desecho generado, por cantidad de producto obtenido en un proceso $(\mathrm{kg}$ material de desecho / kg Producto de interés). En la Tabla 1.2 se muestra la magnitud del problema en los distintos ámbitos de la Química Industrial; muy al contrario de lo que cabría pensar, las industrias farmacéutica y de Química Fina son las que relativamente más productos secundarios generan. Los valores de factor $\mathrm{E}$ tan grandes para este tipo de procesos, son debidos a la necesidad de varios pasos de síntesis, al uso de catalizadores homogéneos en proporción estequiométrica y a la necesidad de emplear etapas de neutralización y aislamiento del producto final.

\begin{tabular}{ccc}
\hline Industria & Volumen de Producción (Tm) & Factor E \\
\hline Refinería & $10^{6}-10^{8}$ & 0.1 \\
Productos a gran escala & $10^{4-10^{6}}$ & $1-5$ \\
Química Fina & $10^{2}-10^{4}$ & $5-50$ \\
Farmacéutica & $10-10^{3}$ & $25-100$ \\
\hline
\end{tabular}

Tabla 1.2.- Factor E de las diversas industrias químicas.

Cuanto mayor es el factor E, mayor cantidad de productos de desecho y consecuentemente mayor impacto medioambiental. Evidentemente el ideal de "comportamiento verde" supondría un factor E cero, lo que implicaría que todos los materiales que intervienen en un proceso, quedaran integrados en el producto final.

Sin embargo, no solo es importante considerar la cantidad de subproductos generados, sino también la naturaleza y grado de toxicidad de los reactivos utilizados, así como de los desechos finales, ya que las legislaciones vigentes en países desarrollados son muy exigentes en lo relativo al vertido de 
efluentes, residuos sólidos, transporte, almacenamiento y uso de reactivos peligrosos y nocivos para el hombre y el medio ambiente. De hecho, para hacer una evaluación real de los procesos industriales, se utiliza un factor de impacto $\mathrm{Q}$, que gradúa la agresividad hacia el medio ambiente de un reactivo, multiplicado por el Factor E. Como resultado se obtiene un Factor Medioambiental EQ9.

$\mathrm{EQ}=(\mathrm{kg}$ residuo $/ \mathrm{kg}$ producto) $\times$ (agresividad medioambiental)

El factor de impacto $Q$ se determina a partir de las frases $R$ de cada uno de los compuestos empleados y del impacto medioambiental que supone su producción, éste a su vez, se cuantifica a partir de los precios de mercado de los productos, puesto que un aspecto importante del desarrollo sostenible es que los precios de los productos deben reflejar todos los costes, no solo económicos sino también medioambientales y sociales. $\mathrm{Y}$ finalmente, el factor de impacto $\mathrm{Q}$ también considera la potencial eco y biotoxicidad.

\section{4}

\section{Catálisis, Catalizadores y Procesos}

Los principios de la Química Verde consideran la catálisis una de las herramientas más importantes para la consecución de los objetivos marcados por los propios principios. El empleo de catalizadores en las reacciones químicas consigue que éstas se puedan llevar a cabo con menor aporte energético, que se aumente la selectividad y así que sean menores los residuos derivados del proceso y finalmente, que en general, los procesos sean menos tóxicos y más seguros.

La catálisis homogénea y la heterogénea son consideradas ámbitos diferentes de un mismo tema y de hecho tradicionalmente se han estudiado por separado. Mientras que los catalizadores homogéneos se preparan mediante síntesis orgánicas y tienen centros activos muy bien definidos, que permiten

\footnotetext{
9 Trost B.M., Science, 1991, 254, 1471.
} 
conocer perfectamente los mecanismos de reacción, los catalizadores heterogéneos necesitan de síntesis orgánico-inorgánicas que dan como resultado materiales sólidos con estructuras muy interesantes, pero mucho más complicadas de entender a nivel mecanístico. La tendencia actual en catálisis consiste en ir acercando poco a poco las dos vertientes.

Aproximadamente el 95\% de los catalizadores heterogéneos empleados en la industria, son usados para procesos petroquímicos y solo entre un 3-5\% en la industria de la Química Fina ${ }^{10}$. En los últimos 20 años se han multiplicado las regulaciones medioambientales y con ello la necesidad de planteamientos alternativos en las distintas tecnologías industriales. Uno de los casos más evidentes es el desarrollo de nuevos catalizadores, más eficientes, más selectivos y que permitan que la producción se encuentre dentro de esas regulaciones ${ }^{11}$.

La producción de intermedios orgánicos y productos de Química Fina se lleva a cabo, en su mayoría, utilizando catalizadores homogéneos (ácidos o bases tipo Brønsted o Lewis) en proporciones estequiométricas, lo que genera una gran cantidad de productos de desecho, además de una serie de inconvenientes como son:

๙ Problemas de corrosión de sistemas (tubos, reactores...)

« Neutralización de los catalizadores con la problemática de acumulación de grandes cantidades de sales inorgánicas como productos de desecho.

\& Imposibilidad de reciclaje de los catalizadores.

Bajo estas perspectivas, resulta interesante contemplar las posibilidades que brindan los catalizadores heterogéneos como sustitutos de los homogéneos, puesto que además de poder ser diseñados ajustándose a las demandas de cada reacción (número de centros activos, distribución de fuerzas ácida o básica y selectividad de forma), presentan numerosas ventajas para la industria química, entre las que cabe destacar:

× Manejo cómodo y seguro, sin problemas de corrosión.

* Fácil separación, recuperación y posible reuso o regeneración (algunos catalizadores heterogéneos tienen una elevada estabilidad

\footnotetext{
${ }^{10}$ Hoelderich W.F., Catalysis Today, 2000, 62, 115.

${ }^{11}$ Clark J.H., Accounts of Chemical Research, 2002, 35, 791.
} 
térmica que permite regenerarlos por calcinación a altas temperaturas).

x Reducción de productos de desecho y ausencia de vertidos contaminantes.

Es por esto que en los últimos años se está poniendo gran interés en el estudio de los procesos de Química Fina con catalizadores heterogéneos. Así por ejemplo, la obtención de 4-metoxiacetofenona, importante intermedio para otros productos como el PARSOL $1789^{\circledR}$, se llevaba a cabo en fase líquida con diclorometano como disolvente y $\mathrm{AlCl}_{3}$ como catalizador, lo que generaba 4500 $\mathrm{kg}$ de sales inorgánicas por tonelada de producto final. Actualmente Rhodia produce 4-metoxiacetofenona mediante un proceso en continuo con reactor de lecho fijo y sin disolvente, utilizando zeolita Beta como catalizador heterogéneo ${ }^{12}$ y reduciendo de este modo la cantidad de residuos.

Una forma de aproximación entre los dos ámbitos de la catálisis debe pasar por el diseño y la introducción de nuevos materiales que permitan aunar las ventajas de cada una de las vertientes catalíticas y a la vez reducir al máximo los inconvenientes que éstas puedan presentar.

1.5

\section{Otras alternativas catalíticas: Líquidos lónicos} 1.5.1

\section{Breve desarrollo histórico}

Dependiendo del punto de vista desde el cual se pretendan estudiar, los líquidos iónicos pueden ser clasificados como una nueva clase de disolventes o como un tipo de materiales con múltiples y muy diversas aplicaciones. Sin embargo la forma más aceptada de definirlos es como sales con temperatura de fusión por debajo de $100^{\circ} \mathrm{C}$, que no deja de ser una definición bastante ambigua, pero al menos informa de su naturaleza completamente iónica y del estado en que se pueden encontrar según la temperatura a la que se vayan a utilizar.

\footnotetext{
12 Spagnol M., Gilbert L., Guillot H., Tirel P.J., WO Patent 9748665, 1997.
} 
La principal característica que diferencia a los líquidos iónicos de las sales fundidas, es el amplio margen de temperaturas en el que los líquidos iónicos son líquidos comparados con las sales tradicionales.

Mucho más a menudo de lo que cabría esperar, se han confundido los términos o se han empleado indistintamente líquidos iónicos y sales fundidas, sin embargo las diferencias van mucho más allá del rango de temperaturas en el que son líquidos unos y sólidas las otras.

Abordado desde la perspectiva química, la composición de los líquidos iónicos es especialmente consistente, aunque sus propiedades y componentes varían enormemente dentro del mismo tipo de materiales. Los líquidos iónicos están constituidos por un catión orgánico y un anión inorgánico poliatómico en la mayoría de los casos, lo que hace que el número de líquidos iónicos sea indeterminado puesto que hay una enorme cantidad de cationes y aniones disponibles para generarlos. De hecho, desarrollar un nuevo líquido iónico es relativamente sencillo, quizás lo que complique el proceso es la

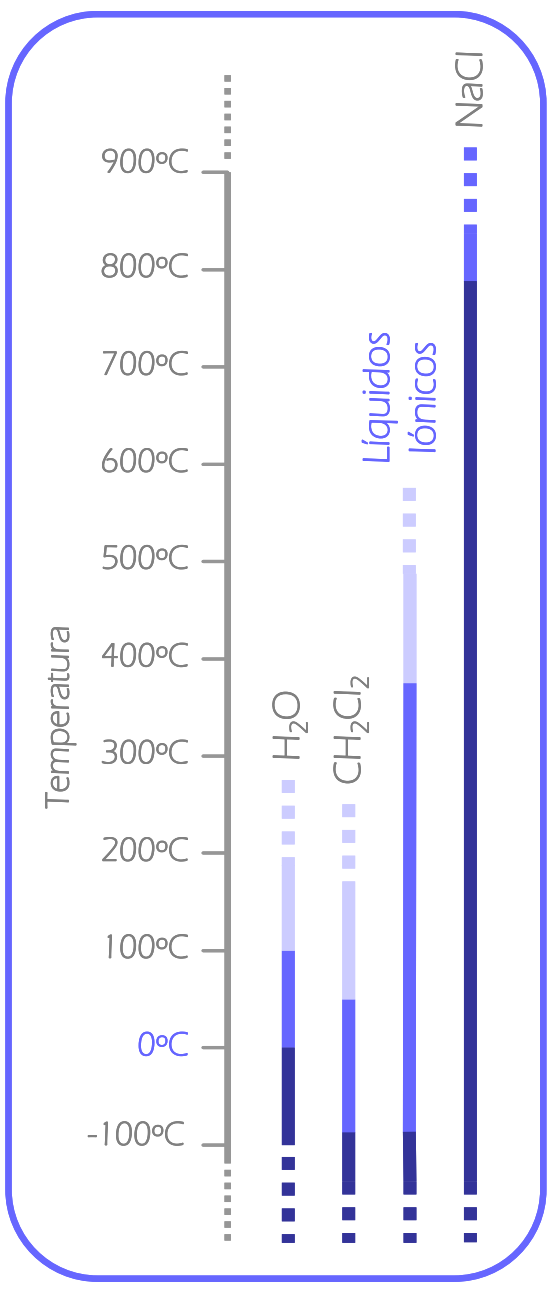

Figura 1.1.- Comparativa de estados físicos. Rangos de temperatura de distintos compuestos. caracterización físico-química del compuesto generado. Pero sin duda uno de los grandes méritos de los líquidos iónicos es que puedan ser sintetizados de acuerdo con las necesidades específicas del proceso al que posteriormente se vayan a aplicar. Es lo que se suele llamar síntesis "a medida" o "a la carta" de líquidos iónicos.

Desde la perspectiva histórica, el primer material que encajaría con la definición actual de líquido iónico se observó a mediados del S.XIX, en una reacción de Friedel-Crafts, siendo una interfase líquida de aspecto oleaginoso que acabó designándose "red oil". Más adelante, con el desarrollo de la espectroscopía de resonancia magnética nuclear, se determinó que lo denominado "red oil" era un compuesto iónico. 
Durante los primeros años del S.XX se observó que algunos nitratos de alquilamonio eran líquidos a temperatura ambiente ${ }^{13}$, la primera referencia bibliográfica que se conoce a este respecto es de Sugden ${ }^{14}$ que sintetizó en 1914 el nitrato de etilamonio con punto de fusión $12^{\circ} \mathrm{C}$. Posteriormente, Hurley ${ }^{15}$ patentó en 1948 el primer líquido iónico con cloroaluminato como baño salino para la electrólisis de aluminio. A mediados de los años sesenta, en la Universidad del Estado de Oregón, John Yoke publicó que la mezcla de cloruro de cobre (I) y cloruros de alquilamonio daba como resultado sales líquidas a bajas temperaturas ${ }^{16}$. En 1967 Swain $^{17}$ describió el benzoato de tetra-n-hexilamonio como disolvente para investigaciones electroquímicas En los setenta Jerry Atwood en la Universidad de Alabama, descubrió un tipo de sales líquidas a las que llamó "liquid clathrates"18 que estaban compuestas por una sal y un alquilo de aluminio que acababan formando compuestos con una o más moléculas aromáticas. La fórmula general de estos compuestos era $\mathrm{M}\left[\mathrm{Al}_{2}\left(\mathrm{CH}_{3}\right)_{6} \mathrm{X}\right]$ siendo $\mathrm{M}$ el catión que podía ser orgánico o inorgánico y $\mathrm{X}$ que siempre era un haluro.

De todos los materiales presentados hasta el momento, ninguno fue considerado antecesor directo de los líquidos iónicos actuales. La historia real comienza en el ejercito estadounidense, más concretamente en la U.S. Air Force Academy, en 1963. El Mayor (Dr.) Lowell A. King encargado de un proyecto de investigación en pilas, trataba de encontrar sustitutos viables para las sales fundidas de $\mathrm{LiCl}-\mathrm{KCl}$, que por entonces se empleaban como electrolitos. Los cloroaluminatos, mezclas de haluros de alquilo y cloruro de aluminio, se fueron introduciendo en el campo de la electroquímica ya que conseguían temperaturas de fusión mucho más bajas de lo que se esperaba para este tipo de sales inorgánicas, además no se comportaban como simples mezclas binarias, el sistema que formaban y sus características ácido-base de Lewis proporcionaban una serie de aniones del tipo $\mathrm{Cl}^{-},\left[\mathrm{AlCl}_{4}\right]^{-},\left[\mathrm{Al}_{2} \mathrm{Cl}_{7}\right]^{-}$y $\left[\mathrm{Al}_{2} \mathrm{Cl}_{10}\right]^{-}$. Uno de los ejemplos de cloroaluminatos que más ampliamente se estudió y que tuvo inmediatamente una aplicación en forma de electrolitos para pilas, fue la mezcla

\footnotetext{
13 Walden P., Bull. Acad. Imper. Sci.,1914, 1800.

14 Sugden S., Wilkins H. J. Chem. Soc. 1929, 1291.

15 Hurley F.H., U.S. Patent 2446 331, 1948.

16 Yoke J.T., Weiss J.F., Tollin G., Inorg. Chem., 1963, 2, 1210.

17 Swain C.G., J. Am. Chem. Soc., 1967, 89, 2648.

18 Atwood J.L., Atwood J.D., Inorganic Compounds with Unusual Properties, Advances in Chemistry Series № 150, American Chemical Society: Washington DC, 1976, 112.
} 
eutéctica $\mathrm{NaCl}-\mathrm{AlCl}_{3}$, con una temperatura de fusión de $107^{\circ} \mathrm{C}$ (curiosamente cercana a la de un líquido iónico).

A raíz del potencial demostrado por algunas sales de aluminio para ser aplicadas en la fabricación de pilas, los investigadores de la Air Force Academy se dedicaron a ahondar en la literatura existente sobre baños electrolíticos, sales de aluminio y aplicaciones electroquímicas. Una de las patentes ${ }^{19}$ que encontraron fue la de Hurley de 1948, en la que describía una mezcla conductiva constituida por $\mathrm{AlCl}_{3}$ y haluros de 1-etilpiridinio. Posteriormente se encontró un mejor comportamiento en la mezcla pseudobinaria cloruro de 1-butilpiridinio$\mathrm{AlCl}_{3}$. Su descubrimiento y caracterización se publicaron ${ }^{20}$ en 1978, y se considera en la actualidad la primera muestra de líquido iónico. A partir de esa publicación y de su consiguiente patente, químicos e ingenieros de todo el mundo comenzaron a mostrar interés por lo que, en principio, se consideraron disolventes totalmente iónicos no acuosos.

Conforme se amplió su aplicación, el catión alquilpiridinio demostró demasiada facilidad para ser reducido, así que nuevos miembros de la Air Force Academy como Charles Hussey y John S. Wilkes desarrollaron un programa para la predicción y síntesis de cationes más resistentes a la reducción pero que a la vez mantuvieran las características que tanto habían interesado del primer líquido iónico. Tras varios intentos, se consiguió la clase de cationes del tipo dialquilimidazolio, y en particular 1-etil-3-metilimidazolio, [Emim] $]^{+}$. El cloruro de 1-etil-3-metilimidazolio [Emim] $\mathrm{Cl}$ mezclado con $\mathrm{AlCl}_{3}$ dio lugar a un líquido iónico ${ }^{21}$ con temperatura de fusión por debajo de $\operatorname{los} 25^{\circ} \mathrm{C}$. Sin lugar a dudas, las propiedades de este nuevo material abrían una perspectiva ideal para su aplicación como electrolito en pilas, pero además se empezó a vislumbrar la posibilidad de aplicarlo en reacciones orgánicas como Friedel-Crafts, demostrándose así, que no solo era idóneo para su empleo en electroquímica sino que además podía comenzar a emplearse en otros ámbitos ya no solo como disolvente sino también como catalizador ${ }^{22}$. Durante la década de los ochenta, Seddon ${ }^{23}$ comenzó a emplear las sales de cloroaluminatos como disolventes

\footnotetext{
19 Wier T.P.Jr., Hurley F.H., U.S. Patent 4446 349, 1948, Wier T.P.Jr., U.S. Patent 4446 350, 1948.

${ }^{20}$ Gale R.J., Gilbert B., Osteryoung R.A., Inorg.Chem., 1978, 17, 2728; Nardi J.C., Hussley C.L., King L.A., U.S. Patent 4122 245, 1978.

${ }^{21}$ Wilkes J.S., Levisky J.A., Wilson R.A., Hussey C.L., Inorg. Chem., 1982, 21, 1263.

${ }^{22}$ Boon J., Levisky J.A., Pflug J.L., Wilkes J. S., J. Org. Chem., 1986, 51, 480.

${ }^{23}$ Seddon K.R., Inorg. Chem., 1983, 22, 2099.
} 
polares para la investigación con complejos de metales de transición y más adelante, a principios de los noventa, Chauvin ${ }^{24}$ aplicó líquidos iónicos como disolventes para reacciones de catálisis homogénea también con metales de transición.

Por el momento, todo eran ventajas, sin embargo pronto fue evidente que los líquidos iónicos sintetizados hasta entonces, basados en cloroaluminatos de piridinio e imidazolio tenían la desventaja de ser especialmente reactivos con el agua, así fue como en 1990 Mike Zaworotko se propuso el reto de desarrollar, sintetizar y caracterizar completamente sales con dialquilimidazolio como catión, pero que dispusieran de aniones estables en agua.

El proceso químico era bastante simple, teniendo en cuenta lo revolucionaria e interesante de la idea de partida. El trabajo en el laboratorio se hizo sencillo, dejó de ser necesario trabajar en atmósfera exenta de humedad ${ }^{25}$. Las nuevas sales, con aniones del tipo: tetrafluoroborato, hexafluorofosfato, nitrato, sulfato y acetato, demostraron ser mucho más estables a la hidrólisis, al menos a temperaturas bajas, y aunque el propósito inicial era emplearlas de nuevo como electrolitos en pilas, resultaron ser especialmente útiles en otras aplicaciones. Nuevos colaboradores, como Joan Fuller ${ }^{26}$ dedicaron varios años a ampliar el catálogo de líquidos iónicos estables en agua, a desarrollar nuevos procesos de síntesis y a caracterizar mucho más profusamente tanto los de nueva generación como los líquidos iónicos ya existentes.

Fuller sintetizó nuevas series de líquidos iónicos con cationes de monoalquilimidazolios y trialquilimidazolios y combinó estos cationes con los aniones estables en agua que había desarrollado años atrás, más una serie adicional de aniones del tipo: bromuros, cianuros, bisulfuros, yoduros, sulfonatos, tosilatos, tartratos, etc. Es evidente que esto dio como resultado una cantidad ingente de combinaciones y de posibles líquidos iónicos con un rango de tamaños muy grande y posibilidades de aplicación casi infinitas. Hoy en día el catálogo de cationes y aniones es todavía mayor, lo que hace que la posibilidad de crear nuevos líquidos iónicos, prácticamente no tenga acotaciones y que las aplicaciones de éstos estén tan solo limitadas por nuestra propia imaginación.

\footnotetext{
${ }^{24}$ ChauvinY., J. Chem. Soc. Chem. Commun. 1990, 1715.

${ }^{25}$ Wilkes J.S., Zaworotko M.J., J.Chem. Soc., Chem. Commun., 1992, 965.

${ }^{26}$ Fuller J., Carlin R.T., DeLong H.C., Haworth D., Chem. Commun., 1994, 299.
} 


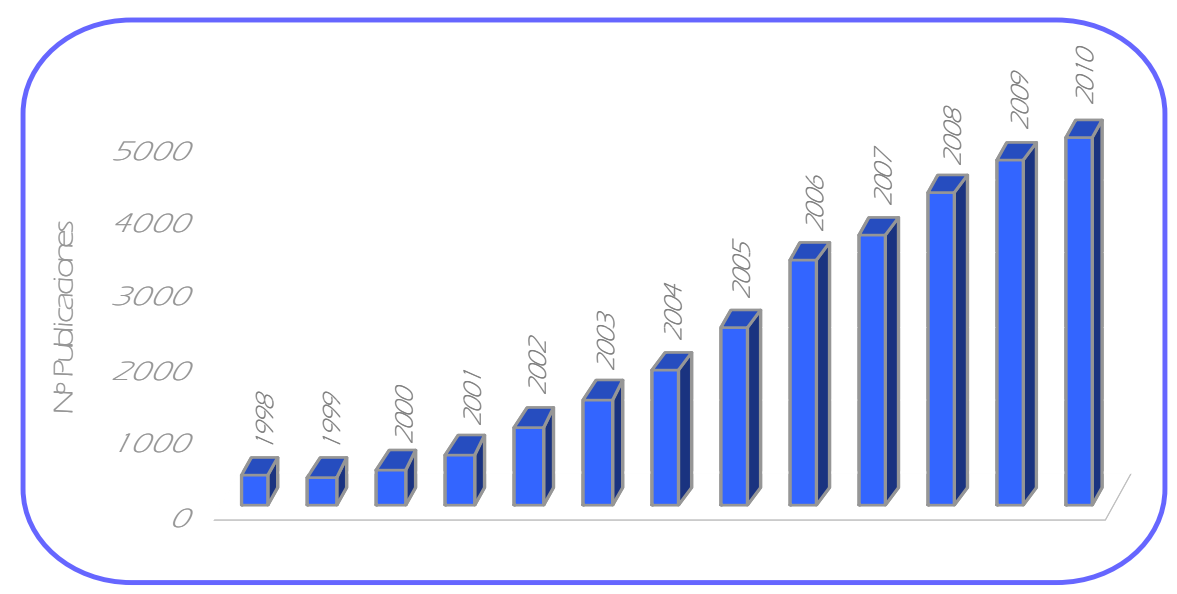

Figura 1.2.- Evolución del número de publicaciones sobre líquidos iónicos en los últimos doce años

Una de las formas de demostrar la amplia difusión que los líquidos iónicos están teniendo, tanto en el ámbito científico como en el de las aplicaciones industriales, es a partir de la tasa de crecimiento del número de publicaciones existentes sobre este tema. La Figura 1.2 muestra el contundente crecimiento del número de artículos relacionados con este área, de doce años atrás al día de hoy.

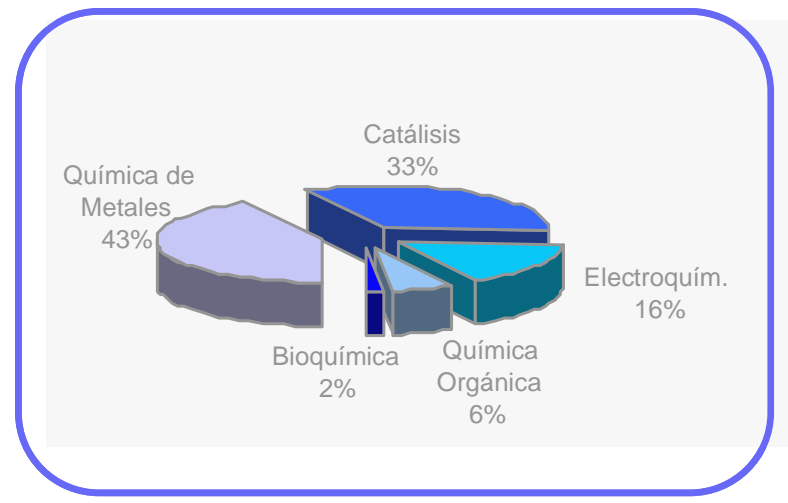

Figura 1.3.- Reparto de las aplicaciones de los líquidos iónicos en los distintos ámbitos de la química.

Aunque originalmente se usaron de forma exclusiva en electroquímica con aplicaciones muy limitadas, poco a poco se han ido ampliando las expectativas, haciendo que los líquidos iónicos estén ya presentes en muchos campos de la química, tal y como se puede apreciar en la Figura 1.3. Cabe destacar que no solo la química se aprovecha de ellos, más adelante se comentarán otros ámbitos en los que se están aplicando. 


\section{5 .2}

\section{Síntesis de Líquidos lónicos}

La síntesis de líquidos iónicos se suele dividir en dos pasos: el primero consiste en la formación del catión y el segundo en el intercambio del anión según las necesidades específicas. En muchas ocasiones, el primer paso es suficiente para obtener el producto deseado ya que es fácil encontrar un precursor del anión que pueda a la vez, mediante adición, generar el catión. En otros casos el catión que se necesita está disponible comercialmente y por lo tanto es suficiente con el intercambio aniónico.

En este apartado se tratará principalmente la síntesis de líquidos iónicos basados en el catión 1,3-dialquilimidazolio, ya que es uno de los más utilizados por sus interesantes propiedades, pero las técnicas que se proponen pueden ser igualmente empleadas para la síntesis de muchos otros tipos de cationes, algunos de los cuales se muestran en la Figura 1.4.

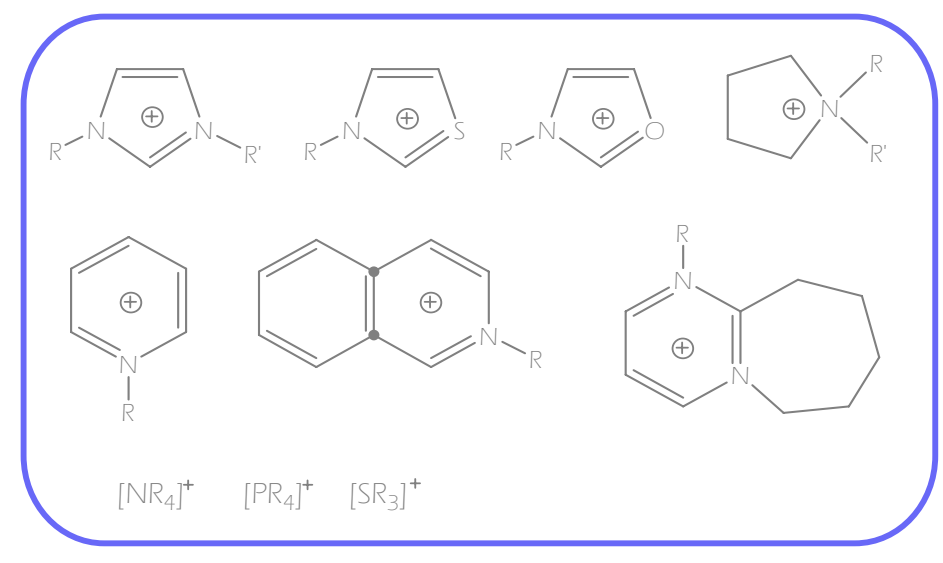

Figura 1.4.- Algunos de los cationes más empleados en la formación de líquidos iónicos.

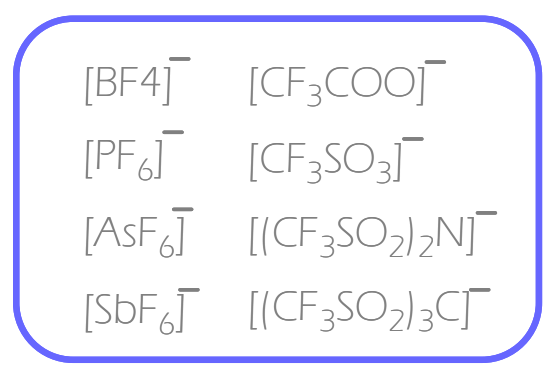

Figura 1.5.- Algunos de los aniones más empleados en la formación de líquidos iónicos.

\subsubsection{1}

\section{Reacciones de cuaternización o formación de cationes}

La formación del catión se suele llevar a cabo mediante protonación de la molécula que constituirá la parte catiónica del líquido iónico, con un ácido (los más empleados son el ácido clorhídrico, nítrico, tetrafluorobórico o hexafluorofosfórico) que cederá su carga aniónica como anión del líquido iónico así formado, o por cuaternización de una amina, fosfina o sulfuro, normalmente con el empleo de un haloalcano. 


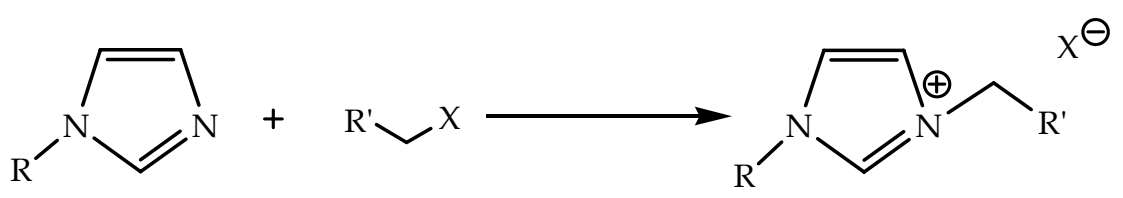

Esquema 1.1.- Reacción básica de alquilación.

La alquilación presenta ciertas ventajas frente a la protonación, entre otras, (i) que hay un amplio rango de haloalcanos susceptibles de ser empleados como agentes alquilantes y son muy baratos, (ii) que este tipo de reacciones son mucho más suaves que las protonaciones, en parte por la naturaleza de los reactivos utilizados, y (iii) que las sales que se forman por esta vía, fácilmente se pueden convertir en otras distintas con un sencillo intercambio aniónico. Las cadenas laterales introducidas sobre los heteroátomos de lo que acaba siendo el catión, pueden ser de gran complejidad, aunque originalmente eran básicas cadenas alifáticas de pocos miembros. En general, la reacción se lleva a cabo usando cloroalcanos, bromoalcanos o yodoalcanos. Cuanto mayor es el haluro, mejor grupo saliente resulta, y por lo tanto más apacibles son las condiciones de reacción (por esta misma razón no suelen emplearse los fluoroalcanos, resultan poco reactivos). En cuanto a las cadenas alquílicas, hacen decrecer la reactividad cuanto mayor es su longitud.

La cuaternización es un proceso muy sencillo, tan solo se necesita disponer de la amina o fosfina en cuestión, mezclada con el agente alquilante escogido y todo ello en agitación durante un cierto tiempo y a una determinada temperatura. En general, partiendo de 1-metilimidazolio con un cloroalcano, será necesaria la agitación durante 2-3 días a unos $80^{\circ} \mathrm{C}$ para la completa cuaternización. La reacción equivalente con un bromoalcano necesitaría tan solo 24 horas y unos $50^{\circ} \mathrm{C}$ y la misma reacción con un yodoalcano puede completarse a temperatura ambiente, pero son necesarias ciertas precauciones ya que el producto de yodo formado suele ser fotosensible. Por otra parte, la atmósfera de reacción debe ser inerte para evitar la intrusión de agua u oxígeno que puede aportar cierta coloración indeseada al producto final.

Por lo general, las sales obtenidas tras este proceso, suelen ser sólidas a temperatura ambiente, en algunos casos, cuando las cadenas laterales tienen una determinada longitud, se pueden encontrar productos oleaginosos de alta viscosidad, que con el tiempo acaban cristalizando. Aunque no es lo habitual, se dan casos de sales cuaternarias que pese a su alta pureza se mantienen siempre en forma de aceites. 
El proceso de cuaternización explicado a grandes rasgos en este apartado para el 1,3-dialquilimidazolio, se puede emplear de forma similar en el caso de necesitar otros tipos de reactivos de partida, tanto para precursores del catión entre los que cabe destacar: piridina ${ }^{27}$, isoquinolina ${ }^{28}, 1$-metilpirrolidina ${ }^{29}$, trialquilaminas ${ }^{30}$ y fosfinas ${ }^{31}$, como para los precursores del anión, entre los que encontramos: alquiltosilato ${ }^{32,33}$, alquilsulfatos ${ }^{34}$, triflatos y trifluoroacetatos ${ }^{35}$ además de muchos otros, que se utilizan a la vez como agentes de alquilación directa.

En el caso de emplear otro tipo de agentes alquilantes, es necesario tomar una serie de precauciones, pues a diferencia de los haloalcanos, suelen dar lugar a reacciones altamente exotérmicas que necesitan de la adición controlada de los reactivos. La manipulación debe ser cautelosa debido a la alta toxicidad de los compuestos iniciales, normalmente se emplea un ligero exceso de nucleófilo para evitar cualquier traza de agente alquilante en el producto final que en todos los casos pierde por completo la toxicidad.

Con estos nuevos reactivos se consigue de forma directa sintetizar un gran número de líquidos iónicos (resulta innecesaria la siguiente etapa de intercambio aniónico), además se evitan productos secundarios difíciles de tratar como los haluros. Para finalizar la cuaternización, tan solo es necesario que cualquier traza de reactivos de partida sea eliminada mediante continuos lavados con un disolvente inerte e inmiscible o por mantenimiento a vacío del producto final.

\footnotetext{
27 Gordon C.M., Holbrey J.D., Kennedy A.R., Seddon K.R., J. Mater. Chem., 1998,8, 2627.

28 Visser A.E., Holbrey J.D., Rogers R.D., Chem. Commun., 2001, 2484.

${ }^{29}$ MacFarlane D.R., Meakin P., Sun J., Amini N., Forsyth M., J. Phys. Chem. B, 1999, 103, 4164.

30 Sun J., Forsyth M., MacFarlane D.R., J. Phys. Chem. B, 1998, 102, 8858.

31 Bradaric C.J., Downard A., Kennedy C., Robertson A.J., Zhou Y., Green Chem., 2003, 5, 143.

32 Waffenschmidt H., Dissertation, RWTH Aachen, Alemania, 2000

${ }^{33}$ Karodia N., Guise S., Newlands C., Andersen J. A., Chem. Commun., 1998, 2341.

${ }^{34}$ Holbrey J.D., Reichert W.M., Swatloski R.P., Broker G.A., Pitner W.R., Seddon K.R., Rogers R.D., Green Chem., 2002, 4, 407.

35 Sugden S., Wilkins H. J. Chem. Soc. 1929.
} 


\subsubsection{2}

\section{Reacciones de intercambio aniónico.}

Se han desarrollado dos vías de intercambio, una implica la reacción directa entre el líquido iónico original formado con un haloalcano, con ácidos de Lewis y la otra supone la formación de nuevos líquidos iónicos vía metátesis del anión.

\section{Reacción con ácidos de Lewis}

Esta fue la vía que se utilizó durante las primeras etapas del desarrollo de los líquidos iónicos. En general, la reacción entre una sal de haluro cuaternaria y un ácido de Lewis produce varias especies en equilibrio, según las proporciones que se empleen de ambos reactivos. Por ejemplo:

El equilibrio (1) se dará cuando el [Emim]Cl esté en exceso frente al ácido y el producto de reacción será un líquido iónico básico. Conforme se incremente la cantidad de ácido en reacción, se darán de forma mayoritaria los equilibrios (2) y (3) que producirán líquidos iónicos de carácter ácido.

$$
\begin{aligned}
& {[\mathrm{Emim}]^{+} \mathrm{Cl}^{-}+\mathrm{AlCl}_{3} \rightleftharpoons[\mathrm{Emim}]^{+}\left[\mathrm{AlCl}_{4}\right]^{-}} \\
& {[\mathrm{Emim}]^{+}\left[\mathrm{AlCl}_{4}\right]^{-}+\mathrm{AlCl}_{3} \rightleftharpoons[\mathrm{Emim}]^{+}\left[\mathrm{Al}_{2} \mathrm{Cl}_{7}\right]^{-}} \\
& {[\mathrm{Emim}]^{+}\left[\mathrm{Al}_{2} \mathrm{Cl}\right]^{-}+\mathrm{AlCl}_{3} \rightleftharpoons[\mathrm{Emim}]^{+}\left[\mathrm{Al}_{3} \mathrm{Cl}_{10}\right]^{-}}
\end{aligned}
$$

Además de cloroaluminatos, muchos otros ácidos de Lewis han sido empleados en este proceso, como más representativos aparecen en bibliografía: AlEtCl $2^{36,37}, \mathrm{BCl}_{3}{ }^{38}, \mathrm{CuCl}^{39}, \mathrm{SnCl}_{2}{ }^{40}, \mathrm{FeCl}_{3}{ }^{41}$, y con todos ellos se utilizó la misma metodología. A partir de las propuestas de Hitchcock y col., muchos autores han intentado también trabajar con haluros metálicos con muy poco carácter ácido

\footnotetext{
${ }^{36}$ Chauvin Y., Einloft S., Olivier H., Ind. Eng. Chem. Res.,1995, 34, 1149.

${ }^{37}$ Gilbert B., Chauvin Y., Olivier H., DiMarco-van Tiggelen F., J. Chem. Soc., Dalton Trans., $1995,3867$.

38 Williams S.D., Schoebrechts J.P., Selkirk J.C., Mamantov G., J. Am. Chem. Soc., 1987, 109, 2218.

${ }^{39}$ Chauvin Y., Olivier-Bourbigou H., CHEMTECH, 1995, 25, 26.

40 Parshall G.W., J. Am. Chem. Soc., 1972, 94, 8716.

${ }^{41}$ Sitze M.S., Shreiter E.R., Patterson E.V., Freeman R.G., Inorg. Chem., 2001, 40, 2298.
} 
como $\mathrm{NiCl}_{2}{ }^{42}, \mathrm{CoCl}_{2}, \mathrm{VOCl}_{2}{ }^{43}$. En estos casos se da exclusivamente el equilibrio (1) y el producto de reacción acaba siendo un líquido iónico con carácter neutro.

Experimentalmente, el proceso es sencillo, se trata de poner en contacto, de forma controlada ambos reactivos, teniendo especial cuidado en el incremento de la temperatura porque son reacciones muy exotérmicas que pueden llevar a la descomposición de los haluros o al deterioro del producto final. El trabajo se lleva a cabo en caja seca pues los líquidos iónicos generados de este modo, son muy sensibles a la humedad y al aire.

\section{Reacción de metátesis de aniones}

A partir de las investigaciones de Wilkes y col. se desarrolló un nuevo método de síntesis mediante el que conseguir líquidos iónicos estables al aire. La preparación de estos nuevos compuestos implicaba un intercambio del anión con el que se llevaba a cabo la cuaternización (por lo general un haluro) por otro de mayor interés, mediante el empleo de distintas sales.

Los primeros experimentos se hicieron con sales de plata $\left(\mathrm{Ag}\left(\mathrm{NO}_{3}\right), \mathrm{Ag}\right.$ $\left.\left(\mathrm{NO}_{2}\right), \quad \mathrm{Ag}_{2}\left(\mathrm{SO}_{4}\right), \quad \mathrm{Ag}\left(\mathrm{BF}_{4}\right)\right)$ y $[\mathrm{Emim}] \mathrm{I}$ como reactivos, y en metanol o metanol/agua como medio de reacción. Esquema 1.2.

$$
[\mathrm{Emim}]^{+} \mathrm{I}^{-}+\mathrm{Ag}\left(\mathrm{NO}_{3}\right) \longrightarrow[\mathrm{Emim}]^{+}\left(\mathrm{NO}_{3}\right)^{-}+\mathrm{AgI}
$$

Esquema 1.2.- Reacción general de formación de líquidos iónicos a partir de sales de plata.

Aunque resultó un método óptimo para la síntesis de líquidos iónicos miscibles en agua y estables en distintas condiciones, presentaba una serie de desventajas como el coste excesivamente alto de las sales "argénticas" y las enormes cantidades de residuos sólidos generados. De modo que pocos años después comenzaron a aparecer publicaciones en las que se proponían mayor diversidad de sales con las que poder sintetizar líquidos iónicos de diversa índole, pero con importantes semejanzas con respecto a los originales de sales de plata: alta pureza y estabilidad, a la vez que se intentó reducir al máximo las desventajas que conllevaban el uso de éstas.

${ }^{42}$ Hitchcock P.B., Seddon K.R., Welton T., J. Chem. Soc., Dalton Trans., 1993, 2639.

${ }^{43}$ Hitchcock P.B., Lewis R.J., Welton T., Polyhedron, 1993, 12, 2039. 
Como curiosidad cabe destacar que algunos autores ${ }^{44}$ han propuesto como método alternativo de intercambio aniónico, el empleo de resinas, especialmente para producción a gran escala de líquidos iónicos. Sin lugar a dudas es un método muy eficaz para conseguir productos de muy alta pureza tal y como han sugerido Wasserscheid y Keim, autores ${ }^{45}$ con larga experiencia en el tema.

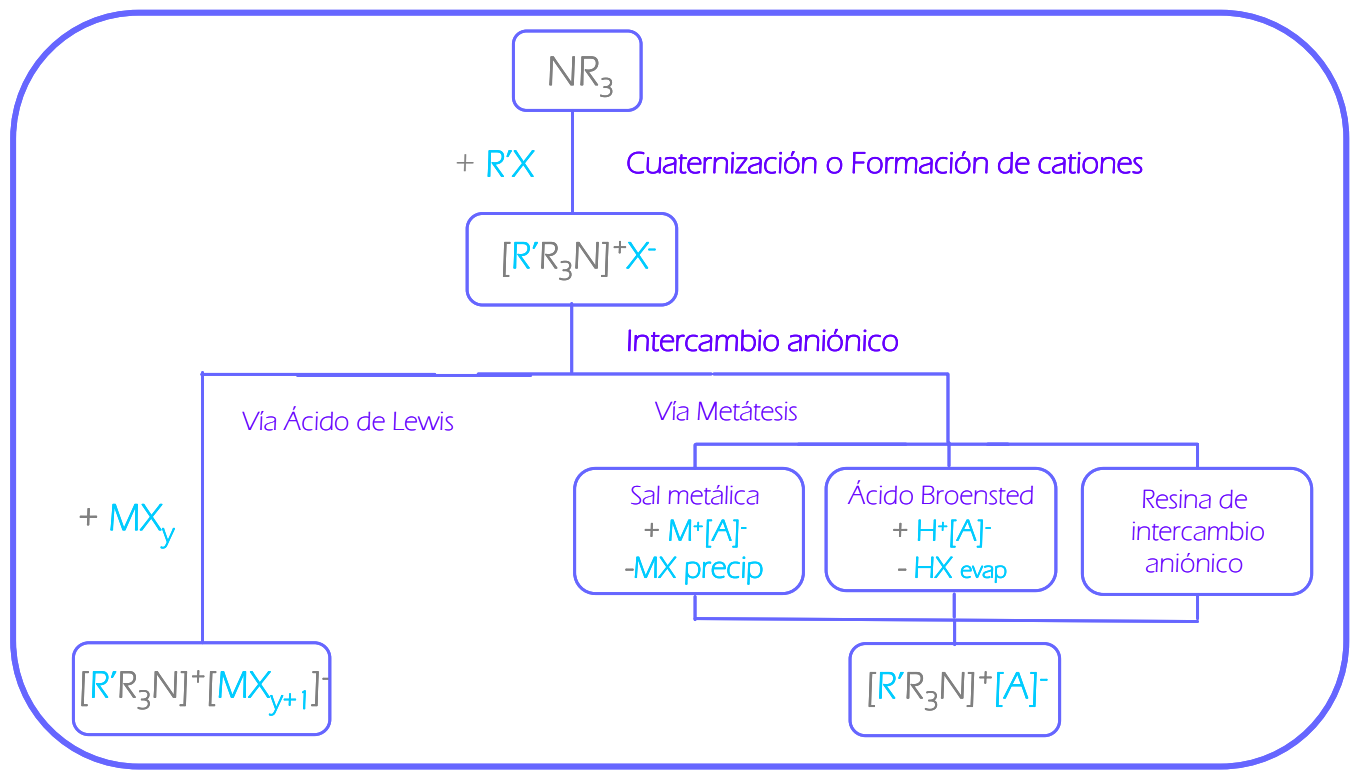

Figura 1.6.-Diagrama de flujo simplificado de síntesis de líquidosiónicos a partir de una sal de amonio.

Pero la mejor alternativa para la síntesis de líquidos iónicos, es la alquilación directa, con la que se evitan los procesos de intercambio y a la vez se consigue reducir al mínimo la formación de productos secundarios, lo que aumenta la eficiencia atómica del proceso. Como ejemplos de agentes de alquilación directa que se emplean actualmente: dialquilsulfatos, trialquilfosfatos o alquiltriflatos, por mencionar algunos. La mayoría de ellos son líquidos, lo que facilita el manejo y la mezcla durante la reacción. Todas estas mejoras a las que ha sido sometido el proceso de síntesis de líquidos iónicos hacen que cada día estén disponibles a mayor escala, con mayor pureza y con precios más asequibles y esto a su vez provoca que se utilicen cada vez más, tanto en el ámbito de la investigación como en el de la producción industrial.

${ }^{44}$ Lall S.I., Mancheno D., Castro S., Behaj V., Cohen J.L.I., Engel R., Chem. Commun., 2000, 2413.

45 Wasserscheid P., Keim W., Angew. Chem. Int. Ed., 2000, 39, 3772. 


\section{5 .3}

\section{Síntesis "a la carta" de Líquidos lónicos}

A finales de los noventa apareció en la bibliografía científica un artículo ${ }^{46}$ en el que se proponía la formación de nuevos líquidos iónicos a partir de la estructura del miconazol (1-(2-(2,4-Diclorobenziloxi)-2(2,4-diclorofenil)etil)- $1 H$-imidazol), que es un agente para tratar infecciones por hongos. Figura 1.7.

Con esta nueva molécula como patrón, se conseguían estructuras grandes y complicadas pero que

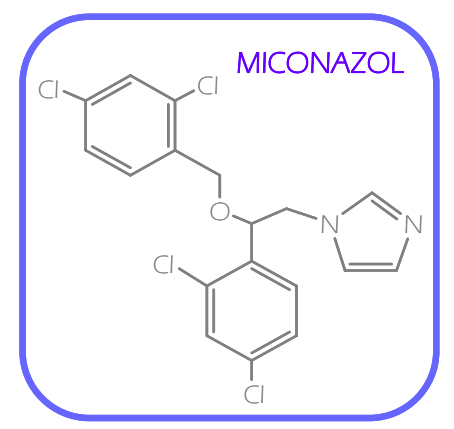

Figura 1.7.- Estructura del miconazol. a la vez mantenían la propiedad de permanecer líquidas a bajas temperaturas e incorporaban distintos grupos funcionales. Cada grupo funcional o la mezcla de ellos, tanto en la parte aniónica como en la parte catiónica del liquido iónico, permitieron desarrollar el término "Líquido iónico con tarea específica" 47 (TSIL: "Task-Specific Ionic Liquid"). La funcionalidad permite que las sales sintetizadas puedan actuar como hasta ahora lo estaban haciendo, como medio de reacción, pero a la vez como reactivo o catalizador en algunos procesos. El TSIL deja de ser un medio inerte para participar activamente en las reacciones en las que se emplea. Esta propiedad también puede incorporarse en los líquidos iónicos convencionales (no es necesario partir siempre de estructuras complejas derivadas del miconazol).

\subsubsection{1}

\section{Proceso general de síntesis de TSILs}

Si la síntesis de líquidos iónicos elementales es ya de por sí un proceso con varias etapas, es de esperar que la de aquellos que incorporan funcionalidad se complique todavía un poco más, aunque esquemáticamente sean muy semejantes.

\footnotetext{
${ }^{46}$ Forrester K.J., Merrigan T.L., Davis J.H.Jr., Tetrahedron Lett., 1998, 39, 8955.

${ }^{47}$ Wierzbicki A., Davis J.H.Jr., Proceedings of the Symposium on Advances in Solvent Selection and Substitution for Extraction, March 5-9, 2000, Atlanta, Georgia. AIchE, New York: 2000.
} 


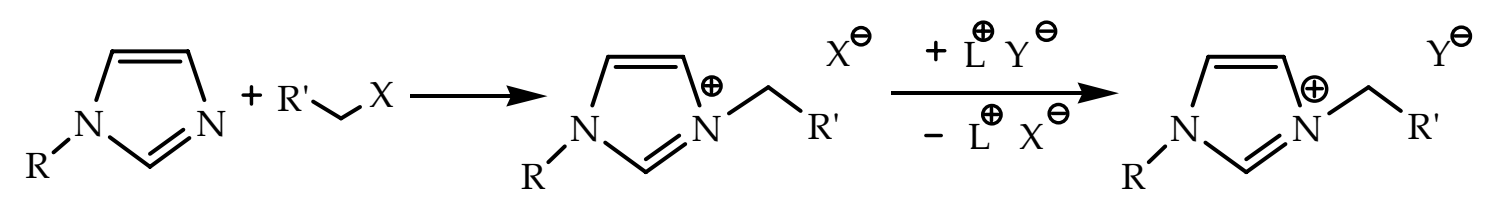

Esquema 1.3.- Reacción general de síntesis de TSILs, donde $R$ y $R^{\prime}$ representan diferentes grupos funcionales.

El primer paso consiste en la elección del centro catiónico del TSIL. Esta primera selección es trascendente para el futuro comportamiento del producto final sintetizado ya que, por ejemplo, la incorporación de fosfonio como catión, otorga al líquido iónico final una gran estabilidad térmica ${ }^{48}$. Los que están basados en un nucleo catiónico de imidazolio consiguen la estabilización más efectiva de metales ${ }^{49}$, lo que permite emplearlos como disolventes en reacciones de catálisis metálica.

El segundo paso implica la búsqueda de la fuente del grupo o grupos funcionales que se pretende introducir. En este punto conviene resaltar que para que el anclaje sea efectivo, es necesario que la molécula que se pretende soportar tenga al menos dos grupos funcionales de distinta reactividad, de tal modo que uno de ellos sea el que haga efectiva la conexión con el soporte y el otro el que acabe siendo grupo funcional o potencial grupo funcional.

Por último, la elección del anión determina en gran medida la relación del TSIL con las moléculas de disolventes en el caso de formar sistemas de dos fases o con el resto de reactivos. Por ejemplo, las sales de nitrato son completamente miscibles en agua mientras que las de hexafluorofosfato completamente inmiscibles y en medio de estos comportamientos tan radicales están las de tetrafluoroborato, que según el catión al que acompañen, serán miscibles o no miscibles en agua.

\section{Cationes funcionalizados: Ejemplos y usos}

Un número considerable de TSILs fueron sintetizados a partir de la cuaternización de N-metil y N-butilimidazolios. Por ejemplo, Bazureau ${ }^{50}$ preparó cationes imidazolio funcionalizados con grupos carboxílicos, que se emplearon

${ }^{48}$ Karodia N., Guise S., Newlands C., Andersen J.-A., Chem. Commun., 1998, 2341.

${ }^{49}$ Mathews C.J., Smith P.J., Welton T., White A.J.P., Williams D.J., Organometallics, 2001, 20, 3848.

${ }^{50}$ Fraga-Dubreuil J., Bazureau J.P., Tetrahedron Lett., 2001, 42, 6097. 
como recambio sólido en soportes poliméricos formando parte de la síntesis heterogénea de pequeñas moléculas orgánicas vía condensación de Knoevenagel.

Otro ejemplo lo representa el centro 1-(3-aminopropil)imidazolio que sirve de andamio para la generación de una extensa familia de TSILs. El grupo amino confiere una gran versatilidad al conjunto, dando lugar a un considerable número de funcionalizaciones, tal y como se puede apreciar en la Figura 1.8.

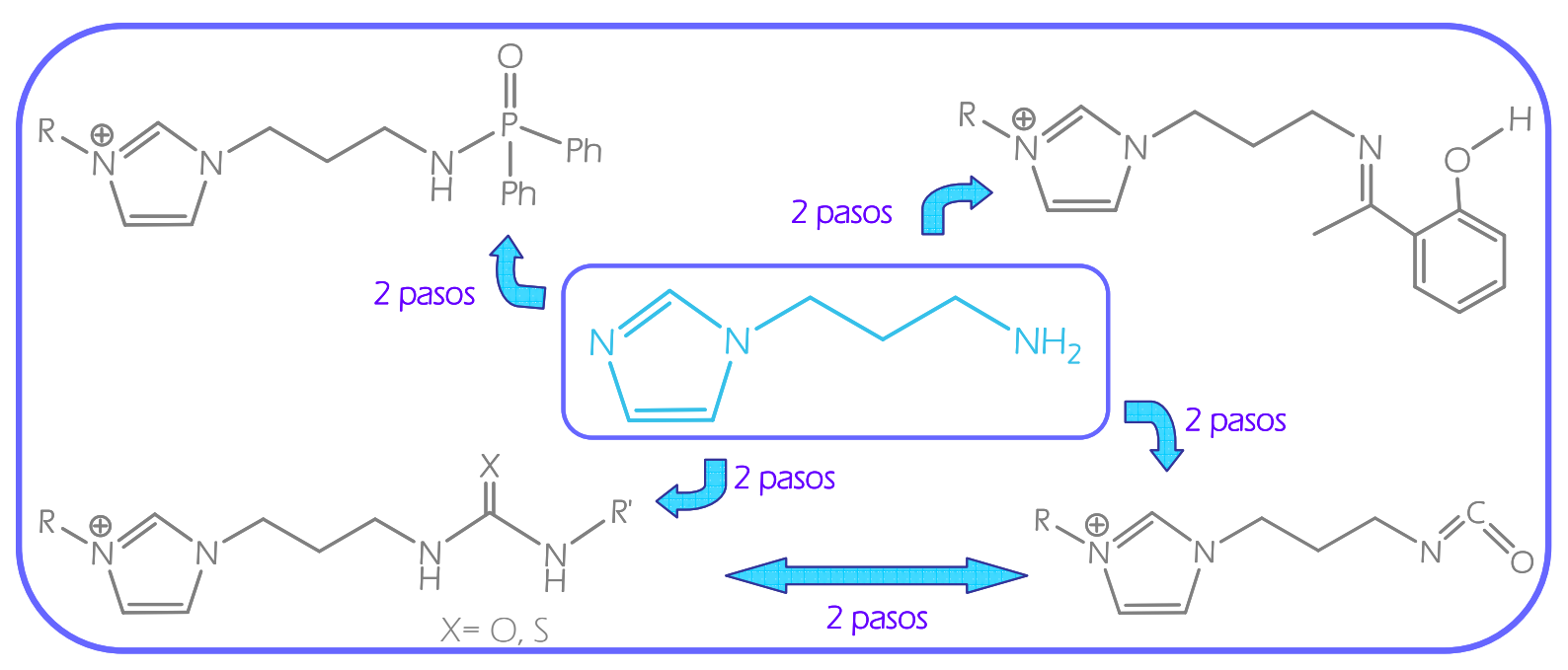

Figura 1.8.- Esquema de obtención de cationes funcionarizados a partir de la amina 1-(3-aminopropil)imidazolio

Hay otros ejemplos de TSILs que se han ido sintetizando en los últimos años, Dyson ${ }^{51}$ y colaboradores publicaron recientemente una completa revisión del diseño y aplicaciones de los líquidos iónicos funcionalizados que hasta el momento se conocían. En la Figura 1.9 se presentan distintos ejemplos de TSILs con la reactividad a ellos asociada.

${ }^{51}$ Fei Z., Geldbach T.J., Zhao D., Dyson P.J., Chem. Eur. J., 2006, 12, 2122. 


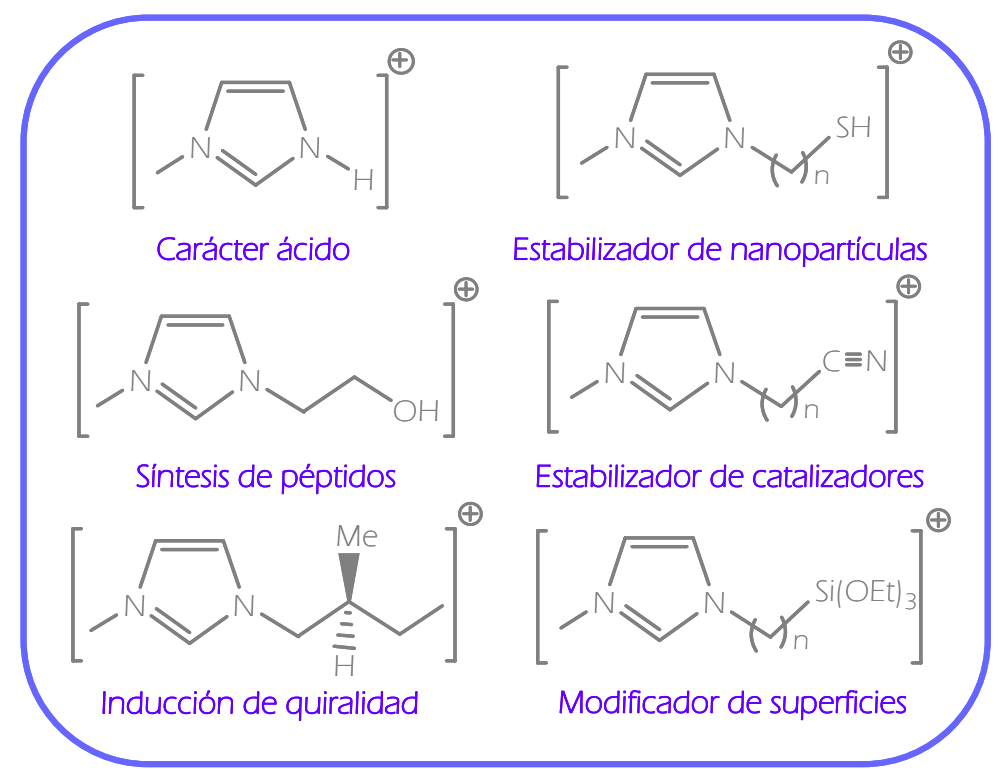

Figura 1.9.- Ejemplos de cationes imidazolio funcionarizados y su potencial aplicación.

\section{Aniones funcionalizados}

La producción de TSILs en los que el anión está funcionalizado no es muy abundante, aunque algunas publicaciones ${ }^{57}$ hacen hincapié en sus potenciales aplicaciones. Los ejemplos más representativos aparecen en la Figura 1.10 .

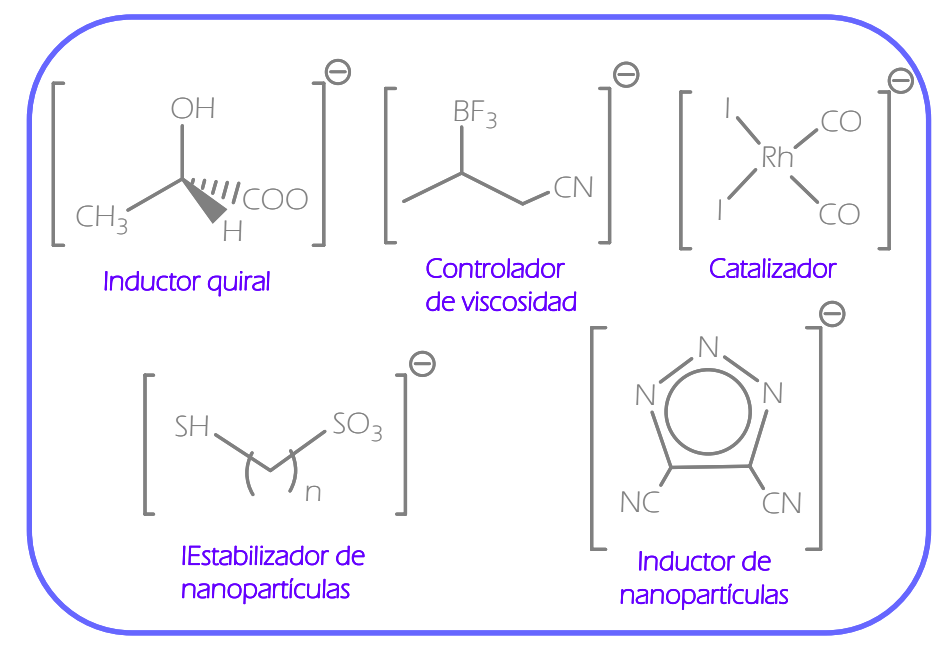

Figura 1.10.- Ejemplos de aniones fucionalizados y su potencial aplicación

Para acabar, y del mismo modo que ya se comentó anteriormente con los líquidos iónicos convencionales, cabe destacar que los límites de producción de TSILs se encuentran en la imaginación de sus diseñadores y que los frentes hasta ahora abiertos dan posibilidades incalculables no solo en la síntesis ${ }^{52}$

52 Zhao D., Fei Z., Ohlin C.A., Laurenczy G., Dyson P.J., Chem. Commun., 2004, 2500. 
(funcionalización de cationes, aniones o mixtas) sino también en la influencia de los diferentes grupos funcionales sobre las propiedades físicoquímicas y de reactividad.

\section{Líquidos iónicos bifuncionales}

Se consideran líquidos iónicos bifuncionales, aquellos que poseen una estructura en la que aparecen varios grupos funcionales activos y que por lo tanto pueden desarrollar diferentes roles en el transcurso de un proceso. Existen en la bibliografía ejemplos de distintas formas de bifuncionalidad, lo que da pie a poder emplearlos tanto en síntesis de materiales como en reacciones de catálisis orgánica u organometálica, procesos de extracción etc...

Por ejemplo, $Y^{4} e^{53}$ y col. publicaron la síntesis de un líquido iónico que en su parte catiónica contenía un grupo hidroxilo y otro amonio. Ambos grupos funcionales interactúan con un metileno activo y con el grupo carbonilo de un aldehído respectivamente, para dar lugar al producto de condensación de Knoevenagel con buenos rendimientos.

También se considera bifuncional al líquido iónico desarrollado por Migliorini ${ }^{54}$ y col., que con una estructura de imidazolio sustituída con cadenas laterales de etilenglicol, puede ejercer de agente director de estructuras a la vez que actúa como catalizador ácido en procesos de síntesis de xerogeles de sílica.

Recientemente varios grupos ${ }^{55,56}$ han publicado que los TSIL pueden emplearse como organocatalizadores asimétricos muy efectivos para reacciones de adición tipo aldol o Michael, así como en procesos catalíticos asimétricos con metales de transición, y todavía se sigue estudiando la posibilidad de aplicar los líquidos iónicos bifuncionales en muchos otros procesos organocatalíticos.

Finalmente, uno de los ámbitos en los que se está utilizando con interesantes resultados la estrategia bifuncional es el de los procesos de extracción. En estos casos los grupos funcionales asociados ${ }^{57}$ o los sistemas

\footnotetext{
53 Yue C., Mao A., Wei Y., Lü M., Catalysis Communications, 2008, 9, 1571.

54 Mingiorini M., Donato R., Benvegnú M., Gonçalves R., Schrekker H., J.Sol-Gel Sci.Technol, 2008, $48,272$.

55 Zhang L., Luo S., Mi X., Liu S., Qiao Y., Xu H., Cheng J-P, Org. Biomol. Chem., 2008, 6, 567.

${ }^{56}$ Luo S., Mi X., Zhang L., Liu S., Xu H., Cheng J-P., Angew. Chem., Int. Ed., 2006, 45, 3093.

${ }^{57}$ Sun X., Ji Y., Hu F., He B., Chen J., Li D., Talanta, 2010, 81, 1877.
} 
binarios de líquidos iónicos ${ }^{58}$, ejercen entre sí efectos sinérgicos que favorecen especialmente las separaciones.

\section{5 .4 \\ Reciclado de Líquidos lónicos}

Es indiscutible que los líquidos iónicos, comparados con los disolventes orgánicos convencionales, son más caros, por eso resulta necesario el desarrollo de procesos de reciclado y reuso eficaces, especialmente destinados a las aplicaciones a gran escala.

El procedimiento que se está empleando en la actualidad, se basa en la baja solubilidad de los líquidos iónicos en disolventes orgánicos, que permite extraer productos y residuos orgánicos del crudo de reacción y mantener los restos salinos en el líquido iónico, si éste además es inmiscible en agua, las sales inorgánicas se eliminarán con sucesivos lavados acuosos (en el caso de líquidos iónicos miscibles en agua, la eliminación es más complicada y en ocasiones se ha de recurrir a otros procedimientos). Si los productos finales e impurezas son suficientemente volátiles, lo más sencillo es una destilación fraccionada, ya que el líquido iónico con toda seguridad no se verá afectado por ésta.

Brennecke $^{59}$ y colaboradores desarrollaron una original forma de reciclado a partir del uso de $\mathrm{CO}_{2}$ supercrítico $\left(\mathrm{scCO}_{2}\right)$ como fluido de extracción, ya que mientras que éste difunde muy bien en la mayoría de los líquidos iónicos, éstos no son solubles en el $\mathrm{scCO}_{2}$ y por lo tanto constituyen un sistema perfecto para la extracción de compuestos orgánicos del medio de reacción solubles en $\mathrm{scCO}_{2}$. A partir de esta primera referencia, el uso de disolventes supercríticos para la extracción en reacciones con líquidos iónicos se ha extendido considerablemente ${ }^{60}$ pues no deja de ser un método muy efectivo para el reciclado (rendimientos de extracción muy altos) pero ante todo especialmente respetuoso con el medio ambiente (el $\mathrm{CO}_{2}$ es un disolvente verde, no tóxico, no inflamable y económico). Otra técnica desarrollada en los últimos años en relación al reciclado de líquidos iónicos, son las membranas ${ }^{61}$, que se suelen

\footnotetext{
${ }^{58}$ Liu Y., Zhu L., Sun X., Chen J., Luo F., Ind. Eng. Chem. Res., 2009, 48, 7308.

${ }_{59}$ Blanchard L.A., Hancu D., Beckman E.J., Brennecke J.F., Nature, 1999, 399, 28.

${ }^{60}$ Beckman E.J., J. of Supercritical Fluids, 28, 2004, 121.

61 Solvent Innovation WO 2003.039.719 (2003).
} 
emplear para determinadas separaciones y resultan muy interesantes a la hora de suprimir algunos disolventes volátiles.

De todos modos, puesto que el reciclado es una parcela muy importante dentro del uso y la comercialización de líquidos iónicos, algunas empresas productoras, por el hecho de tener amplia experiencia en el reciclado y purificación de estos compuestos, proponen a los consumidores hacerse cargo de sus disolventes ya usados, someterlos a un proceso de purificación y devolverlos al consumidor para sucesivos usos.

\section{5 .5}

\section{Propiedades Físico-Químicas de los Líquidos lónicos}

En general, las propiedades de los líquidos iónicos están totalmente condicionadas por el catión y el anión que constituyen cada uno de ellos. Existe una inmensa variedad de posibilidades a la hora de escoger el medio apropiado para una reacción, tan solo se deben tener claros los condicionantes de ésta para establecer cuales deben ser los componentes del líquido iónico a emplear. Siendo así, no es de extrañar que estos compuestos, en algunas publicaciones ${ }^{62}$, sean denominados "disolventes de diseño".

Sería un trabajo titánico intentar detallar las propiedades de cada uno de los líquidos iónicos en este apartado, pero al menos se intentará aclarar las relaciones existentes entre las diferentes estructuras básicas y sus propiedades físicas y químicas más importantes.

\subsubsection{1}

\section{Coloración}

La mayoría de los líquidos iónicos son incoloros. La más o menos leve coloración que se pueda observar en algunos productos, es debida a la presencia de trazas de impurezas con color, en su mayoría originadas por oxidación o degradación térmica de insignificantes cantidades de reactivos de partida. Pese a ello, la coloración de los líquidos iónicos también depende del tipo de catión y anión que estén involucrados en su estructura; por ejemplo, tal y como se muestra en la imagen, las sales de piridinio suelen ser más coloreadas que las de

\footnotetext{
${ }^{62}$ Freemantle M., Chem. Eng. News, 1998, 76, 32.
} 
imidazolio. Si se valora desde el punto de vista comercial, hay tres cuestiones que deben tenerse en cuenta:

x Que las impurezas que dan color a los líquidos iónicos están presentes en ínfimas cantidades y es prácticamente imposible detectarlas por métodos analíticos convencionales (excepto por espectroscopía UV-VIS). De ahí la dificultad de determinar su estructura y procedencia exacta.

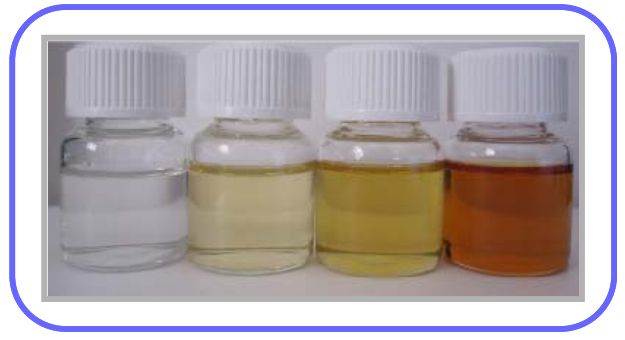

Figura 1.11.- De izq. a dcha.: [Bmim] $\mathrm{PF}_{6}$, [Bmim]BF4, AMOENGTM,100, [Mpim]I.

* Que para casi cualquier aplicación que se les dé a estos compuestos, el color es un parámetro que no afecta a su reactividad.

× Y que la necesidad de trabajar con líquidos iónicos incoloros puede ser incompatible con el objetivo de una producción económicamente rentable pues cualquier proceso de purificación extremo encarece enormemente la producción.

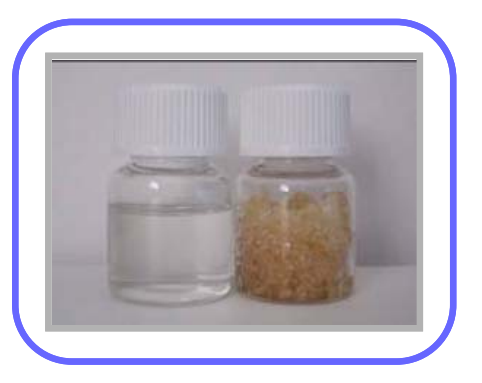

Figura 1.12.- A la izq. [Bmim] $\mathrm{PF}_{6}$, a la dcha. [Mbpy]PF6.

\subsubsection{2}

\section{Puntos de fusión}

Por definición, los líquidos iónicos están completamente ligados a sus puntos de fusión, que a la vez, como en todo compuesto químico está íntimamente relacionado con su estructura.

Si se comparan los puntos de fusión de distintas sales de cloruro ${ }^{63,22}$ (Tabla 1.3), se aprecia una clara influencia del catión. Las sales de metales alcalinos tienen puntos de fusión muy altos, mientras que las de cationes orgánicos funden a temperaturas por debajo de $130^{\circ} \mathrm{C}$. 


\begin{tabular}{llc}
\hline Sal de cloruro & Te $^{\text {a Fusión }}\left({ }^{\circ} \mathrm{C}\right)$ \\
\hline $\mathrm{NaCl}$ & 803 \\
$\mathrm{KCl}$ & 772 \\
& $\begin{array}{l}\mathrm{R}=\mathrm{R}^{\prime}=\mathrm{CH}_{3}([\mathrm{Mmin}] \mathrm{Cl}) \\
\mathrm{R}=\mathrm{CH}_{3}, \mathrm{R}^{\prime}=\mathrm{CH}_{3} \mathrm{CH}_{2}([\mathrm{Emim}] \mathrm{Cl}) \\
\mathrm{R}=\mathrm{CH}_{3}, \mathrm{R}^{\prime}=\mathrm{CH}_{3}\left(\mathrm{CH}_{2}\right)_{3}([\mathrm{Bmim}] \mathrm{Cl})\end{array}$ \\
\hline
\end{tabular}

Tabla 1.3.- Temperaturas de fusión para distintas sales de cloro.

En el caso de los líquidos iónicos, los puntos de fusión tan bajos se explican teniendo en cuenta por una parte, algunas características catiónicas como la poca simetría ${ }^{64,65}$ (que impide la compactación efectiva de la red cristalina), las débiles interacciones intermoleculares ${ }^{66}$ (debido al elevado tamaño de los iones y por lo tanto a la débil atracción anión-catión) y la eficaz distribución de $\operatorname{cargas}^{67}$ en el propio ion. Por otra parte, algunas características aniónicas, en la mayoría de los casos un aumento en el tamaño del anión, provoca la reducción del punto de fusión de la sal ya que la atracción entre los iones es menor y por lo tanto la energía reticular, lo que finalmente deviene en un mayor carácter covalente.

\begin{tabular}{lc}
\hline Sal de imidazolio & $\mathbf{T}^{\mathbf{a}}$ Fusión $\left({ }^{\circ} \mathbf{C}\right)$ \\
\hline$[$ Emim $] \mathrm{Cl}$ & 87 \\
{$[$ Emim $] \mathrm{NO}_{2}$} & 55 \\
{$[$ Emim $] \mathrm{NO}_{3}$} & 38 \\
{$[$ Emim $] \mathrm{AlCl}_{4}$} & 7 \\
{$[$ Emim $] \mathrm{BF}_{4}$} & 6 \\
{$[$ Emim $] \mathrm{CF}_{3} \mathrm{CO}_{2}$} & -9 \\
{$[$ Emim $] \mathrm{CF}_{3} \mathrm{CO}_{2}$} & -14 \\
\hline
\end{tabular}

Tabla 1.4.- Temperaturas de fusión de distintos LI con catión [Emim].

${ }^{64}$ Seddon K.R., J. Chem. Tech. Biotechnol., 1997, 68, 351.

${ }^{65}$ Seddon K.R., Kinet. Catal. Engl. Transl., 1996, 37, 693.

${ }^{66}$ Elaiwi A., Hitchckock P.B., Seddon K.R., Srinivasan N., Tan Y.-M., Welton T., Zora J.A., J. Chem. Soc. Dalton Trans., 1995, 3467.

${ }^{67}$ Stegemann H., Rhode A., Reiche A., Schnittke A., Füllbier H., Electrochim. Acta, 1992, 37, 379. 
En la Tabla 1.4. se puede apreciar el amplio rango de puntos de fusión que puede tener un catión, según el anión con el que forme el líquido iónico. La contribución catiónica y aniónica en el punto de fusión de estos compuestos nunca debe considerarse de forma aislada, las interacciones que los mantienen juntos son las que gobiernan las características finales de los líquidos iónicos.

\subsubsection{3}

\section{Estabilidad térmica y Presión de vapor}

Una de las características que más valiosos hacen a los líquidos iónicos es su baja presión de vapor, especialmente en los procesos de ingeniería ya que facilitan la separación por destilación de los productos de reacción, a la vez que evitan por completo la formación de azeótropos entre disolventes y productos.

Quizás la única pega que puedan presentar es que al contener partes orgánicas, su estabilidad térmica ${ }^{48}$ es limitada. Dependiendo del proceso de síntesis y de la composición catiónica se puede trabajar dentro de un rango considerablemente amplio de temperaturas, por ejemplo, la síntesis de líquidos iónicos vía protonación directa de una amina, restringe notablemente la estabilidad ${ }^{28}$ del compuesto, haciendo que descomponga incluso a temperaturas menores de $80^{\circ} \mathrm{C}$. Si por el contrario la síntesis implica una etapa de alquilación la estabilidad general es bastante mayor. La naturaleza del anión también tiene influencia en la estabilidad térmica del líquido iónico, así se observa que cuanto menor carácter nucleofílico ${ }^{68}$ tenga, más estable será el líquido iónico a altas temperaturas. El orden de estabilidad para algunos aniones convencionales sería: $\mathrm{Cl}^{-}<\left[\mathrm{BF}_{4}\right]^{-} \sim\left[\mathrm{PF}_{6}\right]^{-}<\left[\mathrm{NTf}_{2}\right]^{-}$.

\subsubsection{4}

\section{Densidad}

En general la densidad de los líquidos iónicos comparables decrece conforme se hace más voluminosa la estructura del catión orgánico. Al contrario de lo que ocurre con otras propiedades físico-químicas, la densidad es una de las menos sensitivas a las variaciones de temperatura y al contenido en impurezas del compuesto.

En el ámbito de los líquidos iónicos binarios (los que se sintetizan vía adición de ácidos de Lewis), conforme se aumenta el porcentaje molar ${ }^{22}$ de la sal

${ }^{68}$ Ngo H.L., LeCompte K., Hargens L., McEwan A.B., Thermochim. Acta. 2000, 97, 357 
orgánica frente a la inorgánica, la densidad disminuye sensiblemente, tal y como se aprecia en la Tabla 1.5.

En el caso de los líquidos iónicos no binarios, al comparar series con el mismo catión se advierte que la densidad aumenta conforme aumenta la masa del anión.

\begin{tabular}{|c|c|c|c|}
\hline Sistema LI & Catión & Anión & $\begin{array}{l}\text { Dens. } \\
\left(\text { g.cm }^{-3}\right)\end{array}$ \\
\hline 34-66 mol\% EmimCl- $\mathrm{AlCl}_{3}$ & Emim $^{+}$ & $\mathrm{Al}_{2} \mathrm{Cl}_{7}$ & 1,389 \\
\hline $50-50 \mathrm{~mol} \%$ EmimCl- $\mathrm{AlCl}_{3}$ & Emim $^{+}$ & $\mathrm{AlCl}_{4}$ & 1,294 \\
\hline $60-40 \mathrm{~mol} \%$ EmimCl- $\mathrm{AlCl}_{3}$ & $\mathrm{Emim}^{+}$ & $\mathrm{Cl}^{-}, \mathrm{AlCl}_{4}$ & 1,256 \\
\hline $34-66 \mathrm{~mol} \% \mathrm{BmimCl}-\mathrm{AlCl}_{3}$ & $\mathrm{Bmim}^{+}$ & $\mathrm{Al}_{2} \mathrm{Cl}_{7}$ & 1,334 \\
\hline $50-50 \mathrm{~mol} \% \mathrm{BmimCl}-\mathrm{AlCl}_{3}$ & $\mathrm{Bmim}^{+}$ & $\mathrm{AlCl}_{4}$ & 1,238 \\
\hline
\end{tabular}

Tabla 1.5.- Densidad de algunas sales binarias. Temperatura de medida: $298 \mathrm{~K}$.

\subsubsection{5}

\section{Viscosidad}

La viscosidad de los líquidos iónicos ha sido estudiada bajo la condición de que éstos sean fluidos newtonianos.

La viscosidad de la mayoría de disolventes convencionales es menor que la de los líquidos iónicos, que a temperatura ambiente puede comprender un rango desde los $10 \mathrm{cP}$ hasta los $500 \mathrm{cP}$ (el agua tiene una viscosidad de $0.890 \mathrm{cP}$ pero el glicerol de $934 \mathrm{cP}$ en condiciones normales).

Esta propiedad que poseen todos los fluidos, está muy afectada por los cambios de temperatura ${ }^{69,70}$ y en concreto, en los líquidos iónicos, influye sobremanera el porcentaje de impurezas, es más, cantidades inapreciables de impurezas ${ }^{71,72}$ pueden hacer variar drásticamente la viscosidad de estos compuestos.

Debido a la influencia que ejercen factores externos a los propios compuestos sobre sus viscosidades, es complicado cuantificarlas de forma exacta y determinar cual es la dependencia de la viscosidad con respecto a la estructura de los líquidos iónicos. Al menos cabe destacar que tanto el anión como el catión

\footnotetext{
${ }^{69}$ Baker S.N., Baker G.A., Kane M.A., Bright F.V., J. Phys. Chem. B, 2001, 105, 9663.

${ }^{70}$ Harris S.N., Woolf L.A., Kanakubo M., J. Chem. Eng. Data, 2005, 50, 1777.

${ }^{71}$ Seddon K.R., Stark A., Torres M.J., Pure Appl. Chem., 2000, 72, 2275.

72 Widegren J.A., Laesecke A., Magee J.W., Chem. Commun., 2005, 1610.
} 
intervienen directamente en la viscosidad. En el caso de los aniones, cuanto mayor número de interacciones débiles tipo puente de hidrógeno sean capaces de generar, más aumentará la viscosidad, mientras que los cationes harán que la viscosidad aumente cuanto más grandes y en mayor número estén los sustituyentes orgánicos.

\subsubsection{6}

\section{Solubilidad, Miscibilidad y Solvatación}

Como ya se ha puesto de manifiesto en el apartado anterior, la solubilidad es una propiedad que está directamente relacionada con la polaridad, no solo en los líquidos iónicos sino en cualquier disolvente. En este apartado, se tratará la solubilidad desde la perspectiva de otros compuestos en relación con los líquidos iónicos.

La solubilidad del agua ${ }^{73}$ en los líquidos iónicos puede variar desde la completa miscibilidad hasta la completa inmiscibilidad, tan solo con la variación del anión, por ejemplo de $\mathrm{Cl}^{-}$(completamente miscible) a $\left[\mathrm{PF}_{6}\right]^{-}$(completamente inmiscible), todo depende de la capacidad que tenga cada anión de generar enlaces puente de hidrógeno entre cada una de las especies presentes en el medio. Los alcanos y por lo general las moléculas orgánicas apolares no son miscibles en los líquidos iónicos, por eso suelen utilizarse para generar sistemas bifásicos de reacción (es algo que también se hace con el agua).

La solubilidad de compuestos orgánicos polares y de sales metálicas en líquidos iónicos es un campo muy estudiado por la relevancia que tienen esos sistemas en la síntesis química, especialmente en procesos catalíticos. Las diferentes solubilidades de reactivos, productos y catalizadores, hacen que la metodología de separación y purificación sea extremadamente eficaz. En la Tabla 1.6 se muestran algunos ejemplos de solubilidad de diferentes disolventes en tres líquidos iónicos.

${ }^{73}$ Visser A.E., Swatlowski R.P., Rogers R.D., Green Chemistry, 2000, 2, 1. 


\begin{tabular}{lccc}
\hline Disolvente & {$\left[\mathrm{Bmim}_{\mathbf{P} F_{6}}\right.$} & {$[\mathrm{Bmim}] \mathrm{Cl}-\mathrm{AlCl}_{3}$} & {$\left[\mathrm{Bmim}_{\mathbf{C}} \mathrm{Cl}_{-} \mathrm{Al}_{2} \mathrm{Cl}_{6}\right.$} \\
\hline Agua & $\mathrm{I}$ & $\mathrm{R}$ & $\mathrm{R}$ \\
Metanol & $\mathrm{M}$ & $\mathrm{R}$ & $\mathrm{R}$ \\
Acetonitrilo & $\mathrm{M}$ & $\mathrm{M}$ & $\mathrm{M}$ \\
Acetona & $\mathrm{M}$ & $\mathrm{M}$ & $\mathrm{R}$ \\
Tetrahidrofurano & $\mathrm{M}$ & $\mathrm{M}$ & $\mathrm{R}$ \\
Dióxido de carbono & $\mathrm{I}$ & $\mathrm{I}$ & $\mathrm{I}$ \\
Tolueno & $\mathrm{I}$ & $\mathrm{I}$ & $\mathrm{I}$ \\
Hexano & $\mathrm{I}$ & $\mathrm{I}$ & $\mathrm{I}$ \\
\hline
\end{tabular}

Tabla 1.6.- Miscibilidad de varios disolventes en $[\mathrm{Bmim}] \mathrm{PF}_{6},[\mathrm{Bmim}] \mathrm{Cl}-\mathrm{AlCl}_{3}$ y $[\mathrm{Bmim}] \mathrm{Cl}-\mathrm{Al}_{2} \mathrm{Cl}_{6}$. M: Completamente miscible, R: Reactivos, I: Completamente inmiscible.

\subsubsection{7}

\section{Potencial electroquímico y Conductividad}

Inicialmente los líquidos iónicos fueron desarrollados como disolventes para aplicaciones electroquímicas. Las características que los hacen especialmente indicados para estas aplicaciones son: (i) el amplio rango de potenciales electroquímicos, (ii) la elevada conductividad iónica y térmica, (iii) la efectividad en los fenómenos de transporte y (iv) la capacidad de solvatar moléculas de casi cualquier tipo.

La propiedad que se debe tener en cuenta en la elección de un medio de reacción para investigaciones electroquímicas es su estabilidad frente a los procesos de reducción y oxidación. En el caso de los líquidos iónicos, el rango en el que se puede trabajar depende de la resistencia del catión a la reducción y del anión a la oxidación. Además, es muy importante controlar las impurezas que puedan tener, (especialmente las de haluros y agua), pues afectan drásticamente reduciendo los potenciales red-ox de estos disolventes.

Por su parte la conductividad iónica de los disolventes, informa de la movilidad de los iones que transportan las cargas. En principio, cabe pensar que los líquidos iónicos, por estar constituidos por iones, poseerán una alta conductividad y así es si se comparan con las conductividades de sistemas de electrolitos/disolventes no acuosos. Sin embargo, son menos conductivos que las disoluciones acuosas concentradas de electrolitos, lo que puede atribuirse a los grandes tamaños de los iones, que limitan la movilidad de las cargas. 


\subsubsection{8}

\section{Toxicidad}

Se han realizado diferentes ensayos y estudios para determinar la toxicidad y la biodegradabilidad ${ }^{74}$ de los líquidos iónicos. En ellos se muestra que algunos pueden ser tóxicos, mientras que otros son completamente inofensivos y biodegradables. Sin embargo, un número bastante alto de los líquidos iónicos investigados son irritantes y tienen una toxicidad comparable a la de los disolventes orgánicos convencionales, pero con la ventaja ${ }^{75}$ de que no son volátiles, de modo que se reducen las potenciales vías de exposición, siendo el contacto directo con la piel y la ingestión prácticamente las únicas vías posibles.

Los ensayos realizados "in vitro" dan indicaciones del peligro potencial, pero no implican que deba haber efecto sobre un organismo completo. Para profundizar más en los efectos, hay que estudiar fenómenos de transporte a través de las membranas biológicas y fenómenos de bioacumulación. Los ensayos realizados por el momento, han demostrado actividad inhibidora de la acetilcolinesterasa ${ }^{76}$ (enzima importante del sistema nervioso central de todos los organismos superiores) que se intensifica conforme se alargan las cadenas alquílicas del catión.

\section{5 .6}

\section{Aplicaciones de los Líquidos lónicos}

\subsubsection{1}

\section{Líquidos lónicos en la industria}

Hoy en día existen numerosos ejemplos industriales en los que se emplean líquidos iónicos como catalizadores, soportes o intermedios de reacción

Es interesante remarcar en este punto los innovadores recursos que pusieron de manifiesto las compañías que accedieron a adentrarse en el inexplorado mundo del diseño de plantas industriales empleando líquidos iónicos. En la mayoría de los casos, los resultados superan con mucho las expectativas creadas.

${ }^{74}$ Evans-White, Lamberti, G., A. Envirn. Toxicol. Chem., 2009, 28, 418.

75 Matzke M., Stolte S., Thiele K., Juffernholz T., Arning J., Ranke J., Welz-Biermann U., Jastorff B., Green Chem., 2007, 9, 1198.

${ }^{76}$ Wasserscheid P., Welton T., Ionic Liquids in Synthesis. Wiley-VCH. 2008. 
La Tabla 1.7 presenta algunas de las aplicaciones que se están probando en planta piloto o que ya llevan unos cuantos años funcionando, así como las empresas que las han hecho posibles.

\begin{tabular}{lllr}
\hline Empresa & Proceso & Acción del LI. & Escala aplicación \\
\hline BASF & Eliminación de ácidos & Auxiliar & Comercial \\
& Destilación extractiva & Extractor & Planta Piloto \\
& Cloración & Disolvente & Comercial \\
IFP & Dimerización de olefinas & Disolvente & Planta Piloto \\
Degussa & Hidrosililación & Disolvente & Planta Piloto \\
& Compatibilización & Aditivo & Comercial \\
Arkema & Fluoración & Disolvente & Planta Piloto \\
Chevron Phillips & Oligomerización de olefinas & Catalizador & Planta Piloto \\
Scionix & Electrólisis (Cr) & Electrolito & Planta Piloto \\
Eli Lilly & Escisión de éteres & Catalizador/Reactivo & Planta Piloto \\
Air Products & Almacenamiento de gases & Soporte de líquidos & Planta Piloto \\
Iolitec/Wandres & Limpieza de fluidos & Aditivo & Comercial \\
Linde & Compresión de gases & Pistón para líquidos & Planta Piloto \\
Solar Millennium & Acumulador energético & Disolvente/Reactivo & Comercial \\
\hline
\end{tabular}

Tabla 1.7.- Aplicaciones industriales publicadas ${ }^{92}$ de líquidos iónicos.

\section{Eliminación de Ácidos: Proceso BASIL ${ }^{\text {TM }}$ aBASF}

La síntesis de alcoxifenilfosfinas genera $\mathrm{HCl}$ que originalmente se eliminaba con aminas terciarias, generando una pasta muy difícil de aislar. El proceso BASILTM utiliza 1-Metilimidazolio, que estando en el medio, se protona con el $\mathrm{HCl}$ generado en la síntesis y produce cloruro de 1-Metilimidazolio, que es líquido a temperatura ambiente y no miscible con el crudo de reacción. Este proceso proporciona:

\footnotetext{
× Mayor rendimiento químico.

- Mayor rendimiento espacio-tiempo.

\& Mejor transferencia de calor.

x Menores costes.

$\bowtie \quad$ Proceso sostenible.
} 


\section{Destilación Extractiva}

\section{D-BASF}

La formación de azeótropos es uno de los problemas más comunes a los que suele enfrentarse la industria, entre los más recurrentes están los sistemas agua/etanol o agua/THF. Algunos líquidos iónicos, especialmente higroscópicos, actúan como captadores del agua, haciendo que el otro compuesto pueda ser destilado en su estado puro. Con ello se consigue:

× Rotura eficaz del azeótropo.

* Reducir el consumo energético.

× Reducir el consumo en equipamiento.

$\bowtie$ Menores inversiones.

\section{Cloración de dialcoholes con $\mathrm{HCl}$ como nucleófilo}

La cloración industrial de dialcoholes para obtener dihalogenados, se ha llevado a cabo con fosgeno durante mucho tiempo, es un proceso eficaz pero con un alto grado de peligrosidad por la elevada toxicidad de los fosgenos. Aunque la cloración también se ha intentado con cloruro de hidrógeno, el proceso no es del todo eficaz, pues se genera un gran número de productos secundarios. Cuando se emplea un líquido iónico ${ }^{77}$ como disolvente, la capacidad nucleofílica del $\mathrm{HCl}$ se incrementa, haciendo que el rendimiento de la cloración del dialcohol sea del $100 \%$. Las ventajas del proceso con líquidos iónicos son:

× Eliminación del uso de fosgeno ${ }^{78}$.

a Alta conversión y selectividad.

\section{Dimerización de Olefinas: Tecnología DIFASOL}

El Institut Francaise du Petrol ${ }^{79}$ fue la primera organización que desarrolló un proceso basado en el empleo de líquidos iónicos como disolventes para la producción de dímeros de butenos. Los beneficios derivados:

a Mayor actividad catalítica.

* Mayor estabilización del catalizador.

* Mayor selectividad del proceso.

\section{Hidrosililación degussa.}

77 Jork C., Seiler M., Beste Y.-A., Arlt W., J. Chem. Eng. Data, 2004, 49, 852.

78 WO 02/074718 BASF. WO 05/ 016484 BASF.

79US 6203712 B1. Institut Français du Petrole. US 6284937. Institut Français du Petrole. 
Es un método de síntesis de silanos y siloxanos "organomodificados" con Pt coloidal como catalizador. Para reducir los costes del proceso, el metal se emplea en cantidades significativamente pequeñas, lo que hace que la velocidad de reacción decrezca. Degussa ha desarrollado un sistema bifásico ${ }^{80}$ que consigue una eficaz dispersión del catalizador en la fase del líquido iónico aumentando su reactividad y reduciendo las pérdidas que suelen acaecer en los procesos de separación y purificación de productos. Los beneficios:

× Recuperación y reutilización de la fase catalítica.

x Reducción del tiempo de reacción.

× Mejora en la calidad del producto.

\section{Compatibilizadores de pigmentos degussa.}

Hasta ahora los pigmentos podían ser solubles en agua o solubles en disolventes orgánicos. Degussa ha conseguido desarrollar nuevos pigmentos que pueden ser estables tanto en sistemas acuosos como en disolventes orgánicos, mediante la adición de determinados líquidos iónicos a la pasta de los pigmentos.

\section{Fluoración ARkems}

A partir del Protocolo de Montreal, los hidrocarburos clorofluorados empleados como refrigerantes, fueron poco a poco retirados del mercado por su implicación en la reducción de la capa de ozono y sustituidos por sus homólogos sin cloro. Los refrigerantes fluorocarbonados se obtienen a partir de los clorofluorocarbonados por sustitución del cloro mediante reacción con HF y $\mathrm{SbCl}_{5}$ como catalizador. Para evitar la desactivación reductiva del catalizador, Arkema ${ }^{81}$ emplea en su planta piloto, un líquido iónico basado en imidazolio con [SbF6]- como anión, que consigue eliminar los problemas derivados de la desactivación. Las ventajas de este proceso:

× Mayor selectividad.

* Mayor actividad catalítica.

* Mayor estabilidad del catalizador.

${ }^{80}$ Weyerhausen B., Hell K., Hesse U., Green Chem., 2005, 5, 283.

81 WO 01/81353 ARKEMA 
moouteste Air Products ha desarrollado una nueva tecnología de almacenaje de gases que sustituye los materiales sólidos de adsorción a baja presión por líquidos iónicos. Éstos permiten almacenar una gran cantidad de gases sin necesidad de aplicación de presión (para hacer uso del gas almacenado tan solo es necesaria la aplicación de vacío sobre el cilindro contenedor).

Limale Linde emplea líquidos iónicos en los pistones que introducen los gases en los cilindros que luego se comercializan, así evita los problemas derivados de la utilización de aceites o sales disueltas.

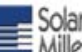

Por su alta capacidad calorífica y su baja presión de vapor, Solar Millennium emplea líquidos iónicos como sustitutos de las disoluciones salinas que se utilizaban como acumuladores energéticos en las estaciones de energía solar. Así se evita la evaporación del agua de las disoluciones y con ella la corrosión y demás problemas derivados de los depósitos salinos formados.

\subsubsection{2}

Otras aplicaciones de Líquidos lónicos. Líquidos lónicos en investigación 1.5.6.2.1

\section{Reacciones de Biocatálisis en Líquidos lónicos}

Aunque el tema es muy atrayente, la biocatálisis en líquidos iónicos lleva poco tiempo siendo estudiada. Por lo general, la catálisis enzimática se ha llevado a cabo en medios acuosos. A principios de los ochenta Klibanov y col. ${ }^{82}$ propusieron el uso de disolventes orgánicos hidrófobos para el trabajo con enzimas. Y en el año 2000 un trabajo de Cull y col. ${ }^{83}$ proponía el uso de [Bmim] $\mathrm{PF}_{6}$ para la hidratación de 1,3-dicianobenceno en un sistema bifásico empleando Rhodococcus 312 como catalizador.

Por su naturaleza iónica los líquidos iónicos afectan a las estructuras enzimáticas, en ocasiones para bien y por lo tanto potencian su actividad catalítica y en ocasiones para no tan bien pues favorecen la desnaturalización de las proteínas. Los trabajos desarrollados en este campo muestran una amplia

82 Zaks A., Klibanov A.M., Proc. Natl. Acad. Sci. U.S.A., 1983, 82, 3196.

${ }^{83}$ Cull S.G., Holbrey V., Vargas-Mora V., Seddon K.R., Lye G.J., Biotechnol.Bioeng., 2000, 69, 227. 
variedad de enzimas ${ }^{84}$ (lipasas sobretodo, pero también, proteasas, glicoxidasas, termolisina, hidrolasas...) cuya actividad en líquidos iónicos es comparable a la observada en sistemas orgánicos o acuosos convencionales e incluso en algunos casos mayor, pues son capaces de proporcionar estabilidad térmica y operacional y además favorecen regio- y enantioselectivamente el proceso.

Finalmente, cabe destacar que los sistemas enzima/líquido iónico permiten el uso de técnicas de reacción o extracción poco convencionales, como sistemas bifásicos agua/líquido iónico o $\mathrm{scCO}_{2} /$ líquido iónico en los que el enzima se mantiene en la fase líquido iónico y reactantes y productos en la acuosa $^{99}$ o supercrítica ${ }^{85}$. Además, gracias a la despreciable presión de vapor de estos disolventes, los productos se pueden ir evacuando del crudo de reacción mediante destilación, haciendo que el equilibrio siempre esté desplazado hacia la producción, hasta conversión completa, y conseguir en el mismo proceso la recuperación del catalizador que por lo general puede ser reusado sin problemas $^{86}$.

\subsubsection{2}

\section{Síntesis de Polímeros en Líquidos lónicos}

Pese a que hasta ahora, una de las características que hacía especiales a los líquidos iónicos (inapreciable presión de vapor) había resultado de extrema importancia para muchas de sus aplicaciones, en el campo de la síntesis de polímeros, la contribución de esta característica no es tan evidente, de hecho, los altos pesos moleculares de los polímeros hacen que el aislarlos tras la síntesis en medio líquido iónico sea completamente inviable, e imprescindible el empleo de disolventes volátiles para la extracción, desvirtuándose así el aspecto "verde" de la aplicación.

Sin embargo, hay otros factores que justifican el empleo de líquidos iónicos y que han hecho proliferar en los últimos años las publicaciones sobre este tema:

^ La polimerización vía radicales libres. Con el uso de líquidos iónicos se incrementa la constante de velocidad de propagación

\footnotetext{
${ }^{84}$ Moon Y.H., Lee S.M., Ha S.H., Koo Y-M., Korean J. Chem. Eng., 2006, 23, 247.

${ }^{85}$ Lozano P., de Diego T., Carrié D., Vaultier M, Iborra J.L. Chem. Commun. 2002, 692.

${ }^{86}$ Rantwijk F.v., Lau R.M., Sheldon R.A., Trends in Biotechnology, 2003, 21.
} 
del polímero ${ }^{87}$, en parte debido a la polaridad del medio, permitiendo además un mayor control del proceso. Por otra parte los líquidos iónicos quirales permiten conseguir excesos enantioméricos determinados ${ }^{88}$, que resultan de vital importancia en algunas síntesis.

× La policondensación y poliadición. Tan solo se conocen unos cuantos trabajos ${ }^{89}$ en esta área, sin embargo son de alto interés por conseguir la poliadición de diaminas y ácido tetracarboxílico para generar las consiguiente poliimidas en ausencia de catalizador, con el único empleo de dialquilimidazolio con distintos aniones como medio de reacción. Y la policondensación de diaminas en las mismas condiciones con resultados igual de sorprendentes.

× La polimerización electroquímica. La electroquímica fue la primera parcela de la química que le dio una utilidad a los líquidos iónicos aunque no precisamente para la polimerización electroquímica. Algunos de los polímeros conductores que se han sintetizado de este modo son: Poli(p-fenileno $)^{90}$, politiofeno ${ }^{91}$, polipirrol $^{92}$ y polimeros $^{93}$ conductores sintetizados a partir de benceno polimerizado anódicamente con líquidos iónicos binarios (cloroaluminatos).

× La polimerización enzimática. La reacción entre la caprolactama y diésteres alifáticos catalizada por lipasa en medio [Bmim] $\mathrm{PF}_{6} / 1,4$-butadiol, produce poliésteres con un rendimiento del $97 \%$ para la polimerización ${ }^{94}$ y del $72 \%$ para la policondensación ${ }^{95}$. En estos trabajos se vuelve a insistir en la magnífica interacción existente entre enzimas y líquidos iónicos.

\footnotetext{
${ }^{87}$ Harrison S., Mackenzie S.R., Haddleton D.M., Chem Commun., 2002, 2850.

88 Biedrón T., Kubisa P., Polym. Int., 2003, 8, 1265.

89 Vygodskii Y.S., Lozinskaya E.I.. Shaplov A.S., Macromol. Rapid Commun., 2002, 80, 676.

90 Kobryanskii V.M.,Arnautov S.A., J. Chem. Soc. Chem. Commun., 1992, 727.

91 Janiszewska L., Osteryoung R.A., J. Electrochem.Soc., 1987, 94, 2787.

92 Pickup P.G., Osteryoung R.A., J. Electroanal. Chem., 1985, 88, 271.

93 Trivedi D.C., J. Chem., Soc., Chem. Commun., 2002, 544.

94 Kubisa P., Prog. Polym. Sci., 2004, 29, 3.

${ }^{95}$ Lau R.M., Van Rantwijk F., Seddon K.R., Sheldon R.O., Org. Lett., 2000, 91, 4189.
} 


\subsubsection{3}

\section{Síntesis Inorgánica y Líquidos lónicos}

La aplicación de líquidos iónicos en la parcela de la química inorgánica no es tan apabullante como lo es en la de la química orgánica y durante bastante tiempo ha sido baldía. Sin embargo, últimamente se ha observado un aumento en los trabajos dedicados a la síntesis inorgánica que han dado un giro inesperado y prometedor al uso de líquidos iónicos.

Comenzando por los compuestos de coordinación, se observó que algunas especies de halógenometalatos ${ }^{96}\left(\left[\mathrm{MoCl}_{6}\right]^{2-}\right)$ se formaban espontáneamente en medio líquido iónico básico, durante procesos de medición electroquímica y que el ion tetracloroaluminato de líquidos iónicos binarios, actuaba como ligando bidentado ${ }^{97}$, generando iones del tipo $\left[\mathrm{M}\left(\mathrm{AlCl}_{4}\right)_{3}\right]^{-.98}$

En cuanto a la síntesis de compuestos organometálicos, uno de los conceptos más interesantes son los "carbenos" (imidazolidenos), ligandos derivados de la estructura básica de los líquidos iónicos basados en imidazolios ${ }^{99}$. Se observó que los complejos NHC-Paladio (así como también los de Ni y Pt) se podían generar a partir de la adición oxidativa de los cationes imidazolio del líquidos iónico, a especies de los metales en su estado fundamental ${ }^{100}$. Hay muchas más reacciones en las que se han aplicado líquidos iónicos, no tanto como ligandos sino más bien como medios de reacción ${ }^{101}$ o incluso como catalizadores ${ }^{102}$ de síntesis organometálicas.

La electrodeposición ${ }^{103}$ es una parcela muy importante dentro de la electroquímica, tanto a nivel industrial como en investigación. La mayoría de los metales pueden obtenerse por electrólisis a partir de sus sales disueltas o fundidas y debido a sus particulares propiedades de conductividad, potencial

\footnotetext{
96 Hussey C.L., Pure Appl. Chem., 1988, 60, 1763.

97 Dent A.J., Seddon K.R., Welton T., J. Chem. Soc., Chem. Commun., 1990, 315.

${ }^{98}$ Dent A.J., Lees A., Lewis R.J., Welton T., J. Chem. Soc., Dalton Trans., 1996, 2787.

99 Welton T., Smith P.J., Adv. Organomet. Chem., 2004, 51, 251.

100 Chianese A.R., Kovacevic A., Zeglis B.M., Faller J.W., Crabtree R.H., Organometallics, 2004, 23, 2461.

101 Surette J.K.D., Green L., Singer R.D., Chem. Commun., 1996, 63.

102 Dyson P.J., Grossel M.C., Srinivasan N., Vine T., Welton T., Williams D.J., White A.J.P., Zigras T., J., Chem., Soc., Dalton Trans., 1997, 3465.

103 Endres F., Abbot A., MacFarlane D. R. Editors “Electrodeposition in Ionic Liquids".Wiley-VCH. ISBN 978-3-527-31565-9.
} 
electroquímico y presión de vapor, los líquidos iónicos resultan de gran interés en este campo.

La aportación de los líquidos iónicos a las síntesis de materiales y más en particular a la de nanoestructuras ha sido gradual durante la última década, sin embargo es muy prometedora a la vista de los trabajos ${ }^{104}$ que se han realizado por el momento. Los líquidos iónicos son un perfecto sistema estabilizador de nanopartículas metálicas que hace de éstas, excelentes catalizadores para muy diversas reacciones. Además de las características que extensamente se detallaron en apartados anteriores, estos compuestos iónicos tienen la rara propiedad de formar sistemas extendidos ${ }^{105}$ de enlaces puentes de hidrógeno cuando se encuentran en estado líquido, que los cataloga como "disolventes supramoleculares" y les permite proporcionar cierto orden nanoestructural a algunas reacciones espontáneas (es una propiedad casi imprescindible en la química de coloides y surfactantes).

\subsubsection{4}

\section{Síntesis Orgánica y Líquidos lónicos}

Los procesos de síntesis orgánica que se han estudiado empleando líquidos iónicos, consideran que éstos pueden actuar como medio de reacción o disolvente, como catalizador o como ligando.

Aunque el empleo como disolventes puede ser obvio (tan solo se trata de que actúen como disolventes orgánicos convencionales) la particularidad del uso estriba en la forma de aislar posteriormente el producto, ya que la destilación, en la mayoría de los casos, está descartada por la baja volatilidad de los líquidos iónicos. Cuando el producto es volátil se puede emplear la destilación indirecta, cuando no es suficientemente volátil, la alternativa la representa la extracción convencional o con fluidos supercríticos. Finalmente cabe destacar que los líquidos iónicos son un medio ideal para hacer reacciones bifásicas o multifásicas, en las que reactivos, productos, catalizadores y demás, están aislados de partida por las particulares miscibilidades de cada uno de ellos.

En cuanto a las reacciones catalíticas, los líquidos iónicos tienen una gran capacidad de disolver complejos de metales de transición o de estabilizar 
nanopartículas metálicas que ejerzan de catalizadores, incluso se conocen casos en los que ellos mismos, sin la presencia de metales, actúan como catalizadores gracias a sus características ácido-base o red-ox.

En lo que respecta a su función complejante, al comienzo del empleo de líquidos iónicos como disolventes, se consideraba que su implicación en la reacción era prácticamente inexistente, solo actuaban como medios inertes. Sin embargo, poco a poco se han ido dando casos en los que estos compuestos interactúan con las especies en disolución haciendo que su actividad y selectividad se incremente y eso ha motivado un estudio más exhaustivo de las coordinaciones/cooperaciones que de forma fortuita se observaron inicialmente.

Hacer mención y catalogar cada una de las reacciones que caben en este apartado sería una tarea ardua e innecesaria (esto no deja de ser la introducción a una tesis doctoral y no un "review" sobre el tema), sin embargo, es interesante destacar algunas de ellas por su relevancia, interés o conexión con los capítulos del trabajo. Se presentan siguiendo un orden basado en el tipo de catálisis que se lleva a cabo en cada una de ellas.

\section{Reacciones catalizadas por metales de transición en medio Líquido lónico}

Los líquidos iónicos son capaces de disolver eficazmente complejos de metales de transición, en consecuencia, el proceso catalítico que desarrollan pasa a ser homogéneo. La catálisis homogénea, como ya se comentó en los primeros puntos de la introducción, presenta como ventaja frente a la heterogénea que sus centros activos están muy bien definidos y por lo general es fácil y muy efectiva su optimización. Además la separación de productos y la recuperación de catalizadores y medio suelen ser sencillas.

En la gran mayoría de los casos, existe una interesante interacción entre el líquido iónico (disolvente) y el complejo metálico, que puede tanto beneficiar (potenciando su actividad) como perjudicar (desactivando) al proceso catalítico, todo depende de la influencia que el disolvente tenga sobre las propiedades electrónicas y estéricas del complejo metálico activado. Cuanto mayor sea el conocimiento que se tenga sobre el mecanismo de reacción y las propiedades del líquido iónico, mayor será el éxito de la nueva reacción.

Algunas de las reacciones más relevantes que se han llevado a cabo dentro del ámbito de este epígrafe son: 


\section{Reacciones de Hidrogenación}

Los sistemas bifásicos que incluían líquidos iónicos como medios de reacción ${ }^{106}$ han proporcionado buenos rendimientos de reacción para hidrogenaciones de todo tipo, desde las más simples (olefinas), hasta las más complejas (asimétricas).Además estos sistemas permiten una fácil separación de productos.

El único problema que puede afectar a estas reacciones es la baja solubilidad del hidrógeno en el medio de reacción ${ }^{107}$ que provoca una muy baja concentración de éste y por lo tanto la necesidad de trabajar a altas presiones para poder conseguir altas conversiones. Sin embargo, la transferencia del hidrógeno desde la fase gaseosa a la del líquido iónico así como la difusión ${ }^{108}$ de éste en el medio, es muy rápida lo cual compensa la baja solubilidad y hace que las reacciones se den con buenos rendimientos.

Los primeros ejemplos de hidrogenación de olefinas aparecieron publicados en 1995, Chauvin ${ }^{109}$ propuso la hidrogenación bifásica del 1penteno con el "Complejo de Osborn" como catalizador y en medio [Bmim] $\mathrm{SbF}_{6}$ según el esquema de reacción presentado a continuación y con los resultados obtenidos dispuestos en la Tabla 1.8.

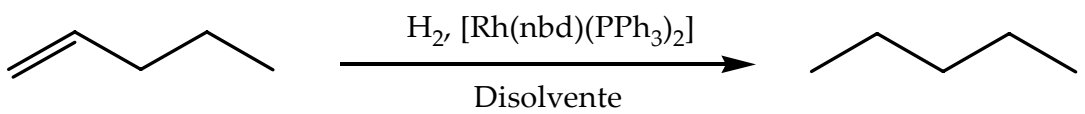

Esquema 1.4.- Hidrogenación del 1-Penteno

\begin{tabular}{|c|c|c|c|c|}
\hline \multirow[t]{2}{*}{ Disolvente } & \multirow{2}{*}{$\begin{array}{l}\text { Convesión (\%) } \\
\text { 1-Penteno }\end{array}$} & \multicolumn{2}{|c|}{ Rendimiento } & \multirow[t]{2}{*}{ TOF $\left(\min ^{-1}\right)$} \\
\hline & & Pentano & 2-Penteno & \\
\hline b Acetona & 99 & 38 & 61 & 0,55 \\
\hline a $\left[\mathrm{Bmim} \mathrm{SbF}_{6}\right.$ & 96 & 83 & 13 & 2,54 \\
\hline
\end{tabular}

Tabla 1.8.- Hidrogenación de 1-Penteno con "Complejo Osborn" como catalizador. $\mathrm{TOF}=$ mol (pentano) por mol de (Rodio) y unidad de tiempo (min).

a Catalizador: 0,05 mmol; 1-Penteno: 8,4 mmol; [Bmim]SbF6: $4 \mathrm{ml}$.

b Catalizador: 0,05 mmol; 1-Penteno: 9,2 mmol; Acetona: $10 \mathrm{ml}$.

$\mathrm{T}=30^{\circ} \mathrm{C}, \mathrm{p}\left(\mathrm{H}_{2}\right)=0,1 \mathrm{MPa} ; \mathrm{t}=2 \mathrm{~h}$.

106 Charloner P.A., Esteruelas M.A., Jóo F., Oro L.A., Homogeneous Hydrogenation, Kluwer Academic Publisher, Dordrecht, 1994.

107 Anthony J.L., Maginn E.J., Brennecke J.F., J. Phys. Chem. B, 2002, 106, 7315.

108 Morgan D., Ferrguson L., Scovazuzo P., Ind. Engl. Chem. Res., 2005, 44, 4815.

${ }^{109}$ Chauvin Y, Mussmann L., Olivier H., Angew. Chem. Int. Ed. Engl., 1995, 107, 2941. 
Existen muchos más ejemplos de hidrogenaciones bajo estas condiciones en la literatura, pero sería tedioso nombrarlos todos, por eso se ha optado por presentar los resultados de una hidrogenación estereoselectiva en la que un líquido iónicos convencional actúa de fase contenedora del catalizador, lo que facilita el reciclado posterior del complejo metálico. En 1997 Dupont $^{110}$ consiguió un 80\% ee para la hidrogenación del ácido 2-arilacrílico al ácido (S)-2-fenilpropiónico con el complejo quiral $\left[\mathrm{RuCl}_{2}(\mathrm{~S})-\mathrm{BINAP}\right]_{2} \mathrm{NEt}_{3}$ como catalizador en $[\mathrm{Bmim}] \mathrm{BF}_{4}$ como disolvente, según el esquema de reacción que se presenta a continuación.

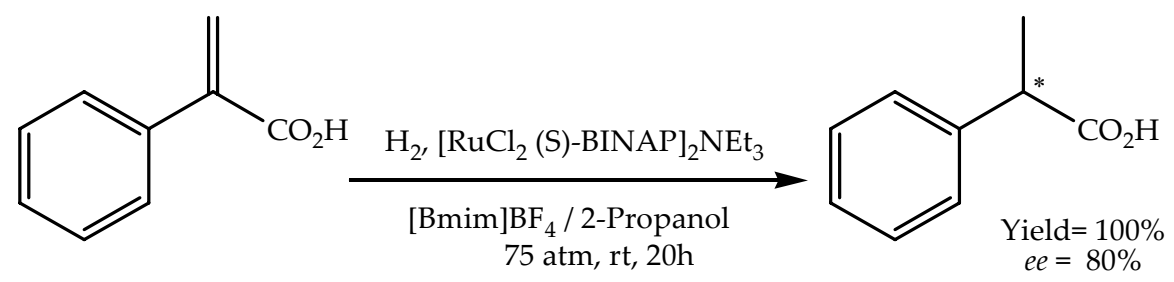

Esquema 1.5.- Hidrogenación del Ácido 2-Arilacrílico al Ácido (S)-2-Fenilpropiónico con el complejo quiral $\left[\mathrm{RuCl}_{2}(\mathrm{~S})-\mathrm{BINAP}\right]_{2} \mathrm{NEt}_{3}$ como catalizador en $[\mathrm{Bmim}] \mathrm{BF}_{4}$.

\section{× Reacciones de Oxidación}

Teniendo en cuenta la importancia que tienen hoy en día las reacciones de oxidación y lo peligrosa que puede llegar a ser la formación de mezclas explosivas de disolventes volátiles y oxígeno, la aplicación de líquidos iónicos en reacciones de oxidación ha atraído el interés de muchos grupos de investigación (debido fundamentalmente a su baja o casi nula presión de vapor). Sin embargo, dos son los inconvenientes que presenta esta aplicación, por una parte la baja solubilidad del oxígeno en la mayoría de los líquidos iónicos y por otra, la alta polaridad que suelen presentar los productos finales de reacción, que hacen que el proceso de extracción ${ }^{111}$, a veces, sea bastante complicado. De todos modos, son problemas que se han podido ir solucionando con el tiempo, trabajando en sistemas bifásicos 
y empleando co-catalizadores que aumentaran la eficacia del oxígeno en el medio.

Existe un gran número de publicaciones que demuestran la viabilidad de estos sistemas, ante todo en oxidaciones de alcoholes a compuestos carbonílicos y de éstos a carboxilos, en epoxidaciones y oxidaciones de tioles. Una de las más representativas es la epoxidación asimétrica de Jacobsen-Katsuki ${ }^{112}$ del 2,2-dimetilcromeno con un complejo de manganeso (catalizador de Jacobsen) en medio $\left[\mathrm{Bmim} \mathrm{PF}_{6}\right.$, tal y como se muestra en el esquema de reacción.

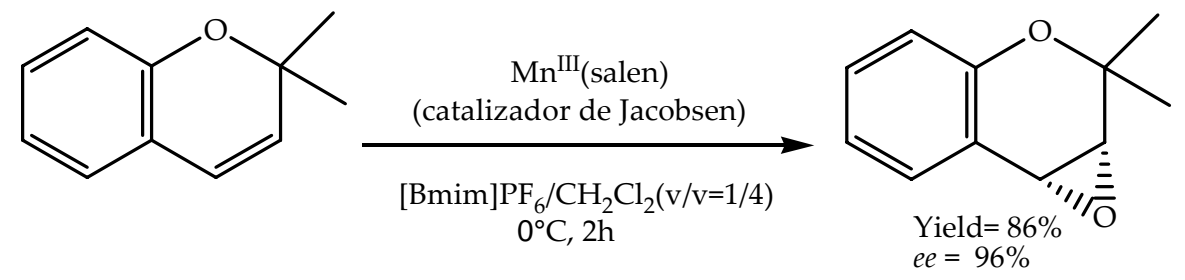

Esquema 1.6.- Epoxidación asimétrica de Jacobsen-Katsuki del 2,2-dimetilcromeno con un complejo de manganeso (catalizador de Jacobsen) en medio [Bmim] $\mathrm{PF}_{6}$.

× Reacciones de acoplamiento C-C (Heck, Suzuki, Stille...)

Este tipo de reacciones tienen gran importancia a nivel sintético y se han utilizado en química fina con el fin de producir nuevas moléculas que aumenten el número de carbonos en su fórmula. El paladio es el metal de transición que mejores resultados ha dado al ser empleado como catalizador, tanto en forma de sales como formando parte de compuestos organometálicos.

La introducción de líquidos iónicos como disolvente para este tipo de reacciones, proporciona estabilidad al catalizador, evitando la precipitación del metal en su estado elemental y alargando la vida media del catalizador. Desde los primeros trabajos ${ }^{113,114}$ que datan de 1996 se pudo comprobar, por los buenos resultados, que la combinación de paladio con líquidos iónicos suponía una gran ventaja sobre los disolventes convencionales, en las reacciones de formación de enlaces C-C. 
En los últimos años muchas reacciones de acoplamiento se han llevado a cabo empleando nanopartículas ${ }^{115,116}$ de paladio como catalizadores, que en su mayoría fueron preparadas, a su vez, en medio líquido iónico. Los resultados son muy interesantes, por eso, en parte, se ha incrementado de forma exponencial el número de grupos de investigación dedicados a este tema. Algunos ejemplos típicos de las reacciones mencionadas durante esta sección están representados en los siguientes esquemas de reacción:

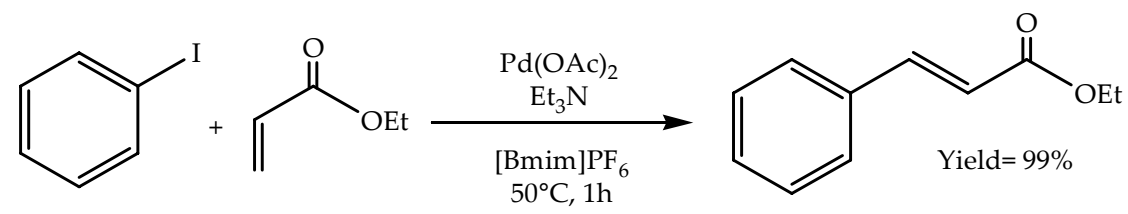

Esquema 1.7.- Reacción de Heck entre el Yodobenceno y el Etilacrilato con Acetato de Paladio como catalizador y $\left[\mathrm{Bmim}_{\mathrm{P}} \mathrm{P}_{6}\right.$ como medio de reacción.

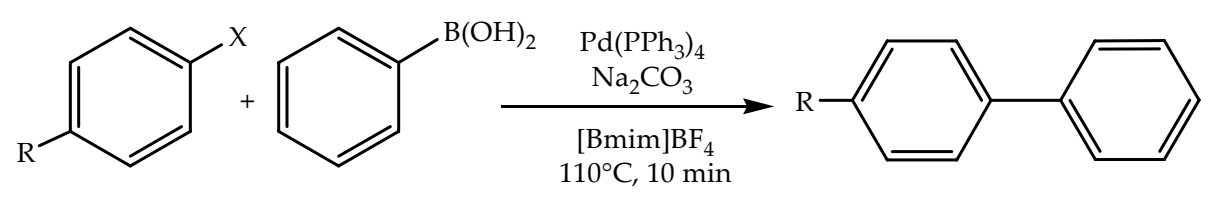

Esquema 1.8.- Reacción de Suzuki entre un haluro de arilo y el Ácido Fenilborónico con Tetratrifenilfosfina de Paladio como catalizador y $\left[\mathrm{Bmim}_{\mathrm{B}} \mathrm{BF}_{4}\right.$ como medio de reacción.

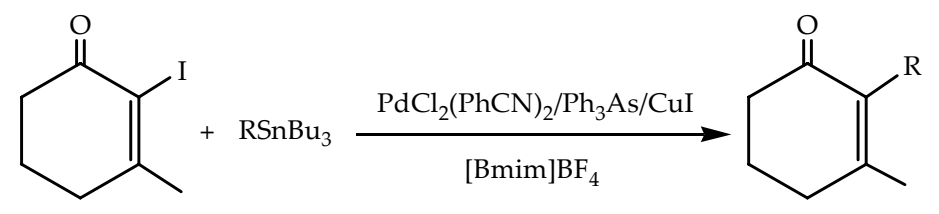

Esquema 1.9.- Reacción de Stille catalizada por un complejo de paladio entre yodoenonas y vinil o arilestanadatos en medio $\left[\mathrm{Bmim}_{\mathrm{B}} \mathrm{BF}_{4}\right.$.

Hay muchos más ejemplos de reacciones catalíticas con metales de transición como centros activos y en las que, poco a poco se están introduciendo los líquidos iónicos como medio de reacción/co-catalizadores: Hidroformilación, Dimerización, Oligomerización, Alcoxicarbonilación, Reacción de Trost-Tsuji, Metátesis de olefinas... sin embargo, y comprensiblemente, se tomó la determinación de proponer una visión general de este tipo de catálisis y de las 
particularidades que entraña el uso de líquidos iónicos, ahondando someramente en las reacciones que se consideraron de mayor importancia o que tienen una relación directa con el trabajo llevado a cabo en la tesis y que más adelante se comentará.

\section{Reacciones de catálisis ácido-base en medio Líquido lónico}

Conforme se ha ido ampliando el número de líquidos iónicos disponibles y mejorando en sus características, el interés de la comunidad científica en estos compuestos ha aumentado apreciablemente. En los inicios, cuando solo se conocían los líquidos iónicos cloroaluminados, su desmedida predisposición a interaccionar con grupos funcionales convencionales, los hacía inservibles en la mayoría de reacciones, pues no conseguía actuar como medio inerte de reacción. Con el descubrimiento de los líquidos iónicos solubles en agua, el rango de reacciones en que se emplean en la actualidad es amplísimo y crece día a día, las aplicaciones son innumerables, pero algunas de las más interesantes o al menos de las que más juego han dado para este proyecto son las siguientes.

\section{Reacción de Michael}

Un gran número de adiciones de Michael se han llevado a cabo en medio líquido iónico con resultados sorprendentes ya que, mientras que en disolventes convencionales era necesario el empleo de catalizadores metálicos para promover la reacción, con estos nuevos disolventes resulta del todo innecesario cualquier tipo de metal en el medio.

Un interesante ejemplo de lo que se acaba de comentar lo propuso Xia ${ }^{117}$ en el 2004 al encontrar aminas que en disolución acuosa de $[\mathrm{Bmim}] \mathrm{BF}_{4}$ reaccionaban con etil o metilacrilato dando el producto de adición de Michael con un rendimiento del 96\%.

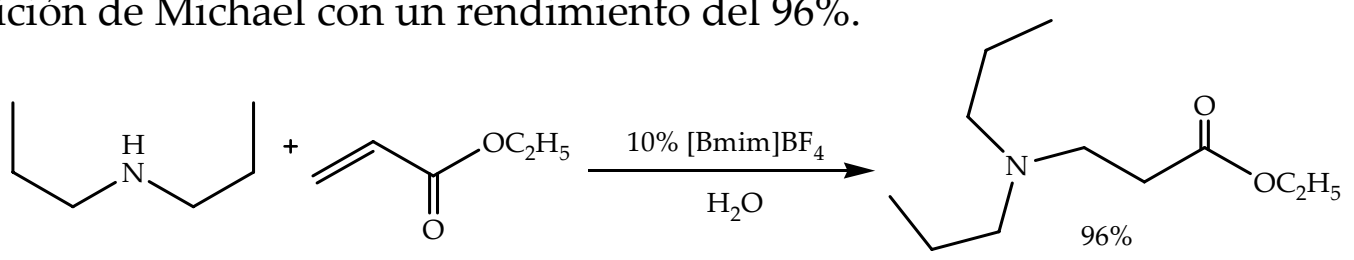

Esquema 1.10.- Adición de Michale entre etilacrilato y dipropilamina en disolución acuosa de $[\mathrm{Bmim}] \mathrm{BF}_{4}$. 


\section{x Reacción Baylis-Hillman}

La reacción de Baylis-Hillman es una variante de la adición de Michael e implica la adición de un aldehído en la posición $\alpha$ de una cetona $\alpha, \beta$-insaturada en presencia de una amina terciaria. Por lo general en este tipo de reacciones no se emplea disolvente, lo que en ocasiones genera problemas cuando los reactivos son sólidos, así que puestos a emplear disolventes, se probaron no solo los convencionales, también algunos líquidos iónicos, con resultados que superaron por mucho los obtenidos en líquidos orgánicos tradicionales. Uno de los primeros ejemplos que aparecen en la literatura es la reacción ${ }^{118}$ de metilacrilato con benzaldehído en $\left[\mathrm{Bmim}_{\mathrm{P}} \mathrm{PF}_{6}\right.$. Los resultados en este caso probaron que el proceso transcurría 20 veces más rápido que en acetonitrilo.<smiles>C=CC(=O)OC</smiles>

Esquema 1.11.- Reacción de Baylis-Hillman entre metilacrilato y benzaldehído en medio [Bmim]PF.

La diasteroselectividad de este tipo de reacciones fue investigada a partir de la adición ${ }^{119}$ de reactivos quirales a la cetona $\alpha, \beta$-insaturada o empleando líquidos iónicos quirales ${ }^{120}$.

\section{× Reacción de Mannich}

La reacción de Mannich se engloba dentro de las reacciones de condensación y supone la interacción entre un grupo carbonilo y una amina. Un ejemplo interesante de la aplicación de líquidos iónicos en la reacción de Mannich lo representa la síntesis en procesos multietapa del ácido isoquinolónico ${ }^{121}$ en medio $\left[\mathrm{Bmim}_{\mathrm{B}} \mathrm{BF}_{4}\right.$ o $\left[\mathrm{Bmim}^{\mathrm{B}} \mathrm{PF}_{6}\right.$ según el esquema de reacción que se presenta a continuación. Por lo general, estas

118 Rosa J.N., Afonso C.A.M., Santos A.G., Tetrahedron, 2001, 57, 4189.

119 Kitazume T., Tamura K., Jiang Z., Miyake N., Kawasaki I., J. Fluorine Chem., 2002, 115, 49.

120 Pérgot B., Vo-Thanh G., Gori D., Loupy A., Tetrahedron Lett., 2004, 45, 6425.

121 Yadav J.S., Reddy B.V.S., Saritha Raj K., Prasad A.R., Tetrahedron, 2003, 59, 1805. 
reacciones están catalizadas por ácidos de Lewis del tipo $\mathrm{BF}_{3}-\mathrm{OEt}_{2}, \mathrm{TiCl}_{4}, \mathrm{O}$ $\mathrm{SnCl}_{4}$, pero con el empleo de líquidos iónicos se hace innecesario cualquier catalizador heterogéneo.

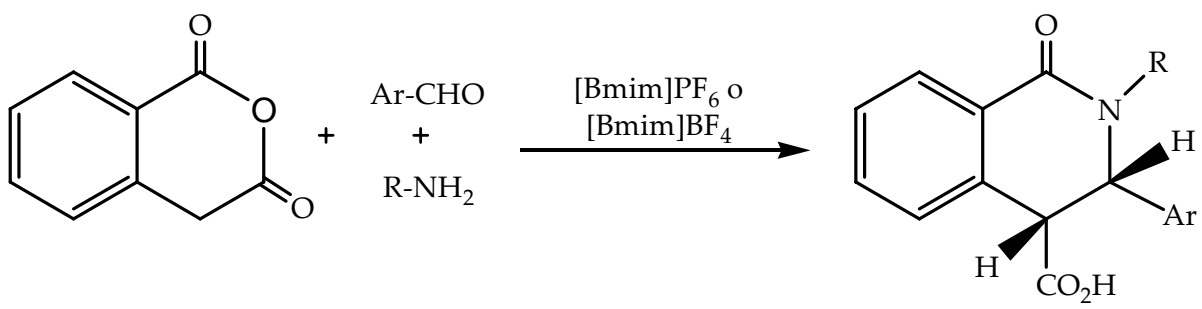

Esquema 1.12.- Reacción de Mannich entre $4 \mathrm{H}$-isocromeno-1,3-diona, un aldehído y una amina en medio $\left[\mathrm{Bmim}_{\mathrm{P}} \mathrm{PF}_{6} \mathrm{o}[\mathrm{Bmim}] \mathrm{BF}_{4}\right.$ sin empleo de catalizadores heterogéneos.

\section{× Condensación aldólica y Reacción de Knoevenagel}

Ambas reacciones representan transformaciones orgánicas básicas que dan lugar a enlaces $C$ - $C$, por eso resultan de gran importancia en el ámbito de la química fina. Tradicionalmente para llevarlas a cabo se han empleado catalizadores con carácter básico, sin embargo en algunos casos también puede emplearse la catálisis ácida para conseguir según qué productos.

En lo referente a reacciones de Knoevenagel, el primer ejemplo de aplicación de líquidos iónicos fue llevado a cabo por Davis ${ }^{122}$ y colaboradores, que emplearon $[\mathrm{Hmim}] \mathrm{PF}_{6}$ para la condensación entre el propano-1,3-dinitrilo y el benzaldehído, al medio se le adicionó glicina como base para generar el anión del dinitrilo.

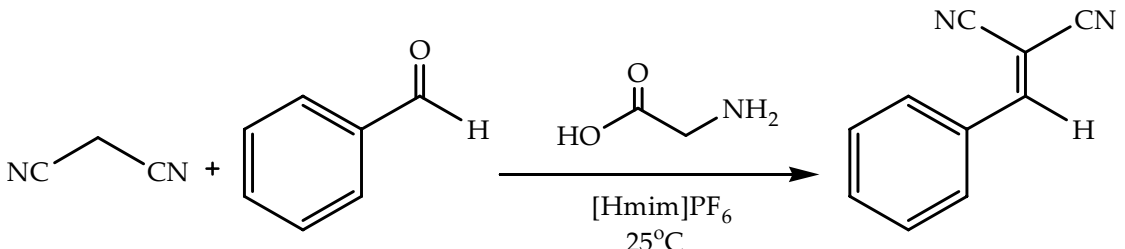

Esquema 1.13.- Síntesis de 1,1-diciano-2-fenileteno mediante reacción de Knoevenagel entre propano-1,3-dinitrilo y benzaldehído en medio [Hmim] $\mathrm{PF}_{6}$, con glicina como base.

\section{$\propto$ Reacción de Diels-Alder}

La reacción de Diels-Alder es una ciclación electrofílica catalizada por ácidos de Lewis, es además una de las reacciones que más ampliamente se han investigado en relación con los líquidos iónicos ya que 
las disoluciones acuosas que con anterioridad se empleaban como medio de reacción, afectaban drásticamente a las constantes de reacción y a la estereoselectividad de los productos obtenidos. Cuando comenzaron a introducirse algunos líquidos iónicos como medio de reacción, se observó un incremento considerable en los rendimientos finales de reacción.

El estudio realizado por Earle ${ }^{123}$ para la reacción entre el ciclopentadieno y el etilacrilato muestra que cuando la reacción se lleva a cabo en medio [Bmim] $\mathrm{PF}_{6}$ es ligeramente más rápida que cuando se hace en agua, pero que la selectividad endo:exo es considerablemente mayor, tal y como se puede apreciar en la Tabla 1.9.

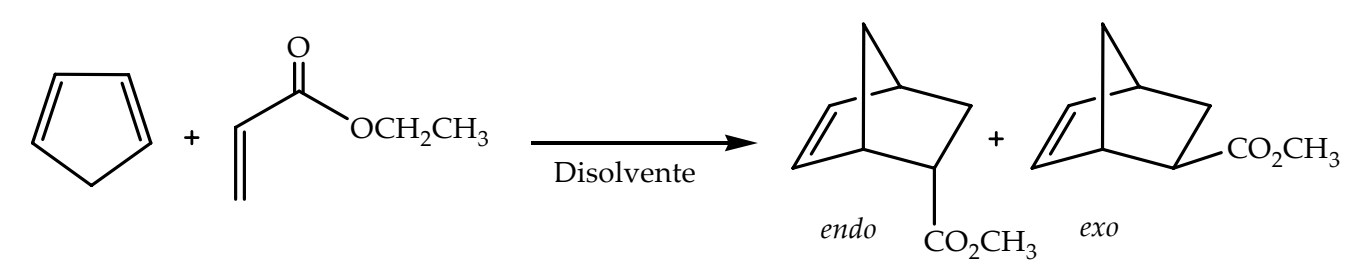

Esquema 1.14.- Reacción de Diels-Alder entre el ciclopentadieno y el etilacrilato.

\begin{tabular}{lccc}
\hline Disolvente & Tiempo (h) & Rendimiento (\%) & Relación endo:exo \\
\hline $\mathrm{H}_{2} \mathrm{O}$ & 1 & 30 & $3: 5$ \\
{$[\mathrm{Bmim}] \mathrm{PF}_{6}$} & 1 & 36 & $8: 0$ \\
\hline
\end{tabular}

Tabla 1.9.- Reacción de Diels-Alder entre el ciclopentadieno y el etilacrilato.

\section{× Reacción de Friedel-Crafts}

La reacción de Friedel-Crafts es otra de las interesantes a la hora de formar enlaces C-C y puede estar catalizada tanto por ácidos fuertes de Brønsted como por ácidos de Lewis. Se suele definir como una alquilación electrofílica, lo que supone la interacción entre un agente alquilante y en este caso un compuesto aromático. Aunque ha sido ampliamente estudiada, uno de los problemas que más afecta a este tipo de reacciones es la polialquilación, puesto que los propios productos finales de reacción suelen ser más reactivos que los materiales de partida, además los mecanismos de la reacción de Friedel-Crafts no son sencillos, lo que

${ }^{123}$ Earle M.J., McCormac P.B., Seddon K.R, Green Chem., 1999, 1, 23. 
provoca que en ocasiones, para una misma reacción se puedan proponer diferentes mecanismos.

La primera referencia que emplea sales fundidas para una alquilación de Friedel-Crafts data de 1953, en ella Baddeley ${ }^{124}$ y Williamson ${ }^{125}$ llevaban a cabo ciclaciones intramoleculares en mezclas de $\mathrm{NaCl}-\mathrm{AlCl}_{3}$. Más adelante $\mathrm{Boon}^{23}$ y colaboradores estudiaron el comportamiento de benceno y tolueno en diferentes mezclas de [Emim] Cl$\mathrm{AlCl}_{3}$. Los resultados con diferentes cloruros de alquilo y mezclas de [Emim]Cl-AlCl3 se presentan en la Tabla 1.10.

\begin{tabular}{lcccccccc}
\hline \multicolumn{1}{c}{ R-Cl } & $\boldsymbol{X}^{\mathrm{a}}$ & R-Cl:C6 6 6:LI & mono- & di- & tri- & tetra- & penta- & hexa- \\
\hline Metil & 0,67 & xs $: 1: 1$ & 1,5 & 58,5 & 1,5 & 26,8 & 1,4 & 10,2 \\
Etil $^{\mathrm{b}}$ & 0,67 & $\mathrm{xs}: 1: 1$ & 11,5 & 10,8 & 33,4 & 24,4 & - & 1,5 \\
n-Propilc & 0,60 & $1,25: 1,25: 1$ & 24,8 & 19,9 & 55,3 & - & - & - \\
n-Butilc & 0,60 & $1,33: 1,33: 1$ & 25,0 & 26,3 & 48,7 & - & - & - \\
Ciclohexil & 0,60 & $10: 10: 1$ & 35,0 & 30,0 & 34,4 & - & - & - \\
Bencil & 0,60 & $0,78: 1,17: 1$ & 50,0 & 34,5 & 15,6 & - & - & - \\
\hline
\end{tabular}

Tabla 1.10.- Productos obtenidos en la reacción de cloruros de alquilo con benceno en medio [Emim]Cl-AlCl 3.

a Relación molar entre [Emim] $\mathrm{Cl}$ y el $\mathrm{AlCl}_{3}$

b Temperatura de reacción: Reflujo del haluro de alquilo.

c Temperatura de reacción: Temperatura ambiente en cámara seca.<smiles>Cc1cccc(C)c1</smiles>

Esquema 1.15.- Reacción de Friedel-Crafts. Alquilación del benceno con cloruro de metilo. 
Existen un sinfín de referencias sobre la interacción entre líquidos iónicos y Friedel-Crafts, en ellas se habla de nuevos agentes alquilantes y diferentes catalizadores, pasando por el empleo de líquidos iónicos quirales ${ }^{126}$ que mejoran el rendimiento estereoespecífico, líquidos iónicos binarios $^{127}$ en los que se introducen un amplio abanico de metales que mejoran las características ácidas del medio, incluso líquidos iónicos en los que se elimina la presencia de ácidos de Lewis ${ }^{128}$, y probablemente en este momento muchos grupos de investigación estén dándole todavía muchas vueltas a este tema.

${ }^{126}$ Qiao K., Yokoyama C., Chem. Lett., 2004, 33. 472.

127 Hodgson P.K.G., Morgan M.L.M., Ellis B., Abdul-Sada A.A.K., AtkinsM.P., Seddon K.R., U.S

Patent, 5994602, 1999. Wasserscheid P., Ellis B., Fabienne H., World Patent. 0041809, 2000.

${ }^{128}$ Keim W., Korth W., Wasserscheid, World Patent, 0016902, 2000. 





\section{Objetivos}

En líneas generales, el objetivo de esta tesis es el desarrollo de nuevos sistemas catalíticos basados en los líquidos iónicos y la aplicación de éstos en la transposición de Beckmann de una determinada oxima y en reacciones de formación de enlaces C-C.

Desde un punto de vista más detallado, el trabajo engloba como primer objetivo el estudio de la utilización de líquidos iónicos como medio de reacción y catalizadores de la transposición de Beckmann de la ciclododecanona oxima. La determinación de los centros responsables de la actividad catalítica se realizará mediante el estudio por resonancia magnética nuclear, ahondando de forma más exhaustiva en el mecanismo de la reacción y en las características que aporta cada líquido iónico, además de la adecuación de las variables del proceso para que éste sea lo más eficiente posible. Así se consigue una aproximación ostensible hacia la química verde, pues se evita el uso de ácido sulfúrico, corrosivo y altamente peligroso, y su posterior neutralización, que genera enormes cantidades de sulfato amónico como subproducto sin apenas valor comercial.

El segundo objetivo es la preparación de un material híbrido orgánicoinorgánico-metal mediante el intercambio parcial de los protones de un polioxometalato con la unidad catiónica de un líquido iónico, seguido de un intercambio de $\mathrm{Pd}^{2+}$. Este nuevo material se caracterizará detalladamente por microscopía electrónica y espectroscopía fotoelectrónica de rayos $\mathrm{X}$ y se utilizará como catalizador heterogéneo en la reacción de Heck de acoplamiento CarbonoCarbono.

El tercer objetivo de esta tesis es la síntesis y el estudio de la actividad catalítica de nuevos organocatalizadores con características típicas de líquidos iónicos, que a la vez poseen bifuncionalidad ácido-base, y que son capaces de emular la actividad de determinados sistemas enzimáticos. La distancia y orientación de ambos centros catalíticamente activos se optimizará para su aplicación en reacciones de formación de enlaces Carbono-Carbono (Knoevenagel, Claisen-Schmidt, Adición de Michael) 

Capítulo III:

\section{Transposición de Beckmann con líquidos iónicos}





\section{1}

\section{Introducción}

\subsection{1}

Transposición de Beckmann. Historia de un proceso

La transposición de Beckmann consiste en la transformación de una oxima en una amida N-sustituida' ${ }^{129130}$. Este proceso, descubierto en 1886 por el químico alemán Ernst Otto Beckmann, tiene valor sintético en la vía de formación de amidas y aminas, por eso ha sido y sigue siendo de gran importancia en investigación.

Pero también tiene interés industrial ya que ciertas oximas cíclicas vía catálisis ácida, experimentan la<smiles>[R]C([R])=NO</smiles>

Oxima<smiles>[R]NC([R])=O</smiles><smiles>O=C1CCCCCCCCCCN1</smiles>

Amida

Amida cíclica: Lactama transposición de Beckmann que da como producto final lactamas, amidas cíclicas que por calentamiento se transforman en poliamidas, denominadas nailon, que se utilizan como fibras sintéticas.

La síntesis industrial de los monómeros que dan lugar a estas fibras sintéticas, se lleva a cabo con ácido sulfúrico concentrado como catalizador, que posteriormente debe ser neutralizado con amoniaco, generando grandes cantidades de sulfato amónico como producto secundario de la reacción ${ }^{131}$. Por ejemplo, en la<smiles>CC(=O)NCCCCCCNC(=O)CCCCC(=O)N(C)C</smiles>
producción de una tonelada de

SOBRE EL NAILON : El nailon es un polímero sólido blanco y opaco. Fue preparado por primera vez en febrero de 1935 por el químico estadounidense Wallace Carothers en los laboratorios de la compañía DuPont.

129 Encyclopaedia of Chemical Technology, Wiley, 1992, 19, 449.

130 Soto, J.L., Química Orgánica, Grupos funcionales y heterociclos, Editorial Síntesis, 2005.

131 Guo S., Deng Y., Catalysis Commun., 2005, 6, 225. 
$\varepsilon$-caprolactama se obtienen $1,7-1,9$ ton de $\left(\mathrm{NH}_{4}\right)_{2} \mathrm{SO}_{4}$ como producto secundario, con prácticamente nulo interés comercial ${ }^{132}$.

Pese a ser un proceso industrial muy competitivo, las grandes cantidades de sulfato amónico generadas, así como el empleo de ácido sulfúrico (con gran poder corrosivo y altamente peligroso) hacen que el proceso actual se encuentre muy lejos de los objetivos propuestos por la química verde y que por lo tanto, sea necesaria una revisión de la síntesis de lactamas para la obtención de nailon.

Una de las líneas de investigación abiertas con respecto a este tema, introduce los fluidos supercríticos como alternativa catalítica y medio de reacción para la producción de lactamas. Los grupos de Boero ${ }^{133}$ y Sato ${ }^{134}$, han propuesto procesos de síntesis empleando respectivamente agua o dióxido de carbono supercríticos ${ }^{135}$. De este modo consiguen evitar los problemas de corrosión y aumentar la selectividad, sin embargo la escasa conversión, así como las condiciones de reacción especialmente severas que exigen estos procesos (en agua supercrítica se trabaja a temperaturas entre $350-400^{\circ} \mathrm{C}$ y presiones de 22,1 $\mathrm{MPa}$ ), hacen que su uso solo sea viable a nivel de laboratorio y con pocas posibilidades de implantación en la producción a mayor escala.

Durante las dos últimas décadas del S.XX se dedicaron muchos esfuerzos a la aplicación de zeolitas y tamices moleculares, como catalizadores ácidos, en la transposición de Beckmann de oximas. El descubrimiento de que los centros ácidos débiles asociados a los grupos silanoles de estos materiales, resultaran más selectivos en la transposición de Beckmann que los centros Brønsted fuertemente ácidos, permitió la industrialización en 1989 por Sumitomo ${ }^{136,137}$ de un proceso para la producción de $\varepsilon$-caprolactama en fase gas, empleando una zeolita tipo MFI alta sílice.

A raíz de esta aplicación se comenzó a estudiar una gran gama de catalizadores ácidos heterogéneos, siempre en busca de alternativas más limpias y eficaces para la transposición de Beckmann. En la Tabla 3.1 se muestran algunos de estos catalizadores, junto con las compañías que los desarrollaron y

\footnotetext{
132 Hölderich W.F., Röseler J., Heitmann G., Liebens A.T., Cat. Today, 1997, 37, 353.

133 Boero M., Ikeshoji T., Liew C., Terakura K., Paninello M., J. Am. Chem. Soc., 2004, 126, 6280.

134 Ikushima Y., Hatakeda K., Sato O., Yokoyama T., Arai M., J. Am. Chem. Soc., 2000, 122, 1908.

135 Sato O., Ikushima Y., Yokoyama T., J. Org. Chem., 1998, 63, 9100.

136 Ichihashi H., Sato H., Appl. Catal. A, 2001, 221, 359.

137 Ichihashi H., Ishida M., Shiga A., Kitamura M., Suzuki T., Suenobu K., Sugita K., Catal. Surv. Asia, 2003, 7, 261.
} 
un pequeño resumen de las condiciones de reacción y los resultados obtenidos en la transposición de Beckmann de la ciclododecanona oxima.

\begin{tabular}{llllllll}
\hline Compañía & $\begin{array}{c}\text { Número } \\
\text { Patente }\end{array}$ & Año & Catalizador & Disolv. & $\begin{array}{c}\text { WHSV }^{\text {a }} \\
\left(\mathbf{h}^{-1} \mathbf{)}\right.\end{array}$ & $\begin{array}{c}\text { Conv. } \\
\mathbf{( \% )}\end{array}$ & $\begin{array}{c}\text { Select. } \\
\mathbf{( \% )}\end{array}$ \\
\hline UOP & US4873325 & 1986 & SAPO-11 & MeCN & 0,54 & 98 & 95 \\
Sumitomo & US4709024 & 1986 & High sílica MFI & Benceno & 3 & 74 & 72 \\
Sumitomo & US4968793 & 1989 & High sílica MFI & MeOH & 3,3 & 99 & 87 \\
Mobil & US4927924 & 1989 & ZSM-5 & Benceno & 0,05 & 99 & 89 \\
Mitsubishi & EP509493 & 1991 & Ta2O5/SiO 2 & Benceno & 1 & 98 & 97 \\
Degussa & DE19608660 & 1995 & B-MFI & MeOH & 0,25 & 99 & 93 \\
Sumitomo & JP-291074 & 1996 & ALPO-5 & EtOH & 0,45 & 27 & 88 \\
Unichem & EP819675 & 1996 & SiO2/Al2O3 amorfa & MeOH & 2 & 99 & 78 \\
Ube & JP10-87612 & 1996 & Zeolita L & Hexanol & 0,83 & 99 & 97 \\
\hline
\end{tabular}

Tabla 3.1.- Algunos de los catalizadores heterogéneos más importantes empleados en la transposición de Beckmann de la ciclododecanona oxima de fase gas. a) WHSV: Weight Hourly Space Velocity (Velocidad espacial).

En los últimos años, los líquidos iónicos están despertando cada vez mayor interés y son en la actualidad una alternativa a aplicar, tanto a nivel de investigación como industrial. Sus curiosas propiedades los hacen aptos para muchos procesos, pues poseen presiones de vapor inapreciables que hacen de ellos el mejor medio para síntesis orgánicas "verdes"138 y el hecho de que estén constituidos por dos componentes (anión y catión) los hace especialmente versátiles, permitiendo diseñar el líquido iónico apropiado para las necesidades de cada reacción ${ }^{139}$.

El uso de líquidos iónicos en procesos catalíticos está ampliamente aceptado. Tanto reacciones orgánicas (Diels-Alder, Friedel-Crafts, Esterificaciones, Cicloadiciones, etc.) como organometálicas (Acoplamientos, Hidrogenaciones, Oxidaciones, etc.) se han llevado a cabo en líquidos iónicos como medio de reacción o catalizadores, con resultados muy atrayentes.

Particularmente en la transposición de Beckmann se han empleado como medio de reacción, líquidos iónicos con cationes de tipo piridinio e imidazolio,

\footnotetext{
${ }^{138}$ Earle M.J., Seddon R., Pure Appl. Chem., 2000, 72, 1391.

${ }^{139}$ Freemantle M., Chem. Eng. News, 1998, 76, 32.
} 
utilizando como catalizadores, compuestos fosforados $\left(\mathrm{PCl}_{5}, \mathrm{POCl}_{3}, \mathrm{P}_{2} \mathrm{O}_{5}\right)^{140,141,142}$ o ácido metabórico ${ }^{131}$. Otra versión de aplicación de líquidos iónicos en la reacción de Beckmann son los sistemas catalíticos consistentes en líquidos iónicos dicatiónicos, con acidez Brønsted proporcionada por dos grupos $\mathrm{SO}_{3} \mathrm{H}$ en la parte catiónica, interconectados por cloruro de zinc $\left(\mathrm{ILs}-\mathrm{ZnCl}_{2}\right)^{143}$.

Recientemente, han aparecido publicaciones que proponen la mezcla de gran número de líquidos iónicos con catalizadores ácidos de Lewis $\left(\mathrm{AlCl}_{3}, \mathrm{TiCl}_{4}\right.$, $\mathrm{SnCl}_{4}, \mathrm{BF}_{3}$ ) como sistema para la transposición de Beckmann de algunas cetoximas, consiguiendo altos niveles de conversión y selectividad ${ }^{144}$. Líquidos iónicos con acidez Brønsted funcionalizados con cloruro de sulfonilo ${ }^{145} \mathrm{o}$ líquidos iónicos basados en una estructura de caprolactamio (con aniones del tipo $\mathrm{BF}_{4}^{-}$, $\left.\mathrm{NO}_{3}{ }^{-}, \mathrm{CF}_{3} \mathrm{COO}^{-}\right)^{146}$ empleados como medio de reacción o catalizadores, han proporcionado resultados interesantes en la transposición de ciertas oximas.

Los últimos estudios que se han llevado a cabo en relación al mecanismo de reacción de la transposición de la ciclohexanona oxima para obtener $\varepsilon$ caprolactama en medio oleum han demostrado que, en realidad, es éste el mayor proceso tecnológico a escala industrial (y probablemente uno de los más antiguos) que se desarrolla en medio líquido iónico pues el ácido inorgánico, genera in situ el catión caprolactamio con el sulfato como anión, y este sistema acaba siendo el motor catalítico del proceso ${ }^{147}$.

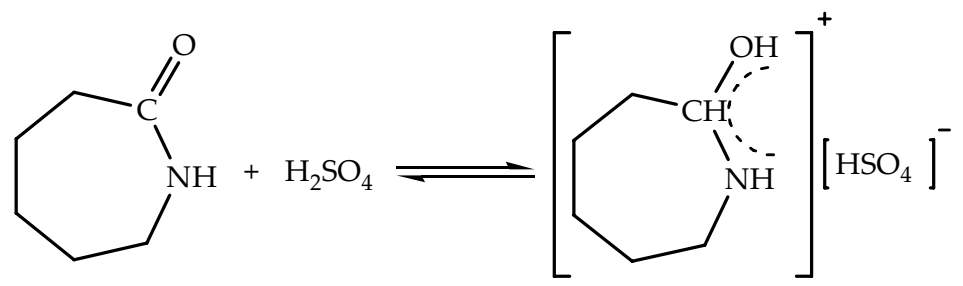

Esquema 3.1.- Esquema simplificado de reacción entre la $\varepsilon$-caprolactama y el ácido sulfúrico a escala industrial.

En cuanto a la síntesis en particular de $\omega$-laurolactama, el monómero a partir del cual se produce el nailon 12, existe un menor número de referencias

\footnotetext{
${ }^{140}$ Peng J., Deng Y., Tetrahedron Lett., 2001, 42, 403.

141 Ren R.X., Zueva L.D., Ou W., Tetrahedron Lett., 2001, 42, 8441.

142 Elango K., Srirambalaji R., Anantharaman G., Tetrahedron Lett., 2007, 48, 9059.

${ }^{143}$ Liu X., Xiao L., Wu H., Chen J., Xia C., Catal. Commun., 2009, 10, 424.

144 Zicmanis A., Katkevica S., Mekss P., Catal. Commun., 2009, 10, 614.

${ }^{145}$ Du Z., Li Z., Gu Y., Zhang J., Deng Y., J. Mol. Catal. A : Chemical, 2005, 237, 80.

${ }^{146}$ Guo S., Du Z., Zhang S., Li D., Deng Y., Green Chem., 2006, 8, 296.

${ }^{147}$ Fabos V., Lantos D., Bodor A., Bálint A-M., Mikca L.T., Sielcken O.E., Cupiera., Horváth I.,

Chem.Sus.Chem., 2008, 1, 189.
} 
bibliográfias pero resulta especialmente interesante el empleo que hacen Corma y col. de zeolitas de tamaño medio de poro, tipo H-ZSM-5148, zeolitas deslaminadas ITQ-2 y Beta-nanocristalinas ${ }^{149}$ o materiales mesoporosos tipo MCM-4150, tanto en reactor "batch" como en lecho fijo, obteniendo selectividades del cien por cien a $\omega$-laurolactama y conversiones significativamente altas. La transposición de Beckmann de la ciclododecanona oxima en fase gas ${ }^{151}$, se ha llevado a cabo también con materiales mesoporosos silicoaluminofosfatos ${ }^{152,153}$ (SAPO) con estructura de tipo MCM-41. Estos materiales mostraron gran actividad tanto en la transposición de la ciclohexanona como de la ciclododecanona oxima, alta selectividad y posibilidad de reutilización. Más recientemente, Eickelberg y Hoelderich ${ }^{154}$ han llevado a cabo la transposición de Beckmann de la ciclododecanona oxima en fase gas empleando catalizadores sólidos como por ejemplo: H-ZSM-5, USY, Aerosil, [B]MFI, MCM-41 pura sílice, etc. y prestando especial atención a las medidas de presiones de vapor dentro del sistema de reacción, ayudados a su vez por cálculos teóricos para obtener información veraz sobre cuales son las mejores condiciones para obtener los más altos rendimientos.

Finalmente, la reacción directa de formación de la lactama a partir de la cetona correspondiente, en un proceso multietapa, fue desarrollada empleando como catalizador síliceácido sulfúrico ${ }^{155}$, como reactantes ciclohexanona y cloruro de hidroxilamina e irradiando con microondas (2450 MHz, $400 \mathrm{~W})$. El

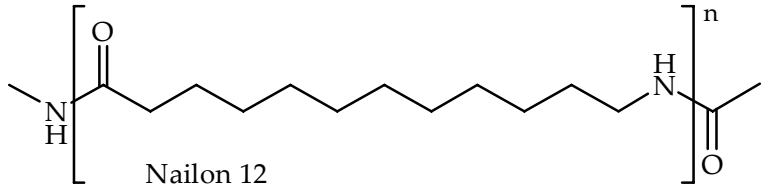

SOBRE EL NAILON 12: Conforme se aumenta el número de carbonos en las cadenas entre grupos amida, se consigue que disminuyan los puntos de fusión de las fibras, pero que aumente su resistencia al agua. El número de carbonos en las cadenas suele ser siempre par, lo que hace que las fibras de nailon sean más compactas y tengan puntos de fusión más altos. El nailon 12 por sus propiedades mecánicas de flexibilidad y resistencia a la abrasión, así como su excelente comportamiento químico se emplea principalmente en productos de alta tecnología como: líneas de combustible, tubos de frenos neumáticos para camiones, revestimientos metálicos o de fibra óptica y últimamente en conducciones de gas ciudad.

\footnotetext{
148 Camblor M.A., Corma A., García H., Semmer-Herlédan V., Valencia S., J. Catal., 1998, 177, 267.

149 Botella P., Corma A., Iborra S., Montón R., Rodríguez I., Costa V., J. Catal., 2007, 250, 161.

150 Climent M.J., Corma A., Fornés V., García S., Miralles J., Rodríguez I., Stud. Surf. Sci. Catal., 2001,

$135,3719$.

151 Conesa T.D., Mokaya R., Yang Z., Luque R., Campelo J.M., Romero R.R., J. Catal., 2007, $252,1$.

152 Zhimyak Y.Z., Klinowski J., Phys. Chem. Chem. Phys., 2001, 3, 2544.

153 Pastore H.o., Coluccia S., Marchese L., Annu. Rev. Mater. Res, 2005, 35, 351.

${ }^{154}$ Eickelberg W., Hoelderich W.F., J. Catal., 2009, 263, 42.

155 Zolfigol M.A., Tetrahedron, 2001, 57, 9509.
} 
rendimiento ${ }^{156}$ de la reacción fue alto, teniendo en cuenta además que el catalizador pudo ser reutilizado varios ciclos y que no se observaron productos secundarios tipo nitrilos o urea.

Puesto que el empleo de líquidos iónicos como catalizadores para la transposición de Beckmann de la ciclododecanona oxima no ha sido un tema especialmente desarrollado en investigación, y las pocas publicaciones ${ }^{143}$ que existen al respecto emplean, por lo general, ácidos de Lewis o sustancias más comprometidas para el proceso catalítico, además de líquidos iónicos como medio de reacción, se propuso como objetivo inicial de este trabajo la obtención de $\omega$-laurolactama a partir de la ciclododecanona oxima empleando líquidos iónicos comerciales que pudieran ejercer a la vez la función de medio de reacción y catalizadores. En definitiva se trata de encontrar una forma "verde" de producción de $\omega$-laurolactama, evitando el uso de co-catalizadores o disolventes en la reacción y haciendo el proceso más rápido, eficaz, limpio y a la larga incluso bastante más barato puesto que los líquidos iónicos empleados pueden ser reutilizados durante un gran número de ciclos sin apreciable deterioro o pérdida de actividad.

\section{1 .2}

Mecanismo general de la transposición de Beckmann
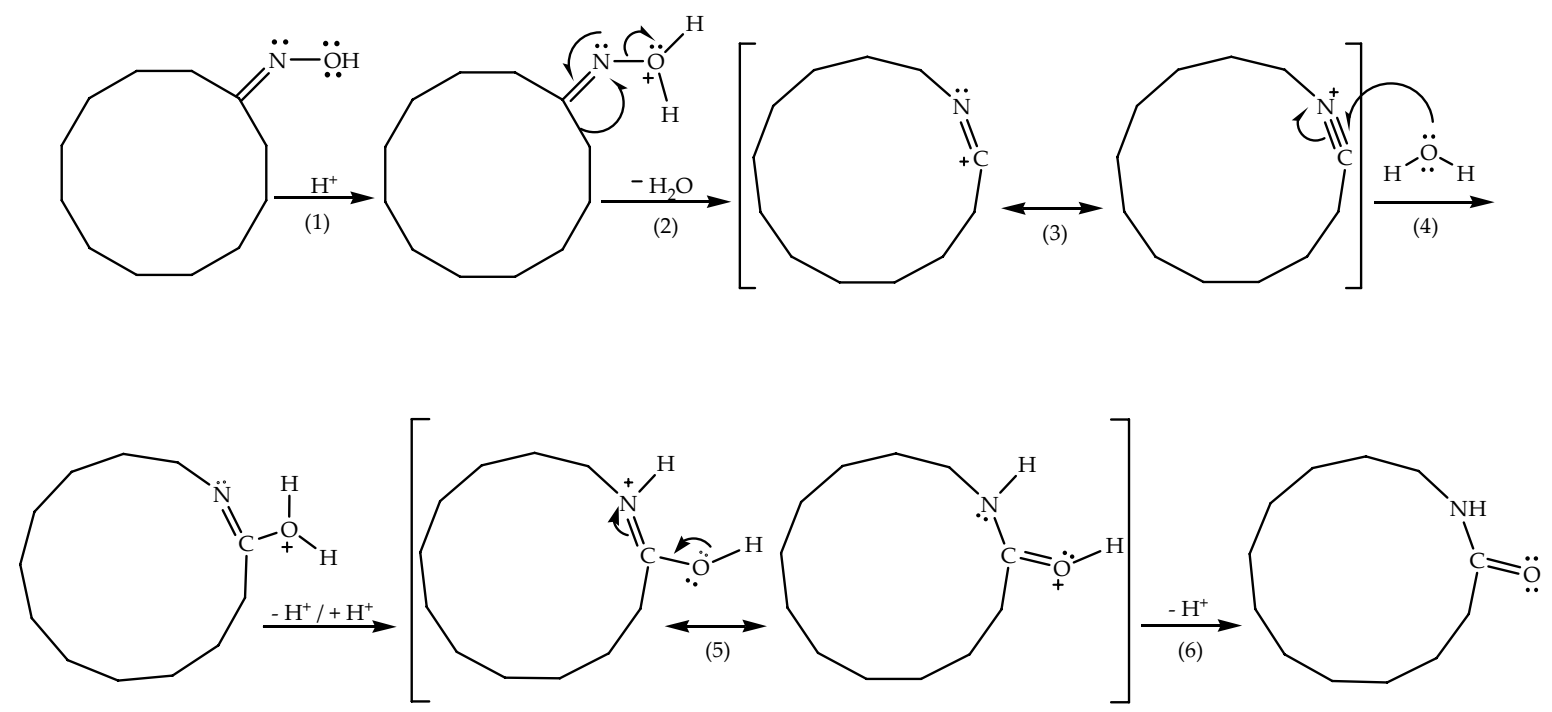

Esquema 3.2.- Mecanismo de reacción de la transposición de Beckmann para la ciclododecanona oxima.

${ }^{156}$ Eshghi H., Hassankhani A., J.Korean Chem. Soc., 2007, 51, 4. 
Tal y como se muestra en el Esquema 3.2, el mecanismo generalmente aceptado para la transposición de Beckmann utilizando ácidos de Brønsted, implica como primer paso (1) la protonación del grupo hidroxilo de la oxima forzando su salida en forma de una molécula de agua. Simultáneamente a la salida del agua se genera la migración del grupo contiguo (2) hacia el propio nitrógeno, provocando la compartición de un par de electrones entre el átomo de nitrógeno y el de carbono. Se llega así a un grupo nitrilo cuaternizado (3) con cierto carácter carbocatiónico que provoca, con mucha facilidad, el ataque de una molécula de agua (4).Tras la pérdida de un protón se genera el tautómero de la amida (5) y finalmente (6) la amida como producto el de la transposición.

\section{2}

\section{Obtención de $\omega$-Laurolactama. Transposición de Beckmann} 3.2.1

Influencia del líquido iónico empleado

Se sabe que los líquidos iónicos basados en el catión imidazolio, forman estructuras poliméricas o clusters a través de puentes de hidrógeno que implican al átomo de hidrógeno más ácido del anillo, es decir, el situado en el carbono C2 entre los dos átomos de nitrógeno. Este carbono con densidad de carga positiva, debido a la deficiencia electrónica del doble enlace $(C=N)$, genera que el átomo de hidrógeno tenga cierta acidez. Teniendo esto en cuenta, se planteó la posibilidad de estudiar la transposición de Beckmann de la ciclododecanona oxima, utilizando líquidos iónicos con catión imidazolio que pudieran actuar como medio y catalizador ácido de la reacción.

A partir de la información de que se disponía, en primer lugar se comenzó a trabajar con el hexafluorofosfato de 1-butil-3-metilimidazolio $\left(\mathrm{BmimPF}_{6}\right)$, pues su uso en reacciones de catálisis ácida, en combinación con otros co-catalizadores, se había constatado en la bibliografía ${ }^{157}$. El proceso de transposición de Beckmann de la ciclododecanona oxima, requiere una acidez moderada y en este caso, se llevó a cabo empleando únicamente $\mathrm{BmimPF}_{6}$ como medio de reacción, obteniéndose resultados inesperados, pues la conversión de

${ }^{157}$ Ren R. X., Zueva L.D., Ou W., Tetrahedron Letters, 2001, 42, 8441. 
la oxima a lactama fue completa y selectiva en más de un 99\% (ver Tabla 3.2, Entrada 1).

Con el objeto de explicar la alta actividad obtenida y entender cuáles eran los efectos que la habían fomentado, se probaron otros líquidos iónicos. El tetrafluoroborato de 1-butil-3-metilimidazolio $\left(\mathrm{BmimBF}_{4}\right)$, mantenía la misma estructura catiónica (continuaba presentando el $\mathrm{H}$ ácido del anillo imidazolio) pero variaba el anión, de modo que, en base a la actividad que desarrollara se podría determinar la importancia de la contribución aniónica en la actividad catalítica de este grupo de líquidos iónicos. También se evaluó la contribución catiónica y en este caso, por una parte se empleó un líquido iónico con catión piridinio, el hexafluorofosfato de 1-butil-4-metilpiridinio $\left(\mathrm{BmpyPF}_{6}\right)$, que tan solo presentaba un heteroátomo dentro del anillo aromático, y por otra parte se mantuvo la estructura del imidazolio, pero se anuló la acidez Brønsted que aportaba el protón ácido del $\mathrm{C} 2$, sustituyéndolo por un metilo en el hexafluorofosfato de 1-butil-2,3-dimetilimidazolio (BmmimPF6), así, en el caso de obtener actividad, se podría asociar irrevocablemente al efecto del anión. Las estructuras de los líquidos iónicos empleados y sus nombre abreviados aparecen en la Figura 3.1. Los resultados obtenidos en la transposición de Beckmann de la ciclododecanona oxima con distintos líquidos iónicos se detallan en la Tabla 3.2.
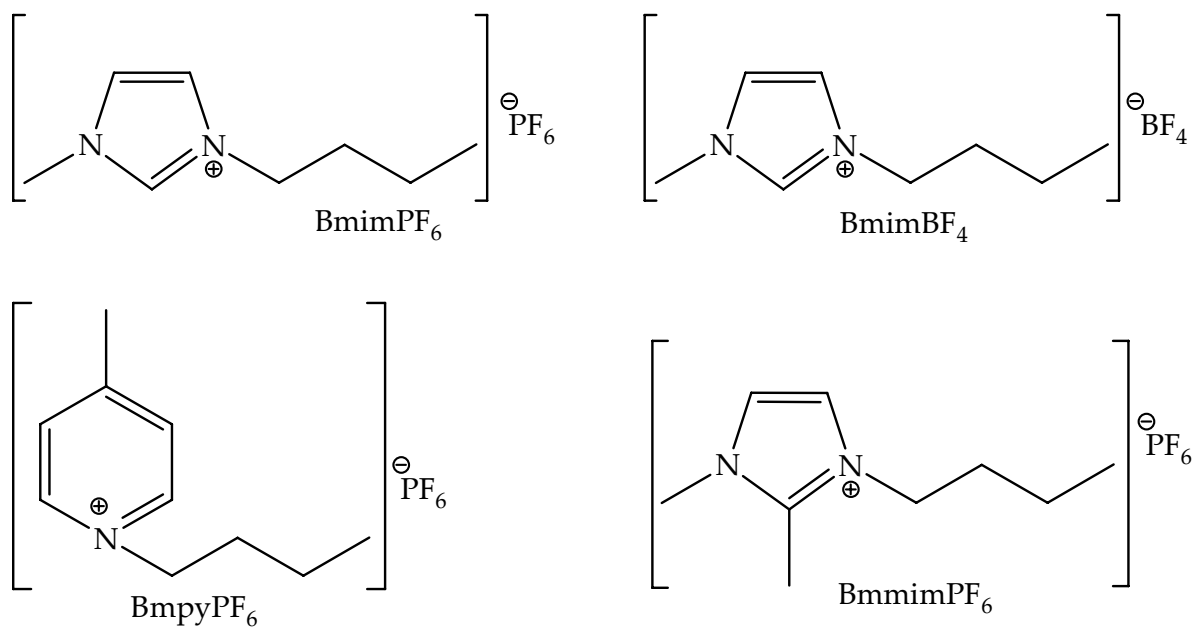

Figura 3.1.- Estructuras y nombres abreviados de los líquidos iónicos comerciales empleados como medio de reacción y catalizador en la transposición de Beckmann de la ciclododecanona oxima. BmimPF6: Hexafluorofosfato de 1-butil-3-metilimidazolio; BmimBF: Tetrafluoroborato de 1-butil-3metilimidazolio; BmpyPF6: Hexafluorofosfato 1-butil-4-metilpiridinio; BmmimPF6: Hexafluorofosfato 1-butil-2,3-dimetilimidazolio. 


\begin{tabular}{clccc}
\hline Ent. & Líquido iónico & $\begin{array}{c}\text { Conversión } \\
\text { Oxima } \\
(\%)\end{array}$ & $\begin{array}{c}\text { Selectividad } \\
\text { Laurolactama } \\
(\mathbf{\%})\end{array}$ & $\begin{array}{c}\text { Balance de } \\
\text { Materia } \\
(\%)\end{array}$ \\
\hline $\mathbf{1}$ & BmimPF $_{6}$ & 100 & $>99$ & 96 \\
$\mathbf{2}$ & BmimBF$_{4}$ & 0 & 0 & 95 \\
$\mathbf{3}$ & BmpyPF $_{6}$ & 99 & 95 & 99 \\
$\mathbf{4}$ & BmmimPF $_{6}$ & 0 & 0 & 94 \\
\hline
\end{tabular}

Tabla 3.2.- Resultados de la transposición de Beckmann de la ciclododecanona oxima en presencia de diferentes líquidos iónicos. Las reacciones se realizaron a $130^{\circ} \mathrm{C}$ durante 2 horas, manteniendo una relación molar oxima/lactama $=0,14$. La conversión de la ciclododecanona oxima se determinó por cromatografía de gases a partir de la cantidad de oxima transformada en lactama. La selectividad también se determinó por cromatografía de gases a partir de la lactama generada.

Tal y como queda de manifiesto en la Tabla 3.2, la actividad de los cuatro líquidos iónicos fue muy dispar. Por una parte, tal y como se comentó con anterioridad, con $\mathrm{BmimPF}_{6}$ (Entrada 1) se consiguió llevar a cabo la transposición de la ciclododecanona oxima, en dos horas de reacción, a $130^{\circ} \mathrm{C}$ y con una relación másica aproximada de 1:10 oxima:líquido iónico, obteniéndose una conversión del $100 \%$ y una selectividad a $\omega$-laurolactama mayor del $99 \%$. El balance de materia tras la extracción de la lactama del líquido iónico con éter dietílico fue del $96 \%$. Cuando la transposición se llevó a cabo en $\mathrm{BmimBF}_{4}$ (Entrada 2), en igualdad de condiciones, no se obtuvo el producto de la transposición y tras la correspondiente extracción se recuperó un 95\% de la oxima empleada.

En el caso del BmpyPF 6 (Entrada 3), tal y como refleja la tabla, la conversión fue del $99 \%$ y la selectividad a $\omega$-laurolactama del $95 \%$. En este caso, el catión no posee en su estructura un protón al que se le pueda asociar acidez Brønsted y por lo tanto parece evidente la contribución aniónica a la capacidad catalítica del líquido iónico. No obstante, para acabar de descartar la influencia catiónica en la actividad y antes de centrar el interés exclusivamente en el anión, se utilizó bajo las mismas condiciones de reacción, el $\mathrm{BmmimPF}_{6}$ (Entrada 4)(nótese en este caso, que el H2 está sustituido, por lo tanto la contribución catiónica a la acidez del medio fue anulada). En principio, si el anión era el responsable de la actividad catalítica, deberían reproducirse los resultados obtenidos con los líquidos iónicos que poseen hexafluorofosfato como anión, sin embargo, tal y como se muestra en la Tabla 3.2, no se observó conversión de la ciclododecanona oxima. 
De modo que, la teoría de que la responsabilidad catalítica del proceso recaía exclusivamente en el anión y que el catión no fuera determinante en el proceso, se vio truncada a raíz de estos resultados.

Por todo esto, y con el propósito de aclarar los resultados experimentales, se estudió mediante espectroscopía de RMN multinuclear en estado sólido e in situ la reacción de transposición de Beckmann de la ciclododecanona oxima en medio líquido iónico.

\subsection{2}

\section{Estudios realizados por RMN}

Puesto que la diferencia entre reactivo y producto en la transposición de Beckmann consiste únicamente en una pequeña variación en el grupo funcional (de oxima $-\mathrm{CH}=\mathrm{N}-\mathrm{OH}$ a amida $-\mathrm{CHO}-\mathrm{NH}$ ), en este estudio se utilizó como reactivo la oxima marcada ( ${ }^{15} \mathrm{~N}$-ciclododecanona oxima) en presencia de $\mathrm{BmimPF}_{6}$, con una relación molar oxima/líquido iónico de 1.

La Figura 3.2 muestra los espectros RMN-MAS de ${ }^{15} \mathrm{~N}$ de la mezcla de reacción en diferentes etapas de ésta: mezcla fresca, sin someter a tratamiento térmico, mezcla a $50^{\circ} \mathrm{C}$ durante cinco y veinte minutos. El espectro de la mezcla fresca muestra un solo pico a $-45 \mathrm{ppm}$ que se corresponde con la ${ }^{15} \mathrm{~N}$-oxima libre.
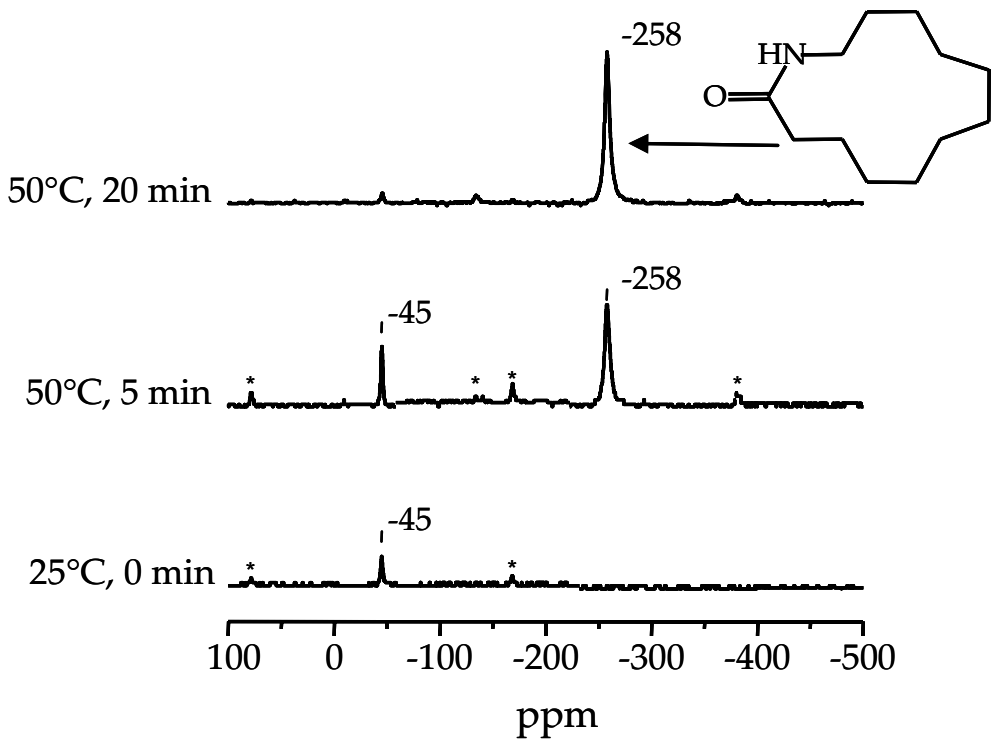

Figura 3.2.- Espectros de RMN-MAS del ${ }^{15} \mathrm{~N}$ de la mezcla de reacción en diferentes estapas de la misma. El pico a -45 corresponde a la señal de la ciclododecanona oxima mientras que el que se aprecia a -258 corresponde a la de la $\omega$-laurolactama. Los asteriscos representan las bandas de rotación de los compuestos determinados. 
Tras el calentamiento a $50^{\circ} \mathrm{C}$ durante cinco minutos, aparece un nuevo pico de mayor intensidad a -258 ppm característico de la ${ }^{15} \mathrm{~N}-\omega$-laurolactama. ${ }^{158,159}$ Tanto a $50^{\circ} \mathrm{C}$ como a $130^{\circ} \mathrm{C}$, tras veinte minutos de reacción, el pico que domina el espectro de la mezcla es el de la ${ }^{15} \mathrm{~N}$ - $\omega$-laurolactama, mientras que la señal asignada a la ${ }^{15} \mathrm{~N}$-oxima es casi inapreciable. El hecho de que se pueda observar actividad catalítica a temperatura de reacción tan baja, se puede explicar gracias a las condiciones de giro de la muestra dentro de la sonda $(5 \mathrm{kHz}$, ángulo mágico) que provocan una drástica agitación.

En el espectro de RMN de ${ }^{19} \mathrm{~F}$ utilizando la técnica MAS realizado a la muestra recién preparada, se observa un doblete a $\delta\left({ }^{19} \mathrm{~F}\right)=-72,2 \mathrm{ppm}$ con una constante de acoplamiento $\mathrm{J}\left({ }^{19} \mathrm{~F}{ }^{31} \mathrm{P}\right)=708 \mathrm{~Hz}$ correspondiente al anión $\left[\mathrm{PF}_{6}\right]^{-160}$; mientras que en el espectro de la muestra calentada a calentada a $50^{\circ} \mathrm{C}$, se puede observar además de este doblete, otro doblete con mucha menor intensidad a $\delta\left({ }^{19} \mathrm{~F}\right)=-82,9 \mathrm{ppm}$ con una constante de acoplamiento $\mathrm{J}\left({ }^{19} \mathrm{~F}{ }^{31} \mathrm{P}\right)=960 \mathrm{~Hz}$ asignado al anión $\left[\mathrm{PO}_{2} \mathrm{~F}_{2}\right]^{-160}$ (Figura 3.3).

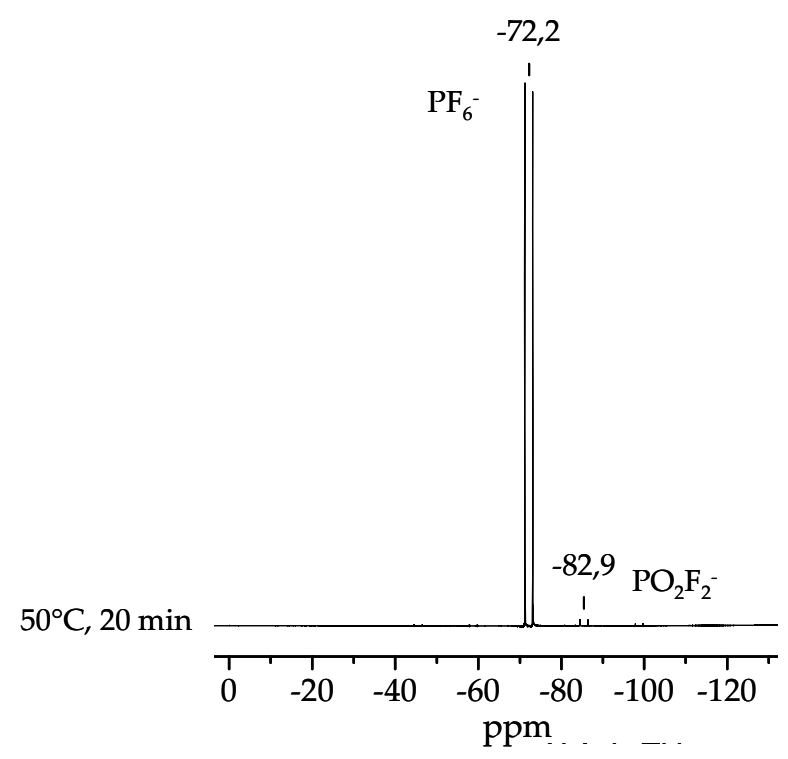

Figura 3.3.- Espectro de RMN-MAS del ${ }^{19} \mathrm{~F}$ de la mezcla de reacción calentada a $50^{\circ} \mathrm{C}$ durante 20 minutos. Se puede apreciar tanto el doblete correspondiente al anión $\mathrm{PF}_{6}{ }^{-}$, como el del producto de hidrólisis $\left[\mathrm{PO}_{2} \mathrm{~F}_{2}\right]^{-}$.

158 Fernández A.B., Boronat M., Blasco T., Corma A., Angew. Chem., Int.Ed., 2005, 44, 2370.

${ }^{159}$ Fernández A.B., Lezcano-González I., Boronat M., Blasco T., Corma A., J. Catal., 2007, $249,116$.

${ }^{160}$ Fernández-Galán R., Manzano B.R., Otero A., Lafranchi M., Pellinghelli M.A., Inorg. Chem., 1994, 33, 2309. 
La formación de esta especie se confirmó mediante espectroscopía de RMN de ${ }^{31} \mathrm{P}$. Tal y como se muestra en la Figura 3.4 una señal correspondiente a $\delta\left({ }^{31} \mathrm{P}\right)=-16,1 \mathrm{ppm}$ de $\left[\mathrm{PO}_{2} \mathrm{~F}_{2}\right]^{-}$aparece exclusivamente en los espectros obtenidos de la mezcla sometida a temperatura durante cinco o veinte minutos, pero no se registró en el de la muestra fresca que tan solo dio la señal de un septuplete ${ }^{160}$ centrado a $\delta\left({ }^{31} \mathrm{P}\right)=-144,3 \mathrm{ppm}$ con una contante de acoplamiento $\mathrm{J}\left({ }^{(11} \mathrm{P}{ }^{19} \mathrm{~F}\right)=708$ $\mathrm{Hz}$.

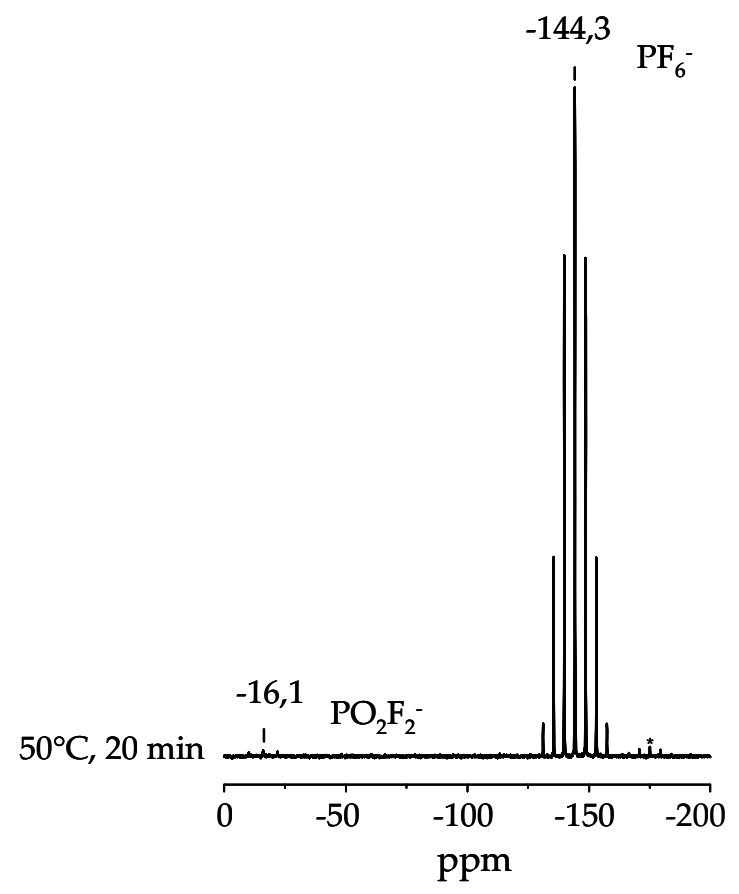

Figura 3.4.- Espectro de RMN-MAS del ${ }^{31} \mathrm{P}$ de la mezcla de reacción calentada a $50^{\circ} \mathrm{C}$ durante 20 minutos. Se pueden apreciar las señales correspondientes al producto de hidrólisis $\left[\mathrm{PO}_{2} \mathrm{~F}_{2}\right]^{-}$y el septuplete que se corresponde con el anión $\left[\mathrm{PF}_{6}\right]^{-}$. Los asteriscos representan bandas de rotación.

El hecho de que tras el tratamiento térmico a $50^{\circ} \mathrm{C}$ se observe mediante RMN in situ la presencia del anión $\left[\mathrm{PO}_{2} \mathrm{~F}_{2}\right]^{-}$, evidencia que el $\left[\mathrm{PF}_{6}\right]^{-}$se ha hidrolizado y por lo tanto que una pequeña cantidad de agua permanece todavía en el medio de reacción, incluso tras haber sido sometido el líquido iónico a vacío durante varias horas, a temperatura ambiente. Los esquemas de reacción presentados a continuación (Esquema 3.3) muestran cuáles son los pasos de la hidrólisis del anión hexafluorofosfato en presencia de agua. 
(1) $\mathrm{PF}_{6}^{-}+\mathrm{H}_{2} \mathrm{O} \longrightarrow \mathrm{POF}_{4}^{-}+2 \mathrm{HF}$

(2) $\mathrm{POF}_{4}^{-}+\mathrm{H}_{2} \mathrm{O} \longrightarrow \mathrm{PO}_{2} \mathrm{~F}_{2}^{-}+2 \mathrm{HF}$

(3) $\mathrm{PO}_{2} \mathrm{~F}_{2}^{-}+2 \mathrm{H}_{2} \mathrm{O} \longrightarrow \mathrm{HF}+\mathrm{PO}_{3} \mathrm{~F}^{2-}+\mathrm{H}^{+}$

(4) $\mathrm{PO}_{3} \mathrm{~F}^{2-}+\mathrm{H}^{+} \longleftrightarrow(\mathrm{OH}) \mathrm{PO}_{2} \mathrm{~F}^{-}$

Esquema 3.3.- Proceso de hidrólisis del anión hexafluorofosfato.

En el proceso de análisis en estado sólido por espectroscopía de RMN del ${ }^{19} \mathrm{~F}$ no se detectó ácido fluorhídrico, sin embargo, teniendo en consideración las reacciones (1), (2) y (3) del Esquema 3.3, la hidrólisis del hexafluorofosfato provoca la formación de HF, que puede actuar como catalizador en la reacción de transposición de Beckmann. Del mismo modo, la hidrólisis se puede dar también cuando la reacción se lleva a cabo en un matraz de reacción y por lo tanto el fluorhídrico formado puede ser el responsable de los resultados observados en los experimentos que se muestran en la Tabla 3.2.

Para tener la certeza de que en los experimentos convencionales realizados en matraz de vidrio, también se producía hidrólisis del anión hexafluorofosfato, se analizó por RMN de ${ }^{31} \mathrm{P}$ una pequeña alícuota de la mezcla final de reacción disuelta en piridina deuterada. En el espectro de resonancia de ${ }^{31} \mathrm{P}$ se pudo observar la señal característica del anión $\left[\mathrm{PO}_{2} \mathrm{~F}_{2}\right]^{-}$, tanto para la reacción de ciclododecanona oxima realizada en $\mathrm{BmimPF}_{6}$ como en la realizada en $\mathrm{BmpyPF}_{6}$. Sin embargo, cuando la reacción se llevó a cabo empleando $\mathrm{BmimBF}_{4}$ (no pudo detectarse el producto de degradación correspondiente al anión $\mathrm{BF}_{4}{ }^{-}$por $\mathrm{RMN}$ de ${ }^{11} \mathrm{~B}$ ). Lo mismo ocurrió en el caso del $\mathrm{BmmimPF}_{6}$. Como se observa en la Tabla 3.2, precisamente $\mathrm{BmimBF}_{4}$ y $\mathrm{BmmimPF}_{6}$ fueron incapaces de desarrollar actividad catalítica alguna, en la transposición de Beckmann de la ciclododecanona oxima.

La cantidad de ácido fluorhídrico producida durante la reacción en presencia de $\mathrm{BmimPF}_{6}$ y $\mathrm{BmpyPF}_{6}$ se estimó a partir de la estequiometría de las reacciones (1)-(3)(Tabla 3.3) y mediante la cuantificación por RMN de ${ }^{31} \mathrm{P}$ del anión $\left[\mathrm{PO}_{2} \mathrm{~F}_{2}\right]^{-}$. Se hace necesario aclarar en este punto que en algunos casos fue complicado cerrar por completo los balances de ácido fluorhídrico formado (y por lo tanto de $\left.\left[\mathrm{PO}_{2} \mathrm{~F}_{2}\right]^{-}\right)$y del agua presente en el medio de reacción. 


\begin{tabular}{ccccc}
\hline Líquido Iónico & $\begin{array}{c}\text { Cantidad de } \\
\mathbf{H}_{2} \mathbf{O} \\
\mathbf{( p p m )}\end{array}$ & $\begin{array}{c}\text { Conversión } \\
\text { Oxima } \\
\mathbf{( \% )}\end{array}$ & $\begin{array}{c}\text { Selectividad } \\
\text { Laurolactama } \\
\mathbf{( \% )}\end{array}$ & $\begin{array}{c}\text { Cantidad de } \\
\mathbf{H F} \\
\text { (ppm) }\end{array}$ \\
\hline $\begin{array}{c}\text { BmimPF } \\
\text { Hexafluorofosfato de }\end{array}$ & 1647 & 100 & $>99$ & 3194 \\
$\begin{array}{c}\text { 1-butil-3-metilimidazolio } \\
\text { BmmimPF }\end{array}$ & 2468 & 0 & 0 & n.d. \\
$\begin{array}{c}\text { Hexafluorofosfato de } \\
\text { 1-butil-2,3-dimetilimidazolio } \\
\text { BmpyPF6 }\end{array}$ & 4068 & 100 & 95,8 & 5338 \\
$\begin{array}{c}\text { Hexafluorofosfato de } \\
\text { 1-butil-4-metilpiridinio } \\
\text { BmimBF }\end{array}$ & 1986 & 0 & 0 & n.d. \\
$\begin{array}{c}\text { Tetrafluoroborato de } \\
\text { 1-butil-3-metilimidazolio }\end{array}$ & & & & \\
\hline
\end{tabular}

Tabla 3.3.- Conversión de la ciclododecanona oxima y selectividad a $\omega$-laurolactama en la transposición de Beckmann a $130^{\circ} \mathrm{C}$ durante 2 horas. Los líquidos iónicos empleados en reacción contenían la cantidad de agua indicada en la tabla y determinada por el método de Karl-Fisher. La cantidad de HF se determinó al final de la reacción a partir de los datos de RMN.

La determinación del contenido en agua por el método de Karl-Fisher de los cuatro líquidos iónicos estudiados, mostró que todos ellos poseían cierto contenido en agua (Tabla 3.3). Sin embargo, para comprobar si una mayor concentración de agua ayudaba a hidrolizar los aniones $\mathrm{BF}_{4}{ }^{-}$y $\mathrm{PF}_{6}{ }^{-}$del $\mathrm{BmimBF}_{4}$ y el BmmimPF 6 respectivamente, se adicionó a todos ellos entre un 2,3 y un 3,0\% de agua con respecto al peso del líquido iónico y la cuantificación de la hidrólisis generada se hizo por RMN de ${ }^{31} \mathrm{P}$ a partir de una alícuota de la mezcla del crudo de reacción. Los resultados de este experimento se muestran en la Tabla 3.4 y evidencian que la conversión de la oxima se da en el caso de los medios de reacción $\mathrm{BmimPF}_{6}$ y $\mathrm{Bmpy} \mathrm{PF}_{6}$, además el espectro de $\mathrm{RMN}$ contiene el triplete típico del anión $\left[\mathrm{PO}_{2} \mathrm{~F}_{2}\right]^{-}\left(\delta\left({ }^{31} \mathrm{P}\right)=-16,1 \mathrm{ppm}, \mathrm{J}\left({ }^{31} \mathrm{P}{ }^{19} \mathrm{~F}\right)=960 \mathrm{~Hz}\right)$ y un doblete $\left(\delta\left({ }^{31} \mathrm{P}\right)=8,26 \mathrm{ppm}, \mathrm{J}\left({ }^{31} \mathrm{P}{ }^{19} \mathrm{~F}\right)=918 \mathrm{~Hz}\right)$ atribuido a la especie $\left[\mathrm{PO}_{3} \mathrm{~F}\right]^{-2}$, que indica innegablemente la hidrólisis del $\left[\mathrm{PF}_{6}\right]^{-}$. En el caso del $\mathrm{BmimBF}_{4}$ y del $\mathrm{BmmimPF}_{6}$, vuelve a pasar lo que ya se había observado, no se aprecia conversión de la oxima y los espectros de $\mathrm{RMN}$ de ${ }^{11} \mathrm{~B}$ y ${ }^{31} \mathrm{P}$ tan solo muestran las señales correspondientes a $\left[\mathrm{BF}_{4}\right]^{-}$y $\left[\mathrm{PF}_{6}\right]^{-}$respectivamente. Así pues, pese a la adición deliberada de agua al medio de reacción, los aniones de los líquidos iónicos $\mathrm{BmimBF}_{4}$ y $\mathrm{BmmimPF}_{6}$ no consiguen hidrolizarse y por lo tanto son incapaces de promover la transposición de la oxima a $130^{\circ} \mathrm{C}$. 


\begin{tabular}{lcccc}
\hline Líquido Iónico & $\begin{array}{c}\text { Cantidad de } \\
\mathbf{H}_{2} \mathbf{O} \\
(\mathbf{p p m})\end{array}$ & $\begin{array}{c}\text { Conversión } \\
\text { Oxima } \\
(\%)\end{array}$ & $\begin{array}{c}\text { Selectividad } \\
\text { Laurolactama } \\
(\mathbf{\%})\end{array}$ & $\begin{array}{c}\text { Cantidad de } \\
\mathbf{H F} \\
(\mathbf{p p m})\end{array}$ \\
\hline BmimPF $_{6}$ & 22497 & 100 & 78 & 63357 \\
BmmimPF $_{6}$ & 22433 & 0,3 & n.d. & n.d. \\
BmpyPF $_{6}$ & 21537 & 100 & 84 & 54049 \\
BmimBF $_{4}$ & 28437 & 1,5 & 68,0 & n.d. \\
\hline
\end{tabular}

Tabla 3.4.- Resultados de la transposición de Beckmann de la ciclododecanona oxima en medio líquido iónico, a $130^{\circ} \mathrm{C}$ durante 2 horas y con adición de un 2,3-3,0\% en peso de agua. La concentración de ácido fluorhídrico se determinó al final de la reacción. (n.d.: no detectado).

Para evaluar la reactividad que poseen los líquidos iónicos con agua, se trabajó con ellos en presencia de agua pero sin adición de oxima. Se calentaron a $130^{\circ} \mathrm{C}$ durante dos horas y la mezcla resultante se analizó por RMN de ${ }^{31} \mathrm{P}$ y ${ }^{11} \mathrm{~B}$. En tales condiciones, no se aprecia producto de hidrólisis de los dos líquidos inactivos para la transposición $\mathrm{BmimBF}_{4} \mathrm{y} \mathrm{BmimPF}_{6}$, mientras que aquellos líquidos iónicos que en experimentos anteriores desarrollaron actividad catalítica BmimPF$_{6}$ y BmpyPF$_{6}$, en este caso, en ausencia de oxima también dan lugar, tan solo con el calentamiento, a las especies fruto de la hidrólisis del anión. Si a posteriori se adiciona la oxima, son capaces de llevar a cabo la reacción de transposición en las mismas condiciones y con los mismos buenos resultados que en los casos anteriores en que se probaron, evidenciando de nuevo la formación de ácido fluorhídrico.

A raíz de los datos aportados hasta el momento, se podría pensar que en el caso de conseguir evitar por completo la presencia de agua en el medio de reacción, se anularía el proceso de hidrólisis de los aniones, no se generaría ácido fluorhídrico y por lo tanto no se apreciaría conversión. Con el fin de demostrar este hecho, el líquido iónico $\mathrm{BmimPF}_{6}$ se secó a vacío dinámico durante 12 horas y a $75^{\circ} \mathrm{C}$, a continuación y bajo atmósfera inerte se llevó a cabo la reacción. Pese al tratamiento, una pequeña cantidad de agua permaneció en el medio y fue suficiente para provocar la hidrólisis del $\left[\mathrm{PF}_{6}\right]^{-}$, lo que se demostró por la presencia de $\left[\mathrm{PO}_{2} \mathrm{~F}_{2}\right]^{-}$en el RMN de ${ }^{31} \mathrm{P}$. Como muestra la Tabla 3.5 (Entrada 1) esa mínima cantidad de ácido fluorhídrico en el medio, es capaz de producir la transposición completa de la ciclododecanona oxima a $\omega$-laurolactama. 


\begin{tabular}{|c|c|c|c|c|c|}
\hline Ent. & Líquido Iónico & $\begin{array}{c}\text { Cantidad de } \\
\mathrm{H}_{2} \mathrm{O} \\
(\mathrm{ppm}) \\
\end{array}$ & $\begin{array}{c}\text { Conversión } \\
\text { Oxima } \\
(\%)\end{array}$ & $\begin{array}{c}\text { Selectividad } \\
\text { Laurolactama } \\
\text { (\%) }\end{array}$ & $\begin{array}{c}\text { Cantidad de } \\
\text { HF } \\
\text { (ppm) } \\
\end{array}$ \\
\hline 1 & $\mathrm{BmimPF}_{6}$ & 460 & 99,5 & 99,5 & 1020 \\
\hline 2 & $\mathrm{BmmimPF}_{6}$ & 19500 & 100 & 36,2 & 4900 \\
\hline 3 & $\mathrm{BmimBF}_{4}$ & 19500 & 90,9 & 69,9 & 4900 \\
\hline
\end{tabular}

Tabla 3.5.- Resultados de la transposición de Beckmann de la ciclododecanona oxima en medio líquido iónico, a $130^{\circ} \mathrm{C}$ durante 2 horas. En la entrada $1 \mathrm{el} \mathrm{BmimPF} 6$ fue secado durante 12 horas a $75^{\circ} \mathrm{C}$. En las entradas 2 y 3 se adicionó una cantidad determinada de ácido fluorhídrico diluido en agua. El contenido en ácido fluorhídrico y agua se determinó antes y después de la reacción.

Otro de los bloques de experimentos desarrollados se basó en la adición de ácido fluorhídrico diluido en agua a aquellos líquidos iónicos que se habían mostrado inactivos frente a la transposición de Beckmann: BmimBF 4 y BmmimPF. Los resultados, que también pueden observarse en la Tabla 3.5 (Entradas 2 y 3 ) indican que en este caso, la ciclododecanona oxima reacciona a $130^{\circ} \mathrm{C}$, durante dos horas dando lugar a la $\omega$-laurolactama con conversiones significativamente altas aunque la selectividad está por debajo de la obtenida en aquellos casos en los que no se adicionó el fluorhídrico diluido en agua, como se puede observar al comparar los datos de la Tabla 3.3 con los de la Tabla 3.5. El agua extra que se emplea en la dilución del ácido y que se adiciona al medio de reacción, provoca además la hidrólisis de la ciclododecanona oxima, que se transforma en cetona, lo que hace que la selectividad quede reducida de forma contundente. Cabe destacar que en aquellos experimentos el los que se adicionó un 2,3-3,0\% en peso de agua y cuyos resultados aparecen en la Tabla 3.4, también se aprecia una reducción en la selectividad a la lactama, sin embargo, dado que en este caso la cantidad de agua es considerablemente menor, no resulta una disminución tan drástica.

Como conclusión, los resultados que se han presentado en este apartado, indican que el catalizador real de la transposición de Beckmann de la ciclododecanona oxima en medio líquido iónico es el ácido fluorhídrico generado a partir de la hidrólisis parcial del anión hexafluorofosfato. Además, se hace necesario remarcar que el anión $\left[\mathrm{BF}_{4}\right]^{-}$del $\mathrm{BmimBF}_{4}$ y el $\left[\mathrm{PF}_{6}\right]^{-}$del $\mathrm{BmmimPF}_{6}$ no se han hidrolizado en las condiciones de reacción empleadas y que probablemente la diferencia en la reactividad del anión hexafluorofosfato en dos líquidos iónicos bastante parecidos, esté relacionada con propiedades microscópicas de las propias mezclas líquido iónico-agua que son especialmente complicadas de explicar. 
Otra alternativa para acentuar la actividad catalítica de aquellos líquidos iónicos que no manifestaban predisposición para la reactividad, consistió en introducir en el medio de reacción una mínima cantidad de ácidos de Lewis del

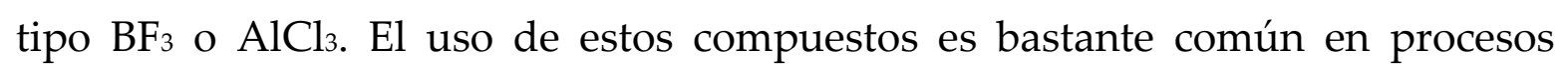
industriales, así que se decidió estudiar la reactividad de los líquidos iónicos no activos adicionando $\mathrm{BF}_{3}$-complejo eterato (10\% en peso) al medio de reacción ya que al no estar diluido en agua, se evitaría la hidrólisis de la oxima y se conseguiría mayor selectividad a $\omega$-laurolactama. Con el sistema $\mathrm{BmmimPF}_{6} / \mathrm{BF}_{3}$ la conversión de la oxima fue del 100\% y la selectividada a $\omega$-laurolactama del 99\%, sin embargo en el sistema $\mathrm{BmimBF}_{4}$ la conversión de la oxima fue tan solo de un $64 \%$ aunque la selectividad a $\omega$-laurolactama se mantuvo en un $98 \%$. Del mismo modo que en los casos anteriores, se hicieron espectros de RMN de las mezclas de reacción y se pudo observar que en medio $\mathrm{BmmimPF}_{6}$ aparecía la señal característica del anión $\left[\mathrm{PO}_{2} \mathrm{~F}_{2}\right]^{-}$que a su vez denota la hidrólisis del anión y la formación de ácido fluorhídrico. Los espectros de RMN de ${ }^{11} \mathrm{~B}$ no mostraron ninguna señal de ácido bórico ni en medio $\mathrm{BmmimPF}_{6}$ ni en $\mathrm{BmimBF}_{4}$, lo que da a entender que no se produjo hidrólisis del $\mathrm{BF}_{3}$ en ninguno de los dos casos. Estos resultados indican que la elevada actividad alcanzada en el caso del $\mathrm{BmmimPF}_{6}$ es debida a la presencia de ácido fluorhídrico. Así, la adición de $\mathrm{BF}_{3}$ en la mezcla ciclododecanona oxima/BmmimPF 6 provoca una marcada modificación en la reactividad del líquido iónico ya que favorece la hidrólisis del anión $\left[\mathrm{PF}_{6}\right]^{-}$. Esta es una prueba más de lo compleja que llega a ser la química de los líquidos iónicos ya que sus propiedades y su reactividad se ven profundamente afectadas no solo por las condiciones de reacción sino por la mezcla con otras sustancias, incluso en concentraciones de ppm.

\subsection{3}

\section{Optimización de las condiciones de reacción}

Una vez confirmado que la actividad catalítica de los líquidos iónicos $\mathrm{BmimPF}_{6}$ y $\mathrm{BmpyPF}_{6}$ era debida a la formación in situ de ácido fluorhídrico durante la reacción, se procedió a optimizar la temperatura de reacción así como la concentración de oxima en el líquido iónico. 


\section{Variación de la temperatura de reacción}

\begin{tabular}{ccccc}
\hline Ent. & $\begin{array}{c}\text { Temperatura } \\
\left({ }^{\circ} \mathbf{C}\right)\end{array}$ & $\begin{array}{c}\text { Conversión } \\
\text { Oxima } \\
(\%)\end{array}$ & $\begin{array}{c}\text { Selectividad } \\
\text { Laurolactama } \\
(\%)\end{array}$ & $\begin{array}{c}\text { Balance de } \\
\text { Materia } \\
(\mathbf{\%})\end{array}$ \\
\hline $\mathbf{1}$ & 100 & 0 & 0 & 99 \\
$\mathbf{2}$ & 130 & 100 & $>99$ & 96 \\
$\mathbf{3}$ & 150 & 97 & 96 & 99 \\
\hline
\end{tabular}

Tabla 3.6.- Resultados de la reacción de transposición de Beckmann de la ciclododecanona oxima en presencia de hexafluorofosfato de 1-butil-3-metilimidazolio (relación molar oxima/líquido iónico $=$ 0,14 ), a diferentes temperaturas de reacción durante 2 horas (excepto en el caso de la reacción a $150^{\circ} \mathrm{C}$, que duró 1,5 horas).

Tal y como muestra la Tabla 3.6, empleando el $\mathrm{BmimPF}_{6}$ como catalizador y medio de reacción, con una relación molar ciclododecanona oxima/líquido iónico $=0,14$, se observó que si se disminuía la temperatura de reacción de 130 a $100^{\circ} \mathrm{C}$ (entrada 1), dejaba de haber actividad catalítica, indicando que bajo estas condiciones, la hidrólisis del anión $\left[\mathrm{PF}_{6}\right]^{-}$no tiene lugar. Es interesante destacar que en los experimento de RMN in situ, se observa hidrólisis a $50^{\circ} \mathrm{C}$ debida probablemente, a las condiciones de la muestra dentro de la sonda (5 kHz y ángulo mágico). Por otra parte, al aumentar la temperatura de reacción a $150^{\circ} \mathrm{C}$ (Entrada 3), sí se observó actividad, pero la selectividad disminuyó debido la hidrólisis de la oxima, que produce ciclododecanona. En este último caso, el tiempo de reacción fue de una hora y media, pero la reducción en el tiempo de reacción no compensa la caída de la selectividad del proceso. En todos los casos, tras la extracción pertinente de reactivos y productos del medio y su posterior secado, el balance de materia se cerró con porcentajes por encima del $95 \%$.

\section{Variación de la concentración de oxima}

Otro de los parámetros en los que se incidió durante el proceso de optimización fue la relación en peso entre oxima y líquido iónico. Puesto que la actividad catalítica es debida a la generación de ppm de ácido fluorhídrico, es interesante determinar qué cantidad máxima de oxima puede introducirse en el medio de reacción para ser completamente transformada en lactama sin pérdida de actividad catalítica ni selectividad. 


\begin{tabular}{cccccc}
\hline Ent. & $\begin{array}{c}\text { Oxima } \\
(\mathbf{\%})\end{array}$ & $\begin{array}{c}\text { Tiempo } \\
\text { (h) }\end{array}$ & $\begin{array}{c}\text { Conversión } \\
\text { Oxima } \\
(\mathbf{\%})\end{array}$ & $\begin{array}{c}\text { Selectividad } \\
\text { Laurolactama } \\
\mathbf{( \% )}\end{array}$ & $\begin{array}{c}\text { Balance de } \\
\text { Materia } \\
(\%)\end{array}$ \\
\hline $\mathbf{1}$ & 10 & 2 & 100 & $>99$ & 96 \\
$\mathbf{2}$ & 20 & 2 & 98 & 95 & 94 \\
$\mathbf{3}$ & 40 & 2 & $>99$ & 98 & 99 \\
$\mathbf{4}$ & 50 & 2 & $>99$ & 96 & 96 \\
$\mathbf{5}$ & 75 & 3 & 99 & 94 & 98 \\
$\mathbf{6}$ & 100 & 3 & 99 & 98 & 95 \\
$\mathbf{7}$ & 120 & 3 & 89 & 96 & 96 \\
$\mathbf{8}$ & 150 & 7 & 89 & 92 & 90 \\
\hline
\end{tabular}

Tabla 3.7.- Resultados de la reacción de transposición de Beckmann de la ciclododecanona oxima $(0,260-7,8 \mathrm{~g})$ en presencia de hexafluorofosfato de 1-butil-3-metilimidazolio (2,6 g) con diferentes relaciones entre oxima y líquido iónico. El porcentaje de oxima detallado en la tabla está en relación con la cantidad inicial del líquido iónico empleado. La temperatura de reacción fue de $130^{\circ} \mathrm{C}$.

Como se observa en la Tabla 3.7 desde la primera relación en peso del 10\% (Entrada 1)(relación molar oxima/líquido iónico $=0,14$ ), hasta la relación del 100\% (Entrada 6)(relación molar oxima/líquido iónico $=1,4$ ) no se observan variaciones en la conversión de la oxima ni en la selectividad del proceso. Tan solo fue necesario ampliar el tiempo de reacción a tres horas en el caso de la relación del 75\% (entrada 5) y del 100\%.

Cuando se pasó de la relación del 100\% al 120\% de oxima (relación molar oxima/líquido iónico $=1,68)$ (Entrada 7 ), se redujo en un $10 \%$ la conversión del proceso, manteniendo el tiempo de reacción en tres horas y cuando de 120 se pasó al 150\% de oxima frente al peso de líquido iónico (relación molar oxima/líquido iónico $=2,10)($ Entrada 8 ) fue necesario ampliar el tiempo de reacción a siete horas para conseguir un $89 \%$ de conversión de la oxima. Sin embargo en ambos casos, la selectividad a $\omega$-laurolactama se mantuvo alrededor del $95 \%$.

De estos resultados podemos concluir que para una concentración de oxima del 100\% (relación molar oxima/líquido iónico $=1,4$ ), con un contenido en agua del líquido iónico de 1647 ppm (ver Tabla 3.3, Entrada 1), se puede alcanzar un rendimiento a $\omega$-laurolactama del $97 \%$, tras tres horas de reacción. 


\section{2 .4}

\section{Reusos del líquido iónico}

Puesto que el precio de los líquidos iónicos está muy por encima del precio del ácido sulfúrico, que es el catalizador homogéneo que se suele emplear en la transposición de Beckmann, es imprescindible demostrar que el uso de los líquidos iónicos está justificado, no solo por el hecho de ser competitivos en cuanto a rendimientos, sino porque además se pueden emplear en varios ciclos de reacción sin perder actividad.

Con el fin de demostrar la viabilidad del reuso del líquido iónico empleado en el proceso de transposición de la ciclododecanona oxima, se llevó a cabo la reacción en Hexafluorofosfato de 1-butil-3-metilimidazolio y en las mejores condiciones determinadas con anterioridad. Tal y como muestra la Tabla 3.8 se llevaron a cabo cinco ciclos seguidos. El primer experimento se desarrolló del mismo modo que en los casos anteriores, se dispuso el líquido iónico fresco en un matraz, en el que seguidamente se introdujo la cantidad de oxima apropiada. Transcurrido el tiempo de reacción se dejó enfriar la mezcla, se extrajo el producto de reacción y una vez comprobado (mediante ${ }^{1} \mathrm{H}-\mathrm{RMN}$ ) que en el líquido iónico no quedaban trazas de reactivos ni productos se empleó ese mismo líquido iónico para el siguiente ciclo, así hasta cuatro veces más. Los resultados muestran que en cada ciclo, se siguen manteniendo las conversiones y selectividades del primer ciclo y que éstas son superiores al 99\%.

\begin{tabular}{ccccc}
\hline Ent. & USO & $\begin{array}{c}\text { Conversión } \\
\text { Oxima } \\
(\mathbf{\%})\end{array}$ & $\begin{array}{c}\text { Selectividad } \\
\text { Laurolactama } \\
(\mathbf{\%})\end{array}$ & $\begin{array}{c}\text { Balance de } \\
\text { Materia } \\
(\%)\end{array}$ \\
\hline $\mathbf{1}$ & 1 & $>99$ & $>99$ & 97 \\
$\mathbf{2}$ & 2 & $>99$ & 98 & 99 \\
$\mathbf{3}$ & 3 & $>99$ & 99 & 98 \\
$\mathbf{4}$ & 4 & 99 & $>99$ & 99 \\
$\mathbf{5}$ & 5 & 99 & $>99$ & 95 \\
\hline
\end{tabular}

Tabla 3.8.- Resultados del estudio de reuso del hexafluorofosfato de 1-butil-3-metilimidazolio (2,6 g) para la reacción de transposición de Beckmann de la ciclododecanona oxima $(0,260 \mathrm{~g})$ a $130^{\circ} \mathrm{C}$. Tiempo de reacción 2 horas. Las cantidades de oxima, tras el primer uso se fueron adecuando según la cantidad de líquido iónico obtenido tras el proceso de extracción. 


\section{3}

\section{Conclusiones}

1.- Los resultados presentados en este capítulo demuestran que tan solo el agua residual presente en algunos líquidos iónicos, puede hidrolizar el anión $\left[\mathrm{PF}_{6}\right]^{-}$del $\mathrm{BmimPF}_{6} \mathrm{O}$ del $\mathrm{BmpyPF}_{6}$ dando lugar a ppm de ácido fluorhídrico. Este ácido fluorhídrico es el verdadero catalizador de la transposición de Beckmann de la ciclododecanona oxima, dando lugar a $\omega$-laurolactama con alta conversión y selectividad. La ventaja del empleo de estos líquidos iónicos como fuente de HF es que se evita el uso de ácidos diluidos en agua que provoca inevitablemente una reducción de la selectividad del proceso por dar lugar a la hidrólisis de la oxima.

2.- La optimización de la temperatura de reacción mostró que la hidrólisis del anión $\left[\mathrm{PF}_{6}\right]^{-}$tiene lugar por encima de los $100^{\circ} \mathrm{C}$, mientras que temperaturas superiores a $\operatorname{los} 130^{\circ} \mathrm{C}$ pueden dar lugar a la hidrólisis de la oxima disminuyendo la selectividad a $\omega$-laurolactama.

3.- La optimización de la relación molar oxima/líquido iónico mostró que trabajando con relaciones molares de hasta 1,4 se logran conversiones y selectividades excelentes a $\omega$-laurolactama.

4.-Los resultados obtenidos en este trabajo abren las puertas al uso de líquidos iónicos en reacciones orgánicas que puedan ser catalizadas por HF, en tales casos, teniendo en cuenta la potencial hidrólisis del anión empleado, se pueden conseguir actividades catalíticas muy interesantes. 

Capítulo IV:

Síntesis y caracterización del material híbrido Polioxometalato-Líquido iónico-Paladio (POM-IL-Pd) 

4.1

\section{Introducción}

4.1.1

Materiales híbridos orgánico-inorgánicos

El desarrollo de nanocompuestos híbridos orgánico-inorgánicos ha resultado ser en los últimos años, una importante línea de investigación en el ámbito de la química de materiales ${ }^{161}$. En general, los nanocompuestos se consideran materiales con potencial para ayudar a superar desafíos en áreas como la energía, el almacenamiento energético, la catálisis y la optoelectrónica ${ }^{162,163,164,165,166 .}$

Los polioxometalatos (POMs) son una familia de clusters aniónicos inorgánicos de óxidos metálicos, que poseen una amplia diversidad de topologías y propiedades físico-químicas ${ }^{167}$, debido a las cuales están resultando de gran interés para la preparación de nanocompuestos. Además, en las últimas décadas, el uso como catalizadores de POMs y de compuestos basados en POMs se ha convertido en un área relevante en investigación. En particular, estos compuestos han atraído la atención de especialistas en el campo de la catálisis y de las reacciones de oxidación debido a sus características ácidas y sus potenciales redox, que pueden llegar a ser controlados a nivel molecular o incluso atómico ${ }^{168}$. La aportación de los contra-cationes, aunque a menudo se pasa por alto, puede llegar a ser determinante para aspectos críticos de los procesos catalíticos (especialmente en procesos que implican reacciones redox) y en el mecanismo de agregación de los propios polioxometalatos ${ }^{169,170}$.

\footnotetext{
161 Sanchez C., Soler-Illia G., Ribot F., Lalot T., Mayer C.R., Cabuil V.,Chem. Mater., 2001, $13,3061$. 162 Sanchez C., Julian B., Belleville P., Popall M., J. Mater. Chem., 2005, 15, 3559.

163 Akiyama R., Kobayashi S., J. Am. Chem. Soc., 2003, 125, 3412.

164 Groppo E., Liu W., Zavorotynska O., Agostini G., Spoto G., Bordiga S., Lamberti C., Zecchina A., Chem. Mater., 2010, ASAP Article DOI: 10.1021/cm903176d.

165 Klingelhofer S., Heitz W., Greiner A., Oestreich S., Forster S., Antonietti M., J. Am. Chem. Soc., 1997, 119, 10116.

166 Okamoto K., Akiyama R., Yoshida H., Yoshida T., Kobayashi S., J. Am. Chem. Soc., 2005, 127, 2125.

167 Baker L.C., Glick D.C., Chem. Rev., 1998, 98, 3.

168 Okuhara T., Chem. Rev., 2002, 102, 3641.

169 Grigoriev V.A., Hill C.L., Weinstock I.A., J. Am. Chem. Soc., 2000, 122, 3544.

170 Grigoriev V.A., Cheng D., Hill C.L., Weinstock I.A., J. Am. Chem. Soc., 2001, 123, 5292.
} 
Por otra parte y pese a la utilidad demostrada de los líquidos iónicos (IL) en la preparación de nuevos materiales ${ }^{171,172,173,174}$, la concepción de nanocompuestos que combinen líquidos iónicos (formadores de cationes) con especies inorgánicas, ha tenido, hasta la fecha, poco impacto. En este sentido, Bourlinos y col. ${ }^{175}$ prepararon un líquido iónico basado en la estructura de un $\mathrm{POM}$, a partir de la sustitución parcial de los protones del heteropoliácido $\left(\mathrm{H}_{3} \mathrm{PW}_{12} \mathrm{O}_{40}\right)$ por cationes de amonio cuaternarios, contenidos en polietilenoglicol (PEG). Por su parte, Rickert y col. ${ }^{176}$ prepararon y caracterizaron una serie de nuevos materiales híbridos orgánico-inorgánicos basados en líquidos iónicos del tipo polioxometalatos de tetraalquilfosfonio.

Pese a la existencia de trabajos de investigación con materiales que combinan líquidos iónicos y POM, sus aplicaciones en catálisis son realmente escasas. En uno de los pocos estudios catalíticos realizados con estos materiales, Chhikara y col. ${ }^{177}$ sintetizaron un material nuevo basado en un catión imidazolio y un anión wolframato (tris(imidazolio)-tetrakis(diperoxowolfro)fosfato) que dio actividad catalítica en la oxidación de alcoholes con peróxido de hidrógeno. Más recientemente, Bosdoloi y col. ${ }^{178}$ publicaron la síntesis de un catión imidazolio intercambiado con ácido molibdovanadatofosfórico $\left(\mathrm{H}_{5}\left[\mathrm{PMo}_{10} \mathrm{~V}_{2} \mathrm{O}_{40}\right] 32.5 \mathrm{H}_{2} \mathrm{O}\right)$ inmovilizado sobre una sílice mesoporosa SBA-15 modificada con un líquido iónico, que al ser empleado como catalizador para la oxidación anaeróbica de diferentes alcoholes mostró una apreciable actividad y una alta selectividad. También Lang y col. ${ }^{179}$ publicaron la preparación de un ácido fosfowolfrámico inmovilizado en un polímero modificado con líquidos iónicos que fue utilizado con éxito como catalizador heterogéneo en la oxidación de alcoholes en presencia de $\mathrm{H}_{2} \mathrm{O}_{2}$ como oxidante.

Curiosamente, el potencial catalítico de materiales híbridos POM-IL intercambiados con cationes metálicos, permanece aún inexplorado; es por eso

\footnotetext{
${ }^{171}$ Adams, C.J., Bradley A.E., Seddon K.R., Aust. Chem., 2001, 54, 679.

172 Nakashima T., Kimizuka N., J. Am. Chem. Soc., 2003, 125, 6386.

173 Yoshio M., Mukai T., Ohno H., Kato T., J. Am. Chem. Soc., 2004, 126, 994.

174 Lee B., Luo H.M., Yuan C.Y., Lin J.S., Dai S., Chem. Commun., 2004, 240.

175 Bourlinos A.B., Raman K., Herrera R., Zhang Q., Archer L.A., Giannelis E.P., J. AM. Chem. Soc., 2004, 126, 15358.

176 Rickert P.G., Antonio M.R., Firestone M.A., Kubatko K.A., Szreder T., Wishart J.F., Dietz M.L., J. Phys. Chem. B, 2007, 111, 4685.

177 Chhikara B.S., Chandra R., Tandon V., J. Catal., 2005, 230, 436.

178 Bordoloi A., Sahoo S., Lefebvre F., Halligudi S.B., J. Catal., 2008, 259, 232.

${ }^{179}$ Lang X.J., Li Z., Xia C., Synth. Commun., 2008, 38, 1610.
} 
que esta parte del trabajo de tesis tuvo como objetivo la preparación y caracterización de nuevos catalizadores heterogéneos basados en materiales híbridos orgánico-POM intercambiados con cationes metálicos. De este modo, la sustitución parcial de los protones superficiales del POM $\left(\mathrm{H}_{5} \mathrm{PO}_{40} \mathrm{~V}_{2} \mathrm{Mo} 10\right)$ por butilmetilimidazolios $\left(\mathrm{bmim}^{+}\right)$permitió obtener un material sólido con carácter prótico POM-IL ([bmim $\left.]_{4} \mathrm{HPO}_{40} \mathrm{~V}_{2} \mathrm{Mo10}\right)$ en el que el protón que todavía permanecía en la estructura del POM fue a su vez intercambiado por un ion metálico, en este caso, $\mathrm{Pd}^{2+}$. A lo largo de este capítulo se mostrará en primer lugar la caracterización que se hizo del material, desmostrándose que lo que teóricamente debía ser: [bmim] ${ }_{4} \mathrm{Pd}_{0,5} \mathrm{PO}_{40} \mathrm{~V}_{2} \mathrm{Mo} 10$, no lo era. En su lugar, el sólido obtenido contenía nanopartículas esféricas de PdO de 2-3 nm muy dispersas, que formaban una estructura secundaria de agregados con aspecto de bayas y de unos $20 \mathrm{~nm}$. Estos clusters decoraban la superficie de las partículas globulares de gran tamaño (1 $\mu \mathrm{m}$ aprox.) generadas a partir de la interacción entre el POM y el líquido iónico. (Figura 4.0).
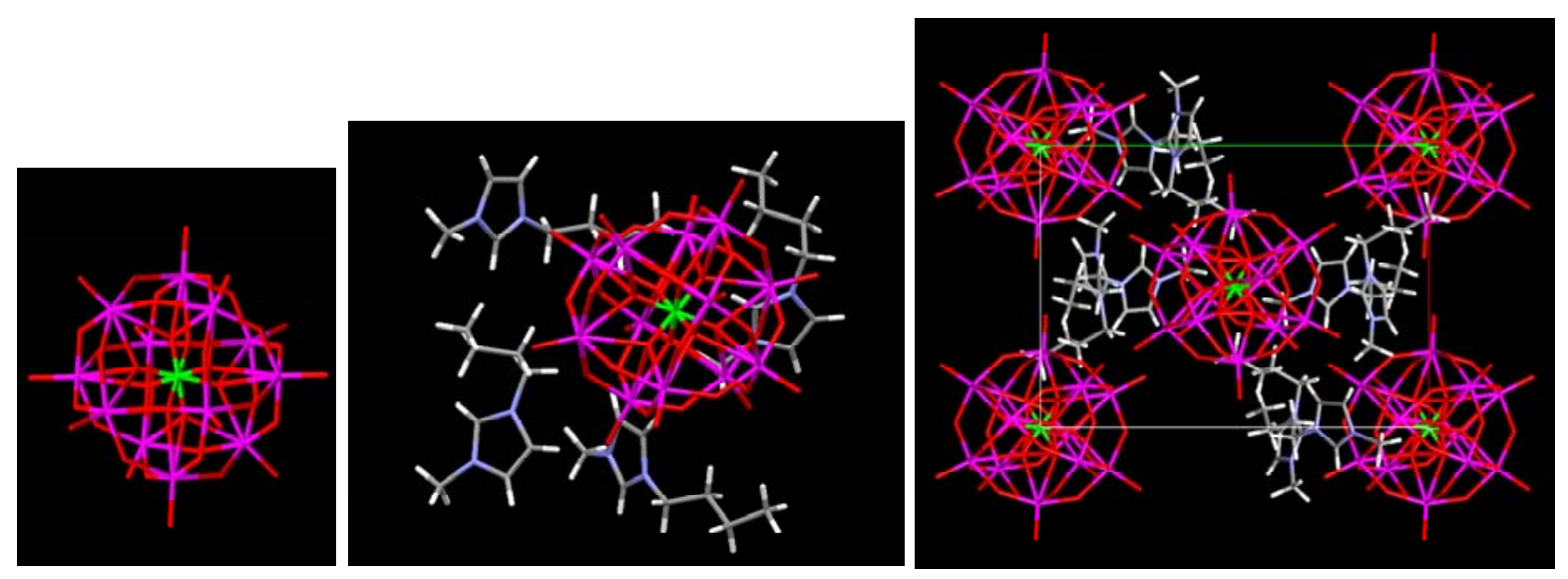

Figura 4.0.- Las imágenes muestran (de izquierda a derecha) las estructuras determinadas por difracción de rayos $\mathrm{X}$ del POM $\left(\mathrm{H}_{5} \mathrm{PO}_{40} \mathrm{~V}_{2} \mathrm{Mo10}\right)$. El POM rodeado de los cuatro cationes imidazolio que sustituyen a los protones de la estructura original del POM. Y una vista general de la red cristalina que forma la estructura secundaria ([bmim $\left.]_{4} \mathrm{HPO}_{40} \mathrm{~V}_{2} \mathrm{Mo} \mathrm{Oo}_{0}\right)$.

Finalmente, se demostrará que este nuevo material puede ser utilizado como catalizador en reacciones de acoplamiento Carbono-Carbono (en este caso se llevó a cabo la reacción de Heck), presentando una excelente actividad, selectividad y estabilidad. 


\subsection{2}

\section{Reacciones de acoplamiento Carbono-Carbono}

Las reacciones de acoplamiento carbono-carbono se pueden considerar, en la actualidad, entre los procesos más empleados para la síntesis orgánica ${ }^{180,181,182}$. La construcción selectiva de nuevos enlaces C-C es, con frecuencia, un paso fundamental tanto en la síntesis de derivados de alto valor añadido (química fina) como en la fabricación de polímeros convencionales y especiales.

Por lo general este tipo de reacciones consisten en el acoplamiento de un haluro orgánico y otra molécula orgánica con carácter nucleofílico. Las condiciones de reacción suelen ser suaves (presión atmosférica y temperaturas por debajo de $\operatorname{los} 150^{\circ} \mathrm{C}$ ) y los catalizadores que se emplean están basados en metales de transición asistidos por un agente básico.

Existe un considerable número de reacciones de acoplamiento $\mathrm{C}-\mathrm{C}$ que se clasifican en función del grupo nucleófilo utilizado para activar uno de los reactivos. El paladio, como catalizador, ha resultado ser muy versátil a la hora de acelerar la interacción entre haluros orgánicos y diferentes agentes organometálicos (Reacción de Negishi183: -ZnX ; reacción de Stille ${ }^{184}$ : -SnR3; reacción de Suzuki-Miyaura ${ }^{185}$ : $-\mathrm{B}(\mathrm{OH})_{2}$ ). El paladio también puede activar directamente dobles y triples enlaces, generando productos de acoplamiento que mantienen la insaturación original (Reacción de Heck ${ }^{186}$, reacción de Sonogashira ${ }^{187}$ ). Recientemente, se han descrito nuevas formas de acoplamientos, como la formación de enlaces C-N o C-O, reacción de Hartwig-Buchwald ${ }^{188,189}$, gracias al uso del paladio en la activación de grupos aminas, amidas, tioles o cetonas como agentes nucleófilos, tal y como se puede apreciar en el Esquema 4.1 .

\footnotetext{
180 Blaser H.U., Indolese A., Schnyder A., Seiner H., Studer M., J. Mol. Cat. A, 2001, 173, 3.

181 Tucker C.E., de Vries J.G., Top. Catal., 2002, 19, 111.

182 De Vries J.G., Can. J. Chem., 2001, 179, 1086.

183 Negishi E., Handbook of Organopalladium Chemistry for Organic Synthesis, 2002, 1, 229.

184 Milstein D., Stille J.K., J. Am. Chem. Soc., 1978, 100, 3636.

185 Miyaura M., Suzuki A., Chem. Rev., 1995, 95, 2457.

186 Heck R.F., Nolley J.P., J. Org. Chem., 1972, 37, 2320.

187 Sonogashira K.T., Hagihara N., Tetrahedron Lett., 1975, 16, 4467.

188 Louie J., Hartwig J.F., Tetrahedron Lett., 1995, 36, 3609.

${ }^{189}$ Guram A.S., Rennels R.A., Buchwald S.L., Angew. Chem., Int. Ed., 1995, 34, 1348.
} 
(1)

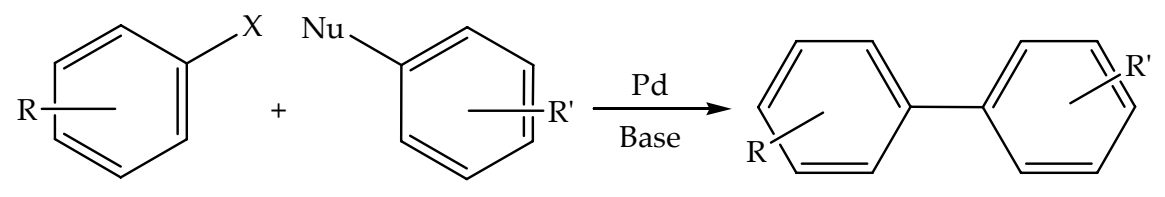

$\mathrm{X}=\mathrm{Cl}, \mathrm{Br}, \mathrm{I}, \mathrm{OTf}$

$\mathrm{Nu}=-\mathrm{MgX},-\mathrm{B}(\mathrm{OH}) 2,-\mathrm{SNR} 3,-\mathrm{Si}(\mathrm{OR}) 3, \mathrm{ZnX}$

(2)

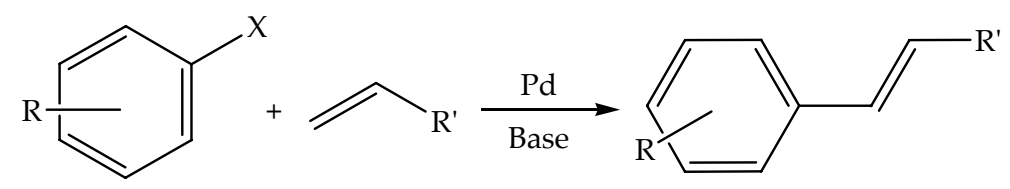

(3)

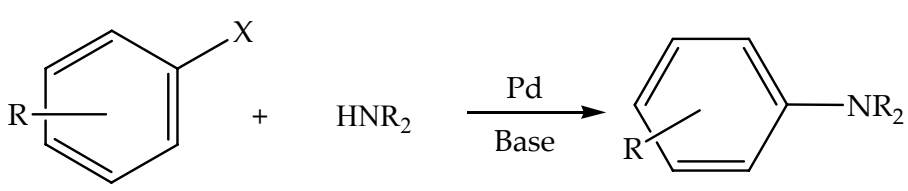

Esquema 4.1.- Esquema de reacción general para reacciones de acoplamiento utilizando distintos agentes nucleofílicos: (1) Organometálicos, (2) Insaturaciones y (3) Aminas.

En lo que respecta a los reactivos, el orden de reactividad de los haluros orgánicos, que a su vez determina la velocidad y selectividad del proceso, está totalmente relacionado con la energía del enlace carbono-halógeno, cuanto mayor es la energía enlazante, menos reactivo será el sustrato ya que obviamente la fuerza de ese enlace desfavorece la formación del producto. En el caso de la reacción de Heck, la reactividad de los alquenos aumenta cuanto mayor es el déficit de electrones y por lo tanto será mayor en el caso de que éste se encuentre sustituido por grupos tales como carbonilo o ciano ${ }^{186}$.

Cuando los reactivos empleados pueden dar lugar a varios isómeros, la distribución de productos está regida por la termodinámica (los productos con mayor estabilidad son los que se formarán y/o perdurarán), aunque algunas variables de la reacción como el disolvente, la base empleada o la especie de paladio que sea activa, pueden interferir en la formación del producto final. En cuanto a las reacciones secundarias que pueden generarse durante el proceso de acoplamiento, cabe destacar las deshalogenaciones del compuesto halogenado y los acoplamientos homolíticos. 


\subsection{3}

Reacción de Heck

El conocimiento preciso del mecanismo de una reacción permite, por lo general, optimizar el proceso y por lo tanto aumentar su eficacia. Sin embargo, no hay unanimidad en cuanto al mecanismo de la reacción de Heck, si bien se acepta que el ciclo catalítico de reacciones de acoplamiento $C-C$ en presencia de $\mathrm{Pd}$, comúnmente, transcurre en tres etapas consecutivas: Adición oxidativa del $\mathrm{Pd}$ al enlace $\mathrm{C}-\mathrm{X}$, transmetalación y eliminación reductiva ${ }^{190}$ (Esquema 4.2), en el caso del acoplamiento de Heck (Esquema 4.3), el ciclo catalítico presenta ligeras diferencias con respecto al resto de acoplamientos, puesto que carece de la etapa de transmetalación.

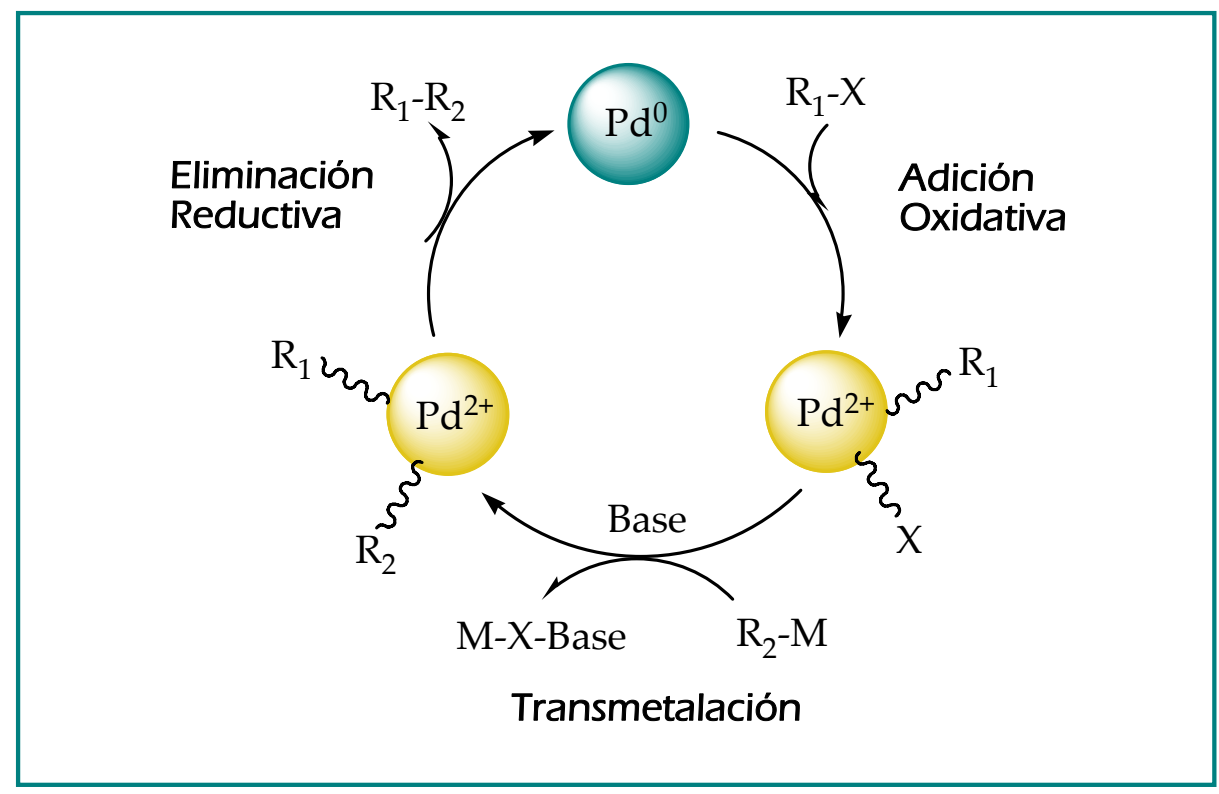

Esquema 4.2.- Ciclo general de reacciones de acoplamiento C-C sobre un catalizador de paladio ( $\mathrm{Pd})$.

El proceso comienza con la adición oxidativa que implica la activación del haluro orgánico sobre el centro de $\mathrm{Pd}^{0}$, lo que produce un cambio en el estado de oxidación del metal $\left(\mathrm{Pd}^{2+}\right)$. Seguidamente, la olefina se activa sobre el centro de $\mathrm{Pd}^{2+}$ por medio de una unión tipo $\pi$ y a continuación tiene lugar la formación del nuevo enlace C-C. El producto final de la reacción se genera tras la deserción de un complejo intermedio $\sigma$-enlazado con el centro metálico. El ciclo catalítico se completa con una eliminación reductiva del halógeno, asistida por la base, que

${ }^{190}$ Hassan J., Sevignon M., Gozzi C., Schulz E., Lemaire M., Chem. Rev., 2002, 102, 1359. 
a la vez devuelve a la especie activa de paladio a su estado de oxidación inicial ${ }^{191,192}\left(\mathrm{Pd}^{0}\right)$.Esquema 4.3.

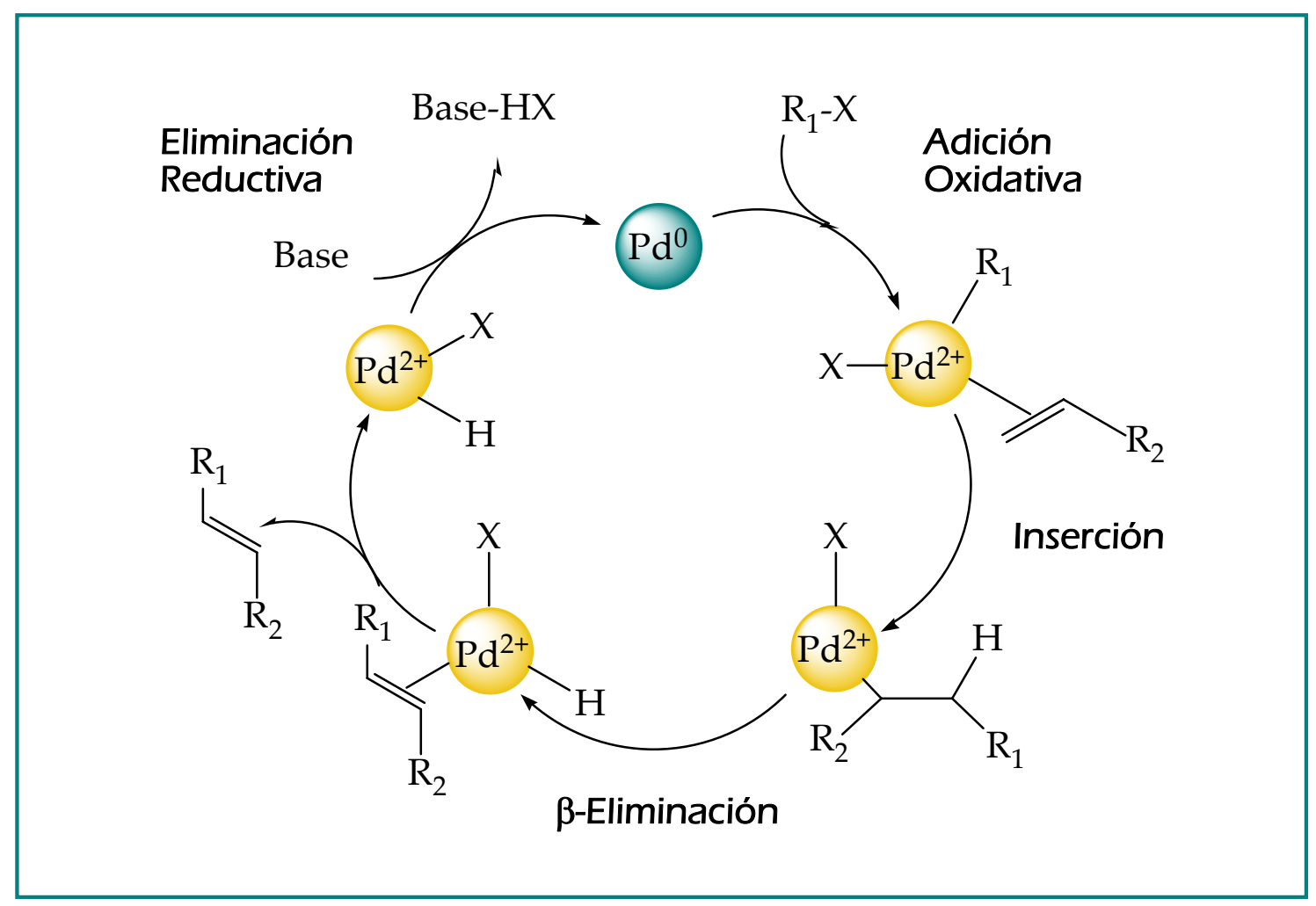

Esquema 4.3.- Ciclo de reacción para acoplamiento de Heck sobre un catalizador de paladio (Pd).

En cuanto a la especie catalíticamente activa, aunque la mayoría de catalizadores, tanto homogéneos como heterogéneos se sintetizan en forma de $\mathrm{Pd}^{2+}$, la hipótesis más aceptada es que el $\mathrm{Pd}^{0}$ es realmente la especie activa y que el compuesto inicial de $\mathrm{Pd}^{2+}$ es un precatalizador que durante el calentamiento inicial, genera la especie de $\mathrm{Pd}^{0}$ que será el auténtico centro catalítico ${ }^{193}$. En cuanto al estado completo del catalizador durante la reacción, una gran mayoría de los ejemplos publicados actualmente, implican complejos organometálicos que actúan como catalizadores homogéneos y por lo tanto las especies de paladio están completamente disueltas en el medio de reacción ${ }^{180}$.

En esta parte de la tesis se mostrará como el material POM-IL-Pd, que posee nanopartículas de óxido de paladio como centros activos, actúa como 
catalizador heterogéneo en el acoplamiento de Heck del yodobenceno con diferentes nucleófilos.

4.2

Caracterización del material

Polioxometalato-Líquido iónico-Paladio POM-IL-Pd

4.2.1

Microscopía electrónica

Los análisis realizados por microscopía a las muestras de POM-IL-Pd fueron determinantes, para esclarecer dónde estaba localizado el paladio que, si bien aparecía en los análisis químicos efectuados a las muestras, era inapreciable en los cristales cuya estructura se determinó por difracción de rayos X. Obviamente el paladio no formaba parte de dichos cristales (que en realidad consistían tan solo en la estructura secundaria del material (Figura 4.0), formada por el POM y los cationes imidazolio) y por eso no se detectó en la determinación cristalográfica, pero sí era parte constituyente del sólido final obtenido.

Las Figuras 4.1 y 4.2 muestran la micrografía electrónica (HAADFSTEM) de la muestra POM-IL-Pd. De acuerdo con el pequeño recuadro que aparece en la Figura 4.1, el material POM-IL-Pd cristaliza formando grandes partículas globulares de aproximadamente $1 \times 0,6 \mu \mathrm{m}$, decoradas con partículas bastante más pequeñas. Una inspección más cercana de la muestra (la imagen del cuerpo principal de la Figura 4.1), revela que estas pequeñas partículas consisten en agregados de alrededor de $20 \mathrm{~nm}$ de diámetro formados por cristales esféricos muy pequeños y uniformes, de unos 2-3 nm (en la Figura 4.3 se aprecian con mayor exactitud estas estructuras). El examen de la composición elemental de la muestra por espectroscopía de energía dispersa de rayos $\mathrm{X}$ (XEDS) ha demostrado que todo el Pd presente en el sólido está concentrado exclusivamente en esos agregados, mientras que las partes no cubiertas de la superficie del soporte, aquellas que no presentan decoración de agregados, tan solo contienen $\mathrm{V}$, Mo y $\mathrm{P}$, en ningún caso se detectaron trazas de $\mathrm{Pd}$, tal y como se puede apreciar en la Figura 4.3. 


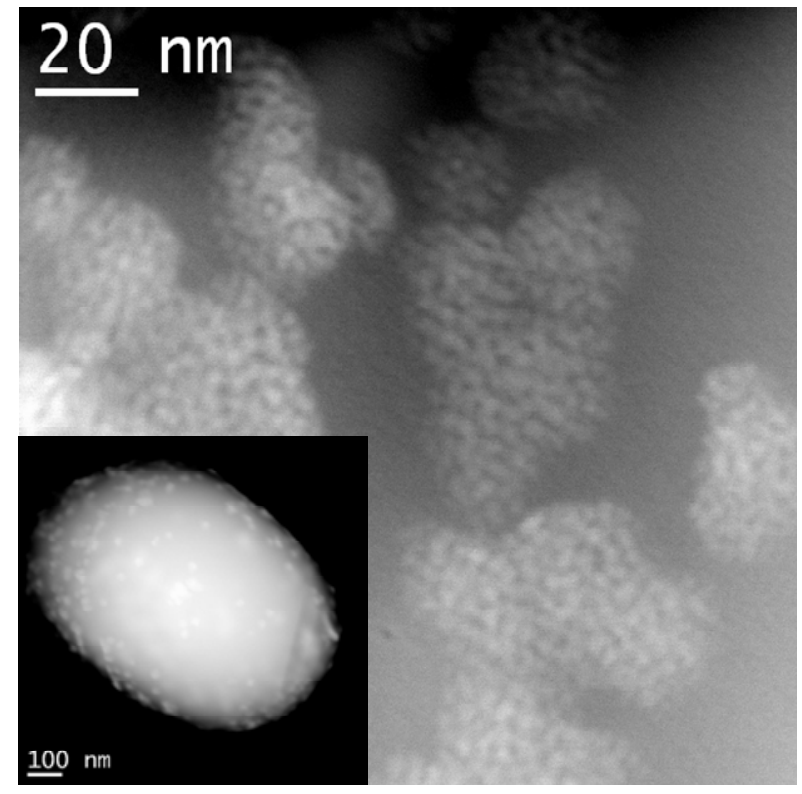

Figura 4.1.- Imagen del material POM-IL-Pd tomada por microscopía electrónica de transmisión (HAADF-STEM).
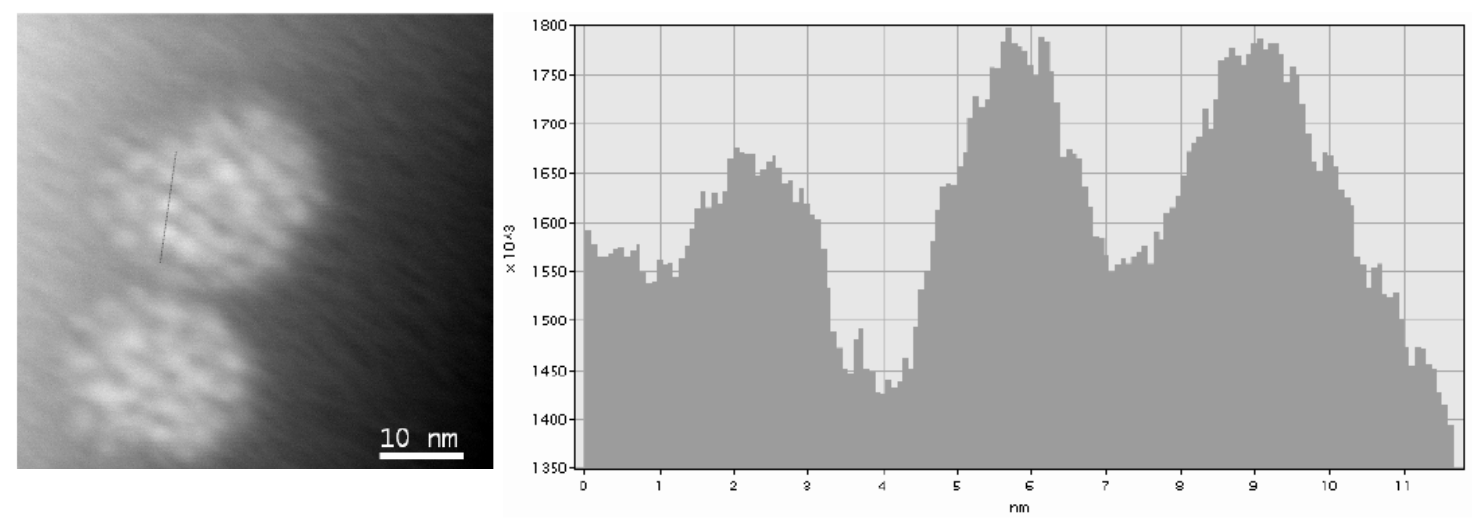

Figura 4.2.- (Derecha) detalles de alta resolución de los agregados de aproximadamente $20 \mathrm{~nm}$, compuesto por pequeñas nanopartículas. (Izquierda) Perfil de alturas a lo largo de la línea recta que se muestra en la imagen de la derecha, en el que se puede ver claramente que el tamaño de las nanopartículas es bastante uniforme, con un diámetro comprendido entre 2 y $3 \mathrm{~nm}$.

En la imagen microscópica de alta resolución (HRTEM) (Figura 4.4) se pueden observar claramente las líneas de interferencia de los dominios cristalinos, que tienen un espaciado regular de 2,24 A. Teniendo en cuenta la imagen de dispersión energética $\mathrm{ED}$, que se presenta en el pequeño recuadro de la Figura 4.4 y las medidas de espaciado interplanar, el espaciado medido se corresponde con nanopartículas de óxido de paladio (PdO), vistas a lo largo del eje [221]. Estas nanopartículas son representativas de toda la muestra, sin embargo, también fue detectada una pequeña porción de partículas de paladio 
metálico, con un tamaño prácticamente igual al de las de óxido. Probablemente las partículas metálicas se generaron in situ debido a la atmósfera reductora necesaria para hacer las mediciones (condiciones de alto vacío y exposición continuada a un haz de electrones).
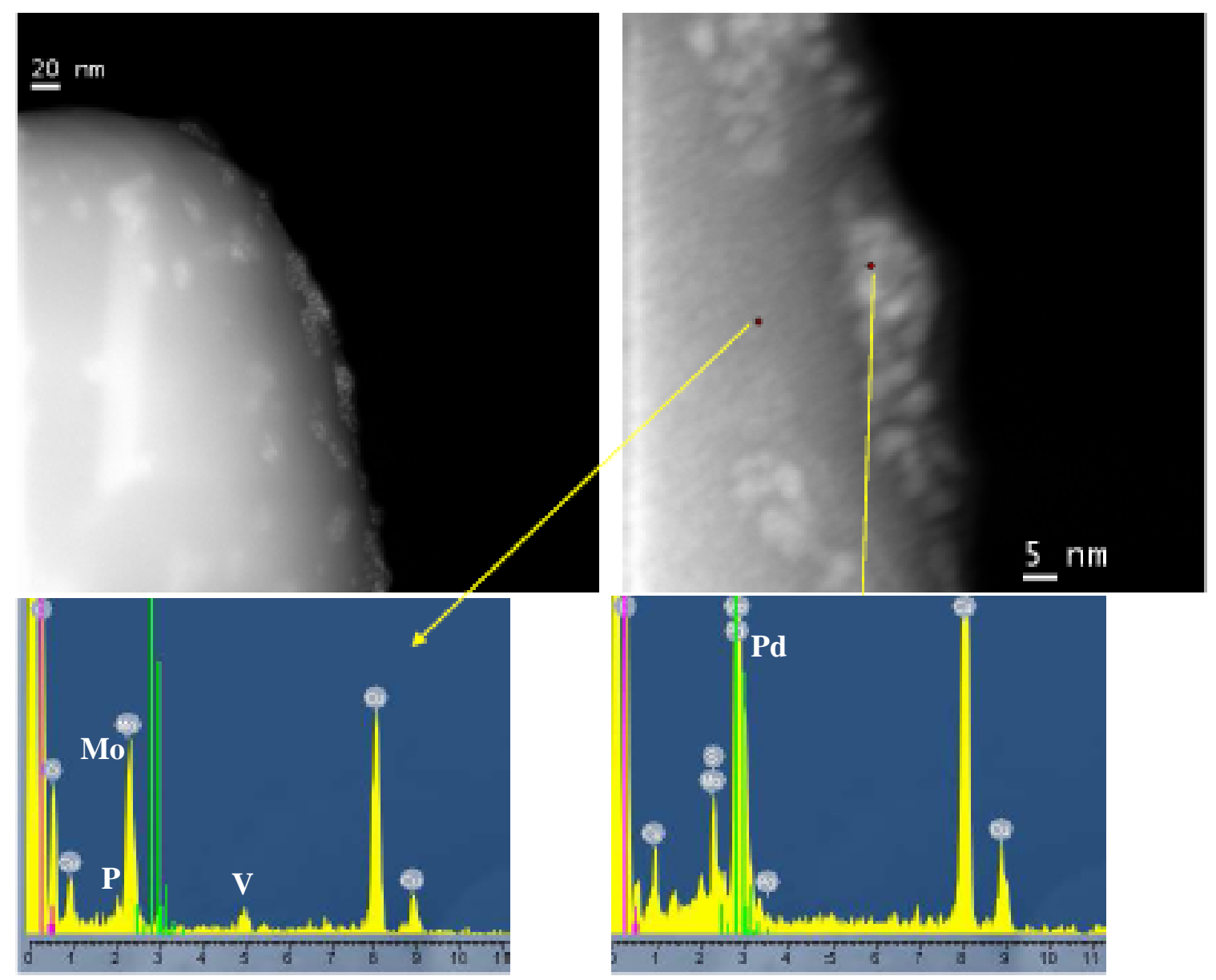

Figura 4.3.- Imágenes (HAADF-STEM) de la muestra POM-IL-Pd, con las correspondientes medidas XEDS en el punto indicado: (izquierda) sobre una superficie desnuda del soporte y (derecha) en uno de los agregados de la zona decorada del soporte. Las principales cumbres de P, Mo, V y Pd están señaladas para mayor claridad. Las líneas verdes corresponden al paladio. 


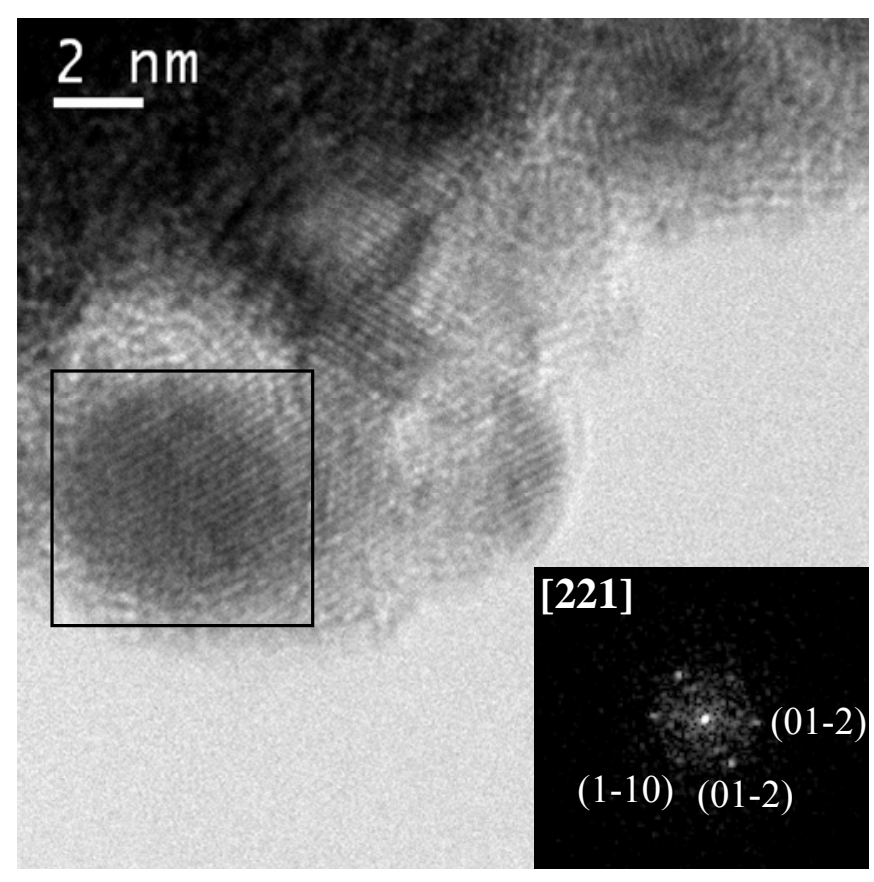

Figura 4.4.- Imágenes de microscopía electrónica de transferencia de alta resolución (HRTEM) de la muestra POM-IL-Pd. El recuadro en la parte inferior corresponde a la imagen de difracción de electrones a lo largo del eje [221] de la nanopartícula señalada en la imagen TEM.

Atendiendo al estudio realizado por microscopía electrónica, se puede concluir que el paladio encontrado en el material POM-IL-Pd, se encuentra en forma de nanopartículas esféricas de óxido de paladio ( $\mathrm{PdO}$ ) con un tamaño uniforme de 2-3 nm. Estas nanopartículas se aglomeran en forma de racimos de unos $20 \mathrm{~nm}$ que acaban decorando la superficie de grandes (1 $\mu \mathrm{m}$ aprox.) partículas globulares de soporte, formado por la interacción entre el POM y el líquido iónico.

\section{2 .2}

\section{Espectroscopía fotoelectrónica de absorción de rayos $\mathrm{X}$}

Los espectros de absorción de rayos X XANES y EXAFS realizados en el sincrotrón, fueron determinantes para acabar de caracterizar las muestras de POM-IL-Pd, pero sobretodo para averiguar cómo se comportaba en reacción y determinar qué lo hacía diferente del resto de materiales que también se estudiaron : POM-Pd, PdO, etc...

El espectro XANES en las proximidades del umbral $\mathrm{K}$ del $\mathrm{Pd}$, del material fresco POM-IL-Pd se muestra en la Figura 4.5a), donde también se puede observar el espectro correspondiente a un óxido de paladio convencional (preparado por calcinación de $\mathrm{Pd}(\mathrm{OH})_{2}$ a $900^{\circ} \mathrm{C}$ ) que se empleó como muestra de referencia. Como se puede apreciar, ambos espectros son muy similares y representan iones de $\mathrm{Pd}$ en estado de oxidación +2 . Teniendo en cuenta la 
similitud en los perfiles de ambos espectros, se puede descartar cualquier contribución significativa de paladio metálico (derivada de una eventual nanopartícula de $\mathrm{Pd}^{0}$ ) en la muestra de POM-IL-Pd.
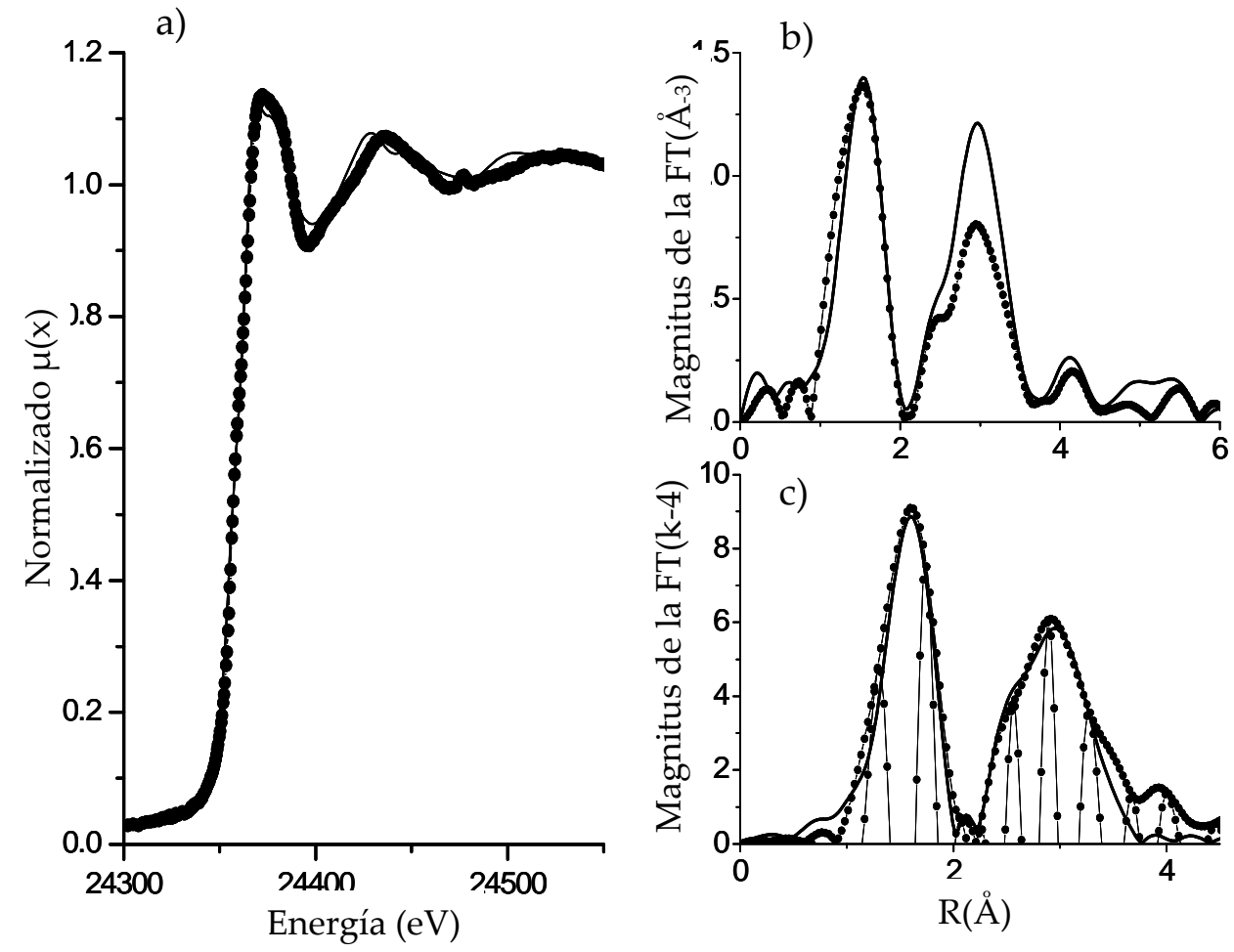

Figura 4.5.- a) Espectros XANES en las proximidades del umbral K del Pd de la muestra de POM-IL$\mathrm{Pd}$ (- - -) y de la muestra de PdO de referencia (línea continua), b) Fase no corregida de la transformada de Fourier $k^{3}$-ponderada, de los espectros EXAFS de las dos muestras contenedoras de $\mathrm{Pd}$; c) Transformada de Fourier en el espacio $\mathrm{R}$ de la señal experimental $k^{3}$ ponderada para la muestra de POM-IL-Pd y su mejor ajuste (línea continua). Se muestra tanto el módulo como la parte imaginaria de las transformadas de Fourier.

En la Figura 4.5b) se compara la transformada de Fourier de la señal EXAFS de la muestra de POM-IL-Pd con la del PdO referencia. En este caso se observa que la posición de las señales correspondientes a la primera esfera de coordinación ( $\mathrm{Pd}-\mathrm{O})$ y a la segunda (Pd-Pd), se encuentran en el mismo lugar, tanto para la muestra objeto de estudio como para la muestra de referencia. Sin embargo, se produce en la muestra de POM-IL-Pd, una reducción significativa de la intensidad de la señal de la segunda esfera (lo que implica una reducción del número de coordinación) con respecto a la muestra de referencia. Esto indica que el POM-IL-Pd contiene partículas de dimensiones muy pequeñas de PdO. De hecho, en el caso de que las partículas fueran mayores de $3 \mathrm{~nm}$, las diferencias en la intensidad de la segunda esfera de coordinación ( $\mathrm{Pd}-\mathrm{Pd})$ con respecto a la 
muestra de PdO de referencia, serían muy difíciles de apreciar por EXAFS. Del mismo modo que ya se vio en el espectro XANES, el EXAFS de la muestra POMIL-Pd no evidencia la presencia de paladio metálico.

Con el objetivo de obtener mayor información sobre el tamaño de las partículas de PdO en el material POM-IL-Pd, se analizó la mayor parte del espectro EXAFS. Los análisis por espectroscopia EXAFS permiten obtener información específica sobre la distancia interatómica entre los elementos, el desorden estructural y el número y tipo de átomos colindantes, a determinadas distancias, del elemento absorbente ${ }^{194}$. El principal parámetro que informa acerca del tamaño de las partículas, es el número de coordinación promedio, que puede determinarse, en principio, hasta la quinta esfera de coordinación del átomo absorbente. La relación entre el tamaño de las partículas y el número de coordinación promedio se basa en el hecho de que una fracción de los átomos de absorción se encuentra en la superficie de la partícula. Estos átomos tendrán, por lo tanto, menores índices de coordinación que los átomos situados en el resto de la partícula (los no superficiales) y la fracción de átomos de superficie, aumentará a medida que disminuye el tamaño de las partículas. Esta relación, entre número de átomos de superficie y el número de los no superficiales, se basa en una descripción precisa de la forma de las partículas y su distribución de tamaños, pero, si se carece de esta información, los resultados serán tan solo indicativos.

En la literatura se han encontrado precedentes en los que se emplearon este tipo de aproximaciones para la determinación de tamaños de partículas metálicas: Desde los trabajos pioneros de Lytle y col.195,196,197,198,199,200,201, a las publicaciones más recientes de Frenkel ${ }^{202,203}$ y col. se han descrito con precisión

\footnotetext{
194 Sayers D., Bunker B., X-ray absorption, Koningsberger D., Prins R. ed., Wiley, 1988.

195 Lytle F.W., Via G.H., Sinfelt J.H., J. Chem. Phys., 1977, 67, 3831.

196 Sinfelt J.H., Via G. H., Lytle F.W., J. Chem. Phys., 1978, 68, 2009.

197 Via G.H., Sinfelt J.J., Lytle F.W., J. Chem. Phys., 1979, 71, 690.

198 Sinfelt J.H., Via G. H., Lytle F.W., J. Chem. Phys., 1980, 72, 4832.

Sinfelt J.H., Via G. H., Lytle F.W., Greegor R.B.,J. Chem. Phys., 1981, 75, 5527.

Sinfelt J.H., Via G. H., Lytle F.W., J. Chem. Phys., 1982, 76, 2779.

199 Greegor R.B., Lytle F.W., J. Catal., 1980, 63, 476.

${ }^{200}$ Marques E.C., Sandstrom D.R., Lytle F.W., Greegor R.B., J. Chem. Phys., 1982, 77, 1027.

${ }^{201}$ Meitzner G., Via G.H., Lytle F.W., Sinfelt J.H., J. Chem. Phys., 1983, 78, 2533.

Meitzner G., Via G.H., Lytle F.W., Sinfelt J.H., J. Chem. Phys., 1983, 78, 882.

Meitzner G., Via G.H., Lytle F.W., Sinfelt J.H., J. Chem. Phys., 1985, 83, 4793.

Meitzner G., Via G.H., Lytle F.W., Sinfelt J.H., J. Chem. Phys., 1985, 83, 353.

202 Frenkel A.I., J. Synchrotron Radiat., 1999, 6, 293.

${ }^{203}$ Frenkel A.I., Hills C.W., Nuzzo R.G., J. Phys. Chem. B, 2001, 105, 12689.
} 
las dependencias funcionales entre el número de coordinación y la forma y distribución de tamaños de las nanopartículas metálicas. Sin embargo, como ya se demostró por XANES y HRTEM, la muestra de POM-IL-Pd no contiene partículas de metales, pero sí partículas de óxidos metálicos. Por lo tanto, las relaciones obtenidas para el metal no se pueden aplicar en este caso, y se hace necesario buscar una nueva relación funcional para las partículas de los óxidos metálicos. Es por esto que se desarrolló un software ad hoc en el que el número de coordinación promedio de los diferentes caminos de interferencia (dispersión simple y múltiple) que contribuyen a las señales EXAFS, se obtiene empíricamente para una serie de grupos de óxidos metálicos de tamaño creciente. Esta nueva forma de abordar el problema, junto con el software desarrollado, que utiliza una rutina PATH modificada, tal y como se aplica en el programa FEFF6 604 , presentan las ventajas de ser independiente de la estructura de la materia en estudio y que se pueden aplicar a los óxidos metálicos y no solo a los metales.

Para deducir el tamaño medio de las partículas de PdO se siguió el siguiente procedimiento:

Se asumió que todas las partículas de PdO en la muestra de POM-IL-Pd eran esféricas (tal y como se confirmó por análisis HRTEM, vide infra) y que todas tenían el mismo tamaño. A continuación se generó, empleando el programa ATOMS 205 , una serie de clusters de tamaños cada vez mayores, que se obtuvieron a partir de la estructura resuelta por difracción de rayos $\mathrm{X}$ de PdO. Para cada uno de estos clusters se calculó el número de coordinación promedio alrededor del paladio, teniendo en cuenta todos los iones paladio de la partícula, es decir, se generó la función del número de coordinación versus el tamaño de partícula: $<\mathrm{N}>$ vs. R. En este caso, el cálculo se extendió a dos trayectorias: la segunda esfera de coordinación Pd-Pd y la tercera esfera Pd-Pd y aunque también se aplicó a la primera esfera Pd-O, no se tuvo en cuenta para la evaluación del tamaño de partícula porque no resulta razonable plantear la hipótesis de una insaturación coordinativa de $\mathrm{Pd}^{2+}$ en condiciones ambientales. Lo que quiere decir, que se supuso que todos los átomos de $\mathrm{Pd}$ en las partículas estaban rodeados de 4 átomos de oxígeno (en este sentido, la intensidad de la señal EXAFS para la primera esfera $\mathrm{Pd}-\mathrm{O}$ es prácticamente igual para ambos 
materiales PdO de referencia y POM-IL-Pd, tal y como se puede observar en la Figura 4.5b). Los valores del número de coordinación promedio también se obtuvieron a partir de la correlación entre el espectro EXAFS experimental del PdO de referencia y el obtenido para la muestra de POM-IL-Pd. La muestra POM-IL-Pd fue analizada utilizando los valores de S02 (parámetros estadísticos) obtenidos para la muestra de referencia $\mathrm{PdO}$, ajustando el número de coordinación con los valores cristalográficos e introduciendo unos límites en los factores de Debye-Waller para las diferentes esferas de coordinación, dentro de un rango de error del $25 \%$ con respecto a los valores obtenidos para el PdO de referencia y de la comparación de ambos con los valores calculados para los clusters generados. Los resultados obtenidos en los análisis EXAFS del PdO de referencia así como de la muestra POM-IL-Pd se presentan en la Tabla 4.1 y la excelente calidad de la correlación de las señales asignadas al material POM-ILPd se pueden confirmar con la Figura 4.5c).

\begin{tabular}{|c|c|c|c|c|}
\hline \multicolumn{5}{|l|}{ PdO referencia } \\
\hline & $\mathrm{R} \pm 0,02(\AA)$ & $<\mathrm{N}> \pm 10 \%$ & $\mathrm{D}-\mathrm{W} \pm 10 \%(\AA)^{2}$ & $\Delta \mathrm{E} \pm 2(\mathrm{eV})$ \\
\hline $\begin{array}{c}\text { Pd-O 1ª Esfera } \\
\quad(2,0176)\end{array}$ & 2,02 & 4,00 & 0,0040 & 7,23 \\
\hline $\begin{array}{c}\text { Pd-Pd 2 }{ }^{a} \text { Esfera } \\
(3,03)\end{array}$ & 3,06 & 4,00 & 0,0060 & 7,23 \\
\hline $\begin{array}{c}\text { Pd-Pd 3 } 3^{\text {a }} \text { Esfera } \\
(3,42) \\
\end{array}$ & 3,44 & 8,00 & 0,0096 & 7,22 \\
\hline \multicolumn{5}{|l|}{ POM-IL-Pd } \\
\hline $\begin{array}{c}\text { Pd-O 1 } 1^{\text {a }} \text { Esfera } \\
(2,0176)\end{array}$ & 2,03 & 3,96 & 0,0042 & 6,31 \\
\hline $\begin{array}{c}\text { Pd-Pd 2 }{ }^{a} \text { Esfera } \\
(3,03)\end{array}$ & 3,05 & 3,09 & 0,0068 & 6,31 \\
\hline $\begin{array}{c}\text { Pd-Pd } 3^{\text {a }} \text { Esfera } \\
(3,42) \\
\end{array}$ & 3,46 & 4,20 & 0,0110 & 6,31 \\
\hline
\end{tabular}

Tabla 4.1.- Análisis de los espectros EXAFS de la muestra de referencia PdO y la muestras POM-ILPd. Los valores entre paréntesis en la primera columna corresponden a las distancias publicadas para la estructura de $\mathrm{PdO}$ resuelto por difracción de rayos $\mathrm{X}$. $\mathbf{R}$ representa el radio medio de cada esfera de coordinación. $\mathbf{N}$ representa el número de coordinación. D-W es el factor de Debye-Waller que informa de la atenuación de la dispersión de los rayos $\mathrm{X}$ al encontrarse con los distintos elementos que conforman la estructura de la materia en estudio.

De acuerdo con los resultados presentados en la Tabla 4.1, se observa una reducción en el número de coordinación promedio del Pd en la muestra 
POM-IL-Pd con respecto a la muestra de referencia PdO, de 4,00 a 3,09 en la segunda esfera de cordinación Pd-Pd y de 8,00 a 4,20 en la tercera esfera Pd-Pd. Por el contrario, y de acuerdo con las aproximaciones hechas, no hay una reducción significativa del número de coordinación promedio en la primera esfera de $\mathrm{Pd}-\mathrm{O}(4,00$ a 3,96). La disminución del número de coordinación promedio es más marcada para la tercera esfera de coordinación de Pd-Pd que para la segunda, ya que la tercera esfera es más sensible a pequeñas variaciones a largo alcance. Por lo tanto, la estimación del tamaño de partículas a partir del análisis de la tercera esfera de coordinación de Pd-Pd se espera que sea más precisa.

Los valores obtenidos de $<\mathrm{N}>$ para la segunda $(3,09)$ y tercera $(4,20)$ esferas de Pd-Pd de la muestra POM-IL-Pd se compararon con los calculados para los clusters "teóricos" de tamaños crecientes. Los resultados se muestran en la Figura 4.6.

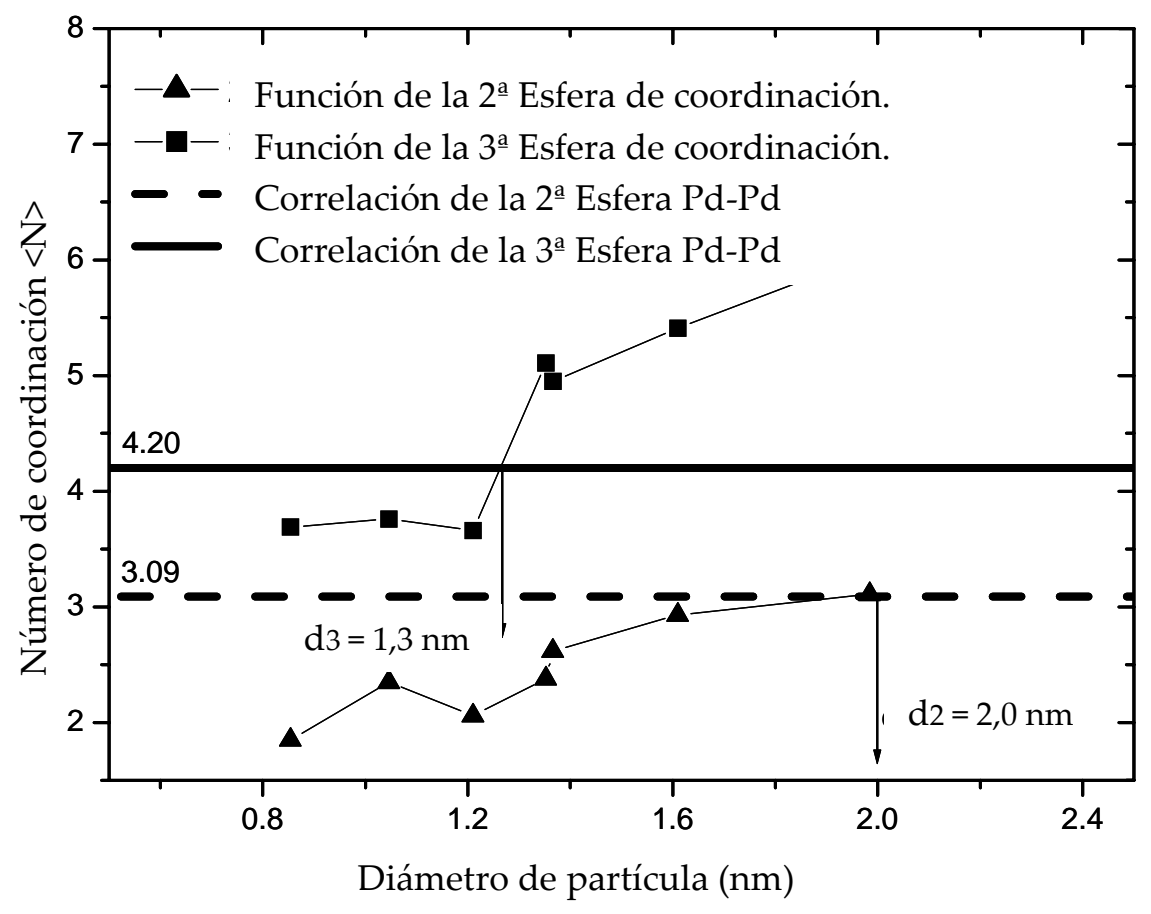

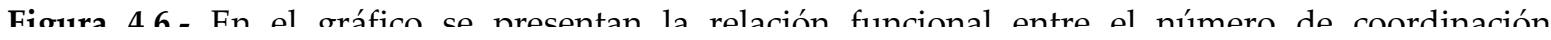
calculado, de la segunda esfera $(-\Delta-)$ y la tercera $(-\square-)$ frente al tamaño de las partículas (para partículas de forma esférica de PdO). Las líneas gruesas representan los valores obtenidos para los ajustes de la segunda y la tercera esfera para la muestra de POM-IL-Pd.

El tamaño de las partículas objeto de estudio, puede estimarse con el gráfico de la Figura 4.6, a partir de la determinación del diámetro del cluster 
"teórico" que tenga aproximadamente el mismo número de coordinación promedio que el obtenido experimentalmente por el ajuste de la señal de EXAFS del POM-IL-Pd. En el gráfico se determina a partir de la intersección entre el número de coordinación $<\mathrm{N}>$ y las medidas de diámetro, que se corresponden con las líneas horizontales. Como se puede observar, los resultados son ligeramente diferentes para el tamaño de partícula que se obtiene utilizando los ajustes de la segunda esfera de Pd-Pd y la tercera: 2 y 1,3 nm respectivamente. Esta discrepancia puede tener dos causas diferentes y muy probablemente, ambas contribuyen a las diferencias observadas: 1) Las partículas no son perfectamente esféricas y 2) Existe una distribución de partículas de diferente tamaño. Se debe tener en cuenta, que la comparación para la estimación del tamaño de partícula se hace con el número de coordinación promedio, que representa todas las partículas de la muestra, pero eso no quiere decir que todas tengan ese tamaño. Si la forma de estas partículas no es esférica, el efecto sobre la correspondencia de la segunda y tercera esfera será diferente, y lo mismo pasa con las partículas de diferente tamaño. En cualquier caso, los dos valores de 2,0 y 1,3 nm para ambas correspondencias, pueden ser considerados como el límite superior e inferior del tamaño de partículas que se podrán encontrar en la muestra, es decir, la mayoría de las partículas de la muestra POM-IL-Pd tendrán unas dimensiones comprendidas entre esos dos valores. Muy probablemente, el valor real estará más próximo a los 1,3 nm obtenidos a partir del ajuste de la señal de la tercera esfera de Pd-Pd, porque tal y como se comentó anteriormente, la tercera esfera proporciona una estimación más precisa del tamaño de partículas. Cabe señalar que existe una buena concordancia entre el tamaño de la partícula estimado a partir del análisis de EXAFS y el medido por HRTEM, estando el tamaño de partícula entre 2 y $3 \mathrm{~nm}$ de diámetro.

La Figura 4.7 muestra las partes de los espectros XANES y EXAFS en las proximidades del umbral $\mathrm{K}$ del $\mathrm{Pd}$, obtenidos para las muestras POM-IL-Pd, tanto fresco como después de haber sido utilizado en dos ciclos catalíticos (POMIL- Pdused) de la reacción de acoplamiento de Heck entre el yodobenceno y el estireno. Para realizar un estudio comparativo, se preparó una muestra de POM intercambiado con paladio (POM-Pd) cuyos espectros EXAFS y XANES se 
presentan en la Figura 4.7, donde también se incluyen los espectros del Pd metálico y del PdO empleados como referencia.

a)

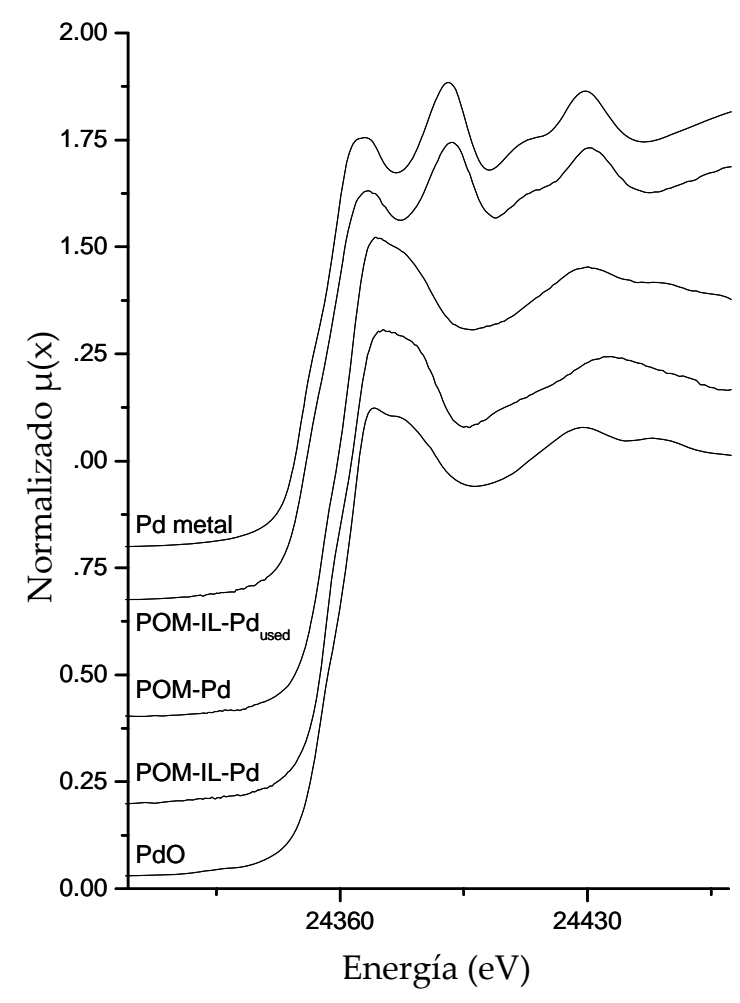

b)

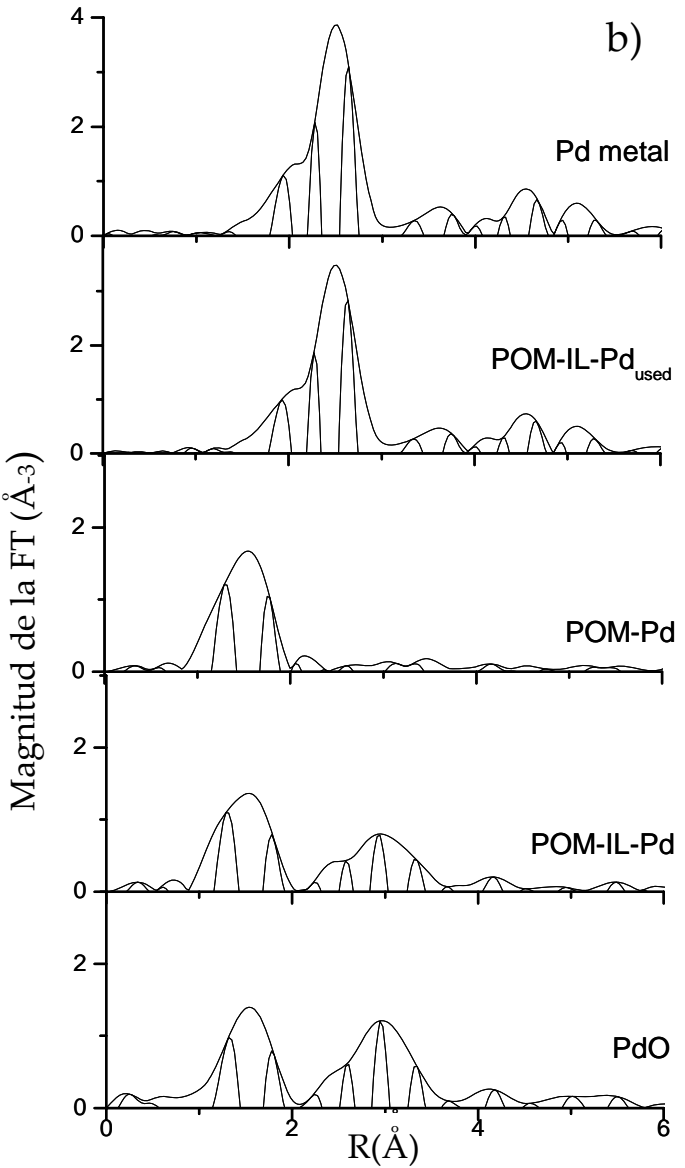

Figura 4.7.- a) Espectros XANES en el borde Pd K de las muestras (de abajo hacia arriba): PdO, POMIL-Pd, POM-Pd, POM-IL-Pdusado y Pdmetálico; b) Fase no corregida de la transformada de Fourier $k^{3}-$ ponderada, de los espectros EXAFS de las mismas muestras. Se reportan tanto el módulo como la parte imaginaria de las transformadas de Fourier.

Tal y como se observa en la Figura 4.7, los espectros XANES y EXAFS de la muestra de POM-IL-Pdusado y los de la de paladio metálico, son prácticamente indistinguibles, lo que quiere decir que, los iones de $\mathrm{Pd}^{2+}$ inicialmente presentes en la muestra fresca de POM-IL-Pd, se van reduciendo progresivamente hasta $\mathrm{Pd}^{0}$ durante la reacción catalítica. Después de dos ciclos catalíticos, la cantidad de $\mathrm{Pd}^{2+}$ en el catalizador es tan pequeña que está fuera de los límites de detección por espectroscopía de absorción de rayos X. Como referencia se ha analizado también el entorno local de paladio en el compuesto binario de POM-Pd. En los resultados que aparecen en la Figura 4.7 se muestra que los espectros para la 
muestra binaria, son diferentes de los observados para la muestra de POM-IL-Pd, tanto fresca como usada. Mientras que el espectro XANES del compuesto binario informa de un estado de oxidación +2 para el $\mathrm{Pd}$, al igual que en la muestra fresca POM-IL-Pd. La parte del espectro EXAFS no muestra la segunda ni la tercera capa de $\mathrm{Pd}-\mathrm{Pd}$ que cabe esperar para el óxido de paladio, es decir, que los iones de paladio están aislados, por lo que se descarta la posibilidad de que existan agregados de nanopartículas de PdO (como en el POM-IL-Pd) y también la existencia de partículas de paladio metálico (como en el POM-IL-Pdusado). Sin embargo, la presencia de una señal EXAFS para la primera capa $\mathrm{Pd}-\mathrm{O}$ en la muestra POM-Pd indica que hay iones aislados de $\mathrm{Pd}^{2+}$ localizados cerca de los átomos de oxígeno del polioxometalato, como cabe esperar en la interacción electrostática $\mathrm{POM}^{5--\mathrm{Pd}^{2+}}$ (donde $\mathrm{POM}^{5-}$ representa una unidad de polioxometalato del tipo sal de Keggin $\left[\mathrm{PO}_{40} \mathrm{~V}_{2} \mathrm{Mo}_{10}\right]^{5-}$ ). En resumen, los datos de XANES y EXAFS sugieren que los cationes de $\mathrm{Pd}^{2+}$ actúan en la muestra de POMPd como carga de compensación (como contraión), de las cargas negativa $\mathrm{POM}^{5-}$, mientras que en POM-IL-Pd, las nanopartículas de PdO decoran la superficie de las partículas de $\sim 1 \mu \mathrm{m}$ formadas por unidades de POM intercambiados con líquidos iónicos.

\section{3}

\section{Actividad catalítica}

El material POM-IL-Pd, se utilizó como catalizador heterogéneo en la reacción de acoplamiento de Heck entre el yodobenceno y el estireno, utilizando trietilamina como base, dimetilformamida como disolvente y unas condiciones de reacción (presión atmosférica, $100^{\circ} \mathrm{C}$ y $0,01 \%$ en peso de $\mathrm{Pd}$ ) bastante más suaves que las empleadas usualmente en los procedimientos que se encuentran en la literatura ${ }^{206}$. La reacción, en tales condiciones, genera como único producto trans-estilbeno (3) (Esquema 4.4) con una conversión del 93\%, una selectividad del 100\% y un TON (Turnover Number) de 15000 en 2 horas de reacción. En la Figura 4.8 se muestra el comportamiento cinético de varios catalizadores, entre ellos: POM-IL-Pd, POM-Pd, un catalizador homogéneo como acetato de paladio y el POM-IL (preparado por intercambio de POM con líquido iónico y que carece de Pd). Como se puede observar en la Figura 4.8, la actividad catalítica de POM-

206 Phan N.T., Van Der Sluys M., Jones C.W., Adv. Synth. Catal., 2006, 348, 609. 
IL-Pd es superior a la conseguida por el POM-Pd y el catalizador homogéneo, mientras que el POM-IL, sin paladio, no desarrolla ninguna actividad para el acoplamiento de Heck. Este comportamiento se puede explicar gracias al hecho de que en el POM-IL-Pd, el paladio se encuentra en forma de nanopartículas esféricas uniformes de $\mathrm{PdO}$ de 2-3 nm, que se agregan formando racimos de unos $20 \mathrm{~nm}$. Finalmente, estos racimos se mantienen sobre la superficie de un soporte híbrido de POM-IL con forma de partículas ovoides de $\sim 1 \mu \mathrm{m}$. La disposición estructural, altamente dispersa, del Pd en el material POM-IL-Pd, en comparación con la disposición en el POM-Pd, donde está en forma de iones $\mathrm{Pd}^{2+}$ compensando las cargas negativas del POM al igual que en el catalizador homogéneo $\mathrm{Pd}^{2+}\left(\mathrm{CH}_{3} \mathrm{COO}^{-}\right)_{2}$, deviene en una mayor actividad catalítica.

\begin{tabular}{|c|c|c|c|c|c|}
\hline Ent. & Catalizador & $\begin{array}{c}\text { Halobenceno } \\
\text { (1) }\end{array}$ & $\begin{array}{l}\text { Olefina } \\
\text { (2) (4) }\end{array}$ & $\begin{array}{l}\text { (\%) Conv. } \\
\text { PhX }\end{array}$ & $\begin{array}{c}\text { TOF } \\
\text { mmols Prod. } \\
{\text { mmols Pd } \text { Pd }^{-1} \text { min }^{-1}}^{-1}\end{array}$ \\
\hline 1 & POM-IL-Pd & Yodobenceno & Estireno & 93 & 200 \\
\hline 2 & POM-Pd & Yodobenceno & Estireno & 79 & 174 \\
\hline 3 & POM-IL & Yodobenceno & Estireno & 0 & 0 \\
\hline 4 & Acetato de Pd & Yodobenceno & Estireno & 70 & 156 \\
\hline 5 & POM-IL-Pd & Bromobenceno & Estireno & 49 & 26 \\
\hline 6 & POM-Pd & Bromobenceno & Estireno & 18 & 5 \\
\hline 7 & POM-IL-Pd & Yodobenceno & Acrilato de metilo & 83 & 190 \\
\hline
\end{tabular}

Tabla 4.2.- Resultados de la reacción de Heck de yodobenceno o bromobenceno ( $3 \mathrm{mmol})$ con estireno o acrilato de metilo $(3,9 \mathrm{mmol})$ y trietilamina $(3,6 \mathrm{mmol})$ en $0,5 \mathrm{~mL}$ de DMF como disolvente y en presencia del $0,01 \%$ en peso de Pd. Las reacciones se realizaron a $100^{\circ} \mathrm{C}$ durante 2 horas.

La diferente actividad entre POM-IL-Pd, POM-Pd y $\mathrm{Pd}^{2+}\left(\mathrm{CH}_{3} \mathrm{COO}^{-}\right)_{2}$ es todavía más notable cuando la reacción de acoplamiento se realiza usando un halobenceno menos reactivo como el bromobenceno (Tabla 4.2, entradas 5 y 6). Además, cuando el acrilato de metilo se utiliza como reactivo (Tabla 4.2, entrada 7), en lugar de estireno, la actividad catalítica es también muy alta dando un $83 \%$ de conversión y el $100 \%$ de selectividad al correspondiente trans-cinamato (5) (Esquema 4.4). 


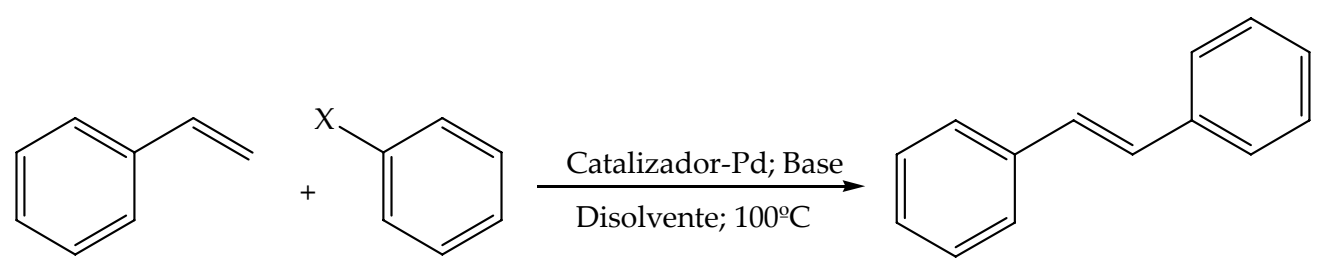

(2)

(1)

(3)

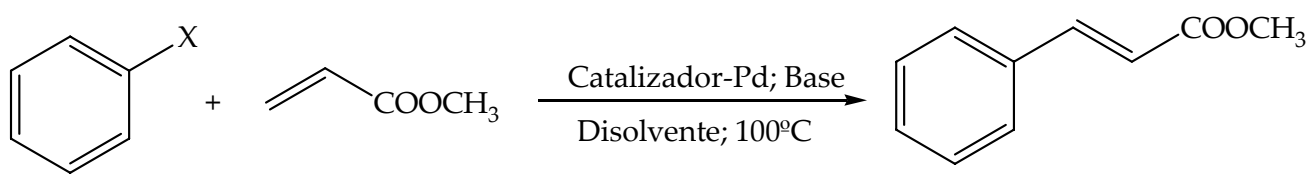

(1)

(4)

(5)

Esquema 4.4.- Esquema de reacción de acoplamiento C-C tipo Heck entre el estireno (2) o el acrilato de metilo (4) y un halobenceno (1).

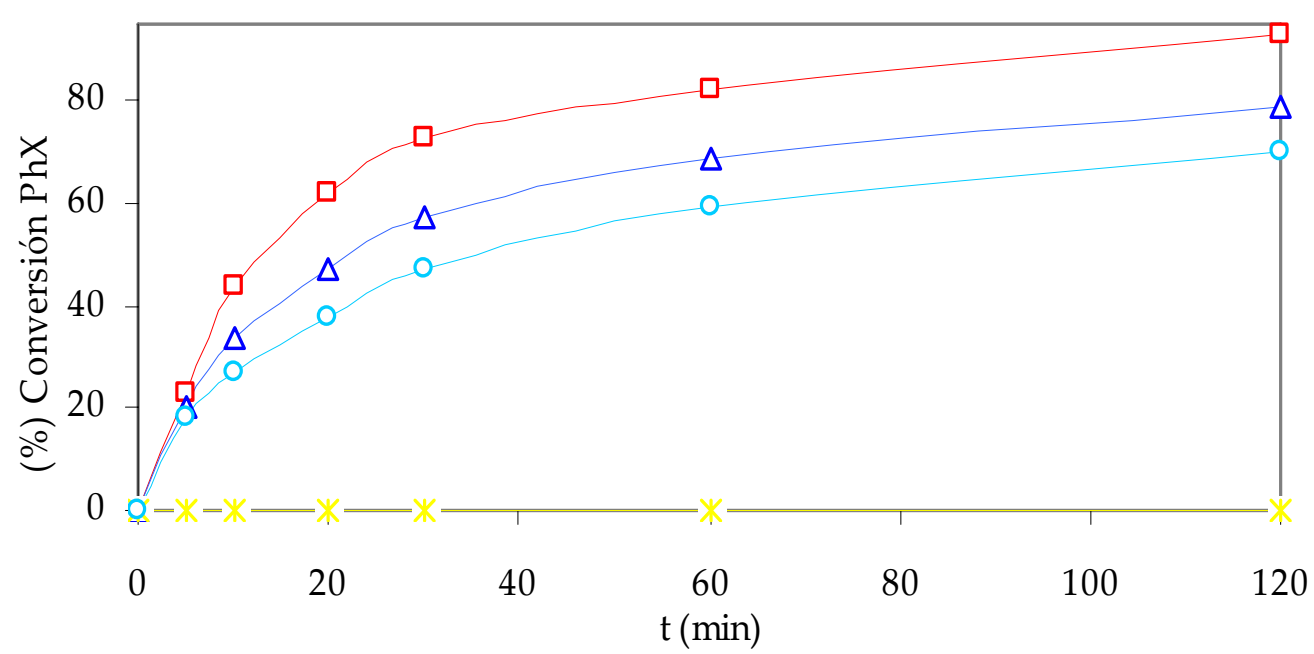

Figura 4.8.- Gráfica tiempo frente a conversión de la reacción de Heck entre yodobenceno ( $3 \mathrm{mmol})$ y estireno (3,9 mmol) en DMF a $100^{\circ} \mathrm{C}$ en presencia de diferentes catalizadores: ( $\square$ ) POM-IL-Pd; $(\Delta)$ POM-Pd; (o) Acetato de paladio; (*) POM-IL.

\subsection{1}

\section{Estudio de la influencia del disolvente y del lixiviado del metal}

La reacción de Heck entre el estireno y el yodobenceno utilizando POMIL-Pd y POM-Pd como catalizadores, se llevó a cabo con disolventes de distintas polaridades. Tal y como se observa en la Tabla 4.3, para ambos catalizadores, la mayor actividad se consiguió en presencia de un disolvente polar, DMF, mientras que con los disolventes apolares, tolueno y xileno el TOF (Turnover Frequency) fue notablemente inferior, a pesar de que la temperatura de reacción 
en estos casos, fue mayor. La reacción de acoplamiento, se realizó también en ausencia de disolvente (una alternativa muy extendida en la actualidad, para reducir el factor E), sin embargo la actividad fue apreciablemente inferior, y la temperatura de reacción se tuvo que aumentar a $140^{\circ} \mathrm{C}$ con el objeto de lograr mayores rendimientos. Como también se puede observar en la Tabla 4.3 (entradas 5-8) en todos los casos el POM-Pd dio menor actividad catalítica.

En la literatura aparecen referencias ${ }^{207,208}$ en las que se emplean disolventes polares y en particular DMF en la reacción de Heck, en ellas se habla de la lixiviación parcial que sufre el paladio del catalizador, quedando el metal disuelto en el medio de reacción, mientras que en aquellas reacciones que se utiliza el tolueno 207,209,210 como disolvente, no se aprecian fenómenos de lixiviado. Así pues, los mayores rendimientos observados en las reacciones con DMF, podrían estar asociados al lixiviado de especies de Pd. Llegados a este punto, se hizo necesario comprobar de qué manera afectaba a la reacción el lixiviado del paladio. Para ello se realizaron experimentos con DMF y tolueno haciendo la filtración en caliente del catalizador, una vez llegada la reacción al 50 \% de la conversión final. En la Figura 4.9 a) se observa como la reacción en DMF, tras la filtración del catalizador, continúa incrementando, aunque ligeramente, la conversión. Sin embargo, tal y como se aprecia en la Figura 4.9 b) en tolueno, en el momento que el catalizador es retirado del medio, la reacción ya no evoluciona a mayores índices de conversión. Otros resultados indican que mientras que el tolueno no promueve el lixiviado del metal, la DMF sí provoca una ligera lixiviación. De todos modos, cabe remarcar que la contribución del Pd lixiviado en el rendimiento final es inferior al $10 \%$, lo cual, no justifica las diferencias en la actividad observada entre ambos disolventes. En este sentido, se debe tener en cuenta que el lixiviado de $\mathrm{Pd}^{2+}$ es mucho más marcado para el catalizador POMPd que para el POM-IL-Pd, lo que refleja que el POM-IL-Pd es más estable y tiene mayor capacidad de retener el Pd en su estado original. De hecho, según el análisis elemental de paladio, el catalizador de POM-Pd pierde el $\sim 75 \%$ del $\mathrm{Pd}$ inicial después de dos ciclos catalíticos (el POM-Pd fresco contiene $2,6 \%$ en peso de paladio, mientras que el material recuperado después de dos ciclos catalíticos

${ }^{207}$ Dams M., Drijkoningen L., Pauwels B., Van Tendeloo G., De Vos D.E., Jacobs P.A., J. Catal., 2002, 209, 225.

${ }^{208}$ Corma A., García H., Leyva A., J. Mol. Catal. A-Chem., 2005, 230, 97.

${ }^{209}$ Corma A., García H., Leyva A., Appl. Catal. A: Gen., 2002, 236, 179.

${ }^{210}$ Corma A., García H., Leyva A., Primo A., Appl. Catal. A: Gen., 2003, 247, 41. 
contenía tan solo un $0,7 \%$ en peso de Pd). En las mismas condiciones, el compuesto ternario POM-IL-Pd pierde $~ 30 \%$ de la carga inicial de $\mathrm{Pd}$ (de $2,7 \%$ en peso en el material fresco a $1,8 \%$ en peso en el catalizador usado).

\begin{tabular}{clcccc}
\hline Ent. & Catalizador & Disolvente & $\begin{array}{c}\text { Temp. } \\
\left({ }^{\circ} \mathbf{C}\right)\end{array}$ & $\begin{array}{c}\text { Rendim. } \\
(\%)\end{array}$ & $\begin{array}{c}\text { TOF } \\
\text { mmols Prod. } \\
\text { mmols Pd-1 min-1 }^{-1}\end{array}$ \\
\hline 1 & POM-IL-Pd & DMF & 100 & 93 & 200 \\
2 & POM-IL-Pd & o-Xileno & 130 & 76 & 42,1 \\
3 & POM-IL-Pd & Tolueno & 110 & 65 & 94,7 \\
4 & POM-IL-Pd & - & 140 & 87 & 231,6 \\
5 & POM-Pd & DMF & 100 & 79 & 174 \\
6 & POM-Pd & o-Xileno & 130 & 50 & 36,8 \\
7 & POM-Pd & Tolueno & 110 & 50 & 63,2 \\
8 & POM-Pd & - & 140 & 74 & 184,2 \\
\hline
\end{tabular}

Tabla 4.3.- Resultados de la reacción de Heck de el yodobenceno ( $3 \mathrm{mmol})$ con el estireno $(3.9 \mathrm{mmol})$ y la trietilamina $(3,6 \mathrm{mmol})$ en $0,5 \mathrm{ml}$ de disolvente, en presencia del $0,01 \%$ en peso de paladio (en la cantidad correspondiente de catalizador). Las reacciones se desarrollaron durante $2 \mathrm{~h}$.

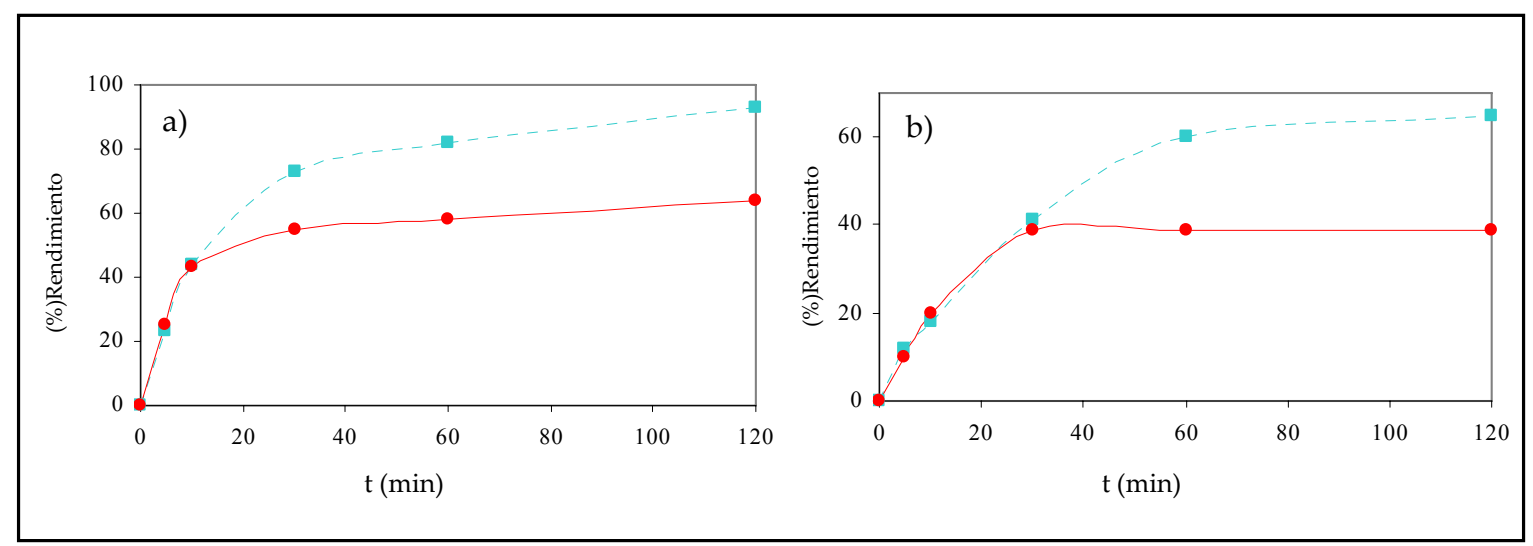

Figura 4.9.- Gráficas de tiempo frente a rendimiento de la reacción de Heck para el yodobenceno (3 $\mathrm{mmol})$ y el estireno $(3,9 \mathrm{mmol})$, con trietilamina como base $(3,6 \mathrm{mmol})$ y POM-IL-Pd $(0,01 \%$ en peso de Pd). La reacción a) se llevó a cabo en $\mathrm{DMF}$ a $100^{\circ} \mathrm{C}$, tras $10 \mathrm{~min}$ de reacción, el catalizador se filtró en caliente y seguidamente la reacción se continuó en las mismas condiciones (línea contínua). La reacción b) se llevó a cabo en Tolueno a $110^{\circ} \mathrm{C}$, tras $30 \mathrm{~min}$ de reacción, el catalizador se filtró en caliente y seguidamente la reacción se continuó en las mismas condiciones (línea contínua). La línea discontínua en ambos casos representa la cinética de la reacción si no se hubiera retirando el catalizador. 


\subsection{2}

\section{Estudio de la estabilidad del catalizador}

Con el fin de estudiar la estabilidad del material POM-IL-Pd, el catalizador se sometió a cinco ciclos catalíticos consecutivos. Como se puede observar en la Figura 4.10, la actividad catalítica se mantuvo prácticamente hasta el tercer ciclo, mientras que a partir del cuarto ciclo se hace evidente una pérdida de actividad del 17\% y ya en el quinto ciclo del $40 \%$. El análisis de SEM realizado a las muestras de los materiales usados, demostró que tras varios usos, las características del material varían. En la Figura 4.11, se muestran la imagenes BSE SEM obtenidas para una muestra POM-IL-Pd usado, que había sido empleada en cuatro ciclos catalíticos consecutivos. En las imágenes, el paladio (el elemento más pesado) aparece en forma de manchas blancas. Evidentemente, tras la reacción catalítica, las nanopartículas de $\mathrm{PdO}$ originales se han reducido y se agregan formando las partículas grandes de paladio metálico. Lo que está de acuerdo con los resultados de EXAFS y XANES presentados en la Figura 4.7.

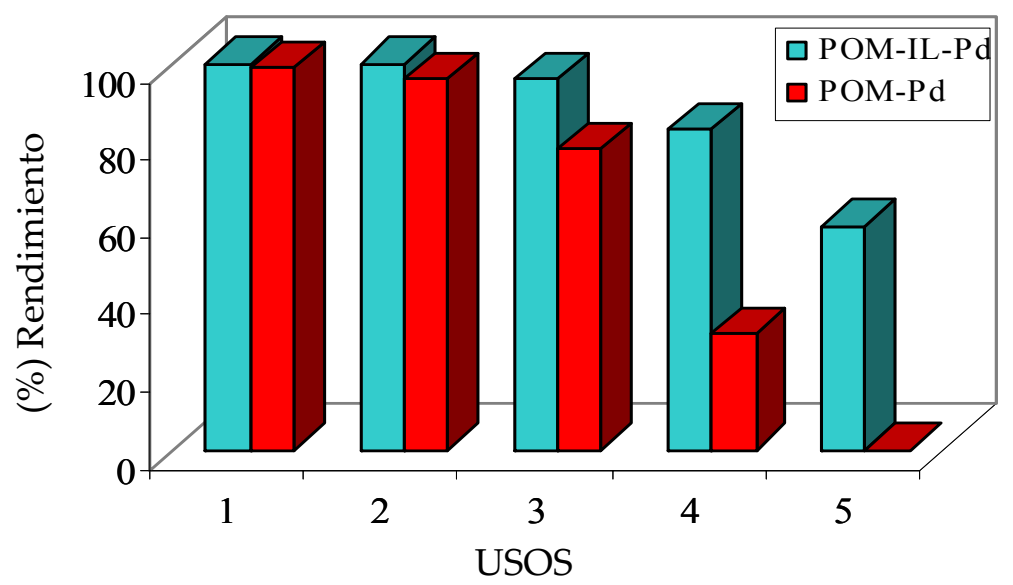

Figura 4.10.- Rendimientos a 1 hora de reacción de Heck entre yodobenceno $(3 \mathrm{mmol})$ y estireno $(3,9$ $\mathrm{mmol}$ ) en DMF a $140^{\circ} \mathrm{C}$, en presencia de POM-IL-Pd y POM-Pd respectivamente.(1) Catalizador fresco. (2-5) Catalizador reusado.

Con el fin de comprobar la estabilidad del POM-Pd, también se hicieron experimentos de reutilización de este material. Tal y como se observa en la Figura 4.10, la actividad catalítica tan solo se pudo mantener durante dos ciclos consecutivos, y con el cuarto ciclo ya se había perdido casi un $70 \%$ de la actividad inicial. Las imágenes SEM de la muestra POM-Pd después de dos 
ciclos consecutivos, no mostraron agregación de partículas metálicas de Pd como ocurrió en el caso de las POM-IL-Pdusado, lo que podría indicar que el $\mathrm{Pd}^{2+}$ sigue actuando de contraión intercambiado en la estructura del POM, sin embargo, el análisis elemental de la muestra demostró que durante cada reacción se produce una fuerte lixiviación del $\mathrm{Pd}$, responsable directa de la acusada pérdida de actividad de este material.

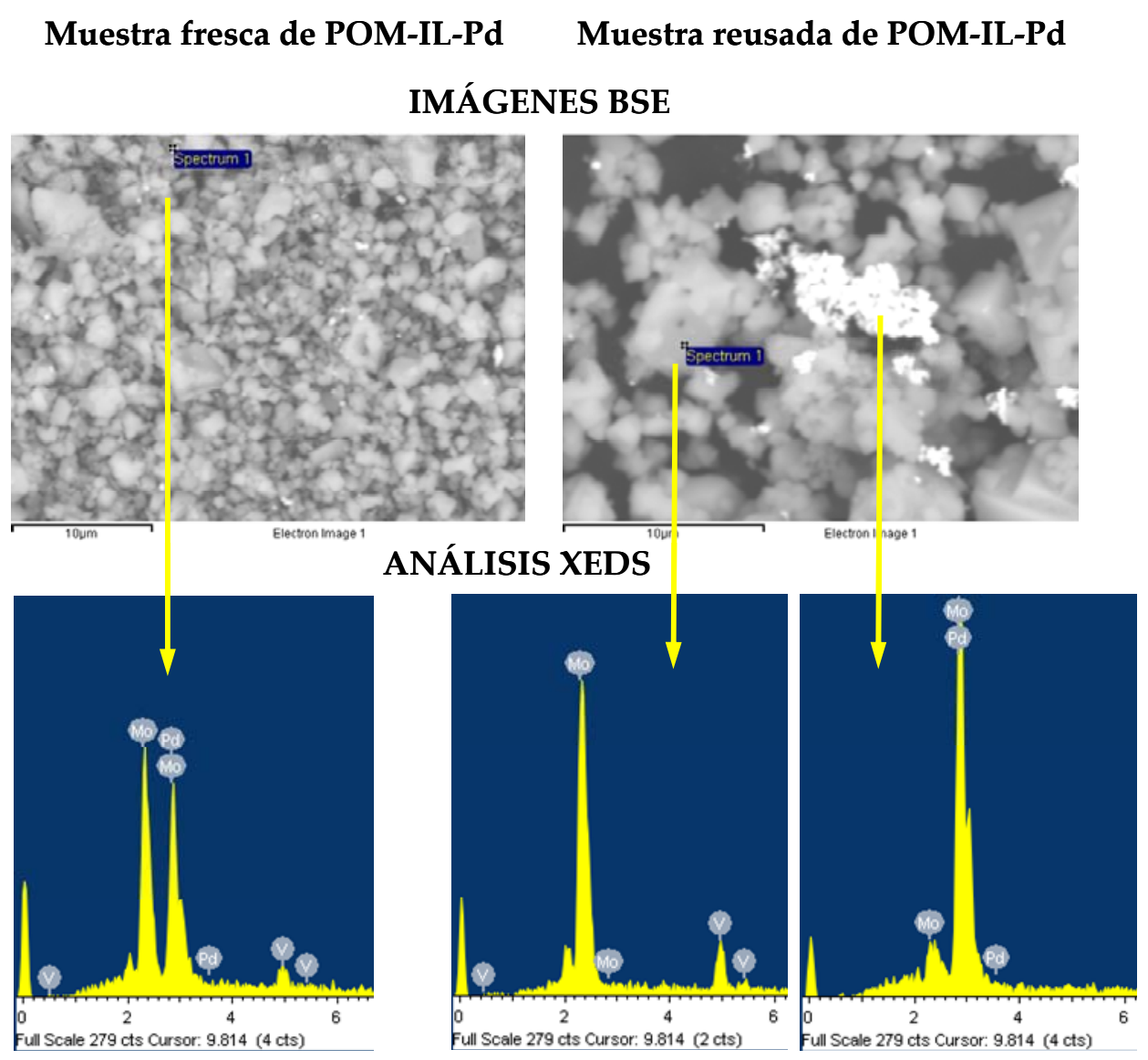

Figura 4.11.- Imágenes BSE SEM de la muestra fresca y la usada así como sus correspondientes análisis XEDS de las zonas indicadas con flechas. En la muestra fresca se aprecia una distribución homogénea de Mo y V provenientes de las unidades de POM y de Pd de las nanopartículas. Por el contrario, la muestra reusada contiene regiones ricas en $\mathrm{Pd}$ (que se muestran como partículas blancas en la imagen de BSE) y regiones en las que el Pd es inexistente (zonas más oscuras en la imagen de BSE), según lo confirmado a partir de los análisis XEDS. 
4.4

\section{Conclusiones}

1.- A lo largo de este capítulo se ha demostrado que a partir del intercambio iónico con líquidos iónicos de una sal de Keggin y la posterior adición de paladio, se pueden sintetizar nanopartículas de óxido de paladio con interesantes aplicaciones en procesos catalíticos. La caracterización del material por microscopía electrónica de transmisión de alta resolución (HRTEM) y espectroscopía de absorción de rayos $X$ (EXAFS-XANES) ha demostrado claramente la formación, durante el proceso de síntesis, de partículas regulares de $2 \mathrm{~nm}$ de óxido de paladio y que éstas están soportadas sobre el material híbrido constituído por el polioxometalato intercambiado con el líquido iónico.

2.- El material es activo y selectivo para la reacción de Heck, especialmente en medios de reacción polares (DMF), pudiendo ser usado hasta tres ciclos consecutivos sin apreciable pérdida de actividad. Sin embargo, en este tipo de disolventes y tras varios ciclos reactivos se produce el lixiviado del metal. Este hecho, junto con la facilidad de reducción del $\mathrm{Pd}^{2+}$, que da lugar a partículas de Pd metálico más voluminosas, deben ser la causa de la desactivación del catalizador tras repetidos ciclos reactivos.

3.- Finalmente, señalar que, el hecho de que este método de preparación consiga nanopartículas con un tamaño tan significativamente pequeño y con una morfología tan regular, ofrece nuevas perspectivas para reacciones catalizadas por paladio en fase líquida, o incluso para reacciones que puedan ser llevadas a cabo en fase gaseosa. 
Capítulo V:

Líquidos iónicos con bifuncionalidad ácido-base y distancia controlada entre los centros catalíícos, como organocatalizadores en la reacción de Knoevenagel. Estudios de su aplicación en síntesis de cumarinas e iminocumarinas 

5. 1

\section{Introducción}

5.1 .1

\section{Líquidos iónicos bifuncionales. Catálisis cooperativa}

Como se ha demostrado a lo largo de la introducción, los líquidos iónicos están despertando un gran interés en síntesis orgánicas, pues son considerados, gracias a sus especiales características, medioambientalmente idóneos $211,212,213,214$ para un gran número procesos. Por otra parte, pueden llegar a ser una especie ilimitada, pues pequeñas alteraciones controladas en su estructura molecular, pueden provocar variaciones drásticas en sus propiedades, lo que amplía exponencialmente el ámbito de sus aplicaciones. Por ejemplo, en las últimas décadas del siglo $\mathrm{XX}$, los líquidos iónicos cloroaluminados se utilizaron en una gran variedad de reacciones (alquilaciones ${ }^{215,216}$, esterificaciones ${ }^{217}$, acrilaciones ${ }^{218}$, dimerizaciones ${ }^{219}$ y reacciones de Diels-Alder ${ }^{220}$ ) como catalizadores ácidos de Lewis; sin embargo, demostraron ser especialmente sensibles al agua, lo que acabó suponiendo una limitación en las expectativas de su uso. La alternativa: líquidos iónicos no cloroaluminados. Uno de los primeros no cloroaluminado ${ }^{221}$ y con carácter ácido, consistió en sales de dialquilimidazolio con cadenas laterales que contenían el grupo $\mathrm{SO}_{3} \mathrm{H}$. Este nuevo tipo de líquido iónico fue utilizado como catalizador y disolvente en muchas reacciones ácido-base convencionales (oligomerizaciones de olefinas $^{222}$, eterificaciones ${ }^{221}$, esterificaciones ${ }^{223}$ y alquilaciones de Friedel-Crafts ${ }^{224}$ ). En cuanto a la acidez Brønsted, los líquidos

211 Welton T., Chem. Rev., 1999, 99, 2071.

212 Earle M.J., Seddon K.R., Pure Appl. Chem., 2000, 72 , 7, 1391.

213 Wasserscheid P., Keim W., Angew. Chem., 2000, 112, 3926; Angew. Chem. Int. Ed., 200, $39,3772$.

214 DuPont J, Souza R., Suarez P., Chem. Rev, 2002, 102, 3667.

215 Qiao K., Deng Y., J. Mol. Catal. A: Chem., 2001, 171, 81.

216 Wang G., Qiao K., Cheng L., Appl. Catal. A: Chem., 2004, 262, 69.

217 Deng Y., Dhi F., Beng J., Qiao K., J. Mol. Catal. A: Chem., 2001, 165, 33.

218 Valkenberg M.H., de Castro C., Holderich W.F., Appl. Catal. A: Chem., 2001, 215, 185.

${ }^{219}$ Kumar A., Pawar S., J. Mol. Catal. A: Chem., 2004, 208, 33.

${ }^{220}$ Lee C., Tetrahedron Lett., 1999, 40, 2461.

${ }^{221}$ Cole A.C., Jensen J.L., Ntai I., Tran K.L.T., Weave K.J., Forbes D.C., Davis J.H., J. Am. Chem. Soc., 2002, 124, 5962.

${ }^{222}$ Gu Y., Shi F., Deng Y., Catal. Commun., 2004, 5, 597.

${ }^{223} \mathrm{Gu}$ Y., Shi F., Deng Y., J. Mol. Catal.A: Chem., 2004, 212, 71.

${ }^{224}$ Qiao K, Yokoyama C., Chem. Lett., 2004, 33, 472. 
iónicos que la poseen, son aquellos sintetizados mediante la combinación de un ácido y una base de Brønsted, como por ejemplo una sal N-protonada de 1alquilimidazolio 225,226 , lactamas ${ }^{227}$ o sales de piridinio ${ }^{228} \mathrm{~N}$-protonadas.

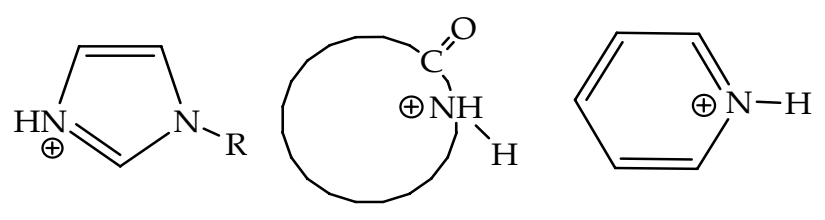

Figura 5.1.- Ejemplo de alguno de los cationes empleados para la síntesis de líquidos iónicos con acidez Brønsted: (de izda. a dcha.) Sal de 1-alquilimidazolio, lactama N-protonada y piridina Nprotonada.

Estos líquidos iónicos próticos se han utilizado en una gran variedad de reacciones orgánicas, como esterificaciones ${ }^{229}$, protección del grupo carbonilo ${ }^{230} \mathrm{y}$ reacción de Mannich ${ }^{231}$. Recientemente, Greaves y Drummond ${ }^{232}$ han publicado un interesante review sobre propiedades y aplicaciones de los líquidos iónicos próticos (incluyendo un amplio resumen de reacciones orgánicas).

Cabe mencionar que el protón localizado en el $\mathrm{C}_{2}$ del anillo de dialquilimidazolio (Figura 5.2) también posee cierta acidez, mucho más débil que la comentada anteriormente, pero causante de determinados efectos catalíticos ácidos bien conocidos ${ }^{233,234}$.

En cuanto a los líquidos iónicos con carácter básico, se han preparado a partir de aniones tipo<smiles></smiles>

Figura 5.2.- Estructura de un catión imidazolio con el protón correspondiente al $\mathrm{C}_{2}$ marcado en negrita. carboxilato (como el lactato 235,236 , formiato 237 , acetato), anión

${ }_{225}$ Yoshizawa M., Xu W., Angell C.A., J. Am. Chem. Soc., 2003, 125, 15411.

226 Ohno H., Yoshizawa M., Ogihara W., Electrochim. Acta, 2004, 50, 255.

${ }^{227}$ Du Z., Li Z., Guo S., Zhang J., Zhu L., Deng Y., J. Phys. Chem. B, 2005, 109, 19542.

${ }^{228}$ Duan Z., Gu Y., Zhang J., Zhu L., Deng Y., J. Mol. Catal. A: Chem., 2006, 250, 163.

${ }^{229}$ Zhu H.P., Yang F., Tang J., He M.Y., Green Chem., 2003, 5, 38.

230 Wu H.H., Yang F., Cui P., Tang J., He M.Y., Tetrahedron Lett., 2004, 45, 4963.

${ }^{231}$ Zhao G., Jiang T., Gao H., Han B., Huang J. Sun D., Green Chem., 2004, 6, 75.

${ }^{232}$ Greaves T.L., Drummond C.J., Chem. Rev., 2008, 108, 206.

${ }^{233}$ Gholap A.R., Venkatesan K., Daniel T., Lahoti R.J., Srinivasan K.V., Green Chem., 2003, 5, 693.

234 Welton T., Coord. Chem. Rev., 2004, 248, 2459.

235 Earle M.J., MacCormackP.B., Seddon K.R., Green Chem., 1999, 1, 23.

${ }^{236}$ Zhu A., Jiang T., Han B., Huang J., Zhang J., Ma X., New J. Chem., 2006, 30, 736. 
hidroxilo $238,239,240$ y dicianamidas ${ }^{241}$.<smiles>O=C[O-]</smiles><smiles>[R]C(=O)[O-]</smiles><smiles>CC(O)C(=O)[O-]</smiles>

Figura 5.3.- Ejemplo de tres aniónes tipo carboxilato empleados en la síntesis de líquidos iónicos básicos. (de izq. a dcha.) formiato, un alquilato en genérico y lactato.

Otra alternativa es la de incorporar una entidad de carácter básico en la parte catiónica del líquido iónico, lo que les aporta la ventaja de ser más estables térmicamente que aquellos cuyo carácter básico es debido al anión. De este modo se han sintetizado una nueva gama de líquidos iónicos con cationes del tipo 1alquil-4-aza-1-azonio-biciclo[2.2.2] octano ( $\mathrm{C}_{\text {ndabco) }}$ en combinación con aniones del tipo bis(trifuorometanosulfonil)amida ${ }^{242}$.

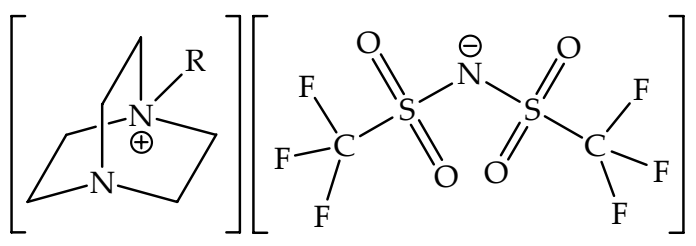

Figura 5.4.- Ejemplo de líquido iónico con centro básico en el catión.

Bis(trifuorometanosulfonil)amidato 1-alquil-4-aza-1-azonio-biciyclo[2.2.2]octano.

Más recientemente Seddon y $\operatorname{col}^{243}$. han publicado la síntesis de una serie de líquidos iónicos básicos de fórmula [Cat ${ }^{+}-\mathrm{Z}$-Bas][X-] donde $\mathrm{Cat}^{+}$contiene una fracción de carga positiva que suele ser un heterociclo, Bas es una fracción básica que debe comprender al menos un átomo de nitrógeno, fósforo, azufre, oxígeno o boro y $\mathrm{Z}$ es una cadena de carbono que une la fracción ácida $\left(\mathrm{Cat}^{+}\right.$) y la básica (Bas). Los autores afirman que estos líquidos iónicos pueden emplearse como promotores o catalizadores para una gran variedad de reacciones tales

237 Bicak N., J. Mol. Liq., 2005, 116, 15.

238 Ranu B.C., Jana R., Eur. J. Org. Chem., 2006, 16, 3767.

${ }^{239}$ Xu J.M., Qian C., Liu B.K., Wu Q., Lin X.F., Tetrahedron, 2007, 63, 986.

240 Yang L., Xu W., Zhou W., Li L., Xia C.G., Tetrahedron Lett., 2006, 47, 7723.

${ }^{241}$ MacFarlane D.R., Forsyth S.A., Golding J., Deacon G.B., Green Chem., 2002, 4, 444.

242 Yoshizawa-Fujita M., Johansson K., Newman P., MacFarlane D.R., Tetrahedron Lett., 2006, 47, 2755.

${ }^{243}$ Earle M.J., Seddon K.R., Forsyth S., Frohlich U., Gunaratne N., Katdare S., WO 2006/072775, 2006. 
como esterificaciones, transesterificationes, reacciones aldólicas, polimerizaciones, anulaciones de Robinson, acoplamientos de Heck y Suzuki, etc.

Las gem-diaminas poseen $\mathrm{pK}$ a altos, por eso son conocidas también como esponjas de protones ${ }^{244,245}$. Debido a su fuerza básica, se han empleado como organocatalizadores en reacciones tipo Knoevenagel y condensaciones aldólicas ${ }^{246,247}$. Recientemente se ha demostrado que anclando la gem-diamina esponja de protones 1,8-bis(dimetilamino)naftaleno (DMAN)(Figura 5.5) sobre un soporte que contenga centros levemente ácidos, se genera un catalizador bifuncional que contiene centros ácidos y básicos, y que el hecho de que coexistan dentro del mismo catalizador hace que aumente la velocidad de la condensación de Knoevenagel entre el benzaldehído y compuestos metileno $\operatorname{activos}^{248}$. El estudio del mecanismo de la reacción demostró que el centro de acidez moderada localizado en el soporte, activaba el grupo carbonilo del benzaldehído, mientras que el centro básico de la esponja de protones se encargaba de la activación del compuesto metileno activo (malonato de dietilo) mediante la abstracción de uno de sus protones.

Este tipo de procesos catalíticos en los que al menos dos entidades catalíticas diferentes, actúan juntas para aumentar la velocidad de una reacción más allá de la suma de las velocidades que se pudieran obtener con las entidades individuales por separado, se conoce como catálisis cooperativa. La cooperatividad en los procesos catalíticos se manifiesta en forma de interacciones químicas múltiples,<smiles>Nc1cccc2cccc(N)c12</smiles>

Figura 5.5.- Gemdiamina esponja de protones. que contribuyen a la mejora significativa de la velocidad de reacción o de la selectividad de los procesos.

El ejemplo más interesante de catálisis cooperativa lo representan los enzimas, que consiguen acelerar las reacciones químicas en los sistemas biológicos a través de las interacciones entre determinados grupos funcionales estratégicamente localizados y los centros enzimáticos activos. Mientras que los enzimas están presentes en todos los sistemas naturales, el número de ejemplos

244 Staab H.A., Saupe T., Angew. Chem., 1998, 100, 895 ; Angew. Chem. Int. Ed. Engl., 1998, $27,865$.

245 Llamas-Saiz A.L., Foces-Foces C., Elguero J., J. Mol. Struct., 1994, 328, 297.

246 Rodríguez I., Sastre G., Corma A., Iborra S., J. Catal., 1999, 183, 14.

247 Climent M.J., Corma A., Domínguez I., Iborra S., Sabater M.J., J. Catal., 2007, 246, 136.

248 Corma A., Iborra S., Rodríguez I., Sánchez F., J. Catal., 2002, 211, 208. 
de catálisis en sistemas sintéticos, ya sea en catálisis homogénea como heterogénea, no es muy elevado, pero poco a poco se va ampliando el número y el ámbito de aplicaciones por las posibilidades que presentan.

Cabe destacar en este punto las diferencias ${ }^{249}$ existentes entre catálisis cooperativa y catálisis bifuncional o sistemas tándem. En catálisis cooperativa se engloban todos aquellos fenómenos catalíticos en los que las interacciones químicas entre centros activos actúan directa o indirectamente sobre la molécula reactante, pero en tan solo un proceso. Al contrario que en los sistemas tándem, que la reacción implica transformaciones con múltiples pasos en secuencias reactivas independientes (en este último caso se pueden aislar los productos intermedios que van generando, mientras que en el caso de la catálisis cooperativa, no es posible aislar los estados intermedios por la propia naturaleza del proceso).

En cuanto a la catálisis cooperativa, existen cuatro formas diferentes de interacción ${ }^{250}$ entre centros catalíticos y reactivos:

i)

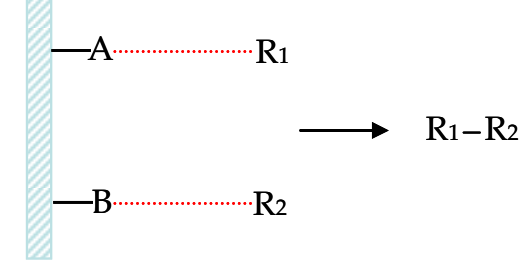

iii)

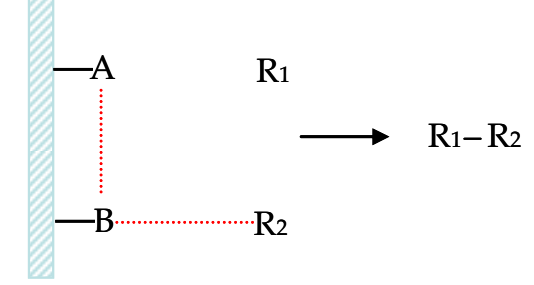

ii)

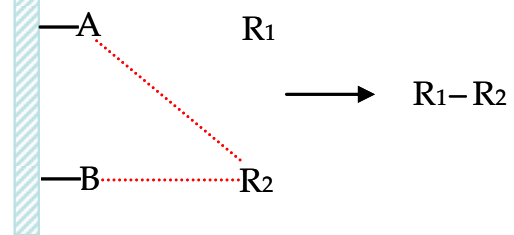

iv)

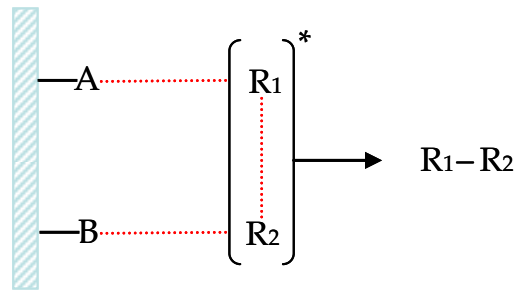

Figura 5.6.- Ejemplos gráficos de cooperatividad de los grupos catalíticos $A$ y $B$ sobre los reactivos $R_{1}$ y R2. i) Activación dual: $A$ activa $R_{1}$ y $B$ activa $R_{2}$. ii) Activación secuencial: $A$ activa $R_{2}$ y seguidamente $B$ actúa sobre $R_{2}$ activado. iii) Autoactivación: A activa $B$ que a su vez activa $R_{2}$. vi) Estabilización múltiple del estado de transición $\left(\mathrm{R}_{1}-\mathrm{R}_{2}\right)^{*}$. 
i) Dos centros catalíticamente activos A y B activan a dos reactantes independientes, por ejemplo, A puede activar a un nucleófilo mientras B activa al electrófilo, lo que hace que la reactividad de ambos aumente. ii) Ambos centros activos aumentan secuencialmente la reactividad de un reactante, por ejemplo, A activa $R$ a $R^{\prime}$ y $B$ activa $R^{\prime}$ a $R^{\prime \prime}$. iii) Los centros activos pueden actuar sobre ellos mismos, de modo que por ejemplo A active a B aumentando su poder catalítico para una reacción determinada. Y finalmente iv) Los centros activos, mediante interacciones débiles, pueden favorecer la estabilización de los estados de transición. Cualquiera de las formas de cooperatividad pueden considerarse a la hora de diseñar un nuevo catalizador, incluso se puede buscar la forma de que varios de estos procesos se puedan dar con un mismo material.

En referencias bibliográficas recientes, se pueden encontrar ejemplos muy representativos de cooperatividad relacionada con reacciones ácido-base. Entre los más destacados Lin y col. ${ }^{251}$ consiguen llevar a cabo la reacción de Henry entre el nitrometano y el $p$-nitrobenzaldehído, empleando una superficie silícea modificada con una mezcla de los grupos ureidopropilsiloxano y 3-[2-(2aminoetilamino)etilamino]propilsiloxano (AEPS) que acaba siendo catalíticamente mucho más activa que la misma superficie modificada por cualquiera de los dos grupos o que la mezcla física de dos superficies modificada cada una con uno de los grupos. El grupo ureido actúa como ácido de Lewis generando un enlace puente de hidrógeno con el carbonilo del nitrobenzaldehído y a la vez el AEPS que desarrolla una función básica, abstrae un protón del nitrometano. Ambas interacciones, cercanas espacialmente, facilitan el ataque nucleofílico al carbono carbonílico y hacen que el rendimiento de la reacción sea mucho mayor. Otro ejemplo, propuesto por Davis y col..252, consiste en la condesación aldólica entre una cetona y otra molécula con un grupo carbonilo. En este caso, la reacción se ve favorecida por efecto cooperativo de un par ácidobase de Brønsted sobre un soporte de SBA-15. El ácido genera un puente de hidrógeno con uno de los grupos carbonilo, mientras que la base hace lo propio con el grupo hidroxilo de la forma enólica de la cetona. De este modo se aumenta en consideración el rendimiento del proceso, siempre que el par ácido-base esté

${ }^{251}$ Huh S., Chen H-T., Wiench J.W., Pruski M., Lin VS-Y., Angew.Chem.Int.Ed., 2005, 44, 1826.

252 Zeidan R.K., Hwang S-J, Davis M.E., Angew.Chem.Int.Ed., 2006, 45, 6332. 
separado por la distancia óptima y tenga la fuerza adecuada para evitar anularse mutuamente.

La cooperatividad bifuncional ácido-base también se da en algunos enzimas, en tales casos la distancia de separación entre ambos centros, así como su configuración geométrica, resultan ser los factores clave en el desarrollo de la actividad enzimática. En el caso de las bases orgánicas ancladas sobre soportes ácidos, es muy complicado controlar los factores antes mencionados. Sin embargo, en los organocatalizadores, tanto la distancia entre el centro ácido y básico como la geometría de la molécula, pueden controlarse eficazmente a partir del diseño especial de rutas de síntesis.

Con todo esto, el objetivo de esta parte de la tesis, ha consistido en la síntesis de líquidos iónicos que a su vez fueran organocatalizadores bifuncionales ácido-base, capaces de llevar a cabo procesos cooperativos (Figura 5.6). Así, mediante la protonación de diaminas de diferente estructura, se han conseguido obtener materiales con dos centros catalíticos (ácido-base) a diferentes distancias y con configuraciones distintas entre ambos, manteniendo estas sales, las propiedades que caracterizan a los líquidos iónicos (separación del medio de reacción por simple extracción, reciclaje y fácil reuso). En este capítulo se mostrará cómo estos nuevos catalizadores bifuncionales, actuando mediante catálisis cooperativa, resultan ser altamente eficaces en la condensación de Knoevenagel

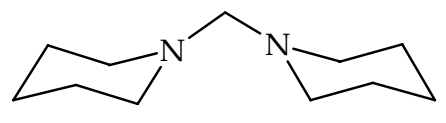

Diamina-A

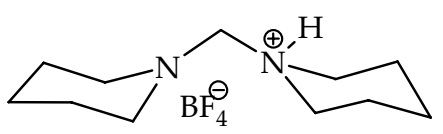

$[$ Diamina-A $] \mathrm{BF}_{4}$

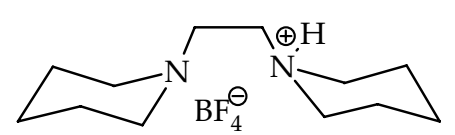

$[$ Diamina-B]BF 4

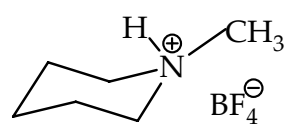

[N-metilpiperidinio $\mathrm{BF}_{4}$

Figura 5.7.- Esquema de la estructura de algunos líquidos iónicos gem-diaminas y su precursor Diamina-A (Dipiperidino metano). [Diamina-A]BF 4 (Tetrafluoroborato de 1-Piperidina-1-metilpiperidinio), [Diamina-B]BF4 4 (Tetrafluoroborato de 1-Piperidina-1-etil-piperidinio) y $[\mathrm{N}-$ metilpiperidinio]BF 4 (Tetrafluoroborato de N-Metilpiperidinio). 
5.2

\section{Resultados y Discusión}

\subsection{1}

\section{Estudio de la actividad catalítica}

Con el objetivo de evaluar la actividad catalítica del nuevo líquido iónico sintetizado [diamina-A] $\mathrm{BF}_{4}$, en el que, como se puede observar en la Figura 5.7, el centro ácido y el básico se encuentran separados por un grupo - $\mathrm{CH}_{2-}^{-}$, se empleó como reacción test la condensación de Knoevenagel entre el benzaldehido y varios compuesto metilenos activos con diferentes valores de $\mathrm{pK}$. La condensación de Knoevenagel es una reacción importante en química orgánica pues promueve la formación de enlaces carbono-carbono con el empleo de catalizadores básicos ${ }^{253}$, ácidos ${ }^{254,255,256}$ o ácido-base ${ }^{257,258 . ~ E l ~ m e c a n i s m o ~}$ generalmente aceptado para esta reacción catalizada por bases, se muestra en el esquema 5.1.
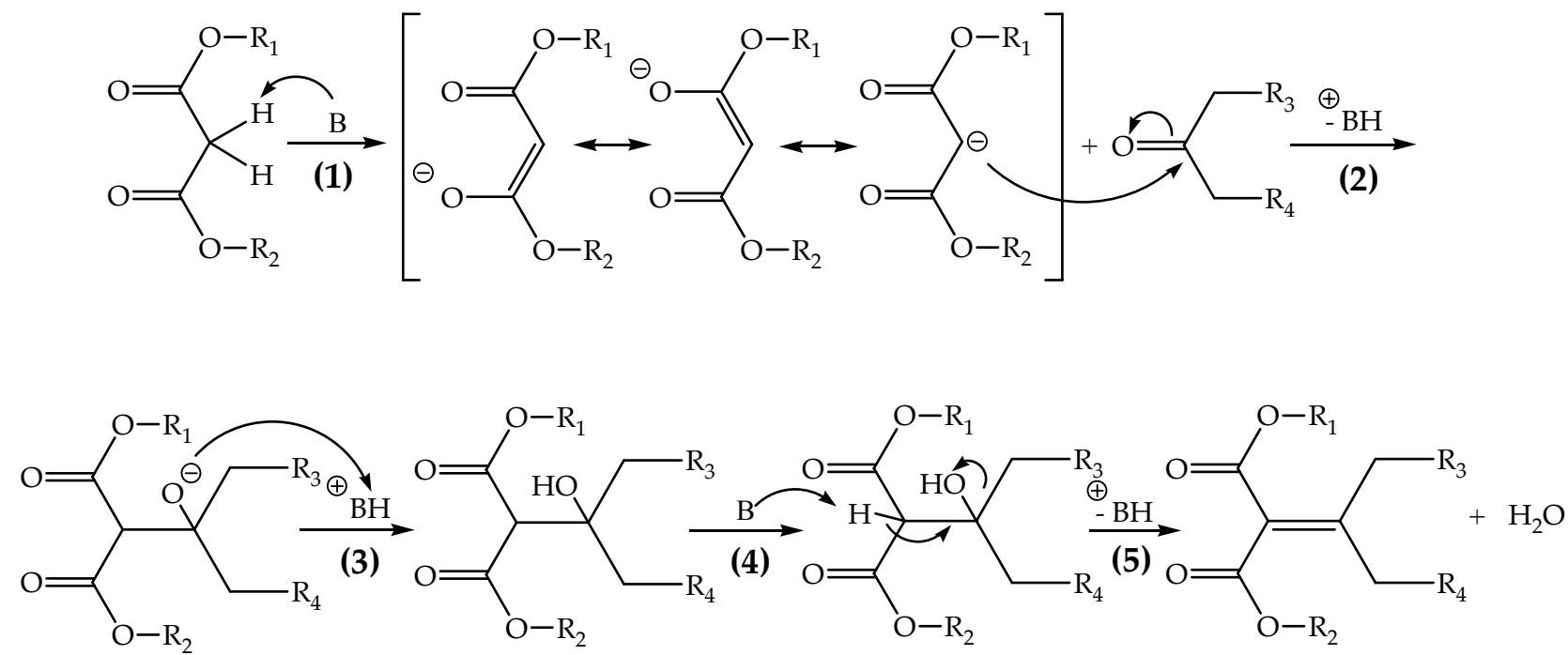

Esquema 5.1.- Mecanismo general de la reacción de Knoevenagel entre un compuesto metileno activo y otro con un grupo carbonilo.

253 Jones G., Organic Reactions, (Ed.: A.C.Cope), Wiley, Nueva York, 1967,15, 204.

254 Attanasi O., Filippone P., Mei A., Synth. Commun., 1983, 13, 1203.

255 Shanthan R.P., Venkataratnam R.V., Tetrahedron Lett., 1991, 32, 5821.

256 Bao W., Zhang Y., Wang J., Synth. Commun, 1996, 26, 3025.

257 Climent M.J., Corma A., Fornés V., Guil-López R., Iborra S., Adv. Synth. Catal., 2002, $344,1090$.

${ }^{258}$ Climent M.J., Corma A., Iborra S., Velty A., J. Mol. Catal. A: Chem., 2002, 182, 327. 
El primer paso de la reacción (1) consiste en la abstracción de un protón del metileno activo por parte de la base, dando lugar a un carbanión del compuesto metilénico, que a continuación (paso 2) ataca al carbono del grupo carbonilo del compuesto carbonílico generándose de este modo el enlace C-C. El oxígeno con carga negativa ataca (paso 3) a la base protonada formada en el paso anterior, generándose así un grupo hidroxilo. A continuación la base abstrae el siguiente protón del metileno activo (paso 4) y simultáneamente se forma un doble enlace que fuerza la salida del grupo hidroxilo (paso 5) dando lugar al producto final de la condensación y a una molécula de agua.

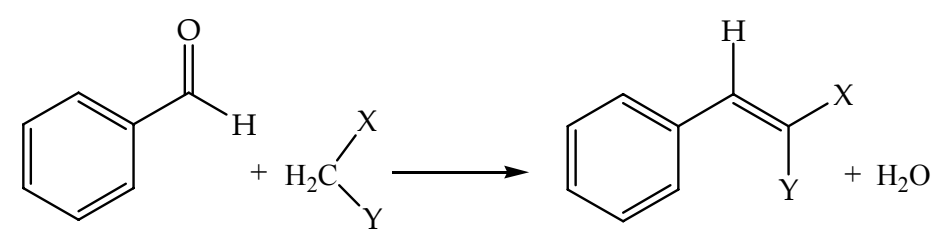

Esquema 5.2.- Condensación de Knoevenagel entre el benzaldehído y distintos compuesto con un metileno activo $\left(X=\mathrm{CN}, \mathrm{CH}_{3}, \mathrm{COOCH}_{2} \mathrm{CH}_{3} ; \mathrm{Y}=\mathrm{CN}, \mathrm{COOCH}_{2} \mathrm{CH}_{3}\right)$.

Así, las reacciones entre el benzaldehído y malononitrilo, cianoacetato de etilo, acetoacetato de etilo y malonato de dietilo (Esquema 5.2) se llevaron a cabo empleando como catalizador el líquido iónico [diamina-A]BF 4 al $1 \mathrm{~mol} \%$ y en ausencia de disolvente, pues reactivos y catalizador forman una mezcla completamente homogénea. Los resultados obtenidos (Figura 5.8), muestran que el orden de reactividad de los diferentes reactivos está en total concordancia con los valores de $\mathrm{pK}$ a de los reactivos (malononitrilo < cianoacetato de etilo < acetoacetato de etilo $<$ malonato de dietilo). La selectividad a cada producto de la condensación fue del 100\% en todos los casos y las características del líquido iónico [diamina-A]BF4 permiten que su extracción del medio de reacción y posterior reciclado sea completamente viable. De hecho, se consiguió llevar a cabo tres ciclos reacción-extracción seguidos utilizando éter dietílico como disolvente de extracción. El balance de masas fue siempre superior a $98 \%$ sin pérdida de actividad aparente. 


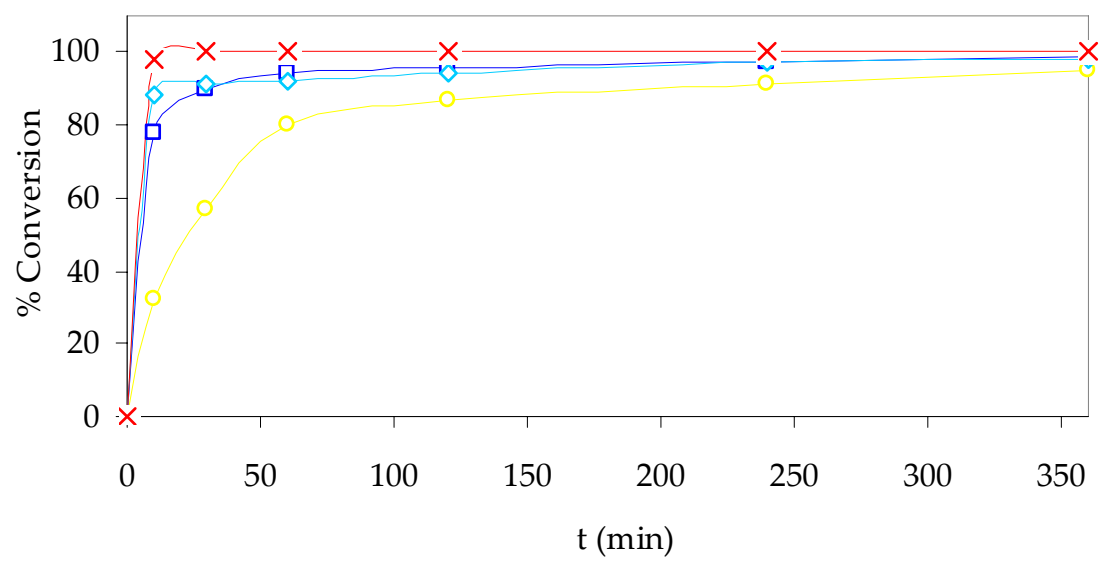

Figura 5.8.- Representación de la conversión del metileno activo en la condensación de Knoevenagel entre el benzaldehído $(32 \mathrm{mmol})$ y diferentes compuestos metilenos activos $(28 \mathrm{mmol})$ en presencia de [diamina- $\mathrm{A}_{\mathrm{BF}} 4(0,28 \mathrm{mmol}):(\mathrm{x})$ malononitrilo a $25^{\circ} \mathrm{C}$; $(\diamond)$ Cianoacetato de etilo a $25^{\circ} \mathrm{C}$; ( $\left.\square\right)$ Acetoacetato de etilo a $60^{\circ} \mathrm{C}$; (o) Malonato de dietilo a $80^{\circ} \mathrm{C}$.

Con el fin de comparar la actividad del líquido iónico [diamina-A]BF 4 con otros catalizadores, la condensación de Knoevenagel entre el benzaldehído y el malononitrilo se llevó a cabo utilizando también, como catalizador ácido [Nmetilpiperidinio]BF 4 y como catalizador básico la gem-diamina-A precursora del líquido iónico. Los resultados obtenidos se presentan en la Figura 5.9. De acuerdo con lo que cabía esperar a partir de los resultados obtenidos con anterioridad, el catalizador básico gem-diamina-A es más activo que el catalizador ácido [N-metilpiperidinio] $\mathrm{BF}_{4}$, pero ambos son menos activos que el catalizador ácido-base [diamina-A]BF 4.

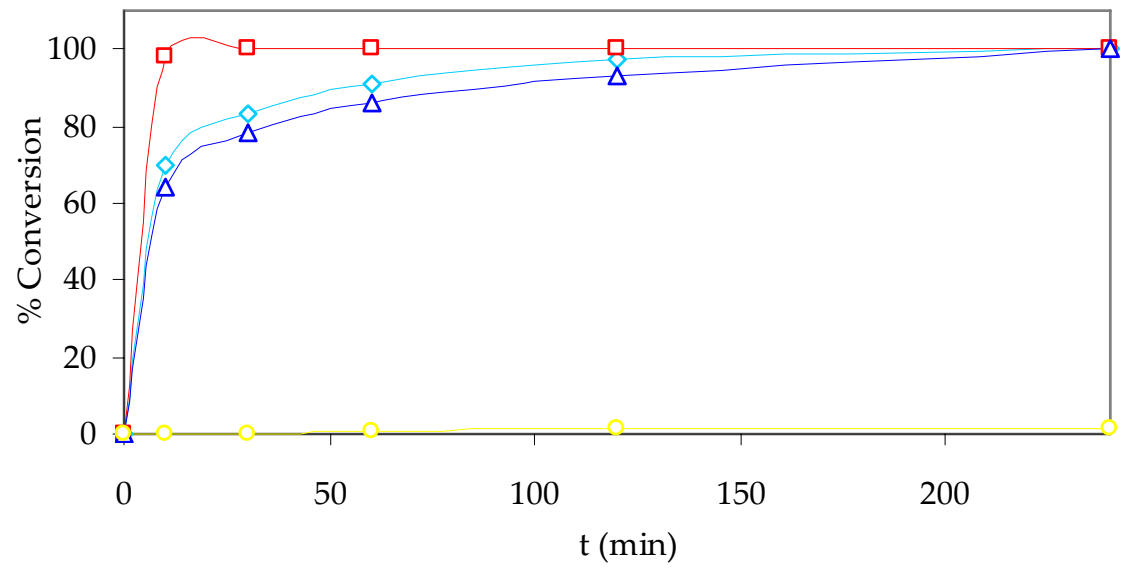

Figura 5.9.- Representación de la conversión del malononitrilo en la condensación de Knoevenagel entre el benzaldehído (32 mmol) y el malononitrilo $(28 \mathrm{mmol})$ en presencia de $(0,28 \mathrm{mmol})$ de $(\mathrm{o})$ [ $\mathrm{N}$ metilpiperidina] $\mathrm{BF}_{4},(\diamond)$ diamina- $\mathrm{A},(\square)\left[\right.$ diamina- $\mathrm{B}_{\mathrm{BF}} 4 \mathrm{y}(\Delta)$ [diamina-B] $\mathrm{BF}_{4}$. 
La mayor actividad del líquido iónico [diamina-A]BF 4 no debe atribuirse a una mayor fuerza básica de la molécula, de hecho la gem-diamina-A es más básica que la [diamina-A]BF. La diferencia clave entre los dos organocatalizadores, es la presencia en la [diamina- $\mathrm{A}_{\mathrm{B}} \mathrm{BF}_{4}$ de un grupo amino protonado moderadamente ácido, localizado muy próximo al centro básico. De hecho, se ha demostrado que los grupos amino protonados del [Nmetilpiperidinio] $\mathrm{BF}_{4}$ y de la [diamina-A] $\mathrm{BF}_{4}$ son lo suficientemente ácidos como para catalizar la acetalización del benzaldehído con trietilortoformiato (TEOF), una reacción que, por lo general, necesita catalizadores ácidos suaves. Sin embargo, no son tan ácidos como para catalizar la condensación de Knoevenagel, tal y como lo demuestra la nula conversión obtenida al intentar realizar la condensación entre diferentes compuestos metilenos activos y el benzaldehído en presencia de $[\mathrm{N}$-metilpiperidinio]BF 4 .

La actividad catalítica desarrollada por el compuesto protonado [diamina-A]BF 4 en la condensación de Knoevenagel, se ha aplicado con éxito en una amplia variedad de compuestos carbonílicos (aldehídos y cetonas) así como con diferentes compuestos metilenos activos. Los resultados se presentan en la Tabla 5.1. En general las reacciones se llevaron a cabo en pocos minutos, a temperatura ambiente y de forma limpia y selectiva con altos rendimientos.

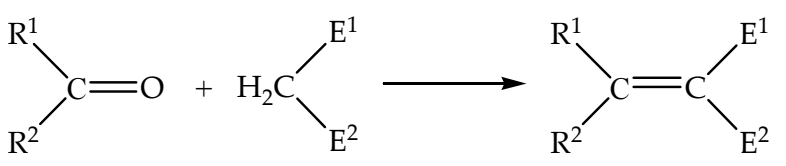

\begin{tabular}{clccccc}
\hline Ent. & \multicolumn{1}{c}{$\mathbf{R}^{1}$} & $\mathbf{R}^{2}$ & $\mathbf{E}^{1}$ & $\mathbf{E}^{2}$ & $\mathbf{t}(\mathbf{m i n})$ & $\begin{array}{c}\text { Rendim. } \\
\text { (\%) }\end{array}$ \\
\hline 1 & $\mathrm{Ph}$ & $\mathrm{H}$ & $\mathrm{CO}_{2} \mathrm{CH}_{2} \mathrm{CH}_{3}$ & $\mathrm{CO}_{2} \mathrm{CH}_{2} \mathrm{CH}_{3}$ & 20 & 99 \\
2 & $i-\mathrm{C}_{3} \mathrm{H}_{7}$ & $\mathrm{H}$ & $\mathrm{CO}_{2} \mathrm{CH}_{2} \mathrm{CH}_{3}$ & $\mathrm{CO}_{2} \mathrm{CH}_{2} \mathrm{CH}_{3}$ & 15 & 99 \\
3 & $n-\mathrm{C}_{7} \mathrm{H}_{15}$ & $\mathrm{H}$ & $\mathrm{CO}_{2} \mathrm{CH}_{2} \mathrm{CH}_{3}$ & $\mathrm{CO}_{2} \mathrm{CH}_{2} \mathrm{CH}_{3}$ & 15 & 100 \\
4 & $\mathrm{Ph}$ & $\mathrm{H}$ & $\mathrm{CN}$ & $\mathrm{CN}$ & 1 & 100 \\
5 & $\mathrm{Ph}$ & $\mathrm{H}$ & $\mathrm{CN}$ & $\mathrm{CO}_{2} \mathrm{CH}_{2} \mathrm{CH}_{3}$ & 1 & 100 \\
6 & $\mathrm{Ph}$ & $\mathrm{H}$ & $\mathrm{COCH}$ & $\mathrm{CO}_{2} \mathrm{CH}_{2} \mathrm{CH}_{3}$ & 10 & 100 \\
7 & $\mathrm{CH}$ & $\mathrm{CH}$ & $\mathrm{CN}$ & $\mathrm{CO}_{2} \mathrm{CH}_{2} \mathrm{CH}_{3}$ & 10 & 100 \\
\hline
\end{tabular}

Tabla 5.1.- Resultados obtenidos para la condensación de Knoevenagel de diferentes sustratos, a temperatura ambiente y empleando como catalizador la [diamina-A]BF4. Condiciones de reacción: [diamina-A]BF4 $(20 \mathrm{~mol} \%)$, compuesto metileno activo (5 mmol), aldehído o cetona $(5 \mathrm{mmol})$, temperatura ambiente, atmósfera inerte. Rendimientos calculados por cromatografía de gases. 
Como se puede apreciar, los aldehídos alifáticos reaccionan más rápido en la condensación con malonato de dietilo que el aromático benzaldehído (Tabla 5.1, entradas 1-3), aunque en las tres reacciones el rendimiento final a producto de la condensación fue cuantitativo. Cabe destacar que los resultados de la reacción mejoran significativamente cuando el benzaldehído se condensa con malononitrilo, cianoacetato de etilo o acetoacetato de etilo (Tabla 5.1, entradas 46). En todos los casos estudiados, los resultados obtenidos con la [diamina-A]BF 4 fueron claramente superiores a los obtenidos con el hidróxido de 1-Butil-3metilimidazolio [ $\mathrm{Bmim}] \mathrm{OH}^{224}$, líquido iónico que en la literatura aparece como paradigma de catalizador básico y que en los procesos de condensación dio lugar al producto con altos rendimientos en cortos periodos de reacción.

Teniendo en cuenta los excelentes resultados catalíticos para la condensación de Knoevenagel obtenidos con el líquido iónico bifuncional [diamina-A]BF $\mathrm{B}_{4}$, resulta difícil dar una explicación a través de la acción independiente de los centros ácido y básico presentes en el organocatalizador. Por lo tanto, en principio cabría pensar en un mecanismo que combine la acción de ambos centros catalíticos, de modo que los centros ácidos de Brønsted débiles, interaccionen vía el grupo amino protonado con el grupo carbonilo del benzaldehído, generando la polarización del enlace $\mathrm{C}=\mathrm{O}$ y provocando un aumento de su electrofilia, con lo que se lograría una mayor predisposición a ser atacado por el carbanión intermedio del metileno, formado en el centro básico de Lewis vecinal asociado al otro grupo amino y dispuesto a la distancia de un $\mathrm{C}$ en la misma molécula de catalizador (Esquema 5.3).

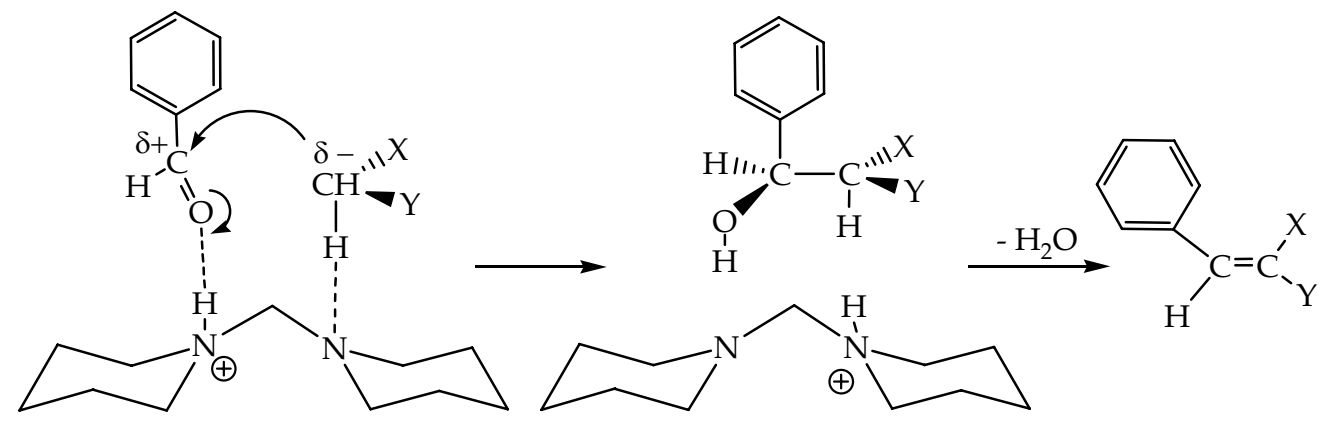

Esquema 5.3.- Propuesta de mecanismo bifuncional ácido-base para la condensación de Knoevenagel mostrada en el Esquema 5.2. 
Si el mecanismo propuesto es realmente operativo, cabe esperar que la distancia entre los centros ácido y básico sea un parámetro crítico para lograr la estabilización de los estados de transición que se dan a lo largo de la reacción, tal y como ocurre en muchos procesos enzimáticos.

El efecto de la distancia entre los centros catalíticamente activos se ha estudiado mediante la síntesis de un líquido iónico análogo al propuesto con anterioridad [diamina-B] $\mathrm{BF}_{4}$ (Figura 5.7) donde los dos átomos de nitrógeno están separados por una cadena $-\mathrm{CH}_{2} \mathrm{CH}_{2}$ - en lugar de un puente $-\mathrm{CH}_{2}$ - En la Tabla 5.2 se presenta un resumen de las propiedades físicas de estas dos sales orgánicas.

\begin{tabular}{|c|c|c|c|c|c|}
\hline Sal orgánica & $\begin{array}{l}\mathrm{T} \text { (dec) } \\
\left({ }^{\circ} \mathrm{C}\right)^{[\mathrm{al}]}\end{array}$ & $\begin{array}{c}\text { Dens. } \\
\left(\mathrm{g} / \mathrm{cm}^{-3}\right)^{[\mathrm{b}]}\end{array}$ & $\begin{array}{l}\text { Estado } \\
\text { físico [c] }\end{array}$ & $\begin{array}{l}\text { Punto de } \\
\text { fusión }\left({ }^{\circ} \mathrm{C}\right)\end{array}$ & $\begin{array}{c}\sigma \\
\left(\mu \mathrm{Scm}^{-1}\right)^{[\mathrm{d}]}\end{array}$ \\
\hline [diamina-A]BF4 & $\begin{array}{c}120,307,392, \\
437\end{array}$ & 1,195 & Sólido & 108,8 & 167,0 \\
\hline [diamina-B] $\mathrm{BF}_{4}$ & $303,344,387$ & 1,196 & Sólido & 72 & 88,4 \\
\hline [N-metilpiperidinio]BF 4 & ${ }_{-}^{[\mathrm{e}]}$ & 1,215 & Líquido & - & 137,0 \\
\hline
\end{tabular}

Tabla 5.2.- Propiedades de las sales orgánicas [diamina- $\mathrm{A}_{\mathrm{B}} \mathrm{BF}_{4}$, [diamina-B]BF, $[\mathrm{N}-$ metilpiperidina]BF4. [a] Las temperaturas de descomposición se determinaron por análisis termogravimétrico en flujo de nitrógeno y con una rampa de termepratura de $10^{\circ} \mathrm{C}$ por minuto. ${ }^{[b]} \mathrm{La}$ densidad se calculó a $30^{\circ} \mathrm{C}$. [c] Estado físico de las sales a $20^{\circ} \mathrm{C}$. [d] Conductividad iónica calculada en disolución acuosa al $10^{-3} \mathrm{M}$ y a $20^{\circ} \mathrm{C}$. [e] No se ha determinado.

La acidez de la sal [diamina-B]BF ${ }_{4}$ se comprobó en la reacción de acetalización entre el benzaldehído y el TEOF. La actividad obtenida con el líquido iónico [diamina-B] $\mathrm{BF}_{4}$ fue muy similar a la conseguida con la [diamina$\mathrm{A}_{\mathrm{BF}}$, lo que indica un grado de acidez similar para ambos catalizadores. Sin embargo, cuando se realizó la condensación de Knoevenagel entre el malononitrilo y el benzaldehído a $25^{\circ} \mathrm{C}$, con la [diamina- $\mathrm{B}$ ] $\mathrm{BF}_{4}$, el rendimiento fue mucho menor que con la [diamina-A]BF 4 (Figura 5.9). Es más, cuando en lugar de malononitrilo, se empleó como metileno activo el malonato de dietilo, la condensación de Knoevenagel con la [diamina-B] $\mathrm{BF}_{4}$ dio lugar a un $1 \%$ de rendimiento, tras seis horas de reacción, mientras que con la [diamina- $\mathrm{A}_{\mathrm{B}} \mathrm{BF}_{4}$ se obtuvo un rendimiento por encima del $85 \%$, que es una actividad catalítica dos órdenes de magnitud por encima de la del material con puente de dos carbonos.

De los resultados expuestos se pueden sacar varias conclusiones. En primer lugar, parece que el anión $\mathrm{BF}_{4}^{-}$, que en principio podía haber actuado como una base débil, no juega ningún papel clave como catalizador básico en la reacción catalítica. En segundo lugar, los resultados corroboran que el mecanismo de reacción no se puede catalogar como puramente ácido y por último, lo más importante, parece que hay una distancia óptima entre el centro 
ácido y básico para lograr el efecto cooperativo entre ambos. Para comprobar esta hipótesis, se realizó un estudio teórico del mecanismo de reacción mediante cálculos de densidad funcional.

\subsection{2}

\section{Estudio computacional del mecanismo de reacción}

El mecanismo de la condensación de Knoevenagel entre el benzaldehído y el malononitrilo catalizado por los líquidos iónicos [diamina-A] $\mathrm{BF}_{4}$ y [diamina$\mathrm{B}_{\mathrm{BF}}$ se estudió teóricamente por medio de cálculos DFT. De acuerdo con el mecanismo bifuncional ácido-base propuesto anteriormente y mostrado en el Esquema 5.3, se supuso inicialmente que el grupo carbonilo del benzaldehído interactúa con el centro ácido N-protonado del catalizador y al mismo tiempo el malononitrilo, queda adsorbido sobre el átomo de nitrógeno del centro básico de la misma molécula de catalizador. La geometría optimizada del complejo formado por la co-adsorción del benzaldehído y el malononitrilo sobre la [diamina-A]BF4 se representa en la Figura 5.10.

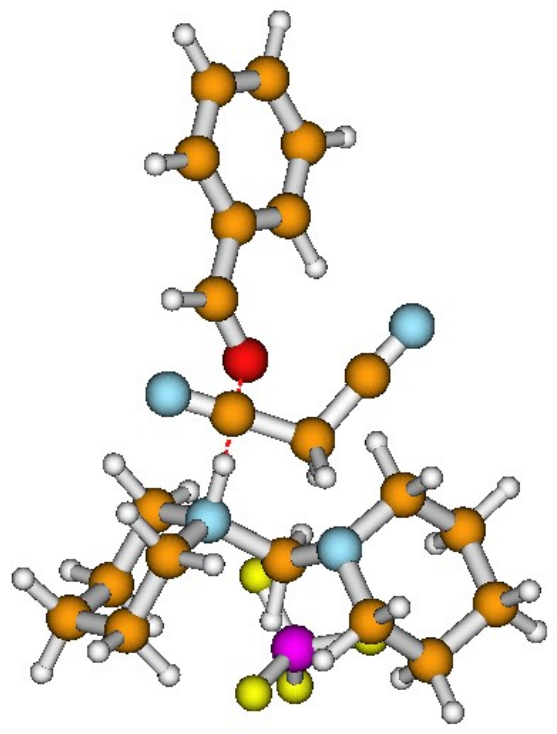

Figura 5.10.- Geometría optimizada para el complejo de co-adsorción del benzaldehído y el malononitrilo sobre la [diamina-A]BF4. Código de colores: O rojo, $\mathrm{C}$ naranja, $\mathrm{N}$ azul, $\mathrm{H}$ blanco, $\mathrm{B}$ rosa, F amarillo.

Como resultado de la interacción del grupo carbonilo del benzaldehído con el protón del centro N-protonado del catalizador, se produce una polarización del doble enlace $\mathrm{C}=\mathrm{O}$, así la longitud del enlace entre el carbono y el oxígeno aumenta de los $1,214 \AA$ en la fase gas a 1,228 $\mathrm{A}$. La distancia calculada 
entre el oxígeno del grupo carbonilo y el protón del N-protonado del catalizador

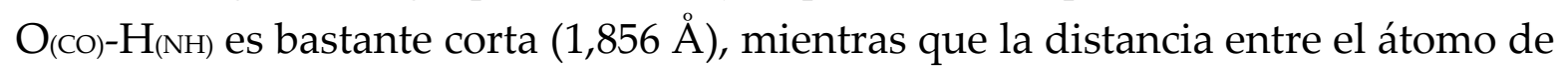
hidrógeno del malononitrilo y el nitrógeno básico de la diamina es considerablemente mayor $(2,286 \AA)$.

La diferencia de fuerza entre las dos interacciones implicadas (benzaldehído-centro ácido del catalizador/malononitrilo-centro básico) también queda reflejada en las energías de adsorción calculadas: $-8,8 \mathrm{kcal} / \mathrm{mol}$ para el benzaldehído-centro ácido y $-2,6 \mathrm{kcal} / \mathrm{mol}$ para la co-adsorción del malononitrilo en el nitrógeno básico del complejo benzaldehído-[diamina-A]BF 4 . También en el caso del líquido iónico [diamina-B] $\mathrm{BF}_{4}$, con un puente de dos carbonos entre los centros catalíticos, la adsorción del benzaldehído sobre el protón del centro ácido es exotérmica $(-5,3 \mathrm{kcal} / \mathrm{mol})$, mientras que la interacción del malononitrilo con el centro básico del complejo benzaldehído-[diamina-B]BF4 es prácticamente despreciable y no pudo obtenerse un valor mínimo para la energía potencial, correspondiente a ese sistema. Sin embargo, cabe destacar que bajo esta hipótesis inicial del mecanismo, no fue posible encontrar un camino de reacción que, a partir del complejo benzaldehído-[diamina-A]BF4-malononitrilo (Figura 5.10) y a través de una desprotonación del malononitrilo simultánea al ataque del carbono con carga negativa, al carbono del grupo carbonilo, diera como resultado de la condensación el alcohol intermedio de reacción mostrado en el Esquema 5.3. En su lugar, se constató que el mecanismo procede en dos etapas: 1) desprotonación del malononitrilo adsorbido, dando lugar al intermedio carbaniónico del metileno activo, que permanece adsorbido en la diamina doblemente protonada, con carga positiva y 2) la co-adsorción del benzaldehído en este sistema y la consiguiente reacción con el carbanión de metileno para formar el alcohol intermedio de la condensación.

Las especies involucradas en el primer paso del mecanismo y los perfiles de energía calculados se muestran en las Figuras 5.11 y 5.12, respectivamente.

Inicialmente, el malononitrilo interactúa con el protón ácido de la [diamina-A]BF4 a través del par de electrones solitario sobre el átomo de $\mathrm{N}$ de uno de los grupos nitrilo $(\mathrm{C} \equiv \mathrm{N})$, así se forma un complejo de adsorción (M-DA) que es $3,6 \mathrm{kcal} / \mathrm{mol}$ más estable que los reactantes por separado. 
a)

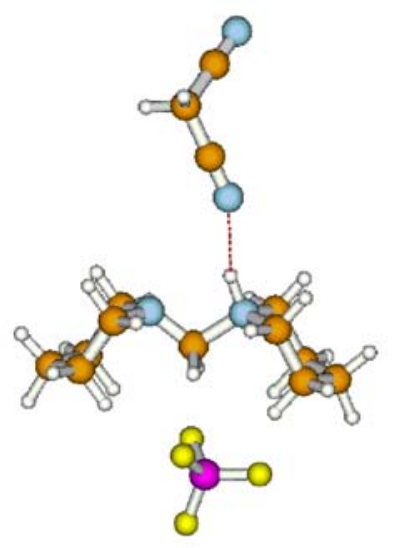

M-DA

b)

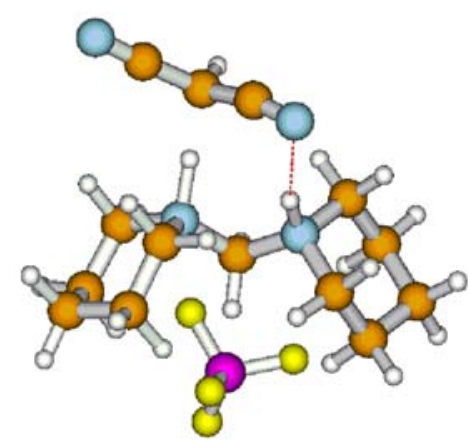

TS1-DA

c)

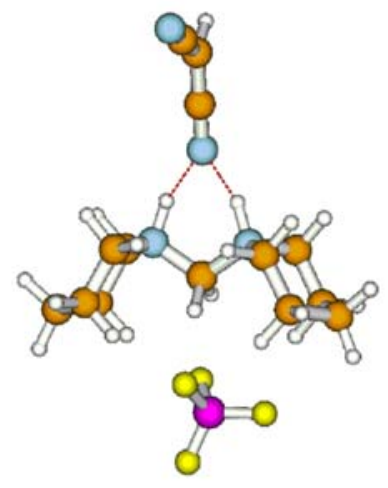

Il-DA

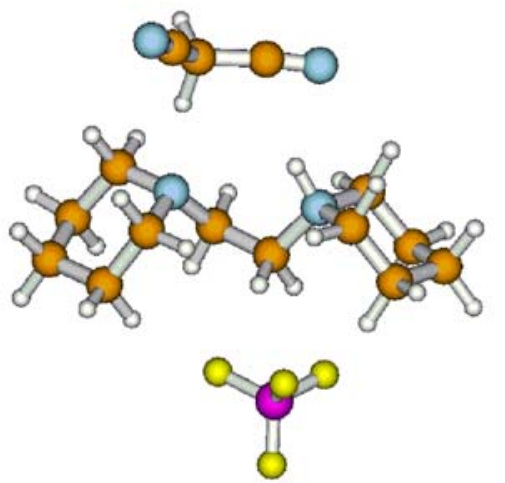

M-DB

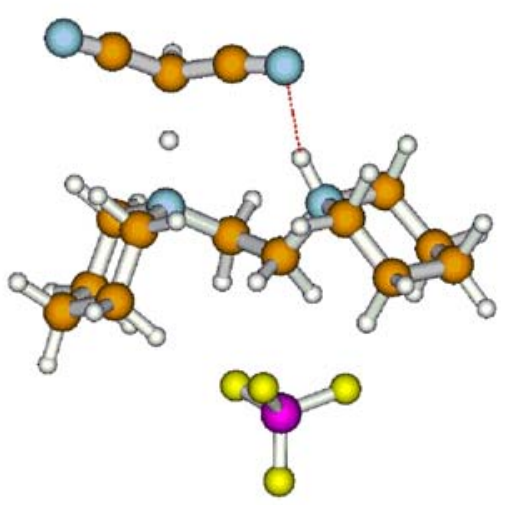

TS1-DB

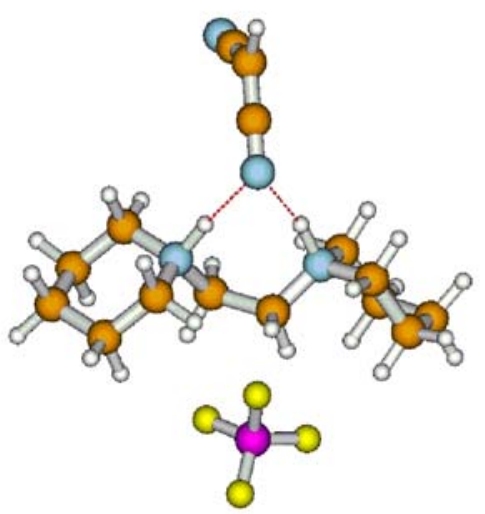

I1-DB

Figura 5.11.- a) Malononitrilo adsorbido, b) Estado de transición para la desprotonación del malononitrilo, c) Intermedio carbaniónico del metileno adsorbido sobre la [diamina-A]BF 4 (izquierda) y [diamina-B] BF 4 (derecha). Código de colores: $\mathrm{C}$ naranja, $\mathrm{N}$ azul, $\mathrm{H}$ blanco, $\mathrm{B}$ rosa, $\mathrm{F}$ amarillo. 
A continuación, el nitrógeno básico de la [diamina-A]BF 4 abstrae uno de los átomos de hidrógeno del malononitrilo, generándose el estado de transición (TS1-DA) representado en la Figura 5.11b, lo que da lugar finalmente a un intermedio carbaniónico (I1-DA) del metileno (Figura 5.11c). En el estado de transición, las distancias correspondientes a los enlaces el $\mathrm{C}_{\text {(metileno) }}-\mathrm{H}$ y H-

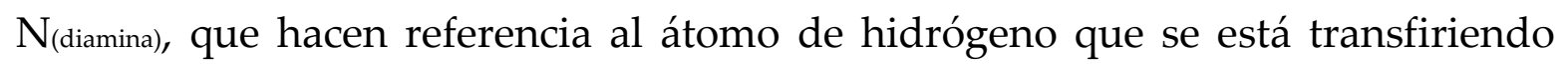
desde el malononitrilo al centro catalítico básico, son de 1,463 y 1,275 ̊̊ respectivamente, mientras tanto el protón del grupo amino $\mathrm{N}$-protonado sigue interactuando con el mismo grupo nitrilo $(\mathrm{C} \equiv \mathrm{N})$ del malononitrilo. En el intermedio carbaniónico del metileno (I1-DA), el átomo de $\mathrm{N}$ de uno de los grupos $\mathrm{C} \equiv \mathrm{N}$ está unido a los dos protones de la [diamina- $\mathrm{A}] \mathrm{BF}_{4}$ diprotonada, las

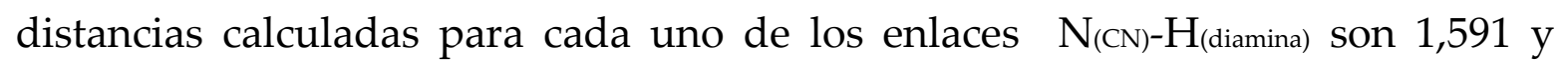
$1,601 \AA$ y a su vez se observa un aumento concomitante de la longitud del enlace $\mathrm{C} \equiv \mathrm{N}$, desde $1,159 \AA$ $\mathrm{en}$ la fase de gas a $1,196 \AA$.

Por otra parte, conforme la geometría del sistema se va optimizando, de forma espontánea, se produce una importante reorganización electrónica.

La carga negativa localizada sobre el átomo de carbono tricoordinado (el que originalmente formaba parte del metileno activo y ahora es el carbanión, pero que no participa en ningún proceso de interacción), se desplaza hasta la interacción entre el átomo de nitrógeno (del nitrilo) con los protones de la diamina, el triple enlace $\mathrm{C} \equiv \mathrm{N}$ se convierte en un doble enlace, y a la vez se forma un nuevo doble enlace $\mathrm{C}=\mathrm{C}$. La energía de activación calculada para este paso es de 10,9 kcal $/ \mathrm{mol}$, sin embargo, la energía del intermedio de reacción es tan solo 0,7 kcal/mol más estable que el estado de transición. La baja estabilidad del intermedio de reacción puede explicarse a partir de la fuerte interacción repulsiva existente entre las dos cargas positivas de la diamina diprotonada, que están localizadas sobre los átomos de nitrógeno protonados y separadas por solo $2,469 \AA$.

Cuando se emplea la [diamina-B]BF 4 como catalizador, el proceso no es completamente equivalente al presentado para la [diamina-A]BF 4 . En el complejo de adsorción inicial (M-DB), el protón ácido de la [diamina-B]BF interacciona con uno de los grupos $\mathrm{C} \equiv \mathrm{N}$, mientras que uno de los átomos de hidrógeno de malononitrilo se adsorbe sobre el $\mathrm{N}$ del centro básico de la diamina. Ambas interacciones son débiles, la energía de adsorción calculada es solo el 0,5 $\mathrm{kcal} / \mathrm{mol}$, sin embargo, la conformación molecular es muy favorable para el proceso de transferencia de hidrógeno y por lo tanto la energía de activación calculada es baja $(1,9 \mathrm{kcal} / \mathrm{mol})$. Al igual que en el intermedio carbaniónico del 
metileno I1-DA, la carga negativa del intermedio de reacción I1-DB no se localiza en el átomo de carbono tricoordinado, sino que se desplaza a la interacción entre el átomo de $\mathrm{N}$ del nitrilo, con los dos protones de la [diamina-B]BF4 diprotonada. Las geometrías optimizadas de los fragmentos carbaniónicos I1-DA y I1-DB son muy similares y las distancias $\mathrm{N}_{(\mathrm{CN})}-\mathrm{H}_{\text {(diamina) }}$ son un poco más largas en el caso de [diamina-B] $\mathrm{BF}_{4}(1,629$ y 1,663 $⿱$ ) $)$. La principal diferencia entre los dos complejos intermedios se encuentra en la distancia $\mathrm{N}_{\text {(diamina) }} \mathrm{N}$ (diamina), que es de 2,469 $\AA$ en el I1-DA y de 3,300 $\AA$ en el I1-DB. Esta distancia es la que separa los dos átomos de $\mathrm{N}$ que contienen la carga positiva en las diaminas diprotonadas y estos valores dan una explicación a la mayor estabilidad del intermedio de reacción I1-DB, ya que la separación de cargas positivas es mayor y por lo tanto menor la repulsión. Así, mientras que el paso 1 es claramente endotérmico cuando la reacción está catalizada por la [diamina-A]BF 4 (Figura 5.12 y Tabla 5.3), es energéticamente favorable con la [diamina-B]BF 4.

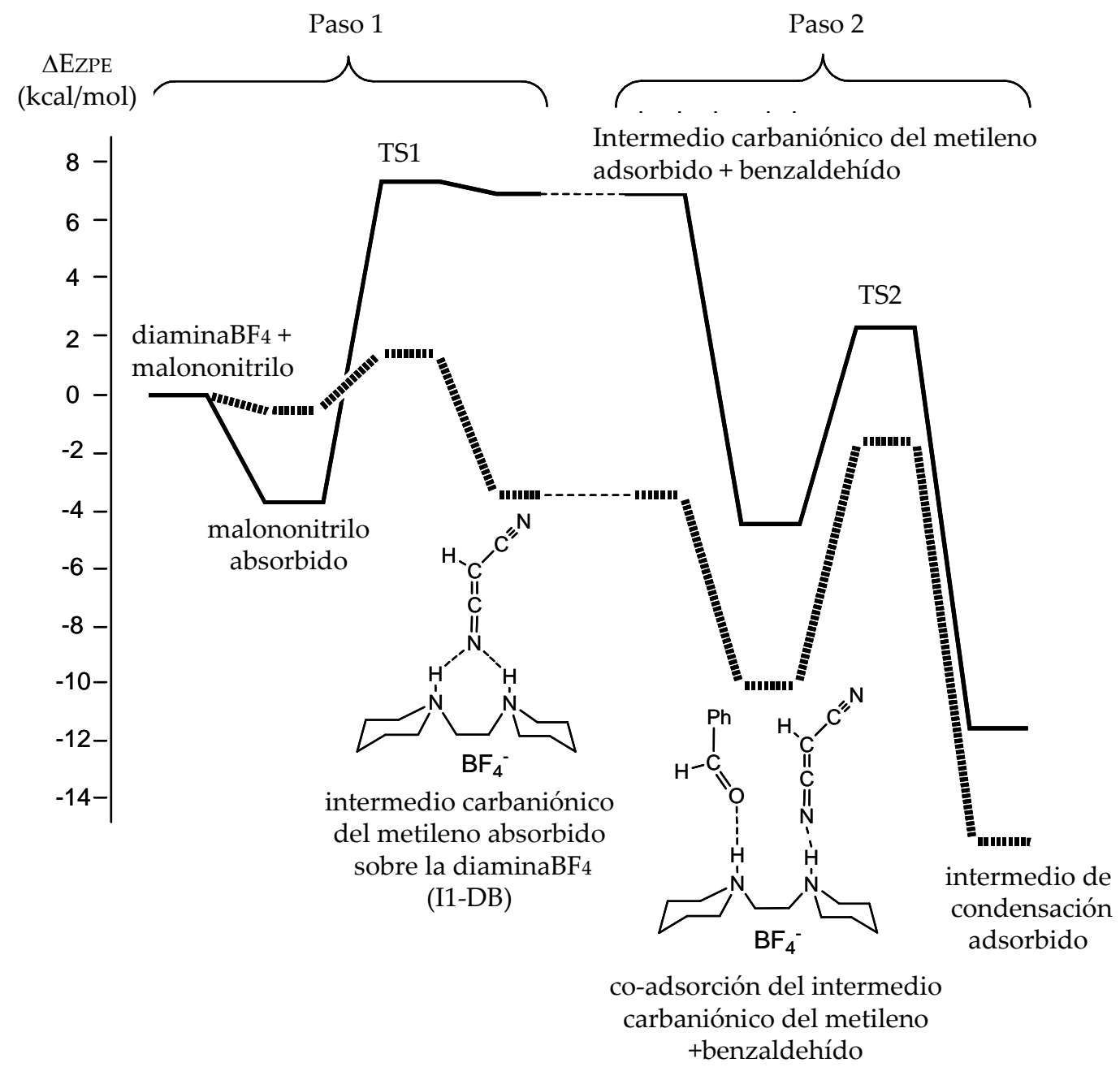

Figura 5.12.- Perfil de energías calculado para la condensación de Knoevenagel del benzaldehído y el malononitrilo catalizada por la [diamina-A]BF (línea continua) y [diamina-B]BF4 (línea discontinua). 
El segundo paso en el mecanismo de reacción consiste en la adsorción del benzaldehído sobre el complejo intermedio carbaniónico del metileno, formado con anterioridad en el paso inicial y el ataque del carbanión del metileno al grupo carbonilo del benzaldehído para formar un alcohol intermedio de condensación. Los reactivos co-adsorbidos (R-DA y R-DB), los estados de transición del proceso (TS2-DA y TS2-DB) y los intermedios de la condensación (I2-DA y I2-DB) se muestran en la Figura 5.13, mientras que las energías de adsorción, activación y entalpía de reacción calculadas se detallan en la Tabla 5.3.

\begin{tabular}{lcccc}
\hline & \multicolumn{2}{c}{ [Diamina-A]BF 4} & \multicolumn{2}{c}{ [Diamina-B]BF4 } \\
& Paso 1 & Paso 2 & Paso 1 & Paso 2 \\
\hline Energía de adsorción & $-3,62$ & $-10,83$ & $-0,50$ & $-6,64$ \\
Energía de activación & 10,92 & 6,68 & 1,92 & 8,64 \\
Entalpía de reacción & 10,23 & $-7,18$ & $-2,90$ & $-5,51$ \\
\hline
\end{tabular}

Tabla 5.3.- Energías de adsorción y activación y entalpía de reacción (kcal/mol) calculadas para los dos pasos del mecanismo de reacción catalizada por [diamina-A]BF y [diamina-B]BF 4 .

En el caso de la [diamina-A]BF4, el benzaldehído muestra una fuerte tendencia a quedar adsorbido sobre uno de los protones ácidos del complejo intermedio I1-DA generado en el primer paso, lo que provoca un parcial desplazamiento del carbanión del metileno. Independientemente de la distancia y la orientación del benzaldehído con respecto al complejo intermedio, la optimización de la geometría siempre conduce a una estructura muy estable (RDA, Figura 5.13a) en la que el grupo carbonilo está unido por el oxígeno a uno de los protones de la diamina y el malononitrilo desprotonado está interactuando con el otro protón ácido a través de uno de sus grupos $\mathrm{C} \equiv \mathrm{N}$. La distancia $\mathrm{C}(\mathrm{CO})$ -

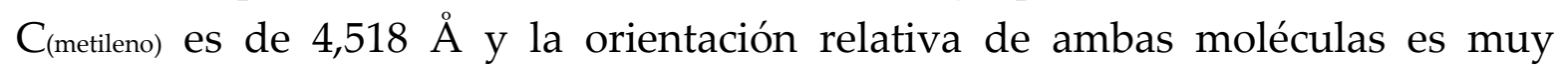
favorable para la reacción de condensación. La geometría molecular del estado de transición (TS2-DA) es bastante similar, con el grupo carbonilo altamente activado $\left(r_{C O}=1,270 \AA\right.$ ), el protón empezando a ser transferido ( $\mathrm{N}_{\text {(diamina) }}-\mathrm{H}_{\text {(diamina) }}$ $=1,115 \AA$ 足 $\mathrm{H}$ (diamina) $-\mathrm{O}_{(\mathrm{CO})}=1,447 \AA$ ) y el carbonilo y los átomos de carbono del metileno separados por solo $2,235 \AA$. 
a)

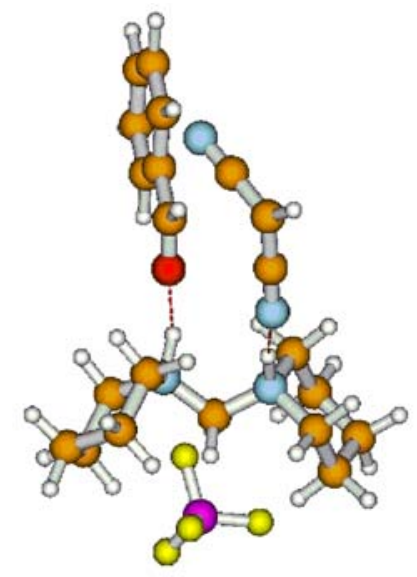

R-DA

b)

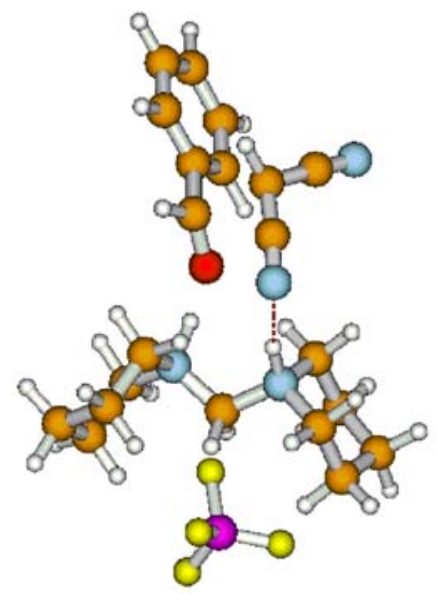

TS2-DA

c)

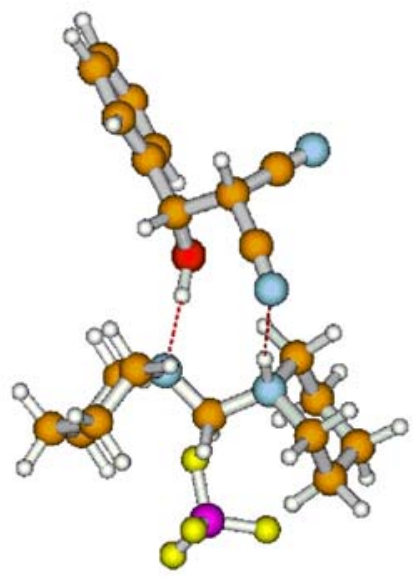

I2-DA

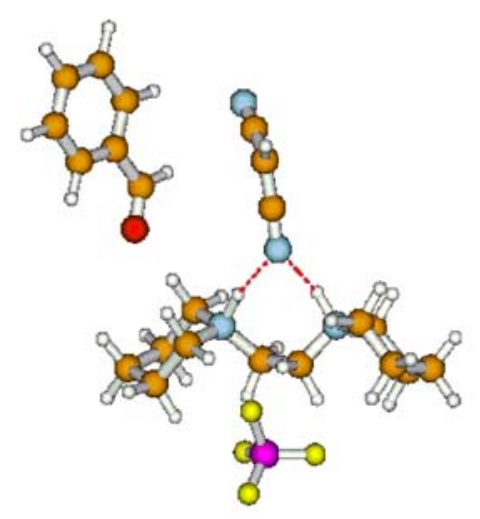

R-DB

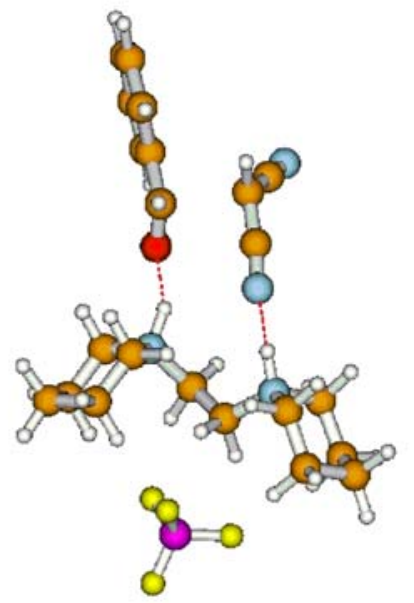

TS2-DB

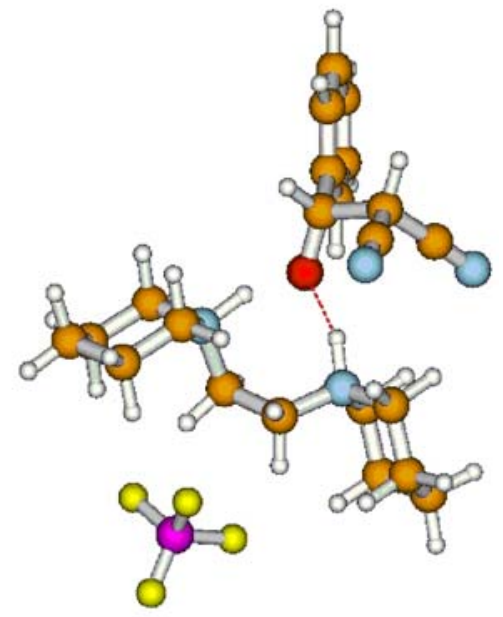

I2-DB

Figura 5.13.- a) Co-adsorción del benzaldehído y el intermedio carbaniónico del metileno. b) Estado de transición en la formación del enlace C-C. c) Alcohol intermedio de la condensación sobre la [diamina-A]BF 4 (izquierda) y [diamina-B]BF 4 (derecha). Código de colores: $\mathrm{O}$ rojo, $\mathrm{C}$ naranja, $\mathrm{N}$ azul, H blanco, B rosa, F amarillo. 
El producto obtenido en este proceso (I2-DA) es un alcohol adsorbido en el catalizador inicial [diamina-A]BF 4 y estabilizado por dos interacciones ácidobase: una entre el N-protonado, que es el centro de ácido de la diamina y uno de los grupos $\mathrm{C} \equiv \mathrm{N}$ (que también existen en el intermedio I1-DA y el estado de transición TS2-DA) y otro entre el átomo de hidrógeno del grupo hidroxilo y el nitrógeno del centro básico del catalizador. La energía de activación obtenida para este paso es de $6,7 \mathrm{kcal} / \mathrm{mol}$, y el alcohol intermedio formado es $7,2 \mathrm{kcal} / \mathrm{mol}$ más estable que los reactivos adsorbidos.

La adsorción del benzaldehído en el intermedio I1-DB es más débil que en el I1-DA y de distinta naturaleza. En este caso, el benzaldehído no es capaz de desplazar el carbanión del metileno de los protones ácidos de la [diamina-B]BF4 diprotonada, por lo tanto, el grupo carbonilo del benzaldehído, solo puede interactuar con los átomos de hidrógeno del anillo de ciclohexano, con una energía de adsorción calculada de 6,6 kcal/mol. Sin embargo, la geometría optimizada del estado de transición TS2-DB es similar a la del TS2-DA. El grupo carbonilo está interactuando fuertemente con el centro ácido del catalizador ( $r$ CO $=1,270 \AA, \mathrm{H}_{\text {(diamina) }}-\mathrm{O}_{(\mathrm{CO})}=1,536 \AA$ ) y la separación entre el átomo de carbono del metileno y el del carbonilo es de tan solo 2,174 Å. La barrera de activación es de $8,6 \mathrm{kcal} / \mathrm{mol}$ y el intermedio formado es $5,5 \mathrm{kcal} / \mathrm{mol}$ más estable que los reactivos separados. En este caso, el intermedio de reacción no es un alcohol absorbido, sino más bien un alcoholato, ya que la transferencia de protones de la diamina no ha ocurrido todavía.

El perfil energético completo para la condensación de Knoevenagel entre el benzaldehído y el malononitrilo catalizada por la [diamina-A]BF y la [diamina-B]BF4 se muestra en la Figura 5.12. La adsorción del malononitrilo sobre la [diamina-A]BF 4 es exotérmica, pero la energía de activación necesaria para su desprotonación es alta y el carbanión intermedio de metileno es una especie muy inestable. La adsorción del benzaldehído en este sistema es energéticamente muy favorable y la energía de activación para la formación de enlaces C-C es inferior a la de desorción del benzaldehído. Esto, junto con la orientación favorable de los reactivos en el complejo R-DA, sugiere que el segundo paso del mecanismo será rápido y que por lo tanto, el paso 1 será el paso determinante de la velocidad de reacción. Por otra parte, la adsorción del malononitrilo sobre la [diamina-B]BF $\mathrm{BF}_{4}$ no es muy favorable, pero el paso de la desprotonación del malononitrilo tiene una barrera energética muy baja y el intermedio de reacción (I1-DB) que se obtiene es más estable que los reactivos 
iniciales, lo que sugiere que con este catalizador, el primer paso de la reacción es rápido. Posteriormente, la adsorción del benzaldehído en el intermedio carbaniónico del metileno es exotérmica, pero no lo suficiente como para superar la barrera de activación que supone el proceso de formación de enlaces C-C. Se necesita mucha más energía para que la reacción tenga lugar y por lo tanto el paso 2 acaba siendo el paso determinante de la velocidad de reacción con este catalizador. Finalmente, tal y como se señaló con anterioridad, el benzaldehído no interactúa directamente con el centro ácido del complejo R-DB, lo que sugiere que los efectos entrópicos pueden tener una fuerte influencia en la velocidad de reacción observada. Para confirmar el mecanismo propuesto y comprobar la influencia de los efectos de la entropía en el comportamiento catalítico de los dos líquidos iónicos diaminas, se llevó a cabo un estudio cinético de la reacción que incluye la determinación experimental de las energías de activación.

\section{2 .3}

\section{Estudio cinético de la reacción}

Las cinéticas de la condensación de Knoevenagel entre el benzaldehído y el malononitrilo catalizada por la [diamina- $\mathrm{A} \mathrm{BF}_{4}$ y la [diamina-B]BF 4 se estudiaron a diferentes temperaturas para obtener las energías de activación experimentales. De acuerdo con el mecanismo propuesto a partir del estudio teórico, el primer paso de la reacción es la adsorción del malononitrilo $(\mathrm{M})$ sobre el catalizador diamina (cat.) [Ec.(1)] y la desprotonación del malononitrilo adsorbido ([M-cat.]) para obtener el carbanión intermedio de metileno ([I1-cat.]) con una constante de reacción $k_{1}$ [Ec.(2)]; y el segundo paso es la co-adsorción del benzaldehído (B) sobre el intermedio [I1-cat.] para formar el complejo reactivo ([R-cat.]) [Ec.(3)] que finalmente se convertirá en el intermedio de la condensación ([I2-cat.]), con una constante de reacción $k_{2}$ [Ec. (4)]:

$$
\begin{aligned}
& M+\text { cat } \stackrel{\mathrm{K} 1}{\longrightarrow} M-\text { cat } \\
& M-\text { cat } \stackrel{k 1}{\longrightarrow} I 1-c a t \\
& I 1-c a t+B \stackrel{\mathrm{K} 2}{\longrightarrow} R-\text { cat } \\
& R-\text { cat } \stackrel{k 2}{\longrightarrow} I 2-\text { cat }
\end{aligned}
$$


Debido a las altas velocidades de reacción alcanzadas, incluso a la temperatura más baja de reacción y a la menor concentración de catalizador que permite el estudio experimental, se han tenido que utilizar una serie de aproximaciones para simplificar las ecuaciones cinéticas y obtener información útil. Cuando el catalizador utilizado es la [diamina-A] $\mathrm{BF}_{4}$, el paso determinante es la desprotonación del malononitrilo [Ec.(2)], que depende directamente de la concentración de malononitrilo adsorbido. Suponiendo que el equilibrio de adsorción [Ec.(1)] es rápido y completo y dado que la concentración de catalizador es constante, la velocidad de reacción $(r)$ puede simplificarse para dar la Ecuación (5):

$$
r=\frac{-d[M]}{d t}=k_{1}[M]
$$

y los resultados experimentales debrían ajustarse a la Ecuación (6):

$$
\ln [M]=\ln [M]_{0}-k_{1} t
$$

Por otra parte, con el catalizador [diamina-B] $\mathrm{BF}_{4}$, la desprotonación del malononitrilo es muy rápida y por lo tanto, se puede suponer que la concentración del intermedio [I1-cat.] será constante e igual a la concentración inicial de catalizador. La etapa determinante de la velocidad [Ec.(4)] depende de la concentración del complejo reactante [R-cat.], que de acuerdo con la Ecuación (3), es directamente proporcional a la concentración de benzaldehído. Por lo tanto, la velocidad de reacción con la [diamina-B] $\mathrm{BF}_{4}$ podría simplificarse para acabar dando la Ecuación (7):

$$
r=\frac{-d[M]}{d t}=\frac{-d[B]}{d t}=k_{2}[B]
$$

Y los resultados experimentales deberían ajustarse a la Ecuación (8):

$$
\ln [B]=\ln [B]_{0}-k_{2} t
$$

Por último, también se tuvo en cuenta el mecanismo de un solo paso propuesto inicialmente (Esquema 5.3), en el que el malononitrilo y el 
benzaldehído están a la vez co-adsorbidos sobre la diamina y de forma simultanea se produce la desprotonación del malononitrilo y el ataque al benzaldehído para dar el intermedio de la condensación. En este caso, la velocidad de reacción dependerá de la concentración de ambos reactivos (benzaldehído y malononitrilo) [Ec.(9)]:

$$
r=\frac{-d[M]}{d t}=\frac{-d[B]}{d t}=k_{3}[M][B]
$$

Si además las concentraciones de malononitrilo y benzaldehído son iguales $[\mathrm{M}]_{0}=[\mathrm{B}]_{0}$, entonces los datos experimentales deberán ajustarse a una ecuación de segundo orden [Ec.(10)]:

$$
\frac{1}{[M]}-\frac{1}{[M]_{0}}=\frac{1}{[B]}-\frac{1}{[B]_{0}}=k_{3} t
$$

Las representaciones de $\ln [\mathrm{M}]$ y $1 /[\mathrm{M}]$ en función del tiempo, que aparecen en la Figura 5.14, indican que cuando la [diamina-A] $\mathrm{BF}_{4}$ se utiliza como catalizador, la velocidad de reacción sigue una cinética de primer orden con respecto a la concentración de malononitrilo, lo que sustenta el mecanismo en dos pasos proveniente del estudio teórico.

No se da la misma claridad, en cuanto al mecanismo, cuando la reacción es catalizada por la [diamina-B]BF4. En este caso, al procesar los datos experimentales con las ecuaciones pertinentes, la calidad de los resultados es similar en los dos modelos, siendo $r^{2}=0,989$ para la reacción de primer orden y $r^{2}=0,977$ para la reacción de segundo orden. Esto sugiere que la adsorción competitiva sobre los centros activos del catalizador o los efectos entrópicos relacionados con la co-adsorción de los reactivos puede llegar a ser muy relevante cuando la reacción es catalizada por la [diamina-B] $\mathrm{BF}_{4}$, como se demostrará más adelante. 

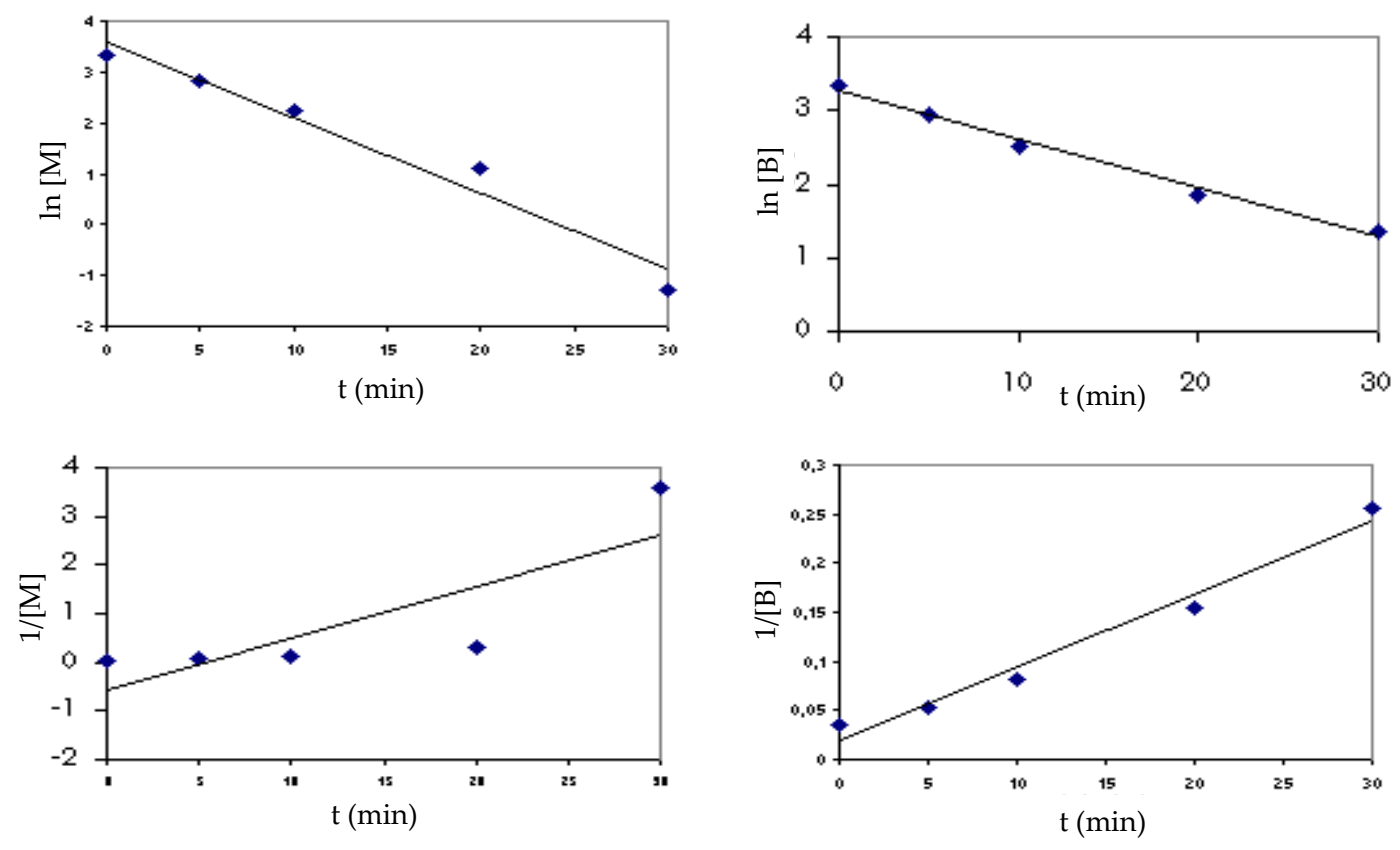

Figura 5.14.- Representación del $\ln [\mathrm{A}]$ y $1 /[\mathrm{A}]$ frente al tiempo, para la condensación de Knoevenagel entre el malononitrilo y el benzaldehído catalizada por la [diamina-A]BF4 (izquierda) y la [diamina$\mathrm{B}_{\mathrm{BF}}$ (derecha) a $25^{\circ} \mathrm{C}$. La A representa la concentración $(\mathrm{mmol} / \mathrm{mL})$ de malononitrilo para la [diamina-A]BF y la concentración $(\mathrm{mmol} / \mathrm{mL})$ de benzaldehído para la [diamina-B]BF 4 .

Las energías de activación (Eact) se calcularon a partir de las constantes de velocidad medidas a diferentes temperaturas ( $\mathrm{T}$ ), de acuerdo con las Ecuaciones (11) y (12) (en las que A representa al factor de frecuencia y $\mathrm{R}$ la constante de gases):

$$
\begin{gathered}
k=A e^{-E a c t / R T} \\
\ln k=\ln A-\frac{E a c t}{R}\left(\frac{1}{T}\right)
\end{gathered}
$$

Como se puede observar en la Figura 5.15, la calidad del ajuste es bueno en todos los casos y las energías de activación obtenidas a partir de las pendientes de las rectas representadas son de $8,4 \mathrm{kcal} / \mathrm{mol}$ para la [diamina$\mathrm{A}] \mathrm{BF}_{4}$ y $7,1 \mathrm{kcal} / \mathrm{mol}$ para la [diamina-B]BF 4 utilizando las constantes de velocidad de primer orden y de 10,2 kcal/mol para la [diamina-B] $\mathrm{BF}_{4}$ al emplear la constante de velocidad de segundo orden. 


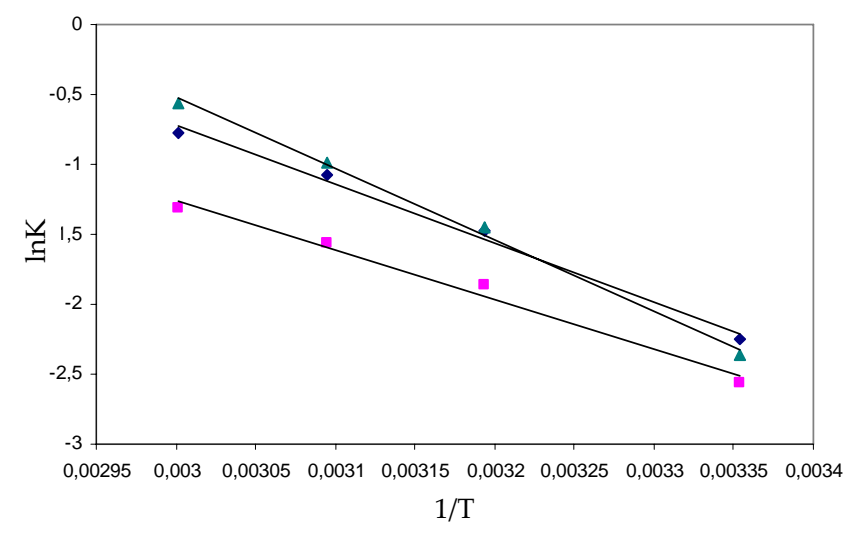

Figura 5.15.- Representación de la constante de la velocidad frente a la inversa de la temperatura $(1 / K)$, para la condensación de Knoevenagel entre el malononitrilo y el benzaldehído catalizada por la [diamina-A]BF $4(\downarrow)$ y la [diamina-B] $\mathrm{BF}_{4}$ considerándola reacción de primer orden $(\boldsymbol{\bullet})$ o de segundo $\operatorname{orden}(\mathbf{\Lambda})$.

En este punto, todavía no es posible establecer definitivamente cual es el mecanismo que sigue la reacción con la [diamina-B] $\mathrm{BF}_{4}$ como catalizador, sin embargo, existe una diferencia importante cuando se consideran los mecanismos de primer y segundo orden con esta diamina. En el caso de un mecanismo de segundo orden, y de acuerdo con la Figura 5.15, debe existir un punto isocinético a la temperatura de reacción de $38^{\circ} \mathrm{C}$, en el que las velocidades de la reacción catalizada por la [diamina-A]BF 4 y la catalizada por la [diamina-B] $\mathrm{BF}_{4}$ son iguales y a partir de los $38^{\circ} \mathrm{C}$, la reacción debe ser más rápida al emplear la [diamina-B] $\mathrm{BF}_{4}$. Por otra parte, cuando se considera el mecanismo de primer orden para ambos catalizadores, el punto isocinético debe darse a menor temperatura de reacción $\left(-11^{\circ} \mathrm{C}\right)$. Para comprobar esta hipótesis, las velocidades iniciales de reacción con las dos diaminas se midieron a diferentes temperaturas entre -10 y $60^{\circ} \mathrm{C}$. Los resultados resumidos en la Tabla 5.4 indican claramente que la reacción es más rápida con la [diamina-A]BF $\mathrm{BF}_{4}$ en prácticamente todo el rango de temperaturas estudiado y que a $-10^{\circ} \mathrm{C}$, las velocidades de reacción para los dos catalizadores están muy cercanas, lo que confirma la existencia de un punto isocinético a la temperatura prevista por el modelo de primer orden. 


\begin{tabular}{ccc}
\hline $\mathbf{T}\left({ }^{\circ} \mathbf{C}\right)$ & [Diamina-A]BF & [Diamina-B]BF 4 \\
\hline-10 & 7 & 9 \\
0 & 28 & 16 \\
25 & 41 & 32 \\
40 & 68 & 54 \\
50 & 82 & 65 \\
60 & 90 & 74 \\
\hline
\end{tabular}

Tabla 5.4.- Rendimientos (\%) de la condensación de Knoevenagel a los cinco minutos de reacción entre el malononitrilo y el benzaldehído a diferentes temperaturas.

Entonces, se puede concluir que con ambos catalizadores la reacción sigue el mecanismo en dos etapas propuesto por el estudio teórico y que la diferencia en el comportamiento catalítico es debida a que la etapa controlante de la velocidad es diferente cuando la distancia entre los centros ácido y básico se modifica.

El estudio comparativo entre las energías de activación experimentales y las calculadas no es sencillo, ya que el mecanismo de reacción consta de varias etapas elementales que incluyen los procesos de adsorción y reacciones consecutivas con barreras de activación diferentes. Pero, tal y como se puede observar en la Tabla 5.5, las energías de activación experimentales se correlacionan bien con las calculadas para las etapas determinantes de la velocidad con cada uno de los catalizadores empleados, (Etapa 1 de [diamina$\mathrm{A} \mathrm{BF}_{4}$ y etapa 2 de [diamina-B] $\mathrm{BF}_{4}$ ) y son aproximadamente $2 \mathrm{kcal} / \mathrm{mol}$ más altas para la [diamina-A]BF 4 que para la [diamina-B] $\mathrm{BF}_{4}$.

\begin{tabular}{lllll}
\hline & \multicolumn{2}{c}{ [Diamina-A]BF4 } & \multicolumn{2}{c}{ [Diamina-B]BF4 } \\
& Paso 1 & Paso 2 & Paso 1 & Paso 2 \\
\hline Calculada & 10,92 & 6,68 & 1,92 & 8,64 \\
Experimental & 8,4 & rápido & rápido & 7,1 \\
\hline
\end{tabular}

Tabla 5.5.- Energías de activación $(\mathrm{kcal} / \mathrm{mol})$ calculadas y obtenidas experimentalmente, para los dos pasos que entraña el mecanismo de la condensación de Knoevenagel entre el malononitrilo y el benzaldehído, catalizadas por la [diamina-A]BF4 y la [diamina-B]BF4.

Que experimentalmente la reacción más rápida se dé con el catalizador que requiere mayor energía de activación, se explica a partir de un factor de frecuencia (A) mayor (Ecuación (11)) con este catalizador, que a su vez debe 
estar relacionado con efectos entrópicos (S) de acuerdo con la Ecuación (13) en la que $k_{\mathrm{B}}$ es la constante de Boltzmann y $h$ la constante de Planck:

$$
A=\frac{k_{B} T}{h} e^{\Delta S^{\mp} / R}
$$

De hecho, el factor de frecuencia (A), obtenido para la [diamina-A]BF4 a partir de la gráfica de la Figura 5.15, es un orden de magnitud mayor que el obtenido para la [diamina-B] $\mathrm{BF}_{4}$, y esta diferencia debe estar relacionada con los efectos entrópicos asociados a la adsorción y reacción del benzaldehído sobre los intermedios del carbanión del metileno I1-DA y I1-DB. Como se expuso anteriormente, el benzaldehído se adsorbe fuertemente en el centro ácido del intermedio I1-DA, adoptando una orientación muy favorable para la reacción de condensación, de modo que los efectos de la entropía en el segundo paso del mecanismo son insignificantes y la velocidad de reacción con la [diamina-A] $\mathrm{BF}_{4}$ como catalizador, tan solo depende de la velocidad de la primera etapa, que a su vez está determinada por la energía de activación. La adsorción del benzaldehído sobre el intermedio carbaniónico I1-DB, es más débil y la orientación relativa de las dos moléculas en el complejo reactante R-DB no es tan favorable (Figura 5.15). Al pasar del complejo de reactantes R-DB al estado de transición TS2-DB, el benzaldehído tiene que estar muy cerca del centro ácido de la diamina y del metileno, como consecuencia, el sistema pierde entropía, lo que se refleja en un factor de frecuencia más pequeño y por lo tanto una menor velocidad de reacción.

5.3

\section{Síntesis de cumarinas e iminocumarinas}

5.3.1

Introducción

Las benzo- $\alpha$-pironas o más comúnmente denominadas cumarinas y todos los compuestos de éstas derivados a partir de sustituciones sobre el anillo aromático, en particular las iminocumarinas (Figura 5.16) son un grupo muy amplio de principios activos fenólicos que se encuentran en algunas familias de plantas medicinales. 
<smiles>[R]c1cc2ccccc2oc1=O</smiles>

Cumarinas<smiles>N#Cc1cc2ccccc2oc1=N</smiles>

Iminocumarinas

Figura 5.16.- Estructura general de cumarinas e iminocumarinas.

Pese a ser productos naturales ampliamente distribuidos en las plantas, con frecuencia es necesario sintetizar industrialmente cumarinas por el interés comercial259,260,261,262,263 que poseen como anticoagulantes, antitrombóticos anticancerígenos, antioxidantes, insecticidas, aditivos de aromas alimentarios, etc. Estos compuestos químicos tradicionalmente se han sintetizado siguiendo varios métodos, entre los que se incluyen la reacción de Pechman, de Perkin, Reformasky y reacciones de Wittig264,265,266,267,268. Sin embargo, la aplicación de estos procesos implica, en la mayoría de los casos, complejas operaciones sintéticas, varios pasos de reacción y procedimientos especialmente largos y costosos. Con el fin de superar los inconvenientes expuestos, algunos líquidos iónicos funcionalizados con centros ácidos o básicos, se han aplicado en la síntesis de cumarinas. Sin embargo, el hecho de que los líquidos iónicos se empleen a la vez como disolventes del proceso, hace que su presencia en exceso, en estas reacciones en particular, haga difícil el trabajo de manipulación y reciclado $^{264,269,270}$ (no siempre se dan estos problemas, pero en el caso de reacciones de condensación suele ser bastante común).

\footnotetext{
${ }^{259}$ Murray R.D.H., Mendez J., Brown S.A., The Natural Coumarins: Occurrence, Chemistry and Biochemistry; John Wiley and Sons: New York, 1982.

${ }^{260}$ Reddy N.S., Mallireddigari M.R., Cosenza S., Gumireddy K., Bell S.C., ReddyE.P., Reddy M.V.R., Bioorg. Med. Chem. Lett., 2004, 14, 4093.

${ }^{261}$ Kontorgiorgis C., Hadjipavlou-Latina D., J. Enz. Inhib. Med. Chem., 2003, 18, 63.

${ }^{262}$ Meuly W.C., Kirk-Othmer, Encyclopedia of Chemical Technology, 3 ${ }^{\text {rd }}$ Ed., John Wiley and Sons: New York, 1979.

${ }^{263}$ Elangdi M.H., Abdallah S.O., Ghoneim K.M., Ebied E.M., Kassab K.N., J. Chem. Res., 1997, 44.

264 a) De S.K., Gibbs R.A., Synthesis, 2005, 1231. b) Potdar M.K., Mohile S.S., Salunkhe M.M.,

Tetrahedron Lett., 2001, 42, 9285.

${ }^{265}$ Rosen T., Comp. Org. Syn., 1991, 2, 395.

${ }^{266}$ Hepworth J.D., Gabbut Ch.D., Heron B.M., Comprehensive in Heterocyclic Chemistry, Pergamon Press, $2^{\text {nd }}$ Ed., 1996.

267 a) Jones G., Org.React., 1967, 15, 204. b) Brufola G., Fringuelli F., Piermatti O., Pizzo F., Heterocycles, 1996, 43, 1257. c) Johnson J.R., Org. React., 1942, 1, 210.

${ }^{268}$ Mohamed H.E., Sanaa O.A., Khadiga M.G., Elzeni M.E., Kawser N.K, J. Chem. Res. Synop, 1997, 44.

${ }^{269}$ Singh V., Kaur S., Sapehiyia V., Singh J., Kad G.L., Catal. Commun., 2005, 6, 57.
} 
Las iminocoumarinas son análogas a las cumarinas, pero bastante menos conocidas, pese a ser importantes inhibidores, de bajo peso molecular, de la proteína tirosina quinasa (PTK). Así, esta familia de cumarinas son especialmente valiosas para el tratamiento de enfermedades que involucran el exceso de proliferación celular, y por otra parte, algunos derivados imino se están estudiando como posibles colorantes láser ${ }^{271,272,273}$. Los métodos clásicos para la síntesis de iminocoumarinas y derivados de cumarinas, tipo Knoevenagel, conllevan grandes deficiencias, como la limitación en el número de sustituyentes que pueden incorporar en su estructura y la gestión problemática de algunos procesos químicos 274,275 .

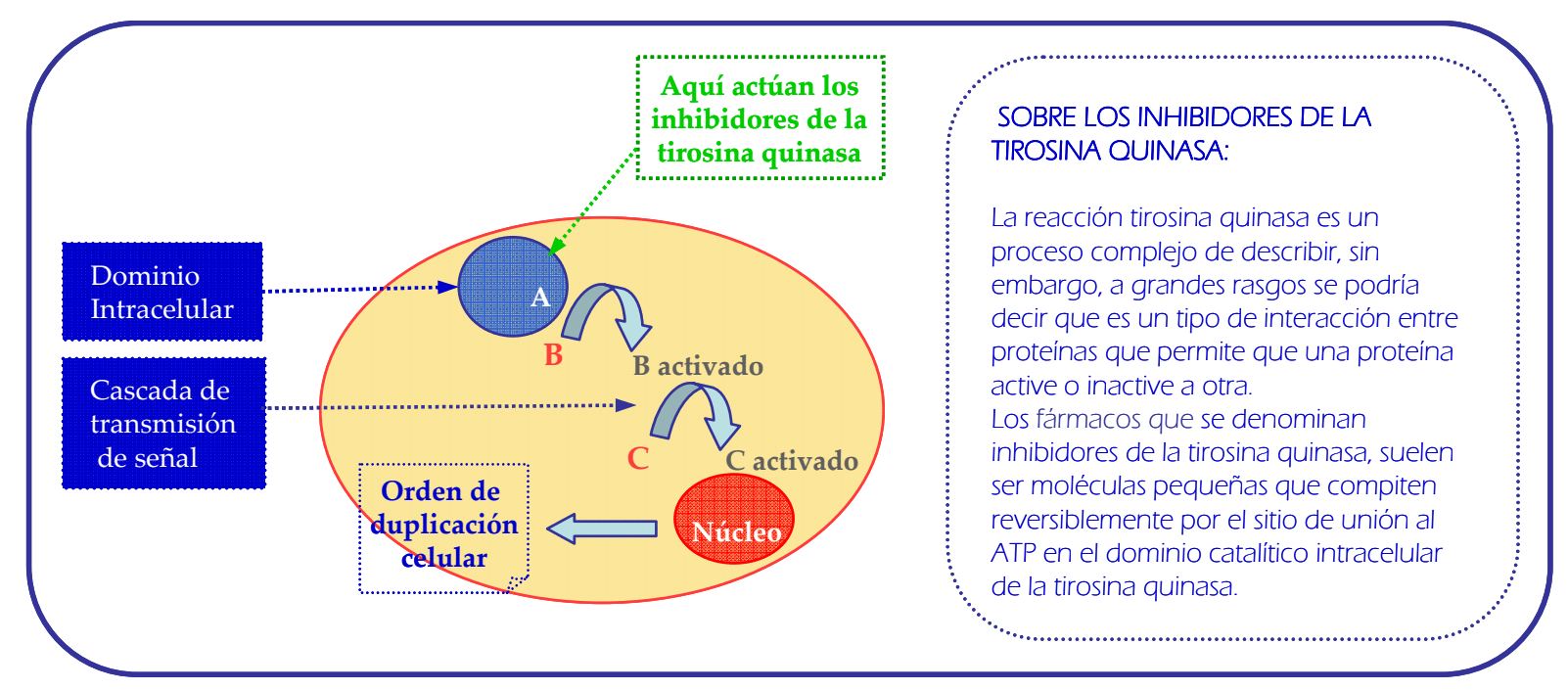

270 Potdar M.K., Rasalkar M.S., Mohile S.S. Malunkhe M.M., J. Mol. Catal. A: Chem, 2005, 235, 249.

${ }^{271}$ Burke T.R., Lim B., Marquez V.E., Li Z-H, Bolem J.B., Stefanova I., Horak I.D., J. Med. Chem., 1993, 36,425 .

272 Volmajer J., Toplak R., Leban I., Le Marechal A.M., Tetrahedron, 2005, 61, 7012.

273 Poenza F., Costa M., Green Chem., 2008, 10, 995.

274 Cui S-L, Lin X-F, Wang Y-G, Org. Letters, 2006, 8, 4517.

275 a) Costa M., Areias F., Abrumhosa L., Venancio A., Proenca F., J. Org. Chem., 2008, 73, 1954; b)

Fringuelli F., Piermatti O., Pizzo F., Synthesis, 2003, 15, 2331. 


\subsection{2}

\section{Estudio de la actividad catalítica}

Un método general de síntesis de cumarinas 3-sustituidas implica la condensación catalizada por bases entre 2-hidroxibenzaldehídos y compuestos metilenos activos derivados de ésteres carboxílicos.

El mecanismo supone un primer paso que es la condensación de Knoevenagel entre el metileno activo y el 2-hidroxibenzaldehído. El aducto de Knoevenagel rápidamente cicla a cumarina mediante una sustitución nucleofílica del grupo fenóxido al grupo carboxilato, eliminándose una molécula de alcohol (Esquema 5.4). Siguiéndose un mecanismo similar, tal y como se muestra en el esquema 5.4, cuando se utiliza malononitrilo como reactivo, se obtienen 3cianoiminocumarinas.

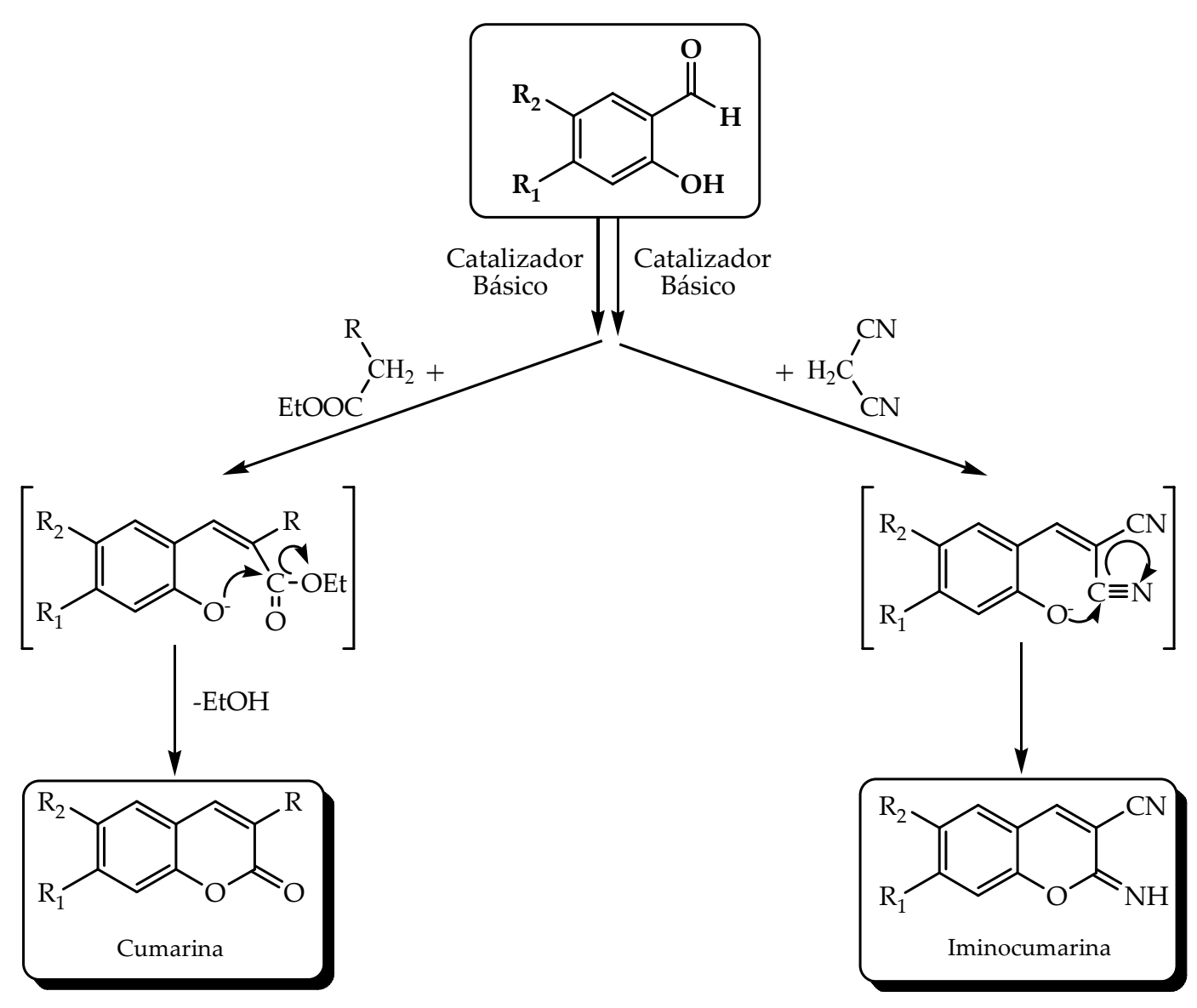

Esquema 5.4.- Representación esquemática de la síntesis de derivados decumarinas e iminocumarinas en presencia de [diamina-A]BF 4 como catalizador. 
Puesto que la [diamina-A]BF $\mathrm{BF}_{4}$ había dado excelentes resultados como catalizador en las reacciones de Knoevenagel, se pensó en aplicarla como catalizador en la síntesis de este tipo de compuestos. Cabe esperar que a nivel molecular, las etapas del mecanismo sean prácticamente idénticas a las descritas en los apartados anteriores. Es decir, la etapa controlante de la velocidad será la desprotonación del metileno activo, mientras que la etapa de deshidratación del aducto de Knoevenagel y posterior ciclación serán etapas mucho más rápidas. Por lo tanto, el catalizador bifuncional ácido-base debe operar de la misma manera, acelerando la velocidad de reacción con respecto a los catalizadores puramente básicos.

Con objeto de comprobar esta hipótesis, la reacción entre el 2hidroxibenzaldehído y el malonato de dietilo se llevó a cabo en presencia de la [diamina-A]BF 4 ( $1 \%$ molar) a la temperatura de $80^{\circ} \mathrm{C}$. Como se observa en la tabla 5.6 (Entrada 1) se obtuvo en dos horas un 99\% de rendimiento con el 100\% de selectividad a la 3-etoxicarbonilcumarina.

Durante el proceso fue imposible detectar el aducto de Knoevenagel intermedio, lo que indica que la ciclación es un paso muy rápido. Para llevar a cabo el estudio comparativo, se empleó la dipiperidinometano (Diamina-A) como catalizador básico, y en ese caso se produjo una disminución del rendimiento de la cumarina (Tabla 5.6, Entrada 2), mientras que la Nmetilpiperidina fue inactiva. Tampoco el tetrafluororborato de $\mathrm{N}$ metilpiperidinio, que actuaría como catalizador ácido de Brønsted mostró ninguna actividad (Tabla 5.6, Entradas 3-4). Es interesante señalar, que la presencia del agua proveniente de la primera etapa, de condensación, no indujo la reacción de hidrólisis del grupo carboxilato en ninguno de los casos.

Con el fin de determinar el alcance reactivo del catalizador [diamina$\mathrm{A}] \mathrm{BF}_{4}$, se prepararon varios derivados de la cumarina. Los resultados se presentan en la Tabla 5.6 (Entradas 6-10) y confirman que, en general, los rendimientos de los procesos en los que se sintetizaron derivados de la cumarina fueron especialmente altos y con una excelente selectividad (100\%). La alta actividad de la [diamina-A]BF 4 para la obtención de cumarinas a partir de la condensación y consiguiente ciclación del salicilaldehído y el malonato de dietilo, contrasta con la baja actividad mostrada por catalizadores sólidos de 
fuerza básica elevada como el óxido de magnesio ${ }^{276}$ empleado en el mismo proceso .<smiles>[R]CC(=O)OCC</smiles>

\begin{tabular}{|c|c|c|c|c|c|}
\hline Ent. & Catalizador & $\mathbf{R}_{1}$ & $\mathbf{R}_{\mathbf{2}}$ & $\begin{array}{c}\mathrm{T} \\
\left({ }^{\circ} \mathrm{C}\right) \\
\end{array}$ & $\begin{array}{c}\text { Rendimiento } \\
(\%)\end{array}$ \\
\hline 1 & & $-\mathrm{H}$ & -COOEt & 80 & $99(2 \mathrm{~h})$ \\
\hline 2 & & $-\mathrm{H}$ & -COOEt & 80 & $87(2 \mathrm{~h})$ \\
\hline 3 & & $-\mathrm{H}$ & -COOEt & 80 & $1(2 \mathrm{~h})$ \\
\hline 4 & & $-\mathrm{H}$ & -COOEt & 80 & $1(2 \mathrm{~h})$ \\
\hline 5 & & $-\mathrm{H}$ & -COOMe & 80 & 99 (1h) \\
\hline \multirow{2}{*}{6} & & \multirow{2}{*}{$-\mathrm{OCH}_{3}$} & \multirow{2}{*}{$-\mathrm{CN}$} & 40 & 75 (2h) \\
\hline & & & & 60 & 78 (1h) \\
\hline \multirow{2}{*}{7} & & \multirow{2}{*}{$-\mathrm{OCH}_{3}$} & \multirow{2}{*}{-COMe } & 60 & $73(2 h)$ \\
\hline & & & & 80 & $100(0,5 \mathrm{~h})$ \\
\hline 8 & & $-\mathrm{OCH}_{3}$ & -COOEt & 100 & 98 (1h) \\
\hline \multirow{2}{*}{9} & & \multirow{2}{*}{$-F$} & \multirow{2}{*}{$-\mathrm{CN}$} & 40 & $70(1 \mathrm{~h})$ \\
\hline & & & & 60 & $90(1 \mathrm{~h})$ \\
\hline
\end{tabular}

Tabla 5.6.- Resultados de la condensación de Knoevenagel para la obtención de cumarinas en presencia de diferentes catalizadores. Condiciones de reacción: Aldehído (32 mmol), Compuesto metileno activo $(28 \mathrm{mmol})$, catalizador $(0,28 \mathrm{mmol})$, atmósfera inerte. El rendimiento de la reacción se determinó por cromatografía de gases a partir de la cantidad inicial de compuesto metilénico. La selectividad en todos los casos fue del $100 \%$.

${ }^{276}$ Ramani A., Chanda B.M., Velu S., Silvasanker S., Green Chem., 1999, 163. 
Por otra parte, cuando la condensación de Knoevenagel se llevó a cabo entre el hidroxibenzaldehído o sus derivados sustituídos y el malononitrilo, aplicando la misma metodología, utilizando un $1 \%$ molar del catalizador y a temperatura ambiente, se obtuvieron las correspondientes 3cianoiminocumarinas con excelentes rendimientos y el 100\% de selectividad a tiempos extremadamente cortos (Tabla 5.7).<smiles>[R3]c1cc(O)c(C(=O)[CH+]CC#N)cc1[R]</smiles>

\begin{tabular}{ccccc}
\hline Ent. & $\mathbf{R}_{\mathbf{1}}$ & $\mathbf{R}_{\mathbf{2}}$ & Catalizador & $\begin{array}{c}\text { Rendimiento } \\
\mathbf{( \% )}\end{array}$ \\
\hline 1 & $-\mathrm{H}$ & $-\mathrm{H}$ & 1 & $100(1 \mathrm{~min})$ \\
2 & $-\mathrm{OH}$ & $-\mathrm{H}$ & 1 & $89(30 \mathrm{~min})$ \\
3 & $-\mathrm{H}$ & $-\mathrm{OH}$ & 1 & $99(5 \mathrm{~min})$ \\
4 & $-\mathrm{OCH} 3$ & $-\mathrm{H}$ & 1 & $99(5 \mathrm{~min})$ \\
\hline
\end{tabular}

Tabla 5.7.- Resultados de la síntesis de iminocumarinas a partir de la condensación de Knoevenagel entre el salicilaldehído y el malononitrilo en presencia de diferentes catalizadores. Condiciones de reacción: Salicilaldehído (32 mmol), malononitrilo $(28 \mathrm{mmol})$, catalizador $(0,28 \mathrm{mmol})$, etanol $(10 \mathrm{~mL})$, temperatura ambiente y atmósfera inerte; el rendimiento se calculó por cromatografía de gases y atendiendo a la cantidad inicial de malononitrilo; la selectividaden todos los casos fue del $100 \%$.

Curiosamente, durante la experimentación con el catalizador bifuncional [diamina-A] $\mathrm{BF}_{4}$, no se han observado ni el producto de la doble condensación 2(2-amino-3-ciano-2H-cromeno-4-il)malononitrilo ni dímeros del 2iminocromeno, cuya formación ha sido descrita en trabajos previos ${ }^{276}$ al emplear como catalizador de la reacción trietilamina en medio $\mathrm{MeOH} / \mathrm{H}_{2} \mathrm{O}$. 
5.4

\section{Conclusiones}

A lo largo de este trabajo, se han sintetizado y caracterizado dos organocatalizadores bifuncionales diferentes, con propiedades de líquidos iónicos, que contienen un centro ácido y otro básico en la misma molécula. La diferencia estructural entre ellos consiste en la distinta distancia entre los dos centros catalíticamente activos.

1.- El estudio de su actividad catalítica en la condensación de Knoevenagel entre el benzaldehído y diferentes compuestos metilenos activos, demostró que, tal y como ocurre con los enzimas, la distancia entre el centro ácido y el básico, es determinante para la actividad de los organocatalizadores bifuncionales.

2.- El catalizador [Diamina-A]BF $\mathrm{BF}_{4}$ que posee un centro ácido y uno básico separados por un solo átomo de carbono, resultó más activo que el catalizador [Diamina-B]BF 4 cuya distancia entre centros activos es mayor (dos átomos de carbono). Además se demostró que el catalizador bifuncional [Diamina-A]BF 4 es más activo que otros catalizadores monofuncionales (ácidos y básicos) con estructuras relacionadas.

3.- Se comprobó que el mecanismo se desarrolla en dos etapas consecutivas: 1) la desprotonación del malononitrilo en el centro básico del catalizador, que da lugar a un intermedio carbaniónico del metileno y 2) la coadsorción y la activación del benzaldehído en el centro ácido del intermedio formado en la primera etapa, seguido de la reacción de formación de un enlace C-C. Los cálculos indican que hay una inversión en la etapa controlante de la velocidad de reacción cuando la distancia entre el centro ácido y el básico se modifica, lo que influye directamente en la velocidad de reacción. Así, con la [diamina-A] $\mathrm{BF}_{4}$ (en la que el centro ácido y básico están separados por un grupo $-\mathrm{CH}_{2}-$ ), la desprotonación del malononitrilo es el paso más difícil del mecanismo y que requiere una energía de activación de $\sim 11 \mathrm{kcal} / \mathrm{mol}$. Pero, una vez producida la desprotonación, la co-adsorción del benzaldehído sobre el complejo intermedio carbaniónico del metileno, que es muy inestable, es espontánea y la disposición molecular en el complejo de reactantes generado es 
tan favorable que la formación del enlace $\mathrm{C}-\mathrm{C}$ se produce fácilmente. Por otra parte, en la [diamina-B] $\mathrm{BF}_{4}$, donde los dos centros $\mathrm{NH}$ con carga positiva del intermedio carbaniónico están separados por un puente $\left(-\mathrm{CH}_{2}-\mathrm{CH}_{2}-\right)$, tanto el estado de transición como el intermedio de la primera etapa, quedan estabilizados y la barrera de activación llega a disminuir hasta $\sim 2 \mathrm{kcal} / \mathrm{mol}$. Sin embargo, la co-adsorción del benzaldehído en el intermedio carbaniónico del metileno y su activación para poder reaccionar formando el producto de la condensación son energética y entrópicamente desfavorables, así que la segunda etapa del mecanismo se convierte en la determinante de la velocidad de reacción.

4.- El estudio cinético y la concordancia entre las energías de activación experimentales y calculadas, así como el punto isocinético, confirman el mecanismo propuesto en dos etapas y explican el diferente comportamiento de los dos catalizadores en cuanto a la diferente etapa controlante de la velocidad, que viene determinada por la distancia entre el centro ácido y básico del catalizador.

5.- El organocatalizador [diamina- $\mathrm{A}^{-} \mathrm{BF}_{4}$, ha resultado ser altamente activo y selectivo en el proceso de síntesis de cumarinas e iminocumarinas mediante la reacción entre el benzaldehído y diferentes compuestos de metilenos activos.

6.- Al comparar la actividad catalítica de la [diamina-A]BF4 con la desarrollada por catalizadores con estructuras semejantes pero carentes de bifuncionalidad, se vuelve a constatar que la diamina bifuncional es muchos más eficaz en el proceso de catálisis básica, obteniendo rendimientos muy superiores a los obtenidos con los catalizadores básicos monofuncionales.

7.- Finalmente, cabe destacar que no se observan procesos de dimerización ni autocondensación de los reactivos, demostrándose de nuevo que el catalizador bifuncional es especialmente selectivo a la formación del producto de Knoevenagel ciclado, en este caso. 
Capítulo Vl:

Líquidos iónicos con bifuncionalidad ácido-base y distancia controlada entre centros catalíticos, como organocatalizadores en la síntesis de chalconas 

6.1

\section{Introducción}

En el capitulo anterior se mostró como el organocatalizador bifuncional [diamina-A]BF $\mathrm{B}_{4}$ que combina un centro básico y uno ácido de carácter débil, posee mayor actividad en reacciones tipo Knoevenagel que otros catalizadores puramente básicos (incluso de mayor fuerza básica) o ácidos. Este hecho se ha atribuido a la existencia de una distancia óptima entre los centros ácido-base, que permite un efecto cooperativo de ambos. Teniendo esto en cuenta, el siguiente objetivo fue estudiar si tales sales, eran capaces de catalizar otras reacciones que, usualmente requieren catalizadores de fuerza básica elevada como las condensaciones aldólicas. Se pensó, que estos sistemas catalíticos podían operar en reacciones de condensación de forma similar a como lo hacen los sistemas enzimáticos en los seres vivos. De hecho, se sabe que las aldolasas Clase II, que catalizan condensaciones aldólicas estereoespecíficas, no utilizan centros básicos fuertes, sino más bien un sistema catalítico bifuncional que combina un grupo básico (encargado de abstraer un protón del carbono en alfa de una cetona) y un ion metálico de transición $\left(\mathrm{Zn}^{2+}\right)$ como centro ácido de Lewis que facilita la desprotonación de la cetona, generando un enolato de Zn que es el encargado de atacar al grupo carbonilo de otra molécula, dando lugar finalmente, a un nuevo enlace Carbono-Carbono. Sin embargo, para que el efecto cooperativo entre ambos centros catalíticos ocurra, es esencial que exista una distancia apropiada entre el centro ácido y básico, pero además, ambos centros deben tener una orientación espacial muy precisa.

De modo que, con el objetivo de estudiar si el nuevo sistema catalítico desarrollado era capaz de mimetizar a los enzimas, se eligió la condensación de Claisen-Schmidt entre la acetofenona y el benzaldehído como reacción modelo. Cabe destacar que la condensación de Claisen-Schmidt es una reacción con gran interés en procesos sintéticos, pues supone la formación de enlaces C-C. En la mayoría de los casos, esta reacción requiere como catalizadores el uso de bases fuertes del tipo hidróxidos alcalinos u óxidos alcalinos o alcalinotérreos, sin embargo, el uso de estos catalizadores, frecuentemente provoca una disminución de la selectividad hacia los productos deseados.

El mecanismo de la condensación de Claisen-Schmidt comienza con la formación de un enolato por acción de un catalizador básico sobre uno de los 
protones del carbono en $\alpha$ al grupo carbonilo de la cetona (paso 1). A continuación, se produce el ataque nucleófilo del enolato al grupo carbonilo del aldehído, dando lugar a la formación del enlace Carbono-Carbono (paso 2). Seguidamente se lleva a cabo una transferencia de protones. El alcóxido desprotona al catalizador básico y acaba siendo un grupo hidroxilo, dando lugar así a una $\beta$-hidroxicetona (paso 3). El último paso de este tipo de reacciones suele ser una deshidratación (pasos 4-5), se pierde una molécula de agua y se obtiene el producto final de la condensación (un compuesto carbonílico $\alpha, \beta$-insaturado).<smiles>[R10]CC([R2])=O</smiles><smiles>[R3]C=C([Y4])C([R2])=O</smiles>

Esquema 6.1.- Mecanismo generalmente aceptado de la condensación de Claisen-Schmidt de una cetona con un aldehído.

Un ejemplo de aplicación de la condensación de ClaisenSchmidt ${ }^{277,278,279,280,281,282}$ es la síntesis de trans-chalconas ${ }^{283}$ (Figura 6.1) que son un importante grupo de compuestos pertenecientes a la familia de los flavonoides (derivados de la 2-fenil cromona) y que se encuentran ampliamente distribuidos en la naturaleza. Estos compuestos son responsables de la coloración de muchas flores, frutos y hojas, protegen de los efectos nocivos de la radiación UV y ejercen una eficaz acción antioxidante. En cuanto a su aplicación en la industria farmacéutica, son compuestos de gran importancia, pues se suelen emplear

277 Rovig K.J., US Patent, 2755299, 1956.

278 Corma A., Climent M.J., Gracía H., Primo J., Catal. Lett., 1990, 4, 85.

${ }^{279}$ Drexler M.T., Amidiris M.D., J. Catal., 2003, 214, 136.

280 Fuentes A., Marinas J.M., Sinisterra J.V., Tetrahedron Lett., 1987, 28, 4541.

281 Climent M.J., Corma A. Iborra S., Velty A., J. Catal., 2004, 221, 474.

282 Shen J., Wang H, Liu H., Sun Y., Liu Z., J. Mol. Catal. A: Chem., 2008, 280, 24.

283 a) Ballesteros J.F., Sanz M.J., Ubeda A., Miranda M.A., Iborra S., Paya M., Alcaraz M.J., J. Med.

Chem., 1995, 2794; b) Yit C.C., Das N.P., Cancer Lett., 1994, 82, 65. 
como diuréticos, coleréticos, espasmolíticos, antibióticos y antineoplásicos, así como en la fabricación de fotoprotectores de plásticos, en cremas solares y aditivos alimentarios.<smiles>O=c1cc(-c2ccccc2)oc2ccccc12</smiles>

2-Fenil- $\gamma$-cromona Flavona<smiles>[R][R]c1ccc(C(=O)/C=C/c2ccc([R])cc2)cc1</smiles>

Flavanona

Trans-Chalconas

Figura 6.1.- Estructura de la 2-Fenil- $\gamma$-cromona y estructura general de flavonoides y trans-chalconas.

\section{2}

\section{Condensación de Claisen-Schmidt}

\subsection{1}

\section{Estudio de la actividad catalítica}

De acuerdo con los objetivos expuestos anteriormente, se sintetizaron diferentes organocatalizadores que combinan en su estructura un centro básico y otro ácido de fuerza débil y están separados por uno, dos y tres átomos de carbono respectivamente. A continuación, se presentan estos compuestos junto con su nombre y la abreviatura que se empleará para designar a cada uno: Tetrafluoroborato de 1-piperidina-1-metil-piperidinio ([diamina-A]BF4) (1), tetrafluoroborato de 1-piperidina-1-etil-piperidinio ([diamina-B] $\mathrm{BF}_{4}$ ) (2) y tetrafluoroborato de 1-piperidina-1-propil-piperidinio ([diamina-C]BF 4 ) (3). (Figura 6.2).

En primer lugar se llevó a cabo la condensación de Claisen-Schmidt entre el benzaldehído y la acetofenona en presencia del catalizador [diamina-A] $\mathrm{BF}_{4}$ ( $3 \%$ molar), en ausencia de disolvente y a temperatura de $130^{\circ} \mathrm{C}$. Tras seis horas de reacción se obtuvo un rendimiento del $80 \%$ con una selectividad a transchalcona del 100\% (Tabla 6.1, Entrada 1) Al emplear un 6\% molar de catalizador la conversión se incrementó hasta casi el 100\%, manteniéndose siempre el 100\% de selectividad (Tabla 6.1, Entrada 2). En ningún caso se observó la generación del producto de autocondensación de la acetofenona. 
(1)

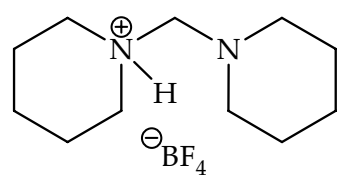

(2)<smiles>[18O-]CCN1CCCCC1</smiles>

(3)

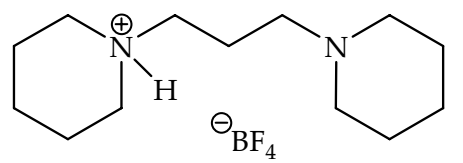<smiles>C1CCN(CN2CCCCC2)CC1</smiles>

Figura 6.2.- Estructura del (1) tetrafluoroborato de 1-piperidina-1-metil-piperidinio, (2) tetrafluoroborato de 1-piperidina-1-etil-piperidinio, (3) tetrafluoroborato de 1-piperidina-1-propilpiperidinio, (4) dipiperidinometano, (5) piperidina, (6) N-metilpiperidina, (7) tetrafluoroborato de $\mathrm{N}$ metil-piperidinio.

Sin embargo, con el catalizador puente de dos carbonos [diamina-B] $\mathrm{BF}_{4}$, tan solo se consiguió un $6 \%$ de conversión de la acetofenona (Tabla 6.1, Entrada 3), mientras que con el de puente de tres carbonos [diamina- $\mathrm{C}$ ] $\mathrm{BF}_{4}$, tras seis horas de reacción no se llegó ni al 2\% (Tabla 6.1, Entrada 4), aunque en ambos casos la selectividad continuó siendo del $100 \%$.

Estos resultados muestran claramente que la distancia entre los centros ácido-base es un factor crítico para la contribución conjunta de ambas funciones catalíticas en la estabilización del estado de transición. Tal y como se ha comprobado en este caso, la longitud máxima de la cadena entre ambos centros, no debe superar el átomo de carbono. Con el fin de poder explicar esta diferencia de actividad, se realizó un estudio teórico del mecanismo de reacción por medio de cálculos DFT, los resultados del cual se presentan en la siguiente sección.

Con el propósito de realizar un estudio comparativo, la reacción de Claisen-Schmidt entre el benzaldehído y la acetofenona se llevó a cabo empleando como catalizadores tres bases relacionadas con las sales descritas anteriormente: la gem-diamina de partida (diamina-A) (4), la piperidina (5), y la N-metilpiperidina (6)(Tabla 6.1, Entradas 1 a 5).

Tal y como se puede observar en los resultados presentes en la Tabla 6.1, los mayores rendimientos a trans-chalcona se obtuvieron al utilizar el catalizador bifuncional [diamina-A]BF4 (1), seguido por las aminas piperidina (5)> dipiperidinometano (4) >> y N-metilpiperidina (6) (Tabla 6.1, Entradas 1, 5-7). 
<smiles>[R]c1ccc(C(=O)[14c]2ccc(C(C)=O)cc2)cc1</smiles>

\begin{tabular}{|c|c|c|c|c|c|}
\hline Ent. & Catalizador & $\mathbf{R}$ & $\begin{array}{c}\text { Conversión }^{[b]} \\
(\%)\end{array}$ & $\begin{array}{c}\text { Selectividad } \\
(\%)\end{array}$ & $\begin{array}{c}\text { Rendimiento } \\
(\%)\end{array}$ \\
\hline 1 & & $\mathrm{H}$ & 80 & 100 & 80 \\
\hline $2^{[a]}$ & & $\mathrm{H}$ & $>99$ & 100 & $>99$ \\
\hline 3 & & $\mathrm{H}$ & 6 & 100 & 6 \\
\hline 4 & & $\mathrm{H}$ & 1 & 100 & 1 \\
\hline 5 & & $\mathrm{H}$ & 25 & 100 & 25 \\
\hline 6 & & $\mathrm{H}$ & 40 & 100 & 42 \\
\hline 7 & & $\mathrm{H}$ & 2 & 100 & 2 \\
\hline 8 & & $\mathrm{H}$ & 42 & 100 & 42 \\
\hline 9 & & $\mathrm{NO}_{2}$ & $>99$ & 100 & $>99$ \\
\hline 10 & & $\mathrm{Cl}$ & 99 & 100 & 99 \\
\hline 11 & & $\mathrm{OCH}_{3}$ & 72 & 100 & 72 \\
\hline
\end{tabular}

Tabla 6.1.- Resultados de la condensación de Claisen-Schmidt entre la acetofenona y derivados del benzaldehído en presencia de catalizadores mono y bifuncionales. Condiciones de reacción: benzaldehído $(32 \mathrm{mmol})$, acetofenona $(28 \mathrm{mmol})$, catalizador $(1 \mathrm{mmol}), \mathrm{T}=130^{\circ} \mathrm{C}$, tiempo $=6 \mathrm{~h}$. [a] Cantidad de catalizador empleado: $2 \mathrm{mmol}$. [b] Determinado mediante cromatografía de gases a partir de la acetofenona convertida. 


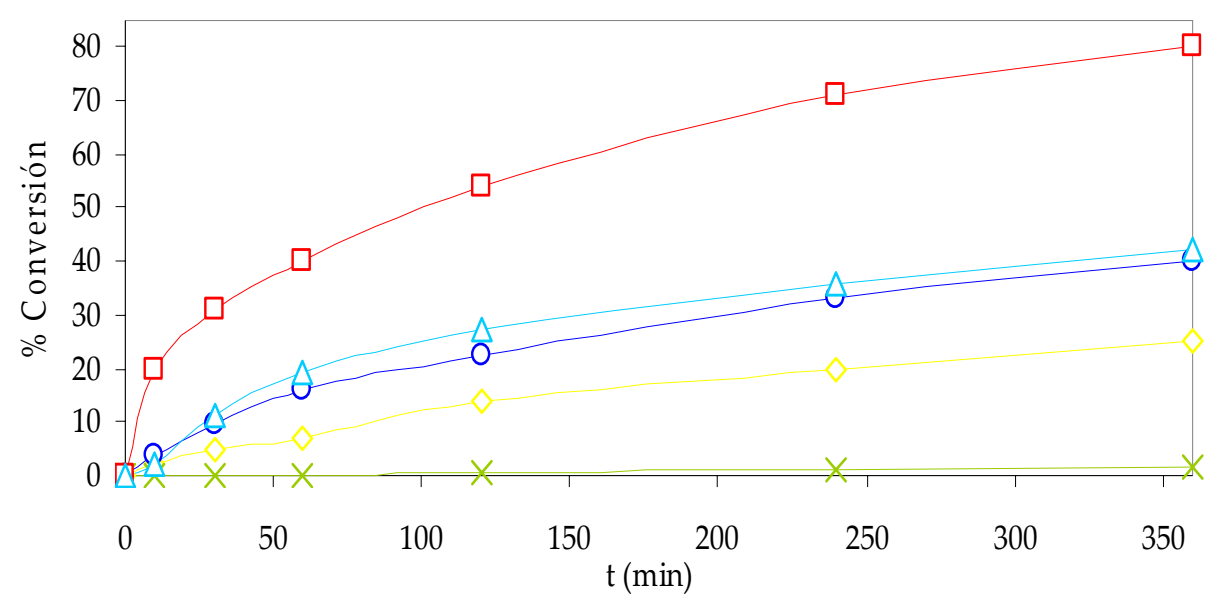

Figura 6.3.- Conversión de la acetofenona para dar trans-chalcona mediante la condensación de Claisen-Schmidt con benzaldehído a $130^{\circ} \mathrm{C}$ y en presencia de [diamina-A]BF 4 (1 mmol) (口), [metilpiperidinio]BF $4(1 \mathrm{mmol})(\Delta)$, piperidina $(1 \mathrm{mmol})(\mathrm{o})$, amina-A $(1 \mathrm{mmol})(\diamond)$ y metilpiperidina $(1 \mathrm{mmol})(\mathrm{x})$.

Al representar la evolución del rendimiento a trans-chalcona con cada uno de los catalizadores, con respecto al tiempo (Figura 6.3), se observa que la velocidad inicial de reacción es más de un orden de magnitud mayor cuando se emplea el catalizador bifuncional [diamina-A] $\mathrm{BF}_{4}$ que cuando se emplean aminas convencionales. Por otro lado, cuando la reacción de condensación entre el benzaldehído y la acetofenona se llevó a cabo en presencia de un ácido de Brønsted como el [N-metilpiperidinio]BF 4 (7) (Tabla 6.1, Entrada 8 y Figura 6.3), el rendimiento a trans-chalcona fue considerablemente más bajo que el obtenido con el catalizador bifuncional [diamina-A]BF 4 (1) (Tabla 6.1, Entradas 1).

Al igual que con lo observado anteriormente en la condensación de Knoevenagel, la superior actividad en la condensación de Claisen-Schmidt del catalizador bifuncional ácido-base [diamina-A] $\mathrm{BF}_{4}$ (1) debe ser atribuída a la existencia de cooperatividad entre los dos centros catalíticos. De hecho, sin uno de los dos, la actividad catalítica disminuye apreciablemente, incluso aunque la fuerza básica o ácida del catalizador monofuncional sea mayor que la fuerza de los centros del bifuncional. 


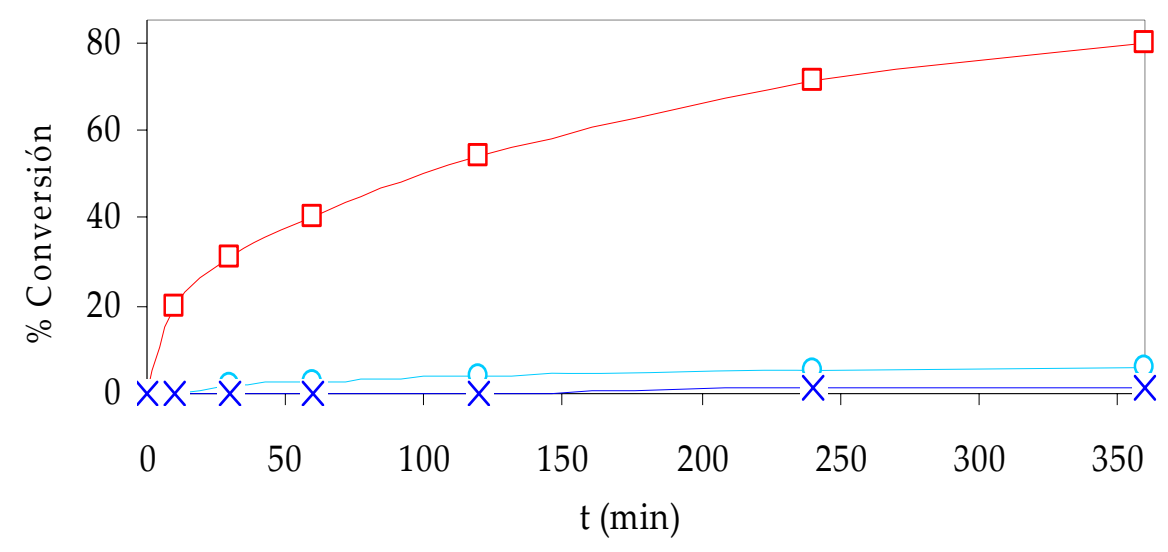

Figura 6.4.- Conversión de la acetofenona para dar trans-chalcona mediante la condensación de Claisen-Schmidt con benzaldehído a $130^{\circ} \mathrm{C}$ y en presencia de [diamina-A]BF 4 ( $\square$ ), [diamina-B]BF 4 (o), $\mathrm{y}[$ diamina-C]BF $4(\mathrm{x})$.

Dada la excelente actividad mostrada por el catalizador [diamina-A] $\mathrm{BF}_{4}$, la condensación de Claisen-Schmidt se aplicó a otros sustratos, utilizando benzaldehído con diferentes sustituyentes en para. Como se puede observar en la Tabla 6.1, los mayores rendimientos a trans-chalcona se obtuvieron con grupos sustituyentes electroatrayentes (Tabla 6.1, Entradas 9-10). En general, los sustituyentes electróatrayentes del anillo aromático, aumentan la velocidad de reacción con respecto a los sustituyentes electrodonantes (Tabla 6.1, Entrada 11), lo que puede deberse al hecho de que los sustituyentes electroatrayente aumentan la electrofilia del grupo carbonilo mediante un efecto inductivo o de resonancia.

La influencia del anión en la actividad catalítica también fue estudiada. En este caso, los cambios en la naturaleza de los contraiones ejercen un efecto notable en la actividad del catalizador. Por ejemplo, los rendimientos a trans-

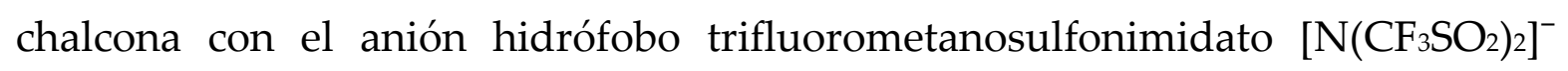
fueron muy bajos, mientras que con el tetrafluoroborato $\left[\mathrm{BF}_{4}\right]^{-}$se consiguieron los rendimientos más altos a trans-chalcona, seguido por $\mathrm{el} \mathrm{Cl}^{-}$(Tabla 6.2). 


\begin{tabular}{lccc}
\hline Ent. & $\begin{array}{c}\text { Conversión } \\
\text { (\%) [a] }\end{array}$ & $\begin{array}{c}\text { Selectividad } \\
\text { (\%) }\end{array}$ & $\begin{array}{c}\text { Rendimiento } \\
\text { (\%) }\end{array}$ \\
\hline 2 & 80 & 100 & 80 \\
\hline
\end{tabular}

Tabla 6.2.- Resultados de la condensación de Claisen-Schmidt entre la acetofenona y el benzaldehído en presencia de catalizadores del tipo [diamina-A] con diferentes aniones. Condiciones de reacción: benzaldehído $(32 \mathrm{mmol})$, acetofenona $(28 \mathrm{mmol})$, catalizador $(1 \mathrm{mmol}), \mathrm{T}=130^{\circ} \mathrm{C}$, tiempo $=6 \mathrm{~h}$. [a] determinado mediante cromatografía de gases a partir de la acetofenona convertida.

\subsection{2}

\section{Estudio del reuso del catalizador}

Puesto que el catalizador [diamina-A]BF 4 tiene características de líquido iónico, es posible una fácil extracción del medio tras la reacción, tan solo empleando el disolvente apropiado. Con la síntesis de este nuevo material se consiguió un acercamiento hacia los requisitos de actividad, selectividad y reciclabilidad, que cabría esperar para un catalizador modélico.

La reutilización de la [diamina-A]BF 4 como catalizador, fue estudiada en la reacción de condensación de Claisen-Schmidt entre la acetofenona y el benzaldehído. Después de la extracción de los productos con éter dietílico, el catalizador, con el fin de mejorar su recogida, se diluyó en diclorometano y posteriormente se secó con una sal anhidra. Tras la eliminación del disolvente por evaporación a presión controlada, el catalizador recuperado se volvió a emplear en reacciones sucesivas. Los resultados obtenidos tras siete ciclos de condensación se muestran en la Figura 6.5. 


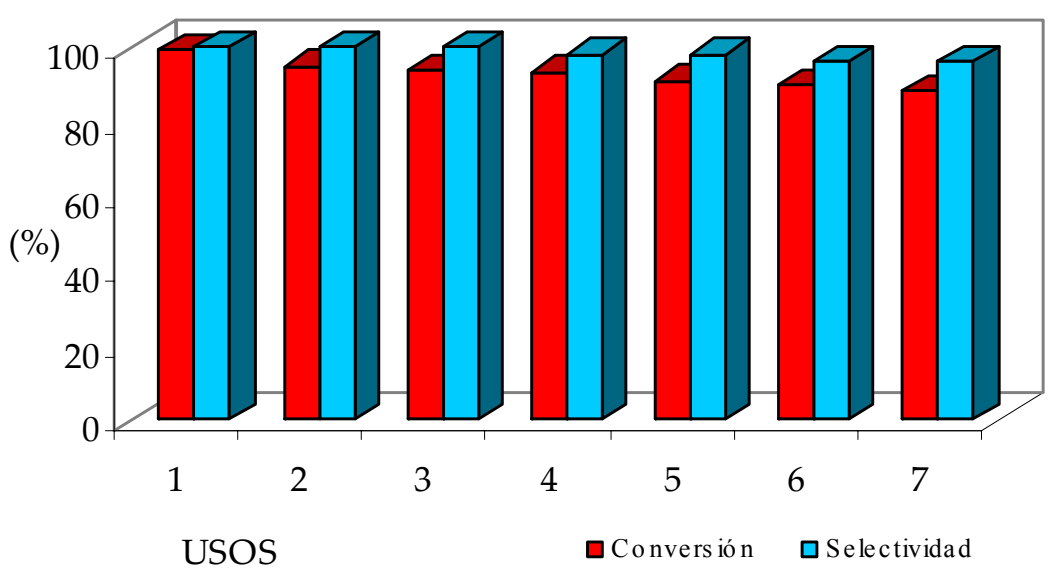

Figura 6.5.- Representación de las conversiones y selectividades a trans-chalcona obtenidas por el catalizador [diamina-A]BF4 tras sucesivos ciclos de uso y reciclado.

Tal y como se puede observar, el catalizador mantuvo una alta actividad y selectividad después de siete ciclos de reacción. Sin lugar a dudas, la recuperación y reutilización del material proporcionan un valor añadido a su comportamiento sobresaliente como catalizador de las reacciones de formación de nuevos enlaces Carbono-Carbono descritas en gran parte de este trabajo.

\subsection{3}

\section{Estudio computacional del mecanismo de reacción}

Con el propósito de explicar a nivel molecular el papel que desempeña la cooperatividad entre los centros ácido y básico de la [diamina-A]BF 4 (1), así como la escasa actividad de la [diamina-B]BF $4(2)$, se investigó teóricamente, por medio de cálculos DFT, el mecanismo de la condensación de Claisen-Schmidt entre la acetofenona y el benzaldehído.

El perfil de energías y las especies involucradas en el mecanismo se esquematizan en la Figura 6.6, así como las geometrías optimizadas de todas las estructuras obtenidas sobre el catalizador [diamina-A]BF4 (1). Las energías de adsorción y activación y la entalpía de reacción, calculadas para el proceso, se resumen en la Tabla 6.3. 


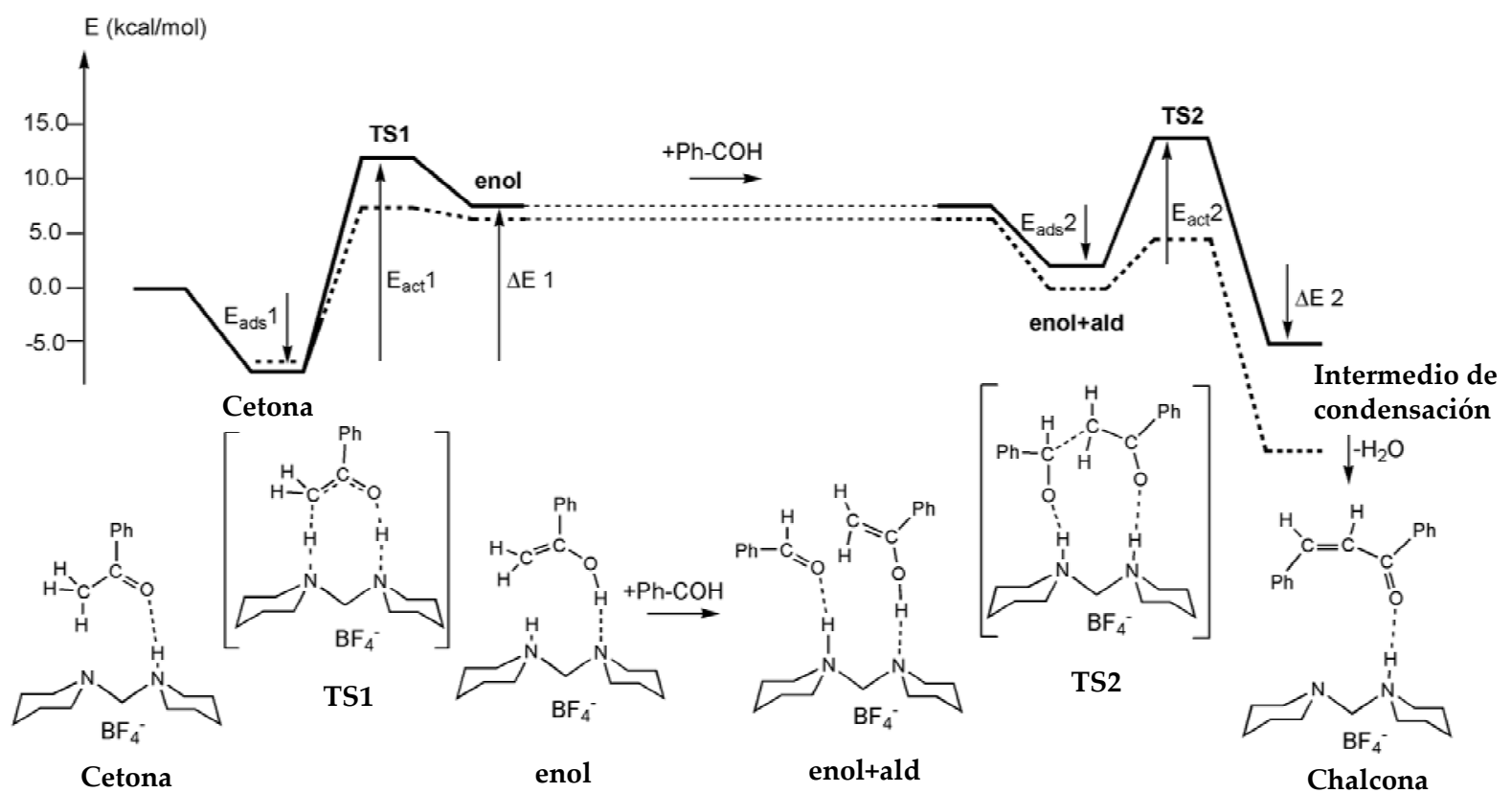

Figura 6.6.- Perfil de energías calculadas para la condensación de Claisen-Schmidt entre la acetofenona y el benzaldehído catalizada por [diamina-A]BF 4 (línea continua) y [diamina-B]BF (línea discontinua).

\begin{tabular}{cccccc}
\hline Catalizador & $\begin{array}{c}\text { Eads } \mathbf{1} \\
\mathbf{( k c a l} / \mathbf{m o l})\end{array}$ & $\begin{array}{c}\text { Eact } \mathbf{1} \\
\mathbf{( k c a l} / \mathbf{m o l})\end{array}$ & $\begin{array}{c}\Delta \mathrm{E} \mathbf{1} \\
\mathbf{( k c a l} / \mathbf{m o l})\end{array}$ & $\begin{array}{c}\text { Eads } \mathbf{2} \\
\mathbf{( k c a l} / \mathbf{m o l})\end{array}$ & $\begin{array}{c}\text { Eact } \mathbf{2} \\
\mathbf{( k c a l} / \mathbf{m o l})\end{array}$ \\
\hline [diamina-A]BF 4 & $-7,6$ & 19,1 & 14,9 & $-5,3$ & 12,5 \\
[diamina-B]BF 4 & $-7,4$ & 14,4 & 13,6 & $-6,3$ & 4,5 \\
\hline
\end{tabular}

Tabla 6.3.- Energías de adsorción y activación y entalpías de reacción calculadas para la primera etapa de la reacción detallada en la Figura 6.5.

La reacción comienza con la adsorción de la acetofenona sobre el catalizador (Figura 6.7a)cetona). El grupo carbonilo de ésta, interactúa fuertemente con el protón ácido de la diamina y la orientación de la molécula es tal que un átomo de hidrógeno del grupo metilo de la acetofenona, consigue también interaccionar con el par solitario de electrones del $\mathrm{N}$ centro básico del catalizador bifuncional. 
a) Cetona

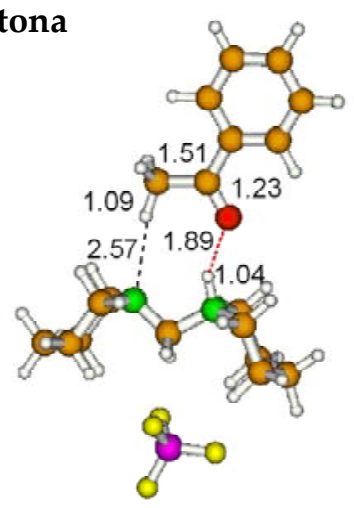

d) enol+ald

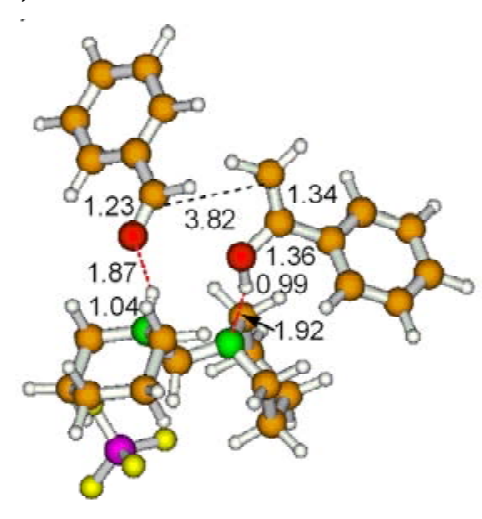

b) TS1

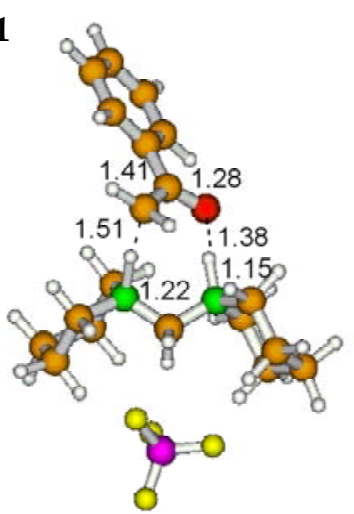

e) TS2

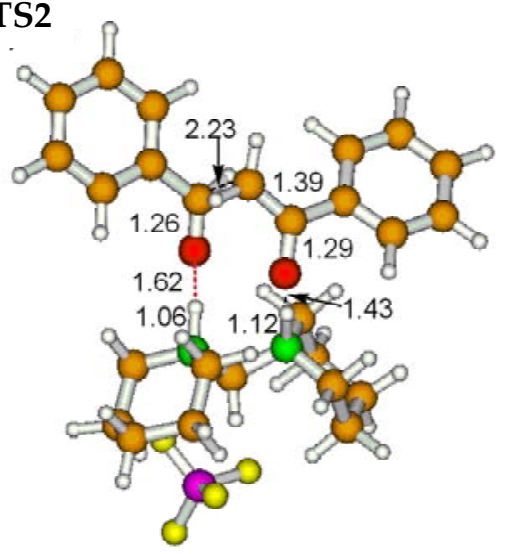

c) enol

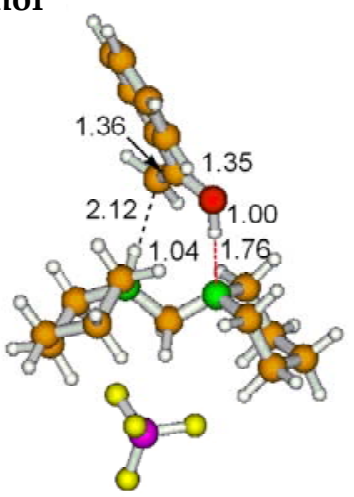

f) Intermedio de condensación

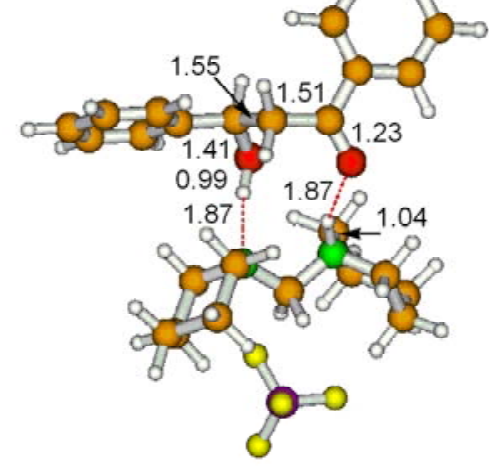

Figura 6.7.- Geometrías optimizadas de las estructuras involucradas en el mecanismo de reacción de la condensación de Claisen-Schmidt entre la acetofenona y el benzaldehído, catalizada por la [diamina-A]BF4. Las distancias se expresan en $\AA$. Código de colores: O rojo, C naranja, N verde, B morado, F amarillo, H blanco.

Luego, en un proceso concertado, el átomo de oxígeno del grupo carbonilo acaba protonado por el centro ácido $\mathrm{N}-\mathrm{H}$, al mismo tiempo que la base $\mathrm{N}$ abstrae un hidrógeno del grupo metilo.

La geometría optimizada del estado de transición (TS1, Figura 6.7b) muestra claramente que la transferencia de los dos átomos de hidrógeno, el cambio del enlace C-C, de simple a doble y la transformación del grupo carbonilo en hidroxilo ocurren de manera simultánea a través de un ciclo de ocho miembros. El resultado de este primer paso, que implica la participación directa y cooperativa del centro ácido y básico del catalizador, es una molécula de 1feniletenol adsorbida sobre la diamina (Figura 6.7c, enol). En el segundo paso, el grupo carbonilo del benzaldehído es absorbido sobre el centro ácido $\mathrm{N}-\mathrm{H}$, desplazando de este modo el doble enlace $\mathrm{C}=\mathrm{C}$, mientras que el enlace puente de hidrógeno entre el grupo hidroxilo y la base $\mathrm{N}$ del catalizador se mantiene 
(Figura 6.7d, enol+ald). En este complejo, la distancia entre el átomo de carbono del grupo carbonilo del aldehído y el carbono terminal del doble enlace olefínico es todavía muy grande, $3,82 \AA$, pero la orientación relativa entre las dos moléculas es la más adecuada para interactuar sin impedimentos estéricos entre los anillos aromáticos. Entonces, otra vez en un proceso concertado a través del estado de transición TS2 (Figura 6.7e), se forma el nuevo enlace C-C y simultáneamente se producen dos transferencias de hidrógeno desde los centros ácido y básico del catalizador, dando lugar a la condensación intermedia mostrada en la Figura 6.7f. En un tercer paso, que no se ha calculado porque es rápido y no determinante de la velocidad, se libera una molécula de agua del producto intermedio dando lugar a la chalcona deseada.

Por otra parte, el estudio computacional del mecanismo de reacción para la [diamina- $\mathrm{B}_{\mathrm{BF}} \mathrm{BF}_{4}$ (2) mostró que en este caso se daban prácticamente los mismos pasos elementales, vinculados a estructuras similares. Los datos sobre las energías calculadas aparecen en la Tabla 6.3, y se corresponden con el perfil energético esquematizado en la Figura 6.6, en ellos se aprecia que la adsorción de la acetofenona en el catalizador es exotérmica $\sim 7 \mathrm{kcal} / \mathrm{mol}$ para ambos catalizadores, que la etapa limitante de la velocidad es la isomerización ceto-enol con energías de activación entre 14 y $19 \mathrm{kcal} / \mathrm{mol}$ y que este primer paso del proceso es endotérmico. La co-adsorción del benzaldehído es energéticamente favorable para las dos diaminas y la energía de activación de la etapa de condensación a través del estado de transición TS2 es mayor cuando se utiliza como catalizador la [diamina-A]BF 4 (1). De estos resultados se puede concluir que, teóricamente, la [diamina-B]BF 4 (2) es mejor catalizador que la [diamina$\mathrm{A}_{\mathrm{BF}}$ (1). Sin embargo, los resultados experimentales presentados en la tabla 6.1, muestran claramente que la diamina con un puente de dos carbonos, es casi inactiva para esta reacción. Con la intención de encontrar una explicación al comportamiento experimental de estos catalizadores, se analizó en profundidad tanto la adsorción inicial de la acetofenona como la isomerización de ésta, con ambos catalizadores y centrando la atención en la posibilidad de encontrar diferentes conformaciones que pudieran influir en la cooperación entre los centros ácido y básico.

Por lo pronto, hay al menos dos formas posibles en que la acetofenona se puede absorber sobre el catalizador [dimania-B]BF4. En la estructura representada en la Figura 6.8a y etiquetada como cetona-2a, el centro ácido y básico del catalizador están orientados hacia la misma región del espacio, 
mientras que en el confórmero de la Figura 6.8b, etiquetado como cetona-2b, los dos centros catalíticos se orientan en direcciones opuestas.

Puesto que los cálculos mecanísticos indican que se requiere una conformación del catalizador en la que los centros catalíticos ácido y básico se encuentren en la misma región del espacio, se consideró la estructura de la cetona-2a como punto de partida para el estudio teórico. Pese a todo, cabe destacar que la estructura de la cetonas- $2 \mathrm{~b}$ es $3,7 \mathrm{kcal} / \mathrm{mol}$ más estable que la cetona-2a y por lo tanto fue necesario investigar más a fondo la estabilidad relativa de los diferentes confórmeros de los catalizadores [diamina- $\mathrm{A}_{\text {] }} \mathrm{BF}_{4} \mathrm{y}$ [diamina-B] $\mathrm{BF}_{4}$, tanto en su forma catiónica como interactuando con el contraión $\mathrm{BF}_{4}^{-}$.

a) Cetona-2a

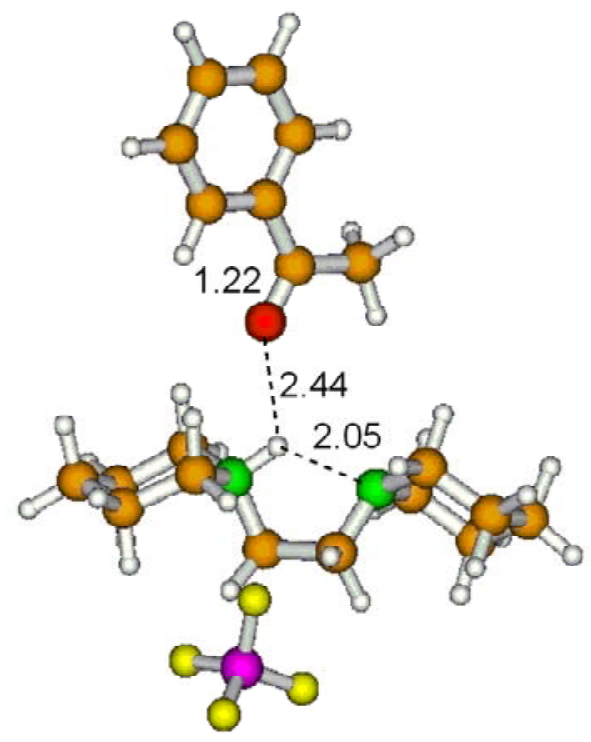

b) Cetona-2b

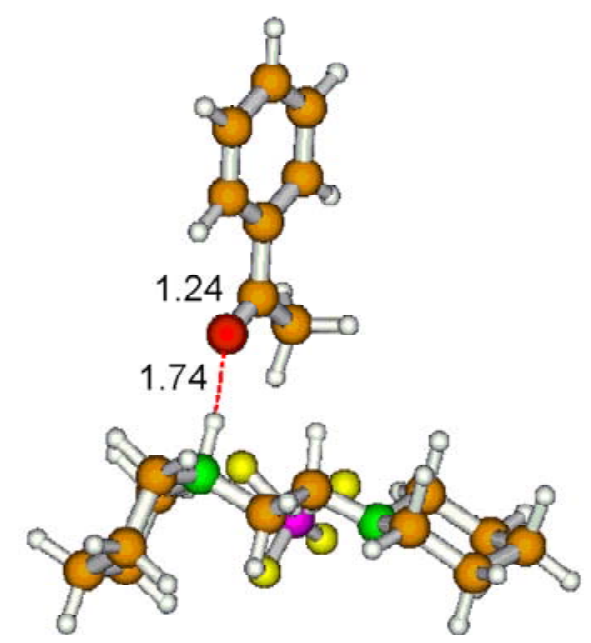

Figura 6.8.- Geometría optimizada para la acetofenona absorbida sobre dos conformaciones diferentes del catalizador [diamina-B]BF4. Las distancias marcadas en las imágenes están en $\AA$. Código de colores: $\mathrm{O}$ rojo, $\mathrm{C}$ naranja, $\mathrm{N}$ verde, B morado, $\mathrm{F}$ amarillo, $\mathrm{H}$ blanco.

Para el catalizador [diamina-A]BF 4 se obtuvieron dos diferentes conformaciones que se muestran en la Figura 6.9a. En la más estable, el grupo ácido $\mathrm{N}-\mathrm{H}$ está formando un ángulo de aproximadamente $50^{\circ}$ con el par de electrones solitario del $\mathrm{N}$ del centro básico, lo que permite la interacción simultánea de la acetofenona con los dos centros catalíticos. Por otro lado, el confórmero con los dos centros apuntando en direcciones opuestas es $5 \mathrm{kcal} / \mathrm{mol}$ menos estable. Cuando la diamina está interactuando con el contraión $\mathrm{BF}_{4}{ }^{-}$, se obtiene la misma estabilidad relativa, por lo tanto se puede concluir que el 
número de moléculas de catalizador [diamina-A]BF 4 con la conformación adecuada será alto, pues es más estable mientras que el contraión no afecta directamente a la estabilidad de la conformación.

Por otra parte, las posibilidades de rotación alrededor de la cadena $-\mathrm{CH}_{2} \mathrm{CH}_{2}$ - que separa el centro ácido del básico en el catalizador [diamina-B] $\mathrm{BF}_{4}$ genera un mayor número de confórmeros, los más estables se representan en la Figura 6.9b. En la forma catiónica, el conformero más estable se corresponde con aquel cuyos centros catalíticos tienen la orientación adecuada, es decir, ambos orientados hacia la misma región del espacio. En esta estructura, la flexibilidad de la cadena - $\mathrm{CH}_{2} \mathrm{CH}_{2}$ - permite la formación de un enlace puente de hidrógeno entre el protón del centro ácido $\mathrm{N}-\mathrm{H}$ y el $\mathrm{N}$ de la base, que queda reflejado en la corta distancia entre N-H---N, 1,94 A. El siguiente confórmero más cercano en energía, pero no adecuado para la reacción, es $9 \mathrm{kcal} / \mathrm{mol}$ menos estable. Sin embargo, al considerar la aportación del contraión, se observa que existe una interacción entre el centro ácido $\mathrm{N}-\mathrm{H}$ y el $\mathrm{BF}_{4}{ }^{-}$que provoca la rotura del enlace intramolecular puente de hidrógeno, y que en la forma catiónica era la fuente de estabilidad, consecuentemente, el orden de estabilidad varía de forma considerable. De este modo, el conformero con los centros ácido y básico orientados hacia la misma región del espacio, acaba siendo $2 \mathrm{kcal} / \mathrm{mol}$ menos estable que el de la estructura con los dos centros apuntando en direcciones opuestas. Al generarse la interacción con la acetofenona, este orden de estabilidad no solo se mantiene, si no que incluso la diferencia de energía entre los dos confórmeros aumenta. Estos resultados nos permiten concluir que la situación real en condiciones de reacción es que la interacción de la acetofenona con la [diamina-B] $\mathrm{BF}_{4}$ da lugar al complejo representado en la Figura 6.8b, en el que la orientación relativa del centro ácido y básico no permite la isomerización ceto-enólica concertada que supone el primer paso del mecanismo. Esta misma figura, permite entender la falta total de actividad del catalizador [diamina-B] BF 4 para la condensación de Claisen-Schmidt y también permite explicar la moderada actividad que se observó con este mismo catalizador para la condensación de Knoevenagel entre el benzaldehído y una serie de compuestos con metilenos activos, que se trató en el capítulo anterior. 
a)

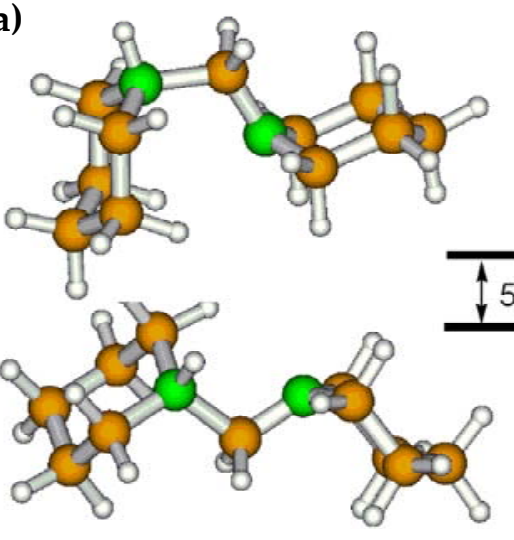

b)
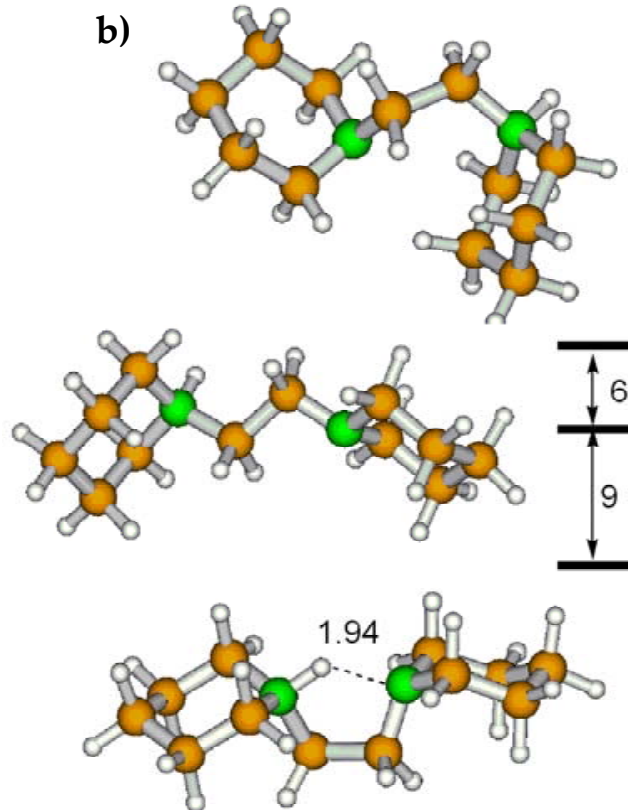
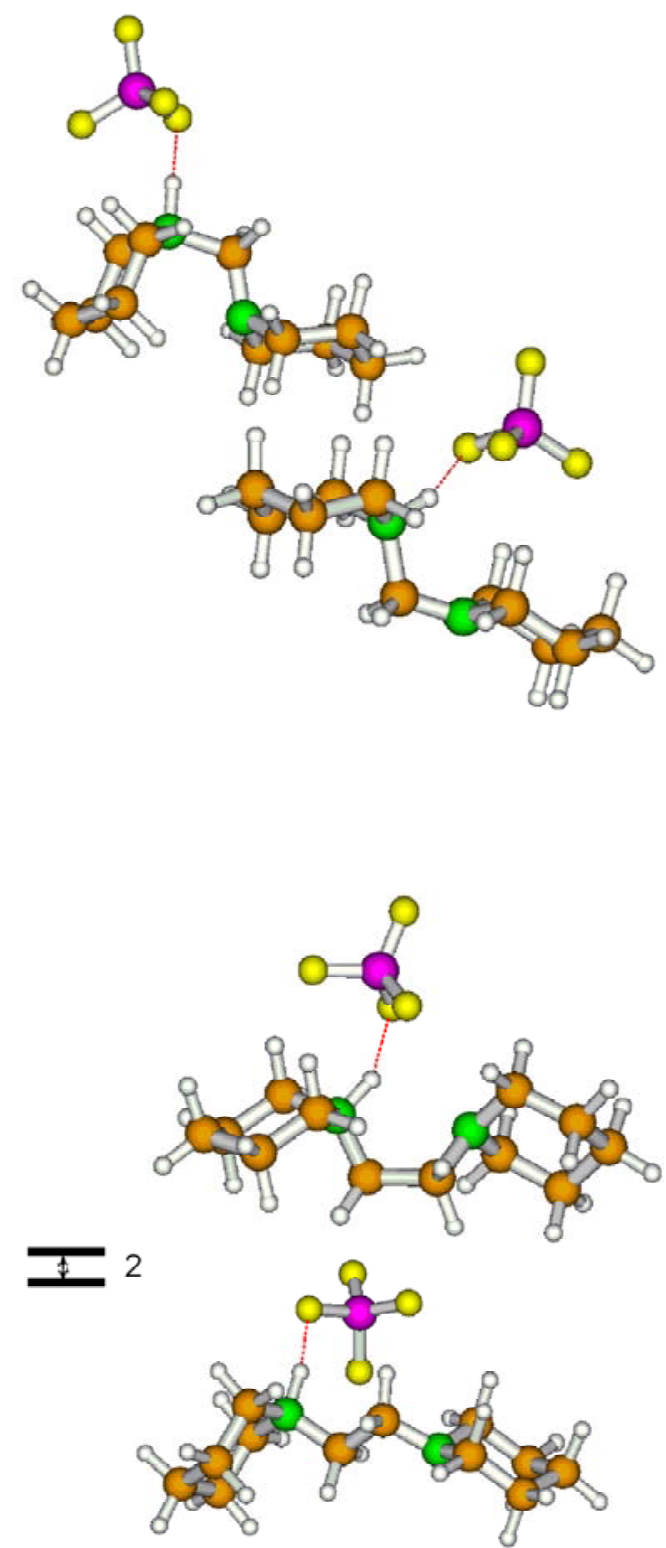

Figura 6.9.- Geometría optimizada y estabilidad relativa de los conformeros más estables obtenidos para los catalizadores [diamina-A]BF 4 y [diamina- $\mathrm{B}^{\mathrm{B}} \mathrm{BF}_{4}$. Las distancias se miden en $\AA$ y los valores energéticos en $\mathrm{kcal} / \mathrm{mol}$. Código de colores: O rojo, C naranja, B morado, $\mathrm{F}$ amarillo, $\mathrm{H}$ blanco.

En ese caso, el mecanismo completo de la condensación entre benzaldehído y el malononitrilo, catalizada tanto por la [diamina-A]BF 4 como por la [diamina-B]BF4 se investigó por medio de cálculos DFT, y se constató que el mecanismo consiste en dos pasos: la desprotonación del malononitrilo para formar el carbanión del metileno y el ataque del intermedio carbaniónico al átomo de $\mathrm{C}$ del grupo carbonilo del benzaldehído. El primer paso, la desprotonación, requiere tan solo de un centro básico, mientras que el segundo paso, se ve favorecido si el benzaldehído está activado sobre el centro ácido, 
aunque esto no es estrictamente necesario. De hecho, la actividad de la [diamina$\mathrm{B}_{\mathrm{B}} \mathrm{BF}_{4}$ en la condensación de Knoevenagel resultó ser similar a la obtenida con el catalizador dipiperidinometano, que es puramente básico (Figura 6.3, compuesto 4), lo que sugiere que solo la parte básica del catalizador [diamina-B] $\mathrm{BF}_{4}$ jugaba un rol en el proceso catalítico, mientras que el rendimiento de la [diamina-A]BF 4 fue mejor porque la orientación de los dos centros, ácido y básico, permite un efecto cooperativo. La situación en la condensación de Claisen-Schmidt es diferente, porque la isomerización ceto-enol en el primer paso del mecanismo requiere la participación concertada de los dos centros catalíticos. Si la conformación del catalizador no permite este efecto cooperativo, la reacción no se dará, y eso es lo que se observa experimentalmente.

Una vez se llega a este nivel de entendimiento del mecanismo de reacción de la condensación de Claisen-Schmidt entre el benzaldehído y la acetofenona con el catalizador bifuncional [diamina-A]BF ${ }_{4}$, cabe destacar la similitud que existe entre los pasos elementales descritos en este mecanismo y los que desarrollan las aldolasas de clase II.

Tal y como se comentó al principio del capítulo, las aldolasas de clase II pertenecen al grupo de los metaloenzimas y se dedican a catalizar estereoespecíficamente y de forma reversible la condensación aldólica en microorganismos (hongos, bacterias y algas). Estos enzimas, disponen de cofactores ácidos de Lewis que suelen ser iones de metales de transición (en el caso de las aldolasas es el $\mathrm{Zn}^{2+}$ ) que facilitan la desprotonación, dando lugar a complejos $\mathrm{Zn}^{2+}$-enolatos. Las aldolasas se clasifican en cinco grupos atendiendo a la especificidad de sustrato que presentan. En el caso de las aldolasas clase II, son altamente específicas para las cetonas pero muy poco específicas para los aldehídos aceptores ${ }^{284,285}$. Por ejemplo, la aldolasa clase II D-Fructosa-1,6-bifosfato (FBPA), presenta una alta especificidad de sustrato para la dihidroxiacetonafosfato (DHAP), y sin embargo varios aldehídos pueden ejercer como aceptores para la FBPA, sobretodo el D-gliceraldehído-3-fosfato (GAP) ${ }^{286}$ (Esquema 6.2)

284Takayama S., Mcgarvey G.J., Wong C.H., Annu.Rev.Microbiol., 1997, 51, 285.

${ }^{285}$ Fessner W.D., Walter C., Bioorg.Chem., 1997, 97, 194.

${ }^{286}$ Fessner W.D., Schneider A., Held H., Sinerius G., Walter C., Hixon M., Schloss J.V., Angew.Chem.Int.Ed., 1996, 35, 2219. 


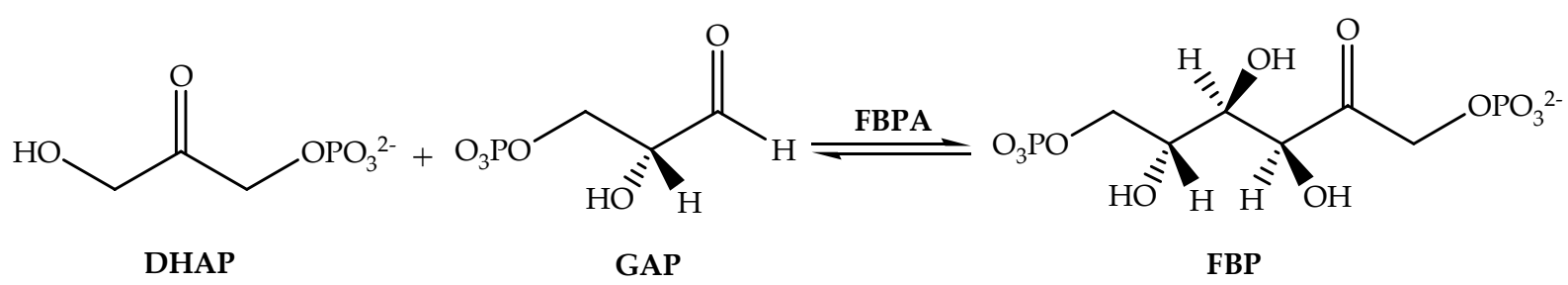

Esquema 6.2.- Representación esquemática de la síntesis de la hexosa D-fructosa-1,6-bifosfato (FBP) mediante la condensación aldólica de la dihidroxiacetonafosfato (DHAP) y el D-gliceraldehído-3fosfato (GAP) catalizada por el enzima D-Fructosa-1,6-bifosfato aldolasa (FBPA).

Los estudios realizados en Escherichia Coli sobre la actividad y la estructura de la D-Fructosa-1,6-bifosfato aldolasa (FBPA) han aportado información detallada sobre el mecanismo de la condensación aldólica bioenzimática. Teniendo en cuenta los resultados de dicho estudio, se puede afirmar que:

1.- La cetona DHAP es la primera que interacciona, en forma de ligando bidentado con el centro activo del enzima $\mathrm{Zn}^{2+}$, así se genera el complejo EnzimaDHAP. (Esquema 6.3)

2.- A continuación, el residuo Glu182 (aminoácido localizado en la proteína enzimática) consigue abstraer el hidrógeno del carbono en $\alpha$ al grupo carbonilo de la cetona, gracias a la intervención del metal divalente $\mathrm{Zn}^{2+}$ del complejo. El residuo Glu182 participa en el proceso catalítico como base y estabilizando el intermedio enediolato generado en el primer paso. (Esquema 6.3.I). 


\section{Mecanismo de la Aldolasa Clase II (1ª Parte)}

Complejo Enzima-DHAP

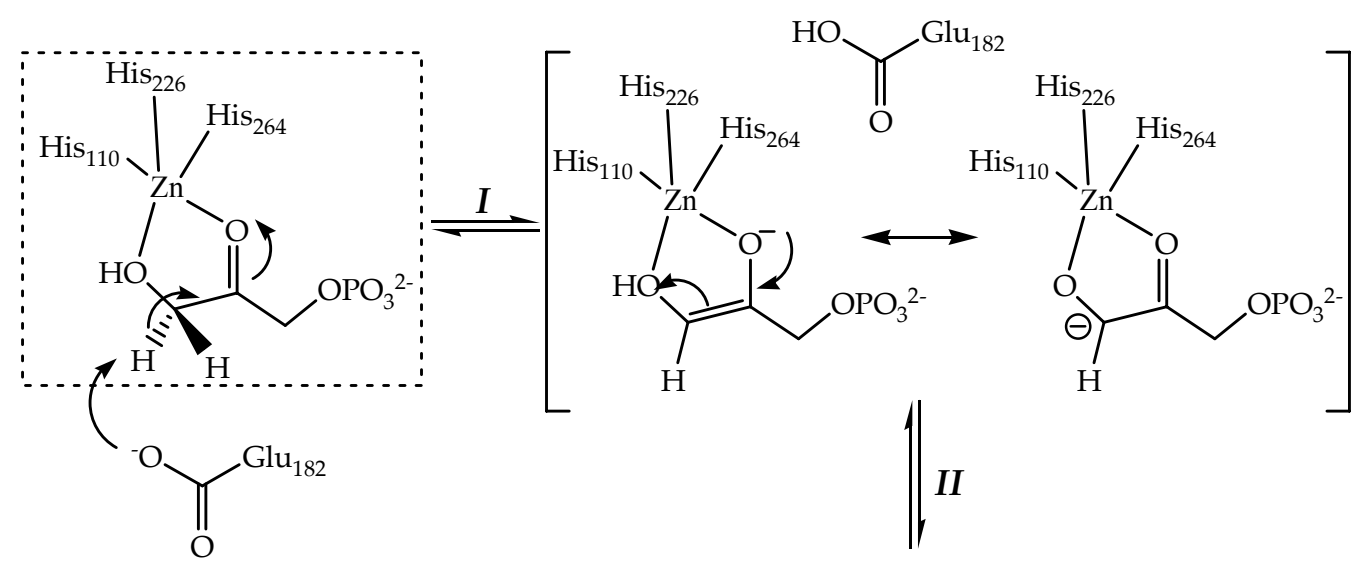

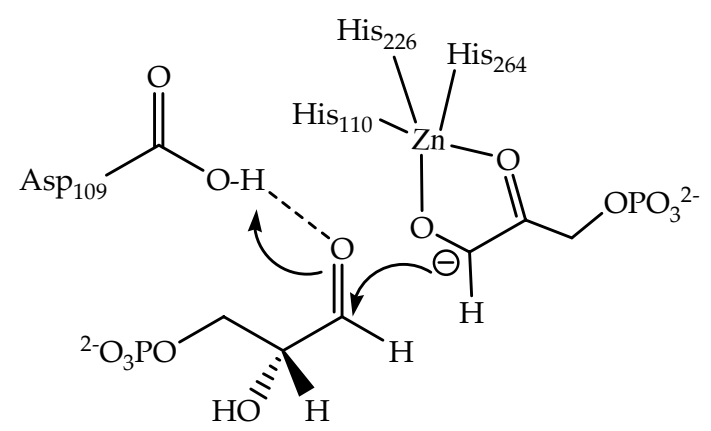

\section{Mecanismo del catalizador bifuncional [diamina-A]BF 4 (1ª Parte)}

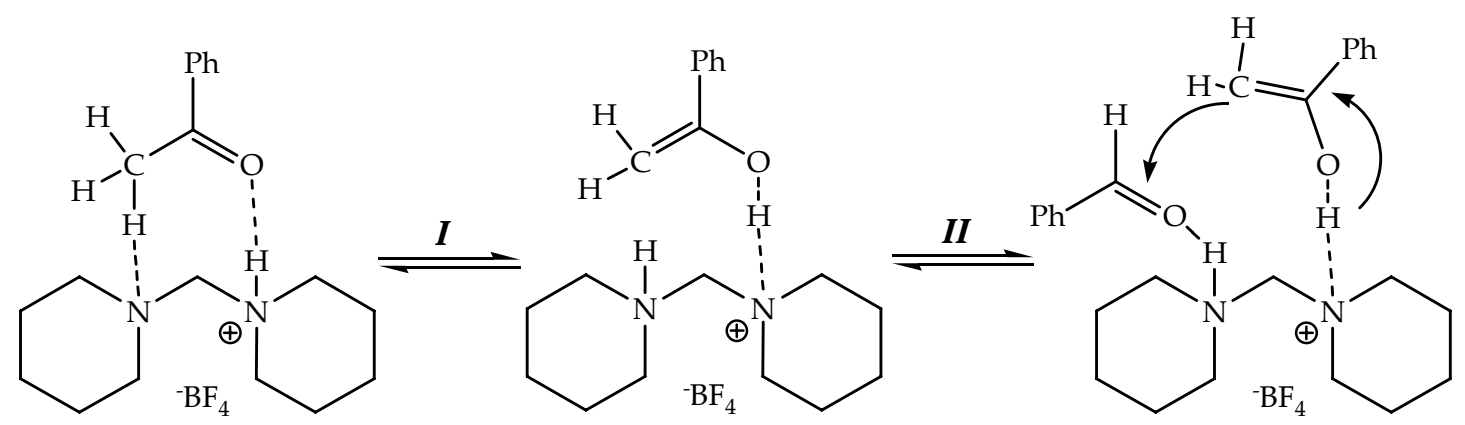

Intermedio Diamina-enol

Esquema 6.3.- Primera parte de los mecanismos de condensación catalizados por la aldolasa clase II y la [diamina-A]BF4. 
Comparando ambos mecanismos de reacción, el bioenzimático de la aldolasa clase II FBPA y el generado por la diamina bifuncional [diamina-A]BF4, se puede establecer un claro paralelismo entre ambos. El papel que desempeña en el enzima el ion metálico divalente $\mathrm{Zn}^{2+}$, lo asume el nitrógeno protonado de la diamina, mientras que la abstracción del protón llevada a cabo por el residuo enzimático Glu182, en el caso de la diamina lo asume el par de electrones solitario del nitrógeno básico (Esquema 6.4).

El siguiente paso del mecanismo consiste en el ataque del cis-enediolato nucleofílico, formado en el primer paso, al grupo carbonilo del aldehído GAP, que a su vez está activado, gracias a la donación de un protón por parte del grupo carboxílico del residuo enzimático Asp109 (Esquema 6.3.II). El ataque nucleofílico da lugar a un nuevo enlace carbono-carbono entre dos triosas y así queda constituido el producto de la condensación, la hexosa D-fructosa-1,6bifosfato (FBP)(Esquema 6.4.III y IV).

De forma muy semejante, tal y como queda representado en el esquema 6.5, durante la condensación de Claisen-Schmidt, el benzaldehído se activa en el centro ácido de la [diamina-A]BF 4 (grupo $\mathrm{N}-\mathrm{H}$ ), atrayendo de este modo el ataque nucleofílico y produciendo el intermedio aldólico que por deshidratación dará lugar a la chalcona como producto final.

\section{Mecanismo de la Aldolasa Clase II (2 ${ }^{\mathrm{a}}$ Parte)}

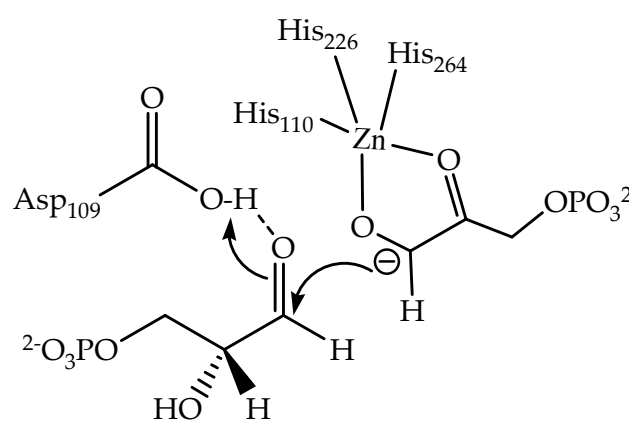

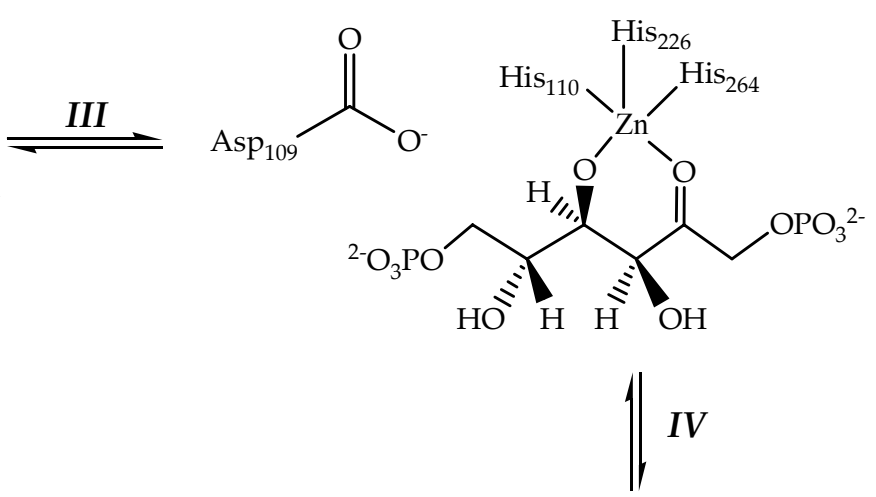<smiles>[R6]OC[C@@H](O)[C@@H](O)[C@H](O)C(=O)CO[Na]</smiles>

FBP 


\section{Mecanismo del catalizador bifuncional [diamina-A]BF 4 (2 ${ }^{\mathrm{a}}$ Parte)}

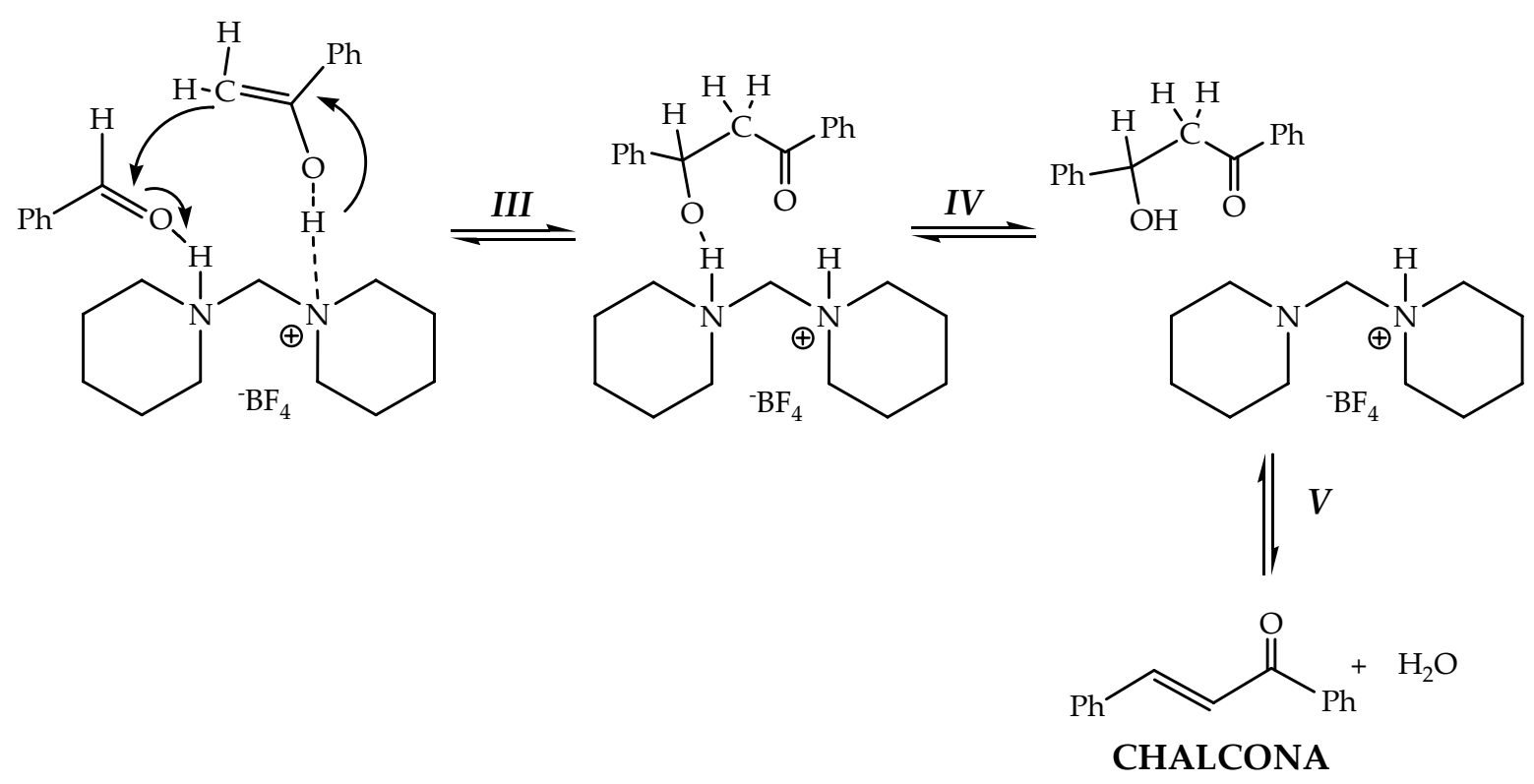

Esquema 6.4.- Segunda parte de los mecanismos de condensación catalizados por la aldolasa clase II y la [diamina-A]BF4. 


\section{3}

\section{Conclusiones}

1.- El organocatalizador bifuncional ácido-base [diamina-A]BF 4 , se ha aplicado con éxito en la reacción de condensación de Claisen-Schmidt obteniéndose trans-chalconas con excelentes rendimientos y selectividades.

2.- Este nuevo material con características de líquido iónico, tiene la capacidad de ser reutilizado manteniendo su actividad y selectividad durante siete ciclos de reacción consecutivos. Por tanto, presenta las ventajas de los catalizadores homogéneos diseñados molecularmente junto con la reciclabilidad de los heterogéneos.

3.- A través del estudio computacional del mecanismo de la reacción de Claisen-Schmidt, se ha podido comprobar que existe un efecto cooperativo entre los dos centros (ácido y básico) que posee el catalizador [diamina-A]BF. Se ha demostrado que la distancia entre ambos centros, así como su orientación espacial son cruciales para el correcto funcionamiento del catalizador, pues el eficaz acoplamiento entre éste y las moléculas reactantes es el punto clave del éxito de la diamina.

4.- El funcionamiento de este nuevo catalizador tiene una gran similitud con el de algunos enzimas, en especial las aldolasas clase II, que llevan a cabo una condensación tipo aldol en sistemas biológicos, siguiendo los mismos pasos que se pudieron verificar para la [diamina-A]BF 4 . 

Capítulo VII:

Líquidos iónicos con bifuncionalidad ácido-base como organocatalizadores en adiciones de Michael y síntesis de 1,3-dinitroalcanos en un proceso multietapa 

Puesto que la sal tetrafluoroborato de 1-piperidina-1-metilpiperidinio [diamina-A]BF4 mostró una excelente actividad y selectividad como organocatalizador bifuncional en las reacciones de condensación de Knoevenagel y Claisen-Schmidt, y siguiendo con los objetivos propuestos para este trabajo de tesis, se planteó estudiar las posibilidades que ofrece esta sal como catalizador en otras reacciones típicamente catalizadas por bases y que conducen a productos de interés en química fina.

En este capítulo se presentan los resultados obtenidos utilizando [diamina-A]BF 4 como catalizador en diferentes reacciones de adición de Michael y en la obtención de 1,3-dinitroalcanos mediante un proceso multietapa. En todos los casos se ha comparado la actividad catalítica de la [diamina-A]BF 4 con la de catalizadores básicos monofuncionales de estructura relacionada.

\section{1}

\section{Adición de Michael}

La reacción de adición de un carbono nucleófilo a un alqueno deficiente de electrones o adición de Michael, es una potente herramienta en síntesis orgánica y un valioso método de producción de intermedios en la síntesis de compuestos de química fina y productos farmacéuticos ${ }^{287}$. En general, la reacción de Michael requiere bases fuertes (entre las más frecuentes hidróxidos de metales alcalinos) o ácidos de Lewis, para activar a los nucleófilos o a los aceptores de Michael, respectivamente ${ }^{288}$. Si bien, la catálisis ideal para esta adición nucleofílica, podría suponer la activación dual simultánea de ambos, electrófilo y nucleófilo por las funciones ácida y básica de dos catalizadores monofuncionales o de uno bifuncional.

El Esquema 7.1 presenta el mecanismo general de la reacción de Michael catalizada por bases, que supone la adición entre un compuesto 1,3-dicarbonílico que actúa como nucleófilo y un compuesto carbonílico $\alpha, \beta$-insaturado como aceptor de Michael.

La desprotonación (1) del compuesto dicarbonílico por parte de la base, genera un carbanión (2) que posee tres estructuras resonantes. El nucleófilo ataca

\footnotetext{
287 Berner O.M., Tesdechi L., Enders D., J.Org.Chem., 2002, 12, 1877.

288 Peter K., Vollhardt C., Schore N.E., Química Orgánica, 2ª Ed., Ediciones Omega: Barcelona, 1996.
} 
al alqueno electrofílico (3) y mediante un proceso de adición conjugada (4) da lugar a un enolato que por abstracción (5) del protón de la base protonada conduce al producto final de la reacción de adición de Michael.

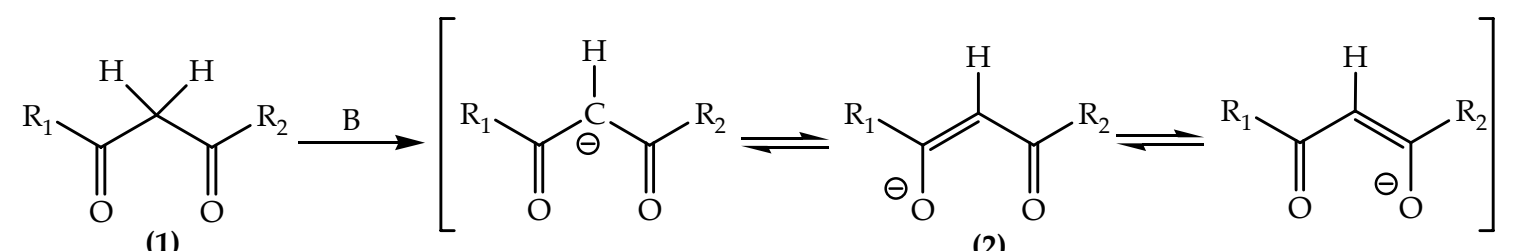

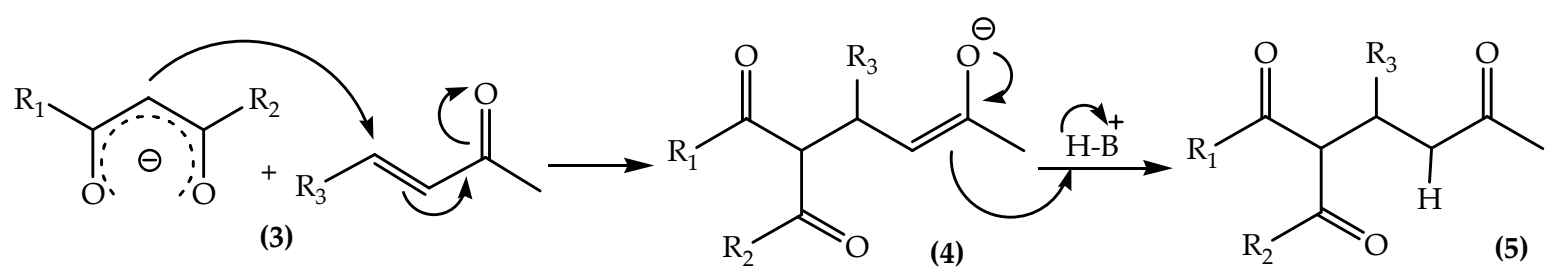

Esquema 7.1.- Mecanismo de reacción general de la adición de Michael entre un nucleófilo y un compuesto carbonílico $\alpha$, $\beta$-insaturado.

Teniendo en cuenta la eficiencia del catalizador bifuncional ácido-base [diamina-A] $\mathrm{BF}_{4}$ en las reacciones de condensación estudiadas hasta el momento, se realizó un estudio del comportamiento del mismo en la adición de Michael de diferentes nucleófilos a compuestos carbonílicos $\alpha, \beta$-insaturados.

Puesto que los aldehídos insaturados son sustratos complicados para la adición de Michael cuando se emplea una base como catalizador, debido a su inestabilidad $289,290,291,292$ en medios básicos, se eligieron diferentes enonas conjugadas y ésteres insaturados como aceptores de Michael. Estos sustratos se enfrentaron a diferentes nucleófilos en presencia del organocatalizador [diamina$\mathrm{A}] \mathrm{BF}_{4}$, y se comparó su actividad y selectividad con la de otras bases de estructura relacionada. En todos los casos, las reacciones se llevaron a cabo en ausencia de disolvente y a temperaturas moderadas.

289 Brunner H., Krumey C., J.Mol.Catal. A: Chem., 1999, 142, 7.

290 Nakajima M., Yamamoto S., Yamaguchi Y., Nakamura S., Hashimoto S., Tetrahedron, 2003, 59,

7307.

${ }^{291}$ Ooi T., Miki T., Taniguchi M., Shiraishi M., Takeuchi M., Marouka K., Angew.Chem.Int.Ed., 2003, $42,3796$.

292 Motoyama Y., Koga K., Kobayashi K., Aoki K., Nishiyama H., Chem.Eur.J., 2002, 2968. 
Como primer ejemplo se eligió la adición de Michael entre la chalcona (1,3-difenil-2-propen-1-ona) y el malononitrilo. El producto de reacción obtenido 2-(3-oxo-1,3-difenil-propil)-malononitrilo, así como derivados de éste, presentan interés farmacológico por su actividad antiparásita ${ }^{293}$ frente a protozoos como la Giardia Iamblia.

Tal y como muestra la Tabla 7.1, el organocatalizador [diamina-A]BF4, da lugar a una excelente actividad y selectividad al producto de adición de Michael. Los otros dos catalizadores, puramente básicos (diamina-A y metilpiperidina) son considerablemente menos activos y selectivos. En los tres casos se obtiene como subproducto el aducto de Knoevenagel entre la chalcona y el malononitrilo.

\section{Adición de Michael sobre chalconas}

\begin{tabular}{|c|c|c|c|c|c|}
\hline Ent. & Catalizador & $\begin{array}{c}t \\
(h)\end{array}$ & $\begin{array}{c}\text { Conversión } \\
(\%)\end{array}$ & $\begin{array}{c}\text { Selectividad } \\
(\%)\end{array}$ & $\begin{array}{c}\text { Rendimiento } \\
(\%)\end{array}$ \\
\hline 1 & [Diamina-A]BF4 & 1 & 99 & 94 & 93 \\
\hline 2 & Diamina-A & 1 & 79 & 58 & 46 \\
\hline 3 & Metilpiperidina & 1 & 85 & 74 & 63 \\
\hline
\end{tabular}

Tabla 7.1.- Adición de Michael sobre chalconas empleando diferentes catalizadores. Condiciones de reacción: Compuesto carbonílico $\alpha, \beta$-insaturado $(2,8 \mathrm{mmol})$, nucleófilo $(2,8 \mathrm{mmol})$, catalizador $(0,28$ $\mathrm{mmol}), \mathrm{T}=80^{\circ} \mathrm{C}$.

Por otra parte, la adición conjugada de tioles a compuestos carbonílicos $\alpha, \beta$-insaturados es una de las estrategias sintéticas más importantes para generar enlaces carbono-azufre ${ }^{294}$, dando lugar a compuestos carbonílicos con una función sulfuro en la posición $\beta$.

Con objeto de estudiar la actividad catalítica del organocatalizador [diamina-A]BF 4 en este tipo de adiciones, se elegió como reacción modelo, la

${ }^{293}$ Montes-Avila J., Díaz-Camacho S., Sicairós F., Delgado F., Bioorganic and Medical Chemistry, 2009, 17, 6780.

${ }^{294}$ Clark J.H., Chem.Rev., 1980, 80, 429. 
adición de Michael entre cetonas cíclicas y tiofenol. Como se puede apreciar en la Tabla 7.2, el catalizador bifuncional es considerablemente más activo y selectivo que el catalizador puramente básico diamina-A. En este caso parece que la mayor basicidad de la diamina-A promueve la autocondensación del tiofenol dando lugar a difenil sulfuro, lo que afecta a la selectividad final del proceso de adición de Michael.

\section{Adición de Michael sobre cicloenonas}

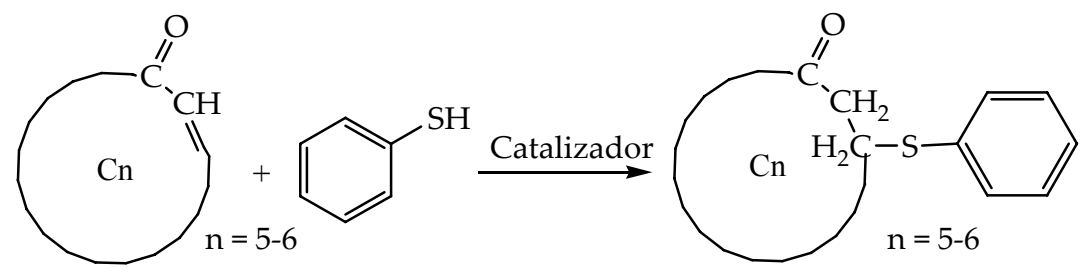

\begin{tabular}{|c|c|c|c|c|c|}
\hline Ent. & Catalizador & Aceptor & $\begin{array}{c}\text { Conversión } \\
(\%)\end{array}$ & $\begin{array}{c}\text { Selectividad } \\
(\%)\end{array}$ & $\begin{array}{c}\text { Rendimiento } \\
(\%)\end{array}$ \\
\hline 1 & {$[$ Diamina-A]BF4 } & & 89 & 100 & 89 \\
\hline 2 & Diamina-A & & 62 & 90 & 56 \\
\hline 3 & [Diamina-A]BF4 & & 92 & 96 & 88 \\
\hline 4 & Diamina-A & & 90 & 87 & 78 \\
\hline
\end{tabular}

Tabla 7.2.- Adición de Michael sobre distintas cicloenonas empleando diferentes catalizadores. Condiciones de reacción: Compuesto carbonílico $\alpha, \beta$-insaturado (aceptor) $(2,8 \mathrm{mmol})$, nucleófilo $(2,8$ $\mathrm{mmol})$, catalizador $(0,28 \mathrm{mmol}), \mathrm{T}=0^{\circ} \mathrm{C}$ y 2 horas de reacción.

Finalmente se estudió la adición de Michael entre nitrometano y metacrilato de metilo. Concretamente, esta reacción tiene interés sintético pues 
supone uno de los pasos de la ruta de síntesis de una serie de fitohormonas, las zeatinas ${ }^{295}$, implicadas en aspectos del crecimiento y desarrollo de las plantas.

En la Tabla 7.3 se presenta el estudio comparativo de diferentes catalizadores básicos. Como se puede observar, aunque todos ellos fueron altamente selectivos, el catalizador bifuncional continúa siendo el más activo, mientras que los catalizadores básicos monofuncionales dan lugar a rendimientos mucho más bajos. En la misma tabla se incluye el resultado descrito en la bibliografía ${ }^{296}$ y obtenido con un catalizador heterogéneo de extremada fuerza básica como es el fluoruro potásico soportado sobre alúmina. Los autores emplean la mezcla de KF/Alúmina/PEG4000 con un gran exceso de nitrometano $(130 \mathrm{mmol})$ y tras cuatro horas de reacción a $70^{\circ} \mathrm{C}$, tan solo se obtiene un $51 \%$ del 2-metil-4-nitrobutanoato de metilo.

\section{Adición de Michael sobre metacrilato de metilo}<smiles></smiles>

\begin{tabular}{cccccc}
\hline Ent. & Catalizador & $\begin{array}{c}\text { tiempo } \\
(\mathbf{h})\end{array}$ & $\begin{array}{c}\mathbf{T} \\
\left({ }^{\circ} \mathbf{C}\right)\end{array}$ & $\begin{array}{c}\text { Selectividad } \\
(\mathbf{\%})\end{array}$ & $\begin{array}{c}\text { Rendimiento } \\
(\mathbf{\%})\end{array}$ \\
\hline 1 & [diamina-A]BF 4 & 1 & 80 & 100 & 70 \\
2 & Diamina A & 1 & 80 & 100 & 48 \\
3 & Metilpiperidina & 1 & 80 & 100 & 61 \\
4 & $\mathrm{KF} / \mathrm{Al}_{2} \mathrm{O}_{3} / \mathrm{PEG} 4000$ & 4 & 70 & 100 & 51 \\
\hline
\end{tabular}

Tabla 7.3.- Adición de Michael sobre metil metacrilato con diferentes catalizadores. Condiciones de reacción: Compuesto carbonílico $\alpha, \beta$-insaturado (aceptor) $(1 \mathrm{mmol})$, nucleófilo $(1 \mathrm{mmol})$, catalizador $(0,1 \mathrm{mmol})$.

En general los resultados obtenidos en las distintas reacciones de adición de Michael estudiadas, apuntan hacia la existencia, también en este caso, de un mecanismo cooperativo entre los centros ácido y básico del organocatalizador, 
que conduce a la estabilización del estado de transición, provocando un aumento de la actividad catalítica. Por otra parte, el hecho de que los centros catalíticos implicados no posean elevada fuerza ácida o básica, es probablemente el responsable de la mayor selectividad observada en algunos casos, con respeto a catalizadores puramente básicos y a la vez con mayor fuerza básica.

Con el propósito de explicar de forma más detallada el mecanismo catalítico de este proceso, se están realizando estudios teóricos adicionales, pero en el momento de la redacción del trabajo todavía no se han concluido.

\section{2}

\section{Reacciones multietapa}

Como se ha demostrado hasta ahora, el catalizador bifuncional [diamina$\mathrm{A}_{\mathrm{BF}}$ es capaz de catalizar eficientemente tanto las reacciones de condensación (Knoevenagel y Claisen-Schmidt) como adiciones de Michael, por lo que se pensó en abordar también el estudio de un proceso multietapa que combinara ambas reacciones utilizando la [diamina- $\mathrm{A}^{\mathrm{B} \mathrm{BF}_{4}}$ como único catalizador del proceso.

En este estudio de planteó la posibilidad de acometer la síntesis de 1,3dinitroalcanos, particularmente los derivados del 2-nitro-1-nitrometilbenceno que se han descrito como agentes estimulantes de la segregación de dopamina ${ }^{297}$ y son compuestos intermedios en la síntesis de fármacos con actividad antidepresiva.

El proceso multietapa propuesto, implicaría en primer lugar, la condensación de Henry entre el benzaldehído y el nitrometano, generando el nitroalqueno correpondiente, que a continuación sufriría la adición nucleofílica de una segunda molécula de nitrometano (adición de Michael)(Esquema 7.4). Esta secuencia de reacciones es lo que en adelante se denominará como proceso multietapa Henry-Michael.

La condensación de Henry es uno de los métodos clásicos de formación de enlaces C-C y consiste en la condensación de nitroalcanos con aldehídos o cetonas en presencia de catalizadores básicos, para dar lugar a nitroalcoholes que posteriormente pueden ser deshidratados a nitroalquenos ${ }^{298}$. 


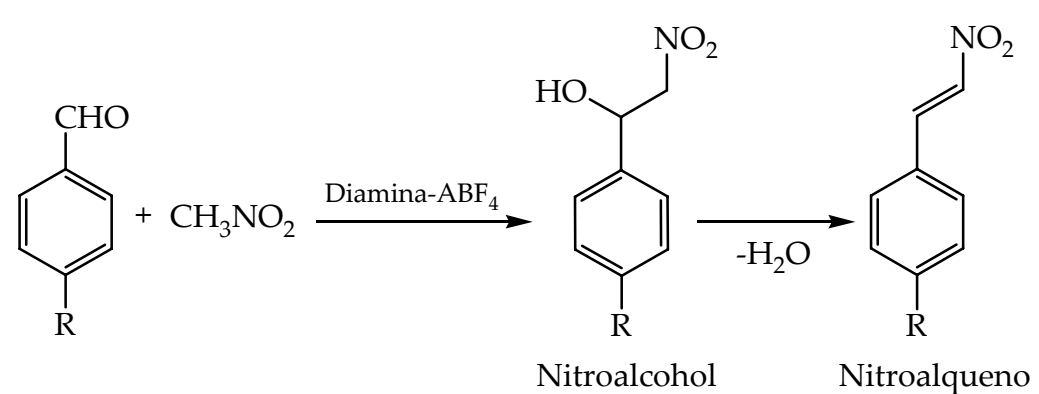

Esquema 7.2.- Esquema básico de condensación de Henry entre el benzaldehído y el nitrometano para dar como producto directo de la condensación el 2-nitro-1-p-alquilfeniletanol (nitroalcohol) y el producto de su deshidratación el 1-alquil-4-((E)-2-nitrovinil)benceno (nitroalqueno).

El mecanismo de la condensación de Henry (Esquema 7.3) es muy similar al de la condensación aldólica, en este caso, la presencia del grupo nitro provoca cierta acidez de los protones localizados en el carbono en $\alpha$, de modo que en presencia de una base ocurre la desprotonación dando lugar a una especie nucleofílica. El ataque que promueve este compuesto al compuesto carbonílico da lugar a un nitroalcohol que, dependiendo del tipo de catalizador empleado y de las condiciones de reacción, puede sufrir la deshidratación dando lugar finalmente a un nitroalqueno.

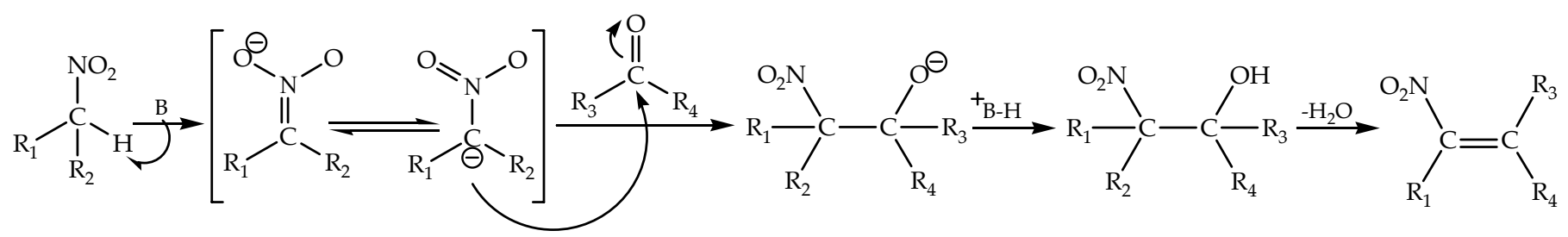

Esquema 7.3.- Mecanismo general de la reacción de Henry entre un nitroalcano y un compuesto carbonílico. El compuesto final del mecanismo es un nitroalqueno formado por deshidratación del nitroalcohol.

Sin embargo, cabe destacar que la síntesis de nitroolefinas $299,300,301$ es a menudo un proceso complejo y por lo general con bajos rendimientos debido a la alta reactividad y fácil generación de productos secundarios de dimerización o polimerización.

${ }^{299}$ Cabrera Escribano F., Alcántara M.P., Gómez-Sánchez A., Tetrahedron Lett., 1988, $29,6001$.

300 Pham-Huu D-P-, Petruosva M., Bemiller J.N., Petrus L., Tetrahedron Lett., 1999, 40, 3053.

${ }^{301}$ Alcántara M.P., Cabrera Escribano F., Gómez-Sánchez A., Dianez M.J., Estrada M.D., López-Castro A., Pérez-Garrido S., Synthesis, 1996, 64. 
Con objeto de estudiar la actividad catalítica de la [diamina-A]BF 4 en este tipo de procesos, la reacción entre benzaldehído y nitrometano se llevó a cabo, en ausencia de disolvente, utilizando un exceso de nitrometano y a temperatura de $50^{\circ} \mathrm{C}$. Tal y como se puede observar en la Tabla 7.4, tras dos horas de reacción se obtuvo la dinitrolefina correspondiente, con un $89 \%$ de rendimiento y un $90 \%$ de selectividad (Entrada 1).

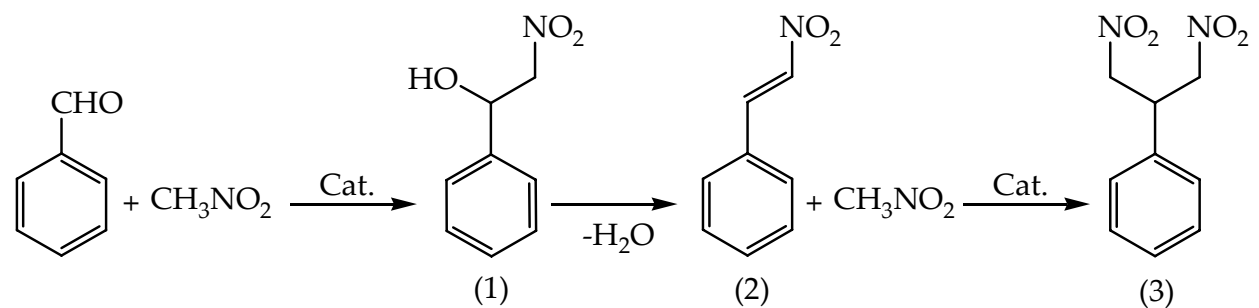

Esquema 7.4.- Esquema del proceso multietapa para la síntesis del 1-(1,3-dinitropropan-2-il)benceno.

\begin{tabular}{|c|c|c|c|c|c|c|}
\hline \multirow[t]{2}{*}{ Ent. } & \multirow[t]{2}{*}{ Catalizador } & \multirow[t]{2}{*}{$\begin{array}{c}\text { Conversión } \\
(\%)\end{array}$} & \multicolumn{3}{|c|}{$\begin{array}{c}\text { Selectividad } \\
(\%)\end{array}$} & \multirow{2}{*}{$\begin{array}{c}\text { Rendimiento } \\
(\%) \\
(3) \\
\end{array}$} \\
\hline & & & (1) & (2) & (3) & \\
\hline 1 & [Diamina-A] $\mathrm{BF}_{4}$ & 99 & - & 10 & 90 & 89 \\
\hline 2 & Diamina-A & 68 & 18 & 3 & 79 & 54 \\
\hline 3 & Metilpiperidina & 28 & 22 & 59 & 19 & 5 \\
\hline 4 & Piperidina & 55 & 25 & 12 & 63 & 34 \\
\hline $5^{[\text {[a] }}$ & $\mathrm{Al}_{2} \mathrm{O}_{3}$ & 87 & 2 & 16 & 82 & 71 \\
\hline
\end{tabular}

Tabla 7.4.- Resultados del proceso multietapa entre el benzaldehído y el nitrometano. Condiciones de reacción: benzaldehído $(2 \mathrm{mmol})$, nitrometano $(37 \mathrm{mmol})$, Catalizador $(1 \mathrm{mmol}), \mathrm{T}=50^{\circ} \mathrm{C}$, tiempo de reacción: $2 \mathrm{~h}$. La conversión se calculó por cromatografía de gases a partir de la cantidad inicial de benzaldehído. El rendimiento se calculó también por cromatografía de gases y a partir de los productos de reacción generados. [a]Las condiciones de reacción con alúmina básica fueron: benzaldehído ( $2 \mathrm{mmol})$, nitrometano $(37 \mathrm{mmol}), \mathrm{Al}_{2} \mathrm{O}_{3}(1 \mathrm{~g}), \mathrm{T}=100^{\circ} \mathrm{C}$, tiempo de reacción: $4 \mathrm{~h}$.

Al comparar estos resultados con los obtenidos por catalizadores semejantes en estructura pero puramente básicos (Entradas 2-4), se aprecia una vez más, que éstos últimos resultan claramente mucho menos activos y sobretodo menos selectivos al dinitrocompuesto (3) que el catalizador bifuncional. Se debe destacar que, el hecho de no observar en la reacción de Henry catalizada por la [diamina-A]BF 4 , el producto de la condensación (1) y sí observarlo con el resto de catalizadores, es una muestra más de la efectividad del sistema bifuncional, que no solo es eficaz con la condensación inicial, sino que además promueve activamente la deshidratación de (1). 
Finalmente, se probó el sistema secuencial con un catalizador heterogéneo de carácter ácido-base como la alúmina, para poder contrastar reactividades de materiales de diferente naturaleza. Tal y como se aprecia en la Tabla 7.4 (Entrada 5), la conversión y la selectividad del catalizador heterogéneo fueron bastante altas, aunque menores que las obtenidas con [diamina- $\mathrm{A}_{\text {] }} \mathrm{BF}_{4}$, sin embargo las condiciones de reacción tuvieron que ser bastante más drásticas ( $100^{\circ} \mathrm{C}$ durante cuatro horas).

La Figura 7.1 muestra la cinética de la reacción multietapa con los cuatro catalizadores homogéneos, como se puede apreciar y pese a que la velocidad inicial de reacción no es especialmente diferente para ninguna de las cuatro aminas, transcurridos los veinte primeros minutos de reacción, la [diamina-A]BF4 se desmarca notablemente de las tres restantes, consiguiendo al final de la reacción, prácticamente un $40 \%$ más de rendimiento.

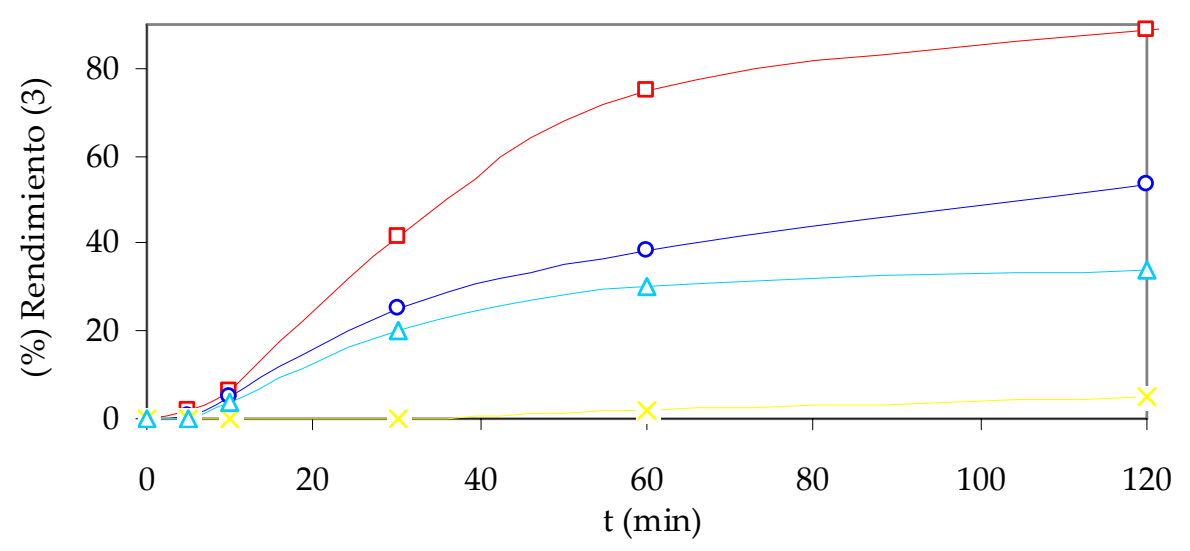

Figura 7.1.- Cinética de la reacción multietapa de Henry-Michael. Se representan los rendimientos al producto final (3) conseguidoa con: [diamina- $\mathrm{A}_{\mathrm{BF}}$ ( $(\mathrm{\square})$, diamina-A (o), piperidina $(\Delta)$ y metilpiperidina $(\mathrm{x})$.

Finalmente, en vista de los excelentes resultados obtenidos, el estudio se extendió a otros benzaldehídos sustituídos (Tabla 7.5). Como se puede observar, la presencia de sustituyentes electroatrayentes disminuye claramente el rendimiento final del dinitrocompuesto, sin embargo la selectividad en todos los casos fue elevada. 
<smiles>[R]c1ccc(C=O)cc1C(=O)O[Na]</smiles>

(1)

(2)

(3)

\begin{tabular}{|c|c|c|c|c|c|c|c|}
\hline \multirow[t]{2}{*}{ Ent. } & \multirow[t]{2}{*}{ Benzaldehído } & \multirow[t]{2}{*}{ Producto } & \multirow[t]{2}{*}{$\begin{array}{l}\text { Conv. } \\
(\%)\end{array}$} & \multicolumn{3}{|c|}{$\begin{array}{c}\text { Selectividad } \\
(\%)\end{array}$} & \multirow{2}{*}{$\begin{array}{c}\text { Rend. } \\
(\%) \\
(3)\end{array}$} \\
\hline & & & & (1) & $(2)$ & (3) & \\
\hline 1 & 4-Metoxibenzaldehído & & 99 & - & 19 & 81 & 80,2 \\
\hline 2 & 4-Clorobenzaldehído & & 72 & - & 16 & 84 & 60,5 \\
\hline 3 & 4-Nitrobenzaldehído & & 68 & 4 & 22 & 74 & 50,3 \\
\hline
\end{tabular}

Tabla 7.5.- Resultados del proceso multietapa entre benzaldehídos sustituídos en para y el nitrometano. Condiciones de reacción: benzaldehído (2 mmol), nitrometano (37 mmol), Catalizador (1 $\mathrm{mmol}), \mathrm{T}=50^{\circ} \mathrm{C}$, tiempo de reacción: $4 \mathrm{~h}$. La conversión se calculó por cromatografía de gases a partir de la cantidad inicial de benzaldehído. El rendimiento se calculó también por cromatografía de gases y a partir de los productos de reacción generados. 


\section{3}

\section{Conclusiones}

1.- Se ha demostrado a lo largo de este capítulo, que el organocatalizador bifuncional [diamina- $\mathrm{A} \mathrm{BF}_{4}$ es activo para la adición de Michael entre varios compuestos nucleófilos y compuestos carbonílicos $\alpha, \beta$-insaturados.

2.- La comparación de la actividad del catalizador bifuncional con la que muestran cualquiera de los otros catalizadores monofuncionales, pone de manifiesto la superior eficacia del organocatalizador bifuncional. Estos resultados pueden ser atribuidos de nuevo a la existencia de un efecto cooperativo entre el centro ácido-base que opera estabilizando el estado de transición y aumentando así la velocidad de reacción en este tipo de adiciones.

3.- El catalizador bifuncional [Diamina-A]BF 4 ha resultado ser altamente activo y selectivo en la reacción multietapa que implica como primer paso una condensación de Henry seguida de una adición de Michael. Siguiendo este protocolo sintético se han obtenido diferentes dinitroalcanos con buenos rendimientos y selectividades. 

Capítulo VIII:

Procedimientos experimentales 

8.1

\title{
Reactivos generales
}

8.1.1

\section{Gases}

Los gases fueron suministrados por Abelló Linde S.A. Gases Técnicos y tienen las siguientes características:

$$
\begin{array}{ll}
\propto & \text { Aire }\left(79 \% \mathrm{~N}_{2}, 21 \% \mathrm{O}_{2}\right), 99,9995 \% . \\
\propto & \text { Helio, 99,999\%. } \\
\propto & \text { Hidrógeno, 99,999\%. } \\
\propto & \text { Nitrógeno, 99,999\%. }
\end{array}
$$

\subsection{2}

\section{Disolventes}

\author{
* Acetona de grado HPLC, Scharlau. \\ × Acetona-d6, 99,9 átomos \% D, Aldrich. \\ Acetonitrilo anhidro, 99,8\%, Aldrich. \\ × Acetonitrilo de grado HPLC, Scharlau. \\ A Acetonitrilo-d 3 , 99,8 átomos \% D, Aldrich. \\ × Agua MiliQ, Millipore. \\ × Agua-d2, 99,9 átomos \% D, Aldrich. \\ × Cloroformo-d, 99,8 átomos \% D, Aldrich. \\ × Diclorometano, 99,5\%, Scharlau. \\ a Dimetilformamida, 99\%, Aldrich. \\ × Dimetilsulfóxido-d6, 99,9 átomos \% D, Aldrich. \\ × Etanol de grado HPLC, Merck. \\ ¿ Éter dietílico, 99\%, Scharlau. \\ × Éter dietílico anhidro, 99,7\%, Aldrich. \\ a Metanol anhidro, 99,8\%, Aldrich. \\ × Piridina, 99\%, Aldrich. \\ × Piridina-d5, 99,95 átomos \% D, Euriso-top.
}




\subsection{3}

\section{Líquidos iónicos comerciales}

Todos los líquidos iónicos comerciales empleados en esta tesis fueron suministrados por Solvent Innovation.

x Hexafluorofosfato de 1-Butil-3-Metilimidazolio ([Bmim] $\left.\mathrm{PF}_{6}\right), 99 \%$.

\exafluorofosfato de 1-Butil-2,3-Dimetilimidazolio ([Bmmim] $\left.\mathrm{PF}_{6}\right)$, $99 \%$.

\exafluorofosfato de 4-Metil-N-Butilpiridinio ([Mbpy] $\left.\mathrm{PF}_{6}\right), 98 \%$.

× Tetrafluoroborato de 1-Butil-3-Metilimidazolio ([Bmim] $\left.\mathrm{BF}_{4}\right), 99 \%$.

\subsection{4}

Reactivos

Acetoacetato de etilo, 99\%, Aldrich.

Acetofenona, 99\%, Aldrich.

A Ácido clorhídrico 2M solución en éter dietílico, Aldrich.

x Ácido clorhídrico 37\% en agua, Aldrich.

× Ácido fluorhídrico, 50\%, Aldrich.

× Ácido Molibdatofosfórico hidrato, puriss, Merck.

a Ácido tetrafluorobórico 48\% en agua, Aldrich.

× Ácido tetrafluorobórico complejo éter dietílico 48\%, Aldrich.

× Benzaldehído redestilado, 99,5\%, Aldrich.

$\propto$ Bromobenceno, 99\%, Aldrich.

x 4-Bromo-4-fluorobenceno, 99\%, Across organics.

× 1-Butilimidazolio, 98\%, Aldrich.

\ Carbonato potásico, 98\%, Aldrich.

a Carbono activo, 99,95\%, Aldrich.

a Trans-Chalcona, 97\%, Aldrich.

x Cianoacetato de etilo, $98 \%$, Aldrich.

× Ciclododecanona, 99+\%, Aldrich.

× Clorhidrato de hidroxilamina, 99\%, Aldrich.

4-Clorobenzaldehido, 97\%, Aldrich.

× Complejo ácido tetrafluorobórico-éter dietílico, 48\%, Aldrich.

× Decano, 99\%, Aldrich.

a Dodecano, 99+\%, Aldrich. 


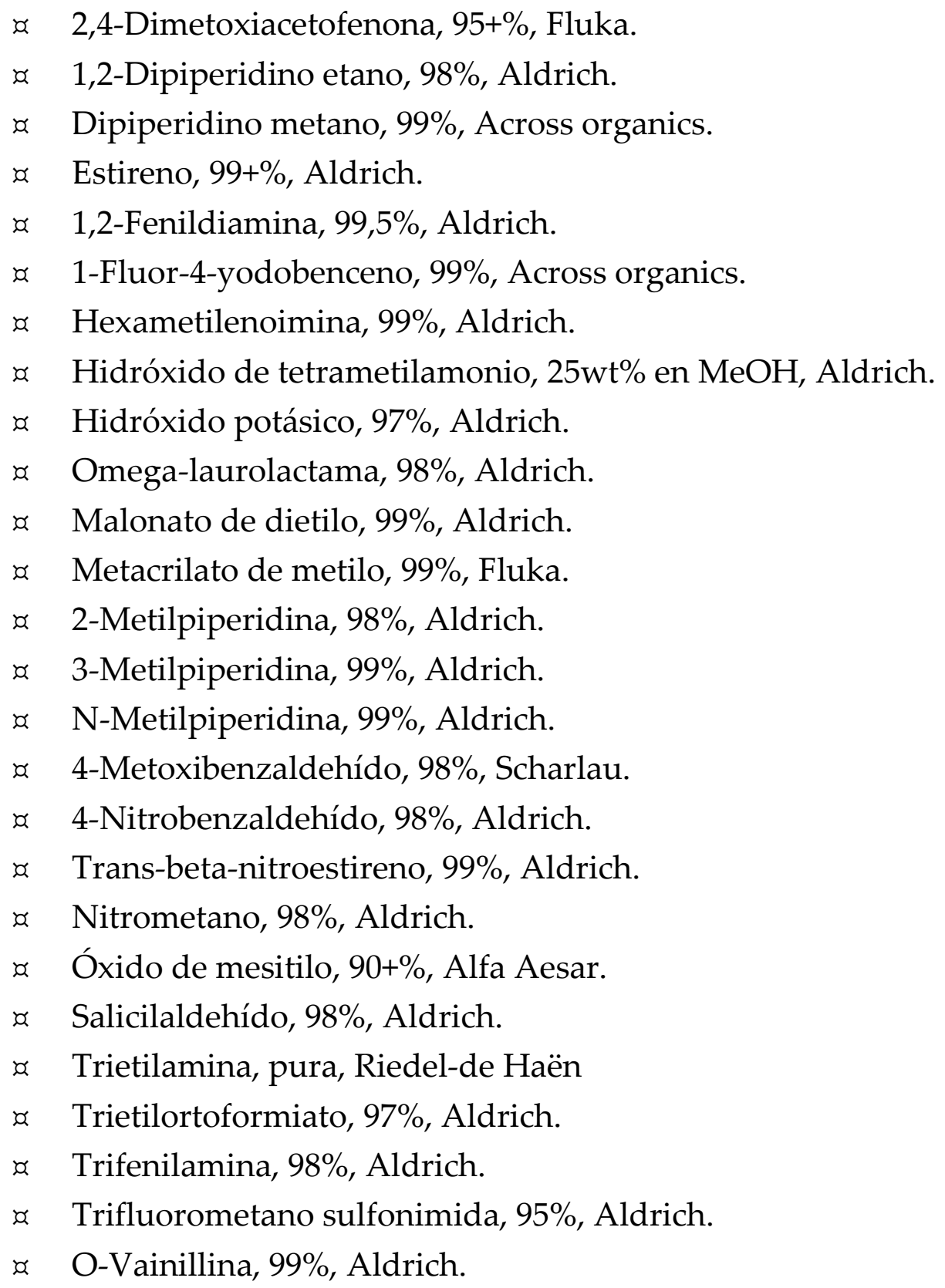




\section{2}

\section{Técnicas de caracterización}

\subsection{1}

\section{Análisis químico}

Esta técnica de análisis se ha empleado tanto para muestras de producto de reacción como para catalizadores. En ambos casos se llevaron a cabo dos técnicas: El análisis elemental, propiamente dicho, para la determinación del contenido orgánico (carbono, hidrógeno, nitrógeno y azufre) y la espectrofotometría de absorción atómica.

× La determinación de contenido orgánico de catalizadores y productos se lleva a cabo en un analizador elemental Fisons EA 1108 CHN-S-0 donde tiene lugar la combustión instantánea de la muestra a $1020^{\circ} \mathrm{C}$, usando como gas portador helio y en presencia de oxígeno. Las muestras no necesitan un tratamiento previo y como estándar para la cuantificación se emplea sulfanilamida.

× La espectrofotometría de absorción atómica $(\mathrm{AAB})$ se basa en la medida de la radiación absorbida por los átomos de la muestra en estado fundamental. La radiación incidente procede de una lámpara de cátodo constituido por un tubo sellado en cuyo interior se encuentra el tungsteno y un cátodo hueco construido con el metal que se está analizando, en este trabajo se determinaron principalmente paladio, molibdeno y vanadio.

La atomización de la muestra se produce por aspiración de una disolución acuosa de sales inorgánicas en la llama de un quemador, provocando la descomposición de las moléculas presentes en las partículas gaseosas.

La preparación previa que deben sufrir los materiales a analizar, consiste en una calcinación de la muestra de alrededor de $30 \mathrm{mg}$ de peso a $950^{\circ} \mathrm{C}$ durante 3 horas y la posterior disgregación con una mezcla en peso 2:1 de $\mathrm{HF}$ (sol. Acuosa al $40 \%$ ) y $\mathrm{HNO}_{3}$ (sol. acuosa al $60 \%$ ) en botes de polipropileno a $60^{\circ} \mathrm{C}$ durante una noche. Finalmente las disoluciones se enrasan con agua MiliQ hasta alcanzar un volumen de $50 \mathrm{ml}$. El equipo empleado fue un Varian SpectrAA-10 Plus. 


\subsection{2}

\section{Análisis termogravimétrico (TGA)}

Esta técnica de análisis de muestras, permite determinar y relacionar entre sí, la pérdida de peso que tiene lugar durante el calentamiento de la muestra a temperatura programada, así como la naturaleza endotérmica o exotérmica de la misma. De este modo se pueden conocer la pérdida de peso asociada al agua y al material orgánico, pero también los cambios estructurales de una fase cristalina, ya que éstos implican procesos exotérmicos sin pérdida de peso asociada.

Los análisis se llevaron a cabo en una termobalanza TGA/SDTA851 de Mettler Toledo, empleando crisoles de platino y un termopar del tipo S (Rh-Pt, $10 \% \mathrm{Pt}$ ). La cantidad de muestra utilizada es de $20 \mathrm{mg}$ y como material de referencia se usó caolín previamente calcinado a $1100^{\circ} \mathrm{C}$. Las medidas se tomaron dentro del rango entre $20^{\circ} \mathrm{C}$ y $800^{\circ} \mathrm{C}$, con un flujo de nitrógeno de $30 \mathrm{~mL} / \mathrm{min}$ y una velocidad de calentamiento de $10^{\circ} \mathrm{C} / \mathrm{min}$.

Esta técnica se empleó para determinar el contenido en agua y en materia orgánica de las muestras de polioxometalatos, polioxometalatos sustituidos con líquidos iónicos así como en el estudio de estabilidad térmica de los líquidos iónicos bifuncionales y sus precursores.

\subsection{3}

\section{Espectroscopía de resonancia magnética nuclear (RMN)}

La espectroscopía de resonancia magnética nuclear (RMN) se basa en la medida de la absorción de radiación electromagnética en la región de las radiofrecuencias aproximadamente de 4 a $600 \mathrm{MHz}$. En contraste con la absorción ultravioleta, visible e infrarroja, en el proceso de absorción están implicados los núcleos de los átomos. En este caso es necesario colocar el analito en un intenso campo magnético, de modo que los estados energéticos del núcleo adquieran diferente energía y den lugar a la absorción.

Las bases teóricas de la espectroscopía de resonancia magnética nuclear sugieren que ciertos núcleos atómicos pueden tener spin y momento magnético y 
que por lo tanto al ser expuestos a un campo magnético de cierta intensidad se producirá un desdoblamiento de sus niveles energéticos ${ }^{302}$.

La mayor parte de los espectrómetros son de pulsos, aunque también existe la técnica de irradiación continua. En el primer caso el emisor está compuesto por un generador de señales sinusoidales (sintetizador de radiofrecuencia), un generador de señales cuadradas (pulsos), un modulador (donde se produce la mezcla de las dos señales anteriores) y un amplificador de potencia. La señal sinusoidal finalmente amplificada tiene una amplitud de 2000 voltios y una duración de varios $\mu$ sec. La señal amplificada es enviada a la bobina de un circuito resonante LC.

Durante la irradiación la muestra recibe energía y durante la recepción la muestra se convierte en el emisor de radiofrecuencia de baja intensidad. La señal emitida por la muestra es recibida por la bobina y enviada al detector a través de un preamplificador. En el detector la señal de radiofrecuencia se transforma en una señal de audio que se transfiere a la estación de datos donde se procede a su análisis, obteniéndose finalmente el espectro de resonancia magnética nuclear.

Cuando esta técnica se aplica sobre muestras sólidas da lugar a bandas anchas y poco resueltas debido a interacciones anisotrópicas de tipo bipolares y cuadrupolares. Para aumentar la resolución del espectro, se aplica la técnica de ángulo mágico (MAS), con la que la muestra es girada a gran velocidad entorno a un eje inclinado $54^{\circ} 44^{\prime}$ con respecto al campo magnético ( $\beta \mathrm{o}$ ) de modo que la línea detectada estará centrada en el valor de desplazamiento químico isotrópico (бiso).

Las muestras analizadas por esta técnica se corresponden principalmente con el capítulo de la transposición de Beckmann en líquidos iónicos y los de los líquidos iónicos bifuncionales. Al trabajar con sustancias solubles en disolventes deuterados y tener una composición casi enteramente orgánica, las señales obtenidas mediante resonancia magnética nuclear dan una información especialmente detallada de la estructura de las moléculas objeto de estudio., habiéndose hecho los espectros necesarios para llegar a hacer una correcta aignación de señales Los espectros de RMN de muestras en disolución se realizaron en un espectrómetro Bruker AV $300(300 \mathrm{MHz})$ Los núcleos estudiados fueron en el caso de la transposición de Beckmann: ${ }^{1} \mathrm{H},{ }^{13} \mathrm{C},{ }^{31} \mathrm{P},{ }^{19} \mathrm{~F}$. En el caso de

302 Becker E.D., High resolution NMR, Ed: Academic Press. Nueva York, 1980. 
los catalizadores bifuncionales fueron: ${ }^{1} \mathrm{H},{ }^{13} \mathrm{C}$. Las disoluciones de las muestras se hicieron en Acetona, Cloroformo, Metanol y Dimetilsulfóxido deuterados.

\subsection{4}

\section{Espectroscopía infrarroja por transformada de Fourier (FT-IR)}

La espectroscopía infrarroja (IR) estudia la interacción entre la materia y la radiación infrarroja, correspondiente a la región del espectro electromagnético que abarca las longitudes de onda entre 0.7 y $1000 \mu \mathrm{m}^{303}$. La espectroscopia de IR es sensible a la presencia de grupos funcionales en una molécula, lo que implica que reacciona de forma semejante ante la presencia de fragmentos estructurales con propiedades químicas comunes. La característica principal de esta espectroscopia es que permite identificar especies químicas a través de la determinación de la frecuencia de vibración (número de ondas) de los distintos grupos funcionales. La intensidad de las bandas de absorción varía según el grupo funcional y es tanto mayor cuanto mayor es la variación del momento dipolar eléctrico del grupo durante la vibración, de modo que las bandas debidas a los grupos más polares, en principio, son más intensas.

La técnica de transformada de Fourier se aprovecha de las posibilidades que brindan las nuevas tecnologías de almacenamiento y procesamiento de grandes cantidades de datos, haciendo un registro simultáneo de todas las frecuencias del espectro IR por parte del detector. El procedimiento consiste en transformar inicialmente el dominio de frecuencias irradiadas en dominio de tiempos y tras el paso de la radiación por la muestra se vuelve a convertir el interferograma (una función del tiempo) en un espectro, mediante la transformación de Fourier (en definitiva se vuelve a un dominio de frecuencias) $)^{304}$.

Mediante esta técnica se analizaron algunos materiales del cuarto capítulo, en concreto el heteropoliácido de molibdeno y vanadio, así como el material obtenido por intercambio con líquidos iónicos. En cuanto a los capítulos de líquidos iónicos bifuncionales, esta técnica se utilizó con el objetivo de determinar los grupos funcionales que poseían las moléculas que se emplearon

\footnotetext{
${ }^{303}$ Nakamoto K., Infrared and Raman spectra of inorganic and coordination compounds. Ed: Wiley, Chischester, 1997.

${ }^{304}$ Hesse M., Meier H., Zeeh B., M,Spektroskopische Methoden in der organischen Chemie. Ed:

Thieme, Nueva York, 1995.
} 
como catalizadores y estudiar cómo podían variar según se empleaban en distintos procesos. Para el correcto análisis de las muestras, se prepararon pastillas de $\mathrm{KBr}$ con las sustancias a analizar. Los espectros se registraron en un equipo Nicolet 710.

\section{2 .5}

Técnicas de Microscopía electrónica de barrido (SEM) y de transmisión (TEM)

La microscopía electrónica ${ }^{305}$, es la técnica apropiada para la determinación de la morfología y distribución del tamaño de partícula de los materiales sólidos sintetizados.

El funcionamiento básico del microscopio electrónico de barrido se basa en la interacción de un haz de electrones focalizado a través de un sistema de lentes magnéticas con la superficie de la muestra. La interacción da lugar a distintos fenómenos: producción de electrones Auger, electrones secundarios, electrones retrodispersados, rayos $X$, etc. Las señales de los electrones secundarios y de los retrodispersados permiten la observación de una imagen directa de la zona enfocada.

Las medidas de microscopía electrónica de barrido se llevaron a cabo con un microscópio JEOL JSM-6300 provisto de un sistema de microanálisis por energía dispersiva Oxford Instruments LINK-ISIS.

En el caso de la microscopía electrónica de transmisión (TEM), la imagen final que se observa de la muestra (dispuesta en forma de una capa ultrafina), es debida a los electrones que la atraviesan.

Los estudios de microscopía electrónica de transmisión se realizaron sobre las muestras de POM, POM-IL, POM-Pd y POM-IL-Pd (tratados íntegramente en el capítulo cuarto de esta tesis) se llevaron a cabo en un microscopio JEOL2010F operando a $200 \mathrm{kV}$ tanto en modo STEM (Scanning Transmission Electron Microscopy) como HREM (High Resolution Electron Microscopy). El microscopio tiene una resolución estructural de 0,19 nm y permite desarrollar análisis de alta resolución espacial. El análisis cristalográfico de fases se realizó sobre la base de transformadas de Fourier aplicadas en pequeñas regiones seleccionadas de las imágenes HREM. Las imágenes STEM se obtuvieron empleando un detector HAADF (High Angle Annular Dark Field). 


\subsection{6}

\section{Difracción de Rayos X}

Es una técnica de muy alta fiabilidad para dilucidar estructuras cristalinas por su precisión y debido a la experiencia acumulada durante décadas de utilización. Las limitaciones de esta se deben a la necesidad de trabajar con sistemas cristalinos, por lo que no es aplicable a disoluciones, a sistemas amorfos o a gases. Sin embargo, se puede trabajar con monocristales o con polvo microcristalino, consiguiéndose diferentes datos en ambos casos. Para la resolución de los parámetros de la celda unidad puede ser suficiente la difracción de rayos $X$ en polvo, mientras que para una dilucidación precisa de las posiciones atómicas es conveniente la difracción de rayos $\mathrm{X}$ en monocristal.

Los rayos $X$ son una forma de radiación electromagnética de elevada energía y pequeña longitud de onda. Cuando un haz de rayos $X$ incide en un material sólido, parte del haz se dispersa en todas direcciones a causa de los electrones asociados a los átomos o iones que encuentra en el trayecto, pero el resto del haz puede dar lugar al fenómeno de difracción de rayos $X$, que se dará si existe una disposición ordenada de átomos y si se cumplen una serie de condiciones determinadas por la Ley de Bragg, que relaciona la longitud de onda de los rayos $\mathrm{X}$ y la distancia entre los átomos del material, con el ángulo de incidencia del haz difractado. Si no se cumple la ley de Bragg, la interferencia es de naturaleza no constructiva y el campo del haz difractado es de muy baja intensidad y por lo tanto la determinación no será válida.

Las estructuras del polioxometalato (POM) así como del compuesto híbrido POM-IL, de los que se obtuvo monocristales, se resolvieron con un difractómetro Bruker APEXII a baja temperatura $\left(-173^{\circ} \mathrm{C}\right)$.

\subsection{7}

\section{Espectroscopía fotoelectrónica de absorción de Rayos X: EXAFS y XANES}

Los rayos $\mathrm{X}$ son útiles para caracterizar los sólidos y sus estructuras. Cuando esta radiación es absorbida por la materia, se dice que se genera una interacción inelástica y produce transiciones electrónicas de los niveles internos de los átomos. Una muestra puede responder de distintas formas a la absorción 
de rayos $\mathrm{X}$, lo que origina un conjunto de técnicas relacionadas que pueden dar información complementaria.

El análisis del espectro de energías absorbidas por la muestra da lugar a las técnicas EXAFS (Extended X-ray Absorption Fine Structure) y XANES (X-ray Absorption Fine Structure).

La técnica EXAFS analiza las variaciones en los bordes de absorción de los diferentes elementos. No necesita orden periódico a larga distancia por eso puede emplearse con materiales amorfos o sistemas muy complejos. Experimentalmente la señal de absorción se mide en transmisión, analizando la relación entre la intensidad incidente y la transmitida mientras va cambiando las energías de las radiaciones, que provienen de un anillo sincrotrón, y que inciden sobre la muestra. Del análisis de estas modulaciones se puede obtener información sobre distancias de enlace y entornos de coordinación de un elemento determinado. Es una técnica menos precisa que la difracción de rayos $\mathrm{X}$ pero tiene la ventaja de poder ser empleada para el estudio de gases, líquidos y sólidos amorfos.

La técnica XANES está muy relacionada con EXAFS, pero en este caso solo se analiza la zona de absorción justo después del borde y permite estudiar los estados de oxidación de los distintos elementos, especialmente de los metales de transición.

Ambas técnicas fueron empleadas para caracterizar todas las muestras de POM, POM-IL, POM-Pd y POM-IL-Pd.

Los experimentos de absorción de rayos $\mathrm{X}$ en las proximidades del umbral K del Pd, se realizaron en el beamline ${ }^{306}$ (BM29) de las instalaciones del sincrotrón de radiación europeo (ESRF) en modo de fluorescencia. El monocromador estaba equipado con dos cristales planos de Si (111) y el rechazo de armónicos se logró utilizando espejos recubiertos de Rh colocados tras el monocromador. La señal de fluorescencia se adquirió con un multicanal Camberra Ge 13-element ${ }^{307}$, tomando muestras en el rango de la señal de fluorescencia del $\mathrm{Pd} \mathrm{K \alpha}$ y aplicando las correcciones pertinentes de los tiempos muertos y de vida útil. Para la sección XANES de los espectros se consideró un paso de muestreo de 0,3 eV mientras que para la sección EXAFS el paso de

\footnotetext{
306 Filipponi A., Borowski M., Bowron D.T., Ansell S., Di CiccoA., De Panfilis S., Itie J.P., Rev.Sci. Instrum., 2000, 71, 2422.

${ }^{307}$ Cramer S., Tench O., Yocum M., George G., Nucl. Instrum. Methods Phys. Res., Sect. A, 1988, 266, 586.
} 
muestreo fue de $0,025 \AA^{-1}$, con un tiempo de integración de 3 s/punto. La extracción de la función $\chi(\mathrm{k})$ se realizó empleando el programa Klementev ${ }^{308}$. La fase y las amplitudes se calcularon con el código ${ }^{309}$ FEFF6, utilizando como base la estructura del PdO resuelta por difracción ${ }^{310}$ de rayos $\mathrm{X}$. A las funciones $\mathrm{k}^{2} \chi(\mathrm{k})$ se les aplicó las transformada de Fourier en el intervalos $\Delta \mathrm{k}=3,00-12,00 \AA^{-1}$. Los ataques se realizaron en el espacio $\mathrm{R}$ en un rango de $\Delta \mathrm{R}=1,00-4,00 \AA$.

\subsection{8}

\section{Otras técnicas de caracterización}

* Determinación de densidad. Se llevó a cabo utilizando un picnómetro de helio Accupyc 1330, las medidas se hicieron a $30^{\circ} \mathrm{C}$ (capacidad de celda: $\left.1 \mathrm{~cm}^{-1}\right)$.

^ Determinación de la conductividad. Las medidas de conductividad iónica se desarrollaron en un conductómetro Orion-160 (modelo de celda de conductividad 016010; $\mathrm{K}$ (constante de celda $=0,609 \mathrm{~cm}^{-1}$ ); valores de referencia : $\mathrm{H}_{2} \mathrm{O}$ Milli $\mathrm{Q} \sigma\left(20^{\circ} \mathrm{C}\right): 1 \mu \mathrm{S} \mathrm{cm} \mathrm{cm}^{-1}$.

a Contenido en $\mathrm{H}_{2} \mathrm{O}$. Los análisis se llevaron a cabo empleando el método Karl Fischer en un equipo METROHM 702 SM Titrino.

« Contenido en Boro. Se determinó por ICP-OES (inductively coupled plasma optical emision spectrometer) en un equipo Varian 715-ES y en combinación con espectroscopía de resonancia magnética de ${ }^{11} \mathrm{~B}$.

* Punto de fusión. Se determinó con un aparato Stuart modelo SMP3.

8.3

\section{Técnicas de identificación y cuantificación de productos}

Los análisis para identificar cada uno de los productos de las reacciones realizadas se llevaron a cabo mediante un espectrómetro de masas conectado a una columna de cromatografía de gases (GC-MS). El aparato empleado fue un espectrómetro de Agilent Technologies $6890 \mathrm{~N}$ acoplado a un detector selectivo de masas de Agilent Technologies 5973N.

\footnotetext{
308 Klementev K.V., Nucl. Instrum. Methods Phys. Res., Sect. A, 2000, 448, 299.

${ }^{309}$ Ankudinov A.L., Conradson S.D., de Leon J.M., Rehr J.J., Phys. Rev. B, 1998, 57, 7518.

310 Moore W.J., Pauling L., J. Am. Chem. Soc., 1941, 63, 1392.
} 
Cuando la espectrometría de masa no dio información suficientemente concisa y los productos de reacción fueron correctamente aislados, se empleó espectrometría de resonancia magnética nuclear de líquidos. Los espectros de ${ }^{1} \mathrm{H}$ $y{ }^{13} \mathrm{C}$ se procesaron en un instrumento Bruker Avance con una frecuencia de 300 MHz. Usando distintos disolventes deuterados.

La determinación de la masa exacta de determinados compuestos se realizó mediante espectrometría de masa por ionización de moléculas mediante bombardeo con átomos rápidos (MS-FAB). Los análisis se llevaron a cabo en un espectrómetro de masas de sector magnético y alta resolución VG-Autospec (Waters).

Los análisis de cuantificación se realizaron en un cromatógrafos de gases Varian 3900 equipado con una columna capilar TRB $5(30 \mathrm{~m} \times 0,25 \mathrm{~mm} \times 0,25 \mu \mathrm{m})$ y un detector FID.

8.4

\section{Estudios computacionales}

Los cálculos incluidos en el estudio teórico del mecanismo de reacción están basados en la teoría del funcional de la densidad (DFT) y se llevaron a cabo utilizando el programa de cálculo Gaussian 03 ${ }^{311}$. Se utilizaron el funcional de intercambio híbrido de Becke (B3) y el funcional de correlación de Perdew y Wang (PW91) con la función de base standard 6-31G(d,p). Se optimizó la geometría de todas las especies implicadas en el mecanismo, incluyendo reactivos, productos, intermedios de reacción y estados de transición, y se caracterizó la naturaleza de los puntos estacionarios encontrados en la superficie

311 Gaussian 03, Revision B.04, Frisch, M. J.; Trucks, G. W.; Schlegel, H. B.; Scuseria, G. E.; Robb, M. A.; Cheeseman, J. R.; Montgomery, Jr., J. A.; Vreven, T.; Kudin, K. N.; Burant, J. C.; Millam, J. M.; Iyengar, S. S.; Tomasi, J.; Barone, V.; Mennucci, B.; Cossi, M.; Scalmani, G.; Rega, N.; Petersson, G. A.; Nakatsuji, H.; Hada, M.; Ehara, M.; Toyota, K.; Fukuda, R.; Hasegawa, J.; Ishida, M.; Nakajima, T.; Honda, Y.; Kitao, O.; Nakai, H.; Klene, M.; Li, X.; Knox, J. E.; Hratchian, H. P.; Cross, J. B.; Bakken, V.; Adamo, C.; Jaramillo, J.; Gomperts, R.; Stratmann, R. E.; Yazyev, O.; Austin, A. J.; Cammi, R.; Pomelli, C.; Ochterski, J. W.; Ayala, P. Y.; Morokuma, K.; Voth, G. A.; Salvador, P.; Dannenberg, J. J.; Zakrzewski, V. G.; Dapprich, S.; Daniels, A. D.; Strain, M. C.; Farkas, O.; Malick, D. K.; Rabuck, A. D.; Raghavachari, K.; Foresman, J. B.; Ortiz, J. V.; Cui, Q.; Baboul, A. G.; Clifford, S.; Cioslowski, J.; Stefanov, B. B.; Liu, G.; Liashenko, A.; Piskorz, P.; Komaromi, I.; Martin, R. L.; Fox, D. J.; Keith, T.; AlLaham, M. A.; Peng, C. Y.; Nanayakkara, A.; Challacombe, M.; Gill, P. M. W.; Johnson, B.; Chen, W.; Wong, M. W.; Gonzalez, C.; and Pople, J. A.; Gaussian, Inc., Wallingford CT, 2004. 
de energía potencial (mínimos o estados de transición) mediante cálculos de frecuencias.

8.5

Preparación de catalizadores

8.5.1

Materiales derivados de sales de Keggin

\subsubsection{Sintesis de $\mathrm{H}_{5} \mathrm{PO}_{40} \mathrm{~V}_{2} \mathrm{MO}_{10} \cdot 27 \mathrm{H}_{2} \mathrm{O}$ (POM)}

La sal de Keggin de molibdeno y vanadio se preparó siguiendo el método descrito por Stobbe-Kremers ${ }^{312}$ y col. Así, 24,4 g de $\mathrm{NaVO}_{3}(0,2$ mols) se disolvieron en $100 \mathrm{~mL}$ de agua desionizada a $100^{\circ} \mathrm{C}$. Poco a poco se fue adicionando una disolución de $7,1 \mathrm{~g}$ de $\mathrm{Na}_{2} \mathrm{HPO}_{4} \cdot 2 \mathrm{H}_{2} \mathrm{O} \quad(0,04$ mols) en $100 \mathrm{~mL}$ de agua. Tras enfriar la mezcla a temperatura ambiente se adicionaron $5 \mathrm{~mL}$ de ácido sulfúrico concentrado haciendo que la disolución se volviera roja. A continuación 121 g Na2 $\mathrm{MoO}_{4} \cdot 2 \mathrm{H}_{2} \mathrm{O}(0,5$ mols) disueltos en $200 \mathrm{~mL}$ de agua se adicionaron a dicha disolución. La mezcla se agitó vigorosamente mientras se adicionaban $85 \mathrm{~mL}$ más de ácido sulfúrico gota a gota. Finalmente la disolución se enfrió de nuevo a temperatura ambiente. Al POM (Polioxometalato) se adicionaron $500 \mathrm{~mL}$ de éter dietílico, lo que provocó la formación de una segunda fase contenedora del complejo POM-eterato, que se separó y evaporó. El producto resultante se disolvió de nuevo en agua para luego recristalizarlo durante cinco días en un desecador y en presencia de ácido sulfúrico, dando como resultado grandes cristales de color rojo anaranjado. Absorción Atómica: Calculado: 1,4\% P, 44,0\% Mo, 4,6\% V. Analizado: 1,8\% P, 42,3\% Mo, 4,4\% V. TGA: 27 moléculas de $\mathrm{H}_{2} \mathrm{O}$.

\subsubsection{Sintesis de $[\mathrm{bmim}]_{4} \mathrm{HPO}_{40} \mathrm{~V}_{2} \mathrm{Mo}_{10}$ (POM-IL)}

4,23 $\mathrm{g} \mathrm{H}_{5} \mathrm{PO}_{40} \mathrm{~V}_{2} \mathrm{Mo} \mathrm{Mo}_{10} 27 \mathrm{H}_{2} \mathrm{O}(2,5 \mathrm{mmol})$ se disolvieron en $10 \mathrm{~mL}$ de agua. Por otra parte, 2,88 $\mathrm{g}$ [bmim] $\mathrm{PF}_{6}(10 \mathrm{mmol})$ se disolvieron en 5 $\mathrm{mL}$ de acetona. La disolución incolora del líquido iónico se adicionó gota 
a gota sobre la disolución anaranjada del POM, durante 20 minutos y con agitación vigorosa, dando como resultado una suspensión de color naranja. Terminada la adición, la mezcla se agitó durante 30 minutos más y posteriormente se filtró a vacío con un filtro de membrana de nailon. El sólido naranja intenso se dejó secar a vacío durante una hora. Análisis elemental: Calculado: 16,1\% C, 4,8\% N, 2,6\% H. Analizado: $15,9 \%$ C, 5,0\% N, 2,7\% H. Absorción atómica: Calculado: 41\% Mo, 4,0\% V. Analizado: $40,8 \% \mathrm{Mo}, 4,4 \% \mathrm{~V}$.

${ }^{1}$ H RMN (DMSO): $\delta(\mathbf{p p m})=0.90(3 \mathrm{H}, \mathrm{t}), 1.25(2 \mathrm{H}, \mathrm{m}), 1.77(2 \mathrm{H}, \mathrm{q}), 2.50$ (DMSO), $3.33\left(\mathrm{H}_{2} \mathrm{O}\right), 3.88(3 \mathrm{H}, \mathrm{s}), 4.20(2 \mathrm{H}, \mathrm{t}), 7.70(1 \mathrm{H}, \mathrm{s}), 7.77(1 \mathrm{H}, \mathrm{s})$, $9.10(1 \mathrm{H}, \mathrm{s})$.

\subsubsection{Sintesis de $\mathrm{Pd}_{0,5} \mathrm{H}_{4} \mathrm{PO}_{40} \mathrm{~V}_{2} \mathrm{Mo}_{10}$ (POM-Pd)}

$125 \mathrm{mg} \mathrm{PdSO} \cdot \mathrm{H}_{2} \mathrm{O}(0,5 \mathrm{mmol})$ se disolvieron en $25 \mathrm{~mL}$ de agua Milli Q y se adicionaron gota a gota a $1,7 \mathrm{~g}$ de $\mathrm{H}_{5} \mathrm{PO}_{40} \mathrm{~V}_{2} \mathrm{Mo}_{10} \cdot 27 \mathrm{H}_{2} \mathrm{O}(1$ $\mathrm{mmol}$ ). La mezcla se agitó durante 2 horas a temperatura ambiente y bajo atmósfera de nitrógeno. El agua se eliminó mediante filtración a vacío con filtro de membrana de nailon y el sólido se lavó profusamente con agua milliQ. Finalmente el sólido obtenido, de coloración marrón oscuro se secó a vacío durante 1 hora. Absorción atómica: Calculado: 52,8\% Mo, 5,6\% V, 2,9\% Pd. Analizado: 50\% Mo, 5,4\% V, 2,6\% Pd.

\subsubsection{Sintesis de $[\mathrm{bmim}]_{4} \mathrm{Pd}_{0,5} \mathrm{PO}_{40} \mathrm{~V}_{2} \mathrm{Mo}_{10}$ (POM-IL-Pd)}

$125 \mathrm{mg} \mathrm{PdSO}_{4} \cdot 2 \mathrm{H}_{2} \mathrm{O}(0,5 \mathrm{mmol})$ se disolvieron en $25 \mathrm{~mL}$ de agua Milli $\mathrm{Q}$ y se adicionaron gota a gota a $2,3 \mathrm{~g}[\mathrm{bmim}]_{4} \mathrm{HPO}_{40} \mathrm{~V}_{2} \mathrm{Mo} 10(1$ mmol). La mezcla se agitó durante 2 horas a temperatura ambiente y atmósfera de nitrógeno. El agua se eliminó mediante filtración a vacío con filtro de membrana de nailon y el sólido se lavó profusamente con agua milliQ. Finalmente el sólido obtenido, de coloración marrón ocre se secó a vacío durante 1 hora. Análisis elemental: Calculado: 16\% C, 4,7\% N, 2,6\% H. Analizado: 16,3\% C, 4,5\% N, 2,5\% H. Absorción atómica: Calculado: $41,2 \%$ Mo, 4,3\%V, 2,3\% Pd. Analizado: 39,5\% Mo, 5,2\% V, $2,7 \% \mathrm{Pd}$. 
${ }^{1}$ H RMN (DMSO): $\delta(\mathbf{p p m})=0.90(3 \mathrm{H}, \mathrm{t}), 1.28(2 \mathrm{H}, \mathrm{m}), 1.77(2 \mathrm{H}, \mathrm{q}), 2.50$ (DMSO), $3.33\left(\mathrm{H}_{2} \mathrm{O}\right), 3.87(3 \mathrm{H}, \mathrm{s}), 4.19(2 \mathrm{H}, \mathrm{t}), 5.76(1 \mathrm{H}, \mathrm{s}), 7.70(1 \mathrm{H}, \mathrm{s})$, $7.77(1 \mathrm{H}, \mathrm{s}), 9.10(1 \mathrm{H}, \mathrm{s})$.

\subsection{2}

Líquidos iónicos bifuncionales

\subsubsection{Síntesis de Tetrafluoroborato de 1-Piperidina-1-metil-piperidinio [Diamina-A]BF 4}

En un matraz de base redonda de $100 \mathrm{~mL}$ se introdujeron $10 \mathrm{~g}$ de dipiperidinometano $(54,85 \mathrm{mmol})$ y $30 \mathrm{~mL}$ de éter dietílico. A continuación el matraz se dispuso en un baño de hielo y sobre la disolución se adicionó gota a gota una cantidad equimolar de ácido tetrafluorobórico/éter dietílico. La mezcla se agitó durante 1 hora a temperatura ambiente. Paulatinamente se formó un sólido amarillo pálido que fue filtrado sobre filtro de membrana de nailon y lavado exhaustivamente con éter dietílico. Finalmente el sólido se secó a vacío durante 12 horas. Rendimiento: 8,1 g (55\%).

${ }^{1} \mathrm{H}$ RMN (300MHz, $\left.\mathrm{CDCl}_{3}\right): \delta(\mathrm{ppm})=1.50$ (brs), 1.65 (brs), 2.85 (brs), 3.65 (s); ${ }^{13}$ C RMN (300MHz, $\left.\mathrm{CDCl}_{3}\right): \delta(\mathbf{p p m})=22,5,23,9,51,0,79,8 ; \mathrm{MS}\left(\mathrm{FAB}^{+}\right)$: $(m / z): 98\left[M-\left(\mathrm{C}_{5} \mathrm{H}_{11} \mathrm{~N}\right)\right]^{+}, 85\left[M-\left(\mathrm{C}_{6} \mathrm{H}_{11} \mathrm{~N}\right)\right]^{+} ;$FT-IR: $v\left(\mathbf{c m}^{-}\right.$ 1) $=3153$ (st), 2937(st), 2853 (st), 2800 (st), 1479 (md), 1453 (md), 1311 (wk), 1116 (st), 1069 (st), 1006 (vst), 511 (wk); Contenido en agua: $(<0,3 \%)$; Contenido en fluoruro:<smiles>[18F]CN1CCCCC1</smiles>

Figura 8.1.[Diamina-A]BF 4 Calculado ([ $\left.\left.\mathrm{C}_{11} \mathrm{H}_{23} \mathrm{~N}_{2} \mathrm{BF}_{4}\right]\right): 28 \%$. Analizado: 27,8\%. Temperaturas de procesos de descomposición $\left({ }^{\circ} \mathrm{C}\right): 120$, 307, 392, 437. Punto de fusión $\left({ }^{\circ} \mathrm{C}\right)$ : 108,8. Densidad(g/mL): 1,195. Conductividad equivalente de un electrolito 1:1( $\mu \mathrm{S} / \mathrm{cm}): 167,0$. 
8.5.2.2 Síntesis de Tetrafluoroborato de 1-Piperidina-1-etil-piperidinio [Diamina-B]BF 4

En un matraz de base redonda de $100 \mathrm{~mL}$ se introdujeron $5 \mathrm{~g}$ de 1,2-di(N-piperidino)etano $(25,47 \mathrm{mmol})$ y $30 \mathrm{~mL}$ de éter dietílico. A continuación el matraz se dispuso en un baño de hielo y sobre la disolución se adicionó gota a gota una cantidad equimolar de ácido tetrafluorobórico/éter dietílico. La mezcla se agitó durante 1 hora a temperatura ambiente. Paulatinamente se formó un sólido amarillo intenso que fue filtrado sobre filtro de membrana de nailon y lavado exhaustivamente con éter dietílico. Finalmente el sólido se secó a vacío durante 12 horas. Rendimiento: 4,25 g (58,7\%).

${ }^{1}$ H RMN (300MHz, $\left.\mathrm{CDCl}_{3}\right): \delta(\mathrm{ppm})=1,65$ (brs), 1,75 (brs), 2,85 (brs), 2,91 (s), 5,63 (s); ${ }^{13} \mathrm{C} \mathrm{RMN} \mathrm{(300MHz,}$ $\left.\mathrm{CDCl}_{3}\right): \delta(\mathrm{ppm})=22,2,23,6,52,0,53,3 ; \mathbf{M S}\left(\mathrm{FAB}^{+}\right):(\mathrm{m} / \mathrm{z})$

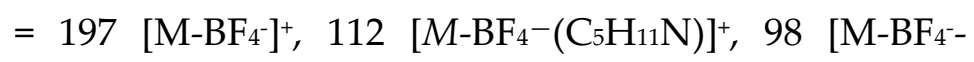
$\left.\left(\mathrm{C}_{6} \mathrm{H}_{13} \mathrm{~N}\right)\right]^{+}$; FT-IR: $v\left(\mathrm{~cm}^{-1}\right)=3137$ (md), 2932 (st), 2858

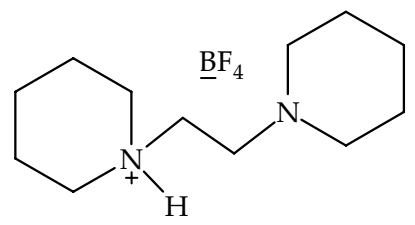

Figura 8.2.$\left[\right.$ Diamina-B] $\mathrm{BF}_{4}$ (md), 2784 (wk), 1458 (md), 1284 (wk), 1121 (st), 1063 (vst). Temperaturas de procesos de descomposición $\left({ }^{\circ} \mathrm{C}\right): 303,344,387$.

Punto de fusión $\left({ }^{\circ} \mathrm{C}\right):$ 72. Densidad $(\mathrm{g} / \mathrm{mL}): 1,196$. Conductividad equivalente de un electrolito 1:1 ( $\mu \mathrm{S} / \mathrm{cm}): 88,4$.

\subsubsection{Síntesis de Tetrafluoroborato de N-Metilpiperidinio [N-Metilpiperidina] $\mathrm{BF}_{4}$}

En un matraz de base redonda de $50 \mathrm{~mL}$ se introdujo $1 \mathrm{~g}$ de $\mathrm{N}$ metilpiperidina $(50,41 \mathrm{mmol})$ y $5 \mathrm{~mL}$ de éter dietílico. A continuación el matraz se dispuso en un baño de hielo y sobre la disolución se adicionó gota a gota una cantidad equimolar de ácido tetrafluorobórico/éter dietílico. La mezcla se agitó durante 1 hora a temperatura ambiente y seguidamente se adicionó a ésta una pequeña cantidad de carbono activo. Posteriormente se filtró a vacío y el disolvente se eliminó por evaporación en rotavapor obteniéndose un líquido viscoso que se dejó secar durante 12 horas a vacío. Rendimiento: 3,39 g (90\%). 
${ }^{1}$ H RMN (300MHz, $\left.\mathrm{CDCl}_{3}\right): \delta($ ppm) = 1,55 (s), 1,77 (s), 2,82

(s), 3,05 (m); ${ }^{13} \mathrm{C}$ RMN (300MHz, $\left.\mathrm{CDCl}_{3}\right): \delta(\mathbf{p p m})=21,0$,

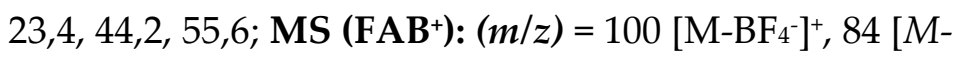
BF$\left._{4}^{-}-\left(\mathrm{CH}_{3}\right)\right]^{+} ;$FT-IR: $v\left(\mathrm{~cm}^{-1}\right)=3575$ (md), 3170 (st), 2960 (st), 2863 (st), 2576 (wk), 2530, 1839, 1634, 1465 (vst),

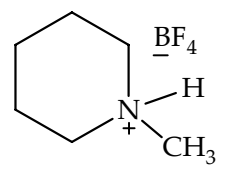

Figura 8.3.[Metilpiperidina]BF4 1409 (vst), 1276 (md), 1122 (br), 846, 768, 518 (st), 456, 410.. Densidad(g/mL): 1,215. Conductividad equivalente de un electrolito 1:1( $\mu \mathrm{S} / \mathrm{cm}): 137,0$.

\subsubsection{Síntesis de Cloruro de 1-Piperidina-1-metil-piperidinio [Diamina-A]Cl}

En un matraz de base redonda de $100 \mathrm{~mL}$ se introdujeron $2 \mathrm{~g}$ de dipiperidinometano $(10,97 \mathrm{mmol})$ y $20 \mathrm{~mL}$ de éter dietílico. A continuación el matraz se dispuso en un baño de hielo y sobre la disolución se adicionó gota a gota una cantidad equimolar de ácido clorhídrico ( $2 \mathrm{M}$ en diclorometano). La mezcla se agitó durante 1 hora a temperatura ambiente. El sólido amarillo formado se recuperó por filtración y se lavó exhaustivamente con éter dietílico. Finalmente se secó a vacío dando lugar a un sólido con ligera coloración amarillenta. Rendimiento: $1,83 \mathrm{~g}(76 \%)$.

${ }^{1} \mathrm{H}$ RMN (300MHz, $\left.\mathrm{CDCl}_{3}\right) \delta(\mathrm{ppm})=1,54(\mathrm{~s}), 1,71(\mathrm{~s})$, 2,90 (s), 3,61 (s); ${ }^{13} \mathrm{C}$ RMN (300MHz, $\left.\mathrm{CDCl}_{3}\right): \delta(\mathbf{p p m})=$ 22,5, 23,6, 51,0, 78,4, 116,9; MS (FAB $\left.{ }^{+}\right):(m / z)=219,183$ $[\mathrm{M}-\mathrm{Cl}]^{+}, \quad 136\left[\mathrm{M}-\left(\mathrm{C}_{5} \mathrm{H}_{11} \mathrm{~N}\right)\right]^{+}, 98 \quad\left[M-\left(\mathrm{C}_{6} \mathrm{H}_{12} \mathrm{~N}\right)\right]^{+} ; \quad$ FT-IR: $v\left(\mathrm{~cm}^{-1}\right)=3420$ (br), 2937 (vst), 2853 (md), 2800 (st), 2758<smiles>ClCN1CCCCC1</smiles>

Figura 8.4.[Diamina- $\mathrm{A}] \mathrm{Cl}$ (st), 2621 (st), 2580 (md), 2526 (st), 2415 (md), 1590 (vst), 1448 (br), 1385 (st), 1264 (md), 1221 (st), 1116 (vst), 995 (vst), 934 (md), 859 (md). Temperaturas de procesos de descomposición $\left({ }^{\circ} \mathrm{C}\right): 151,206,248,282$, 359. Punto de fusión $\left({ }^{\circ} \mathrm{C}\right):>150$. Conductividad equivalente de un electrolito 1:1( $\mu \mathrm{S} / \mathrm{cm}): 176,0$. 


\subsubsection{Síntesis de Trifluorometanosulfonimidato de 1-Piperidina-1-metil- piperidinio [Diamina-A]N $\left(\mathrm{CF}_{3} \mathrm{SO}_{2}\right)_{2}$}

En un matraz de base redonda de $100 \mathrm{~mL}$ se introdujeron $2 \mathrm{~g}$ de dipiperidinometano $(10,97 \mathrm{mmol})$ y $20 \mathrm{~mL}$ acetonitrilo a esta disolución se adicionó gota a gota y en baño de hielo una disolución de 3,25 g de trifluorometanosulfonimida $(10,97 \mathrm{mmol})$ en $2 \mathrm{~mL}$ de acetonitrilo. La mezcla se dejó agitar durante 12 horas a temperatura ambiente. A continuación se concentró a sequedad. El residuo sólido se disolvió en la mínima cantidad de diclorometano y se le añadieron $5 \mathrm{~mL}$ de agua desionizada. La fase acuosa se extrajo con tres alícuotas de $5 \mathrm{~mL}$ de diclorometano y se añadieron a la fase orgánica inicial que se secó con sulfato magnésico. Finalmente se filtró la disolución y se concentró a sequedad, dando lugar a un líquido muy viscoso de color ambarino. Rendimiento: 3,025 g (60\%).

${ }^{1} \mathrm{H} \quad \mathrm{RMN} \quad(300 \mathrm{MHz}, \quad \mathrm{CDCN})$ $\delta($ ppm $)=1,65(\mathrm{~m}), 1,72(\mathrm{~m}), 2,67(\mathrm{~s})$, $3,02 \quad(\mathrm{~m}), \quad 5,91 \quad(\mathrm{~s}) ; \quad{ }^{13} \mathrm{C} \quad \mathbf{R M N}$ $(300 \mathrm{MHz}, \mathrm{CDCN}): \delta(\mathrm{ppm})=22,2$, 25,0, 55,0, 80,1, 113,3, 117,6, 121,8, 126; MS (FAB $\left.{ }^{+}\right):(m / z)=463,276,181$

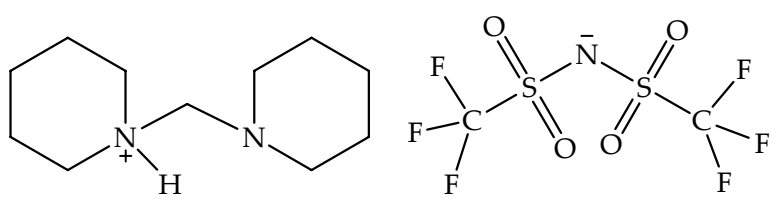

Figura 8.5.-

[Diamina-A] $\mathrm{N}\left(\mathrm{CF}_{3} \mathrm{SO}_{2}\right)_{2}$ $\left[\mathrm{M}-\left(\left(\mathrm{CF}_{3} \mathrm{SO}_{2}\right)_{2} \mathrm{~N}^{-}\right)\right]^{+}, 148\left[\mathrm{M}-\left(\mathrm{C}_{5} \mathrm{H}_{11} \mathrm{~N}\right)\right]^{+}$, $127\left[\mathrm{M}-\left(\mathrm{C}_{6} \mathrm{H}_{12} \mathrm{~N}\right)\right]^{+}, 98,86,56$; FT-IR: $v\left(\mathrm{~cm}^{-1}\right)=3180(\mathrm{br}), 2955(\mathrm{md}), 2862$ (md), 1654 (st), 1613 (md), 1454 (vst), 1357(wk), 1193 (wk), 1132 (md), 1053 (md), 790 (vst), 737 (vst), 646 (vst), 615 (st), 574 (vst), 507 (vst);

Conductividad equivalente de un electrolito 1:1( $\mu \mathrm{S} / \mathrm{cm}): 42,5$.

\subsubsection{Síntesis de Tetrafluoroborato de 1-Piperidina-1-propil-piperidinio [Diamina-C]BF 4}

En un matraz de base redonda de $50 \mathrm{~mL}$ se introdujeron $3 \mathrm{~g}$ de dipiperidinopropano $(11,41 \mathrm{mmol})$ y 7,5 $\mathrm{mL}$ de éter dietílico. A continuación el matraz se dispuso en un baño de hielo y sobre la 
disolución se adicionó gota a gota una cantidad equimolar de ácido tetrafluorobórico/éter dietílico. La mezcla se agitó durante 1 hora a temperatura ambiente. Paulatinamente se formó un sólido amarilloanaranjado que fue filtrado sobre filtro de membrana de nailon y lavado exhaustivamente con éter dietílico. Finalmente el sólido se secó a vacío durante 12 horas. Rendimiento: 3,16 g (74\%).

${ }^{1} \mathrm{H}$ RMN (300MHz, $\left.\mathrm{CDCl}_{3}\right) \delta(\mathrm{ppm})=1,19(\mathrm{q})$, $1,71(\mathrm{t}), 1,83(\mathrm{q}), 2,68(\mathrm{t}), 2,83(\mathrm{t}), 8,98(\mathrm{~s}) ;{ }^{13} \mathrm{C}$ RMN (300MHz, $\left.\mathrm{CDCl}_{3}\right): \delta(\mathbf{p p m})=19,22,23,01,25,32$, $53,80,62,87,76,80,77,23,77,42$.

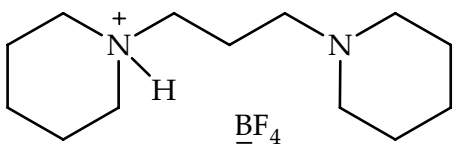

Figura 8.6.[Diamina-C]BF4

8.6

\section{Procedimientos Generales}

\subsection{1}

\section{Transposición de Beckmann}

\subsubsection{Síntesis de Ciclododecanona Oxima}

En un matraz de base redonda de $250 \mathrm{~mL}$ y con una sola boca se adicionaron 5,39 g de ciclododecanona (0,029 moles), 5,52 g de clorhidrato de hidroxilamina (0,075 moles), $5 \mathrm{~mL}$ de piridina $(0,058$ moles) y $50 \mathrm{~mL}$ de etanol. La reacción se llevó a cabo a la temperatura de reflujo del etanol, en aire y empleando un baño de silicona, durante 1 hora con agitación vigorosa. Posteriormente se dejó enfriar la mezcla a temperatura ambiente durante 1 hora, lo que provocó la generación de cristales blancos de forma acicular. Se eliminó el etanol sobrenadante así como el exceso de piridina por decantación y posterior evaporación. El sólido aislado de lavó con abundante agua fría, hasta anular completamente el olor a piridina y se filtró a vacío $(4 \mathrm{mmHg})$, se dejó secar a presión atmosférica. Para la completa purificación de la oxima el sólido se disolvió en la menor cantidad posible de etanol caliente, se filtró en caliente y se dejó recristalizar durante tres días a temperatura ambiente. Rendimiento: 5,12 g (95\%).

\subsubsection{Reacción de transposición de Beckmann A.- Procedimiento}


En un matraz de base redonda de $25 \mathrm{~mL}$ y dos bocas, equipado con un refrigerante, se dispuso una mezcla del $10 \mathrm{wt} \%$ de ciclododecanona oxima (150-240 mg, 0,75-1,25 mmol) y un líquido iónico comercial. La reacción se llevó a cabo en baño de silicona a $130{ }^{\circ} \mathrm{C}$, en aire y con agitación magnética, durante 2 horas. La toma periódica de muestras que se extrajeron con éter dietílico y a las que se les añadió una cantidad conocida de patrón, permitió determinar posteriormente el rendimiento al producto así como la progresión de la reacción con el tiempo.

Acabada la reacción, las especies disueltas en el líquido iónico se extrajeron con éter dietílico. La fase orgánica se concentró a vacío, se pesó para controlar el balance de materia y se analizó por RMN y cromatografía de gases. La fase líquido iónico tras secarla a vacío se pesó y analizó por RMN.

Los experimentos que se realizaron con adición de agua, ácido fluorhídrico o trifluoroborato, se llevaron a cabo en autoclave de teflón de $15 \mathrm{~mL}$, sellados y presurizados a 1 bar de nitrógeno.

× En el caso de los experimentos en los que se adicionó agua $(2,2-2,8 \mathrm{wt} \%)$ las proporciones de reactantes fueron: ciclododecanona oxima (140-176 mg, 0,70-0,90 mmol), líquido iónico (1520-1760 mg, 4,80-7,05 mmol) y agua (33-40 $\mathrm{mg}, 1,80-2,60 \mathrm{mmol})$.

a Las mezclas con ácido fluorhídrico $(0,5 \mathrm{wt} \%$ de una disolución al $20 \mathrm{wt} \%$ en agua) contenían: ciclododecanona oxima (200-215 mg, 1,00-1,10 mmol), líquido iónico (2000$2055 \mathrm{mg}, 6,90-9,10 \mathrm{mmol})$ y HF (11,13 mg, 0,56 mmol).

a Finalmente, las mezclas de reacción de los experimentos con adición de $\mathrm{BF}_{3}$ contenían: ciclododecanona oxima (200-215 $\mathrm{mg}$, 1,00-1,10 mmol), líquido iónico (2000-2055 mg, 6,90-9,10 $\mathrm{mmol})$ y BF3 (10 wt\%, $270 \mathrm{mg}, 0,4 \mathrm{mmol})$.

En estos casos, acabado el tiempo de reacción, las especies disueltas en el líquido iónico se extrajeron con éter dietílico, la fase orgánica se concentró a vacío y el residuo sólido obtenido tras ser pesado se analizó por cromatografía de gases y una porción disuelta en piridina deuterada se analizó por $\mathrm{RMN}\left({ }^{1} \mathrm{H},{ }^{13} \mathrm{C},{ }^{19} \mathrm{~F}\right.$ y $\left.{ }^{31} \mathrm{P}\right)$. 


\section{B.-Identificación de productos}

La transposición de Beckmann de la ciclododecanona oxima en medio líquido iónico dio lugar a la lactama correspondiente y en los casos que se produjo hidrólisis de la oxima se pudo observar como producto secundario la ciclododecanona. Los tiempos de retención de reactantes y productos así como los datos espectroscópicos del producto de interés se detallan a continuación. Tabla 8.1.

Características espectroscópicas del producto de la reacción de Beckmann

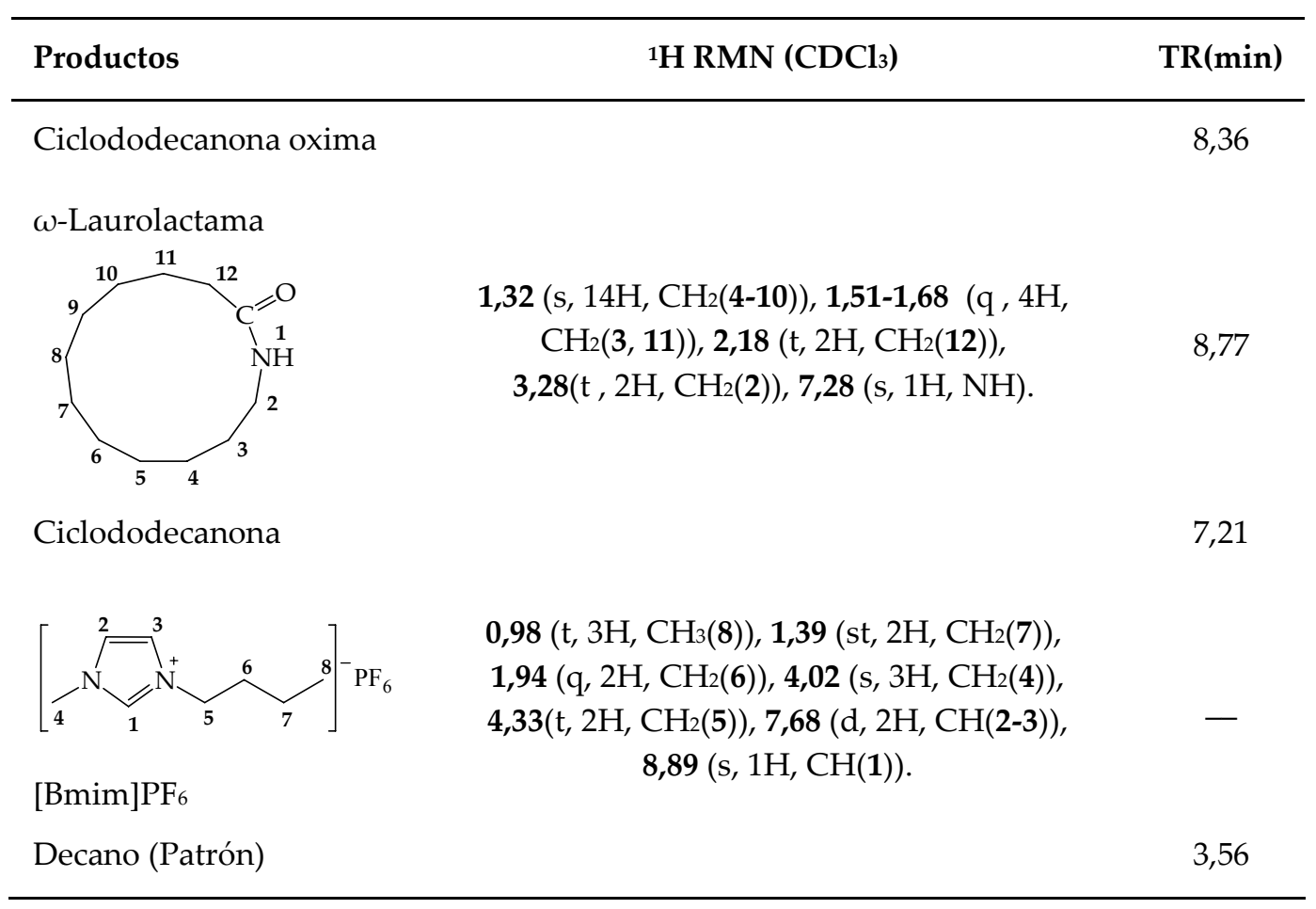

Tabla 8.1.- Tiempos de retención de reactantes y productos y ${ }^{1} \mathrm{H}$ RMN del producto de interés y de uno de los líquidos iónicos empleados como medio de reacción. Programa de temperaturas del análisis por GC: $80^{\circ} \mathrm{C}(2 \mathrm{~min})-20^{\circ} \mathrm{C} / \mathrm{min}-280^{\circ} \mathrm{C}(2 \mathrm{~min})$.

\subsubsection{Experimentos in situ RMN de sólidos}

Aproximadamente $70 \mathrm{mg}$ de una mezcla de $\left[\mathrm{bmim}^{\mathrm{P}} \mathrm{PF}_{6}\right.$ y ciclododecanona oxima (1:1 relación molar) se introdujeron en una ampolla de vidrio que se selló tras ser desgasificada a temperatura ambiente y posteriormente fue sometida a una rampa de temperatura hasta los $130^{\circ} \mathrm{C}$. Los RMNs de ${ }^{15} \mathrm{~N}$ polarización cruzada (CP) y ${ }^{31} \mathrm{P}$ girando el ángulo mágico (MAS) se hicieron en un espectrómetro Bruker AV $400 \mathrm{MHz}$ usando una sonda BL7 y girando la muestra a $5 \mathrm{KHz}$. 


\subsection{2}

POM-IL-Pd

\subsubsection{Reacción de Heck \\ A.- Procedimiento}

$63 \mathrm{mg}$ de POM-IL-Pd (0,04 mmol de Pd) se pesaron dentro de un matraz de base redonda de $10 \mathrm{~mL}$ y dos bocas, que seguidamente se conectó a un refrigerante. Con jeringa de plástico se fueron adicionando al matraz los reactantes: $0,340 \mathrm{~mL}$ de yodobenceno $(3 \mathrm{mmol}), 0,450 \mathrm{~mL}$ de estireno $(3,9 \mathrm{mmol}), 0,5 \mathrm{~mL}$ de trietilamina $(3,5 \mathrm{mmol})$, dodecano como patrón interno y $0,5 \mathrm{~mL}$ de dimetilformamida como disolvente. La mezcla se mantuvo a $100^{\circ} \mathrm{C}$ con agitación vigorosa durante dos horas y se extrajeron muestras a tiempos determinados para controlar la evolución de la reacción. Trascurrido el tiempo, la mezcla se dejó enfriar a temperatura ambiente y a continuación se adicionaron $5 \mathrm{~mL}$ de acetona para que la filtración en membrana de nailon y a vacío fuera posible. El catalizador, que pasó de su coloración original ocre a un color verdeazulado, se lavó con $5 \mathrm{~mL}$ más de acetona y se dejó secar a presión atmosférica y temperatura ambiente. Las aguas madre se dejaron reposar durante un día, lo que generó grandes cristales aciculares blancos de trans-estilbeno, el producto de la reacción, que se aisló por decantación y secado. Rendimiento: $>98 \%$.

Para el reuso del catalizador, después del primer uso, el sólido obtenido tras la filtración y el lavado con acetona se secó a vacío y temperatura ambiente durante dos horas, se pesó y se pudo utilizar directamente.

\section{B.-Identificación de productos}

La reacción de Heck del estireno con yodobenceno puede generar dos isómeros cis y trans-estilbeno, sin embargo durante la experimentación con derivados de POM como catalizadores no se observó la presencia del isómero cis. Los tiempos de retención de reactantes y productos así como los datos espectroscópicos del producto de interés se detallan a continuación. Tabla 8.2. 
Características espectroscópicas del producto de reacción de Heck

\begin{tabular}{|c|c|c|}
\hline Productos & ${ }^{1} \mathrm{H} \mathrm{RMN}\left(\mathrm{CDCl}_{3}\right)$ & $\operatorname{TR}(\min )$ \\
\hline Yodobenceno & & 3,56 \\
\hline Estireno & & 2,23 \\
\hline Trans-estilbeno & $\begin{array}{c}7,09(\mathrm{~s}, 2 \mathrm{H}, \mathrm{CH}(1)), 7,21(\mathrm{~d}, 2 \mathrm{H}, \mathrm{CH}(4)) \\
7,30(\mathrm{t}, 4 \mathrm{H}, \mathrm{CH}(3)), 7,43(\mathrm{~d}, 4 \mathrm{H}, \mathrm{CH}(2))\end{array}$ & 8,35 \\
\hline Trietilamina & & 1,10 \\
\hline Dimetilformamida & & 1,49 \\
\hline Dodecano (Patrón) & & 4,94 \\
\hline
\end{tabular}

Tabla 8.2.- Tiempos de retención de reactantes y productos y ${ }^{1} \mathrm{H}$ RMN del producto de interés. Programa de temperaturas del análisis por GC: : $80^{\circ} \mathrm{C}(2 \mathrm{~min})-20^{\circ} \mathrm{C} / \mathrm{min}-280^{\circ} \mathrm{C}(8$ $\min )$.

\subsection{3}

Líquidos lónicos bifuncionales

\subsubsection{Reacción de Knoevenagel}

A. 1.- Procedimiento general de reacción de Knoevenagel.

De forma general, la reacción de Knoevenagel se realizó en un matraz de base redonda de $25 \mathrm{~mL}$ y dos bocas en el que se pesó, bajo atmósfera inerte, el catalizador $(0,28 \mathrm{mmol})$. En el matraz se introdujo con jeringa de plástico, el compuesto del metileno activo $(28 \mathrm{mmol})$ y una vez alcanzada la temperatura de reacción, se introdujo también con jeringa de plástico, el compuesto carbonílico. La reacción se llevó a cabo bajo atmósfera inerte durante tiempo variable según el metileno empleado y se controló con la extracción periódica de muestras (pequeñas alícuotas que previo análisis se extrajeron con éter dietílico y a las que se añadió un patrón externo).

Acabada la reacción, la separación del crudo de reacción del catalizador fue vía extracción con éter dietílico. La fase líquido iónico se disolvió en diclorometano y se secó con sulfato magnésico, se filtró en 
embudo cónico, se evaporó el disolvente y finalmente se secó a vacío (4 $\mathrm{mmHg}$ ) durante dos horas a $40^{\circ} \mathrm{C}$. Para experimentos en los que el catalizador se utilizó en varios ciclos seguidos, se aumentaron las cantidades de reactantes y catalizador empleadas manteniendo siempre las proporciones, con el fin de que las pérdidas de catalizador durante los procesos de purificación no afectaran al desarrollo de la propia reacción.

\begin{tabular}{|c|c|c|c|c|}
\hline $\begin{array}{l}\text { Compuesto } \\
\text { Carbonílico }\end{array}$ & Metileno activo & $\mathrm{T}\left({ }^{\circ} \mathrm{C}\right)$ & $t(h)$ & Catalizador \\
\hline $\begin{array}{l}\text { Benzaldehido } \\
(3,4 \mathrm{~g}, 32 \mathrm{mmol})\end{array}$ & $\begin{array}{c}\text { Malononitrilo } \\
(1,85 \mathrm{~g}, 28 \mathrm{mmol})\end{array}$ & 25 & 0,5 & $0,28 \mathrm{mmol}$ \\
\hline $\begin{array}{l}\text { Benzaldehido } \\
(3,4 \mathrm{~g}, 32 \mathrm{mmol})\end{array}$ & $\begin{array}{l}\text { Etilcianoacetato } \\
(3,5 \mathrm{~g}, 28 \mathrm{mmol})\end{array}$ & 25 & 4 & $0,28 \mathrm{mmol}$ \\
\hline $\begin{array}{l}\text { Benzaldehido } \\
(3,4 \mathrm{~g}, 32 \mathrm{mmol})\end{array}$ & $\begin{array}{l}\text { Etilacetoacetato } \\
(3,3 \mathrm{~g}, 28 \mathrm{mmol})\end{array}$ & 60 & 4 & $0,28 \mathrm{mmol}$ \\
\hline $\begin{array}{l}\text { Benzaldehido } \\
(3,4 \mathrm{~g}, 32 \mathrm{mmol})\end{array}$ & $\begin{array}{l}\text { Dietilmalonato } \\
(4,48 \mathrm{~g}, 28 \mathrm{mmol})\end{array}$ & 80 & 6 & $0,28 \mathrm{mmol}$ \\
\hline
\end{tabular}

Tabla 8.3.- Condiciones de reacción y proporciones de reactantes para la reacción de Knoevenagel.

\section{A.2.- Identificación de productos}

La reacción de Knoevenagel se llevó a cabo en presencia de catalizadores tipo líquido iónico basados en estructuras moleculares diamínicas. Los productos resultantes de estas reacciones, así como sus características espectroscópicas, se presentan a continuación en la tabla resumen.

Características espectroscópicas de los productos de condensación de Knoevenagel

\begin{tabular}{|c|c|c|}
\hline Compuestos & ${ }^{1} \mathrm{H}$ RMN (DMSO-d6) & $\operatorname{TR}(\min )$ \\
\hline Benzaldehido & & 2,97 \\
\hline Malononitrilo & & 1,92 \\
\hline 1 & $\begin{array}{l}\text { 7,10 (m, 1H, CH(1)), 7,18 (t, 2H, CH(2)), } \\
\text { 7,34 (d, 2H, CH(3)), 7,90 (s, 1H, CH(4)) }\end{array}$ & 6,93 \\
\hline
\end{tabular}




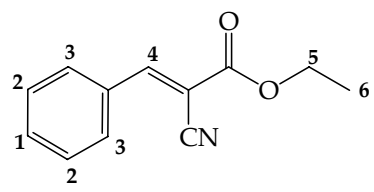

1,32 (t, 3H, $\left.\mathrm{CH}_{3}(6)\right), 4,22\left(\mathrm{c}, 2 \mathrm{H}, \mathrm{CH}_{2}(5)\right)$,

7,14 (m, 1H, CH(1)), 7,22 (t, 2H, CH(2)),

(E)-etil-2-ciano

-3-fenilacrilato

Etilacetoacetato<smiles>CCOC(=O)C(=Cc1ccccc1)C(C)=O</smiles>

(E)-etil-2-bencilideno-3oxobutanoato

Dietilmalonato<smiles>CCOC(=O)C(=Cc1ccccc1)C(=O)OCC</smiles>

Dietil-2-

bencilidenomalonato
1,29 (t, 3H, $\left.\mathrm{CH}_{3}(6)\right), 2,35$ (s, 3H, $\left.\mathrm{CH}_{3}(7)\right)$,

4,20 (c, 2H, $\left.\mathrm{CH}_{2}(5)\right), 7,17(\mathrm{~m}, 1 \mathrm{H}, \mathrm{CH}(\mathbf{1}))$,

7,26 (t, 2H, CH(2)), 7,40 (d, 2H, CH(3)),

7,96 (s, 1H, CH(4))

Tabla 8.4.- Tiempos de retención de reactantes y productos y ${ }^{1} \mathrm{H}$ RMN de los productos obtenidos. Programa de temperaturas del análisis por GC: $80^{\circ} \mathrm{C}(2 \mathrm{~min})-20^{\circ} \mathrm{C} / \mathrm{min}-280^{\circ} \mathrm{C}(2$ $\min )$.

B. 1.- Procedimiento de síntesis de cumarinas e iminocumarinas.

La síntesis de cumarinas e iminocumarinas se llevó a cabo mediante un proceso igual al explicado en el apartado A.1. Procedimiento general de reacción de Knoevenagel. Las proporciones de reactantes y catalizador así como las condiciones de reacción se detallan a continuación en la Tabla 8.5. El rendimiento a producto final de la reacción se determinó por GC con respecto a la cantidad inicial del compuesto del metileno activo. La selectividad en todos los casos fue del $100 \%$

\begin{tabular}{|c|c|c|c|c|}
\hline Compuesto Carbonílico & Metileno activo & $\mathrm{T}\left({ }^{\circ} \mathrm{C}\right)$ & $t(h)$ & Catalizador \\
\hline $\begin{array}{l}\text { Salicilaldehido } \\
(3,9 \mathrm{~g}, 32 \mathrm{mmol})\end{array}$ & $\begin{array}{l}\text { Malononitrilo } \\
(1,85 \mathrm{~g}, 28 \mathrm{mmol})\end{array}$ & 25 & 0,1 & $0,28 \mathrm{mmol}$ \\
\hline $\begin{array}{l}\text { Salicilaldehido } \\
(3,9 \mathrm{~g}, 32 \mathrm{mmol})\end{array}$ & $\begin{array}{l}\text { Dietilmalonato } \\
(4,48 \mathrm{~g}, 28 \mathrm{mmol})\end{array}$ & 80 & 4 & $0,28 \mathrm{mmol}$ \\
\hline
\end{tabular}




\begin{tabular}{lcccc}
\hline $\begin{array}{l}\text { 4-Fluorosalicilaldehido } \\
(4,8 \mathrm{~g}, 32 \mathrm{mmol})\end{array}$ & $\begin{array}{c}\text { Etilcianoacetato } \\
(3,17 \mathrm{~g}, 28 \mathrm{mmol})\end{array}$ & 60 & 1 & $0,28 \mathrm{mmol}$ \\
\hline $\begin{array}{l}4 \text {-metoxisalicilaldehido } \\
(4,8 \mathrm{~g}, 32 \mathrm{mmol})\end{array}$ & $\begin{array}{c}\text { Etilcianoacetato } \\
(3,17 \mathrm{~g}, 28 \mathrm{mmol})\end{array}$ & 60 & 1 & $1 \mathrm{mmol}$ \\
$\begin{array}{l}4 \text {-metoxisalicilaldehido } \\
\text { Etilacetoacetato }\end{array}$ & 80 & 1 & $1 \mathrm{mmol}$ \\
$\begin{array}{l}\text { 4-metoxisalicilaldehido } \\
(4,8 \mathrm{~g}, 32 \mathrm{mmol})\end{array}$ & $\begin{array}{c}(3,31 \mathrm{~g}, 28 \mathrm{mmol}) \\
\text { Dietilmalonato } \\
(4,48 \mathrm{~g}, 28 \mathrm{mmol})\end{array}$ & 100 & 1 & $1 \mathrm{mmol}$ \\
\hline
\end{tabular}

Tabla 8.5.- Condiciones de reacción y proporciones de reactantes para la síntesis de cumarinas e iminocumarinas.

\section{B.2.- Identificación de productos.}

La condensación de Knoevenagel para la síntesis de iminocumarinas y cumarinas, se llevó a cabo en presencia de catalizadores tipo líquido iónico basados en estructuras moleculares diamínicas. Los productos resultantes de estas reacciones así como sus características espectroscópicas, se presentan a continuación en la tabla resumen.

Características espectroscópicas de las iminocumarinas y cumarinas

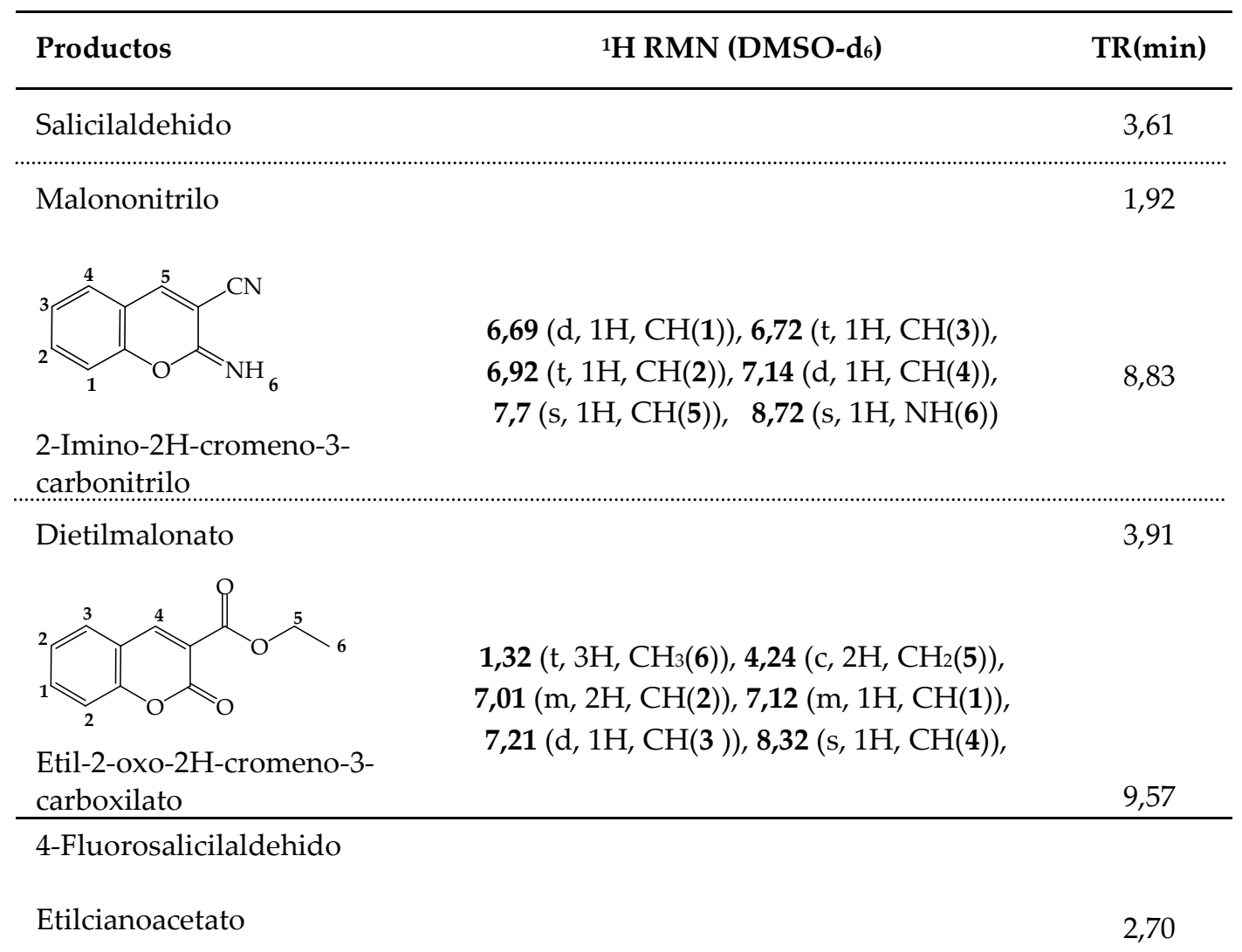


<smiles>CCOC(=O)c1cc2ccc(F)cc2oc1=O</smiles>

Etil-7-fluoro-2-oxo-2H-

cromeno-3-carboxilato
1,27 (t, 3H, $\left.\mathrm{CH}_{3}(6)\right), \mathbf{4 , 1 8}\left(\mathrm{c}, 2 \mathrm{H}, \mathrm{CH}_{2}(5)\right)$, 6,63 (m, 2H, CH (1-2)), 7,13 (m, 1H, CH(3)), $\quad 10,30$ $8,35(\mathrm{~s}, 1 \mathrm{H}, \mathrm{CH}(4))$

4-Metoxisalicilaldehido

Etilcianoacetato<smiles>COc1ccc2cc(C#N)c(=O)oc2c1</smiles>

7-Metoxi-2-oxo-2-cromeno3-carbonitrilo

Etilacetoacetato

3,77 (s, 3H, $\left.\mathrm{CH}_{3}(5)\right), 6,46(\mathrm{~m}, 2 \mathrm{H}, \mathrm{CH}(1-2))$,

7,16 (d, 1H, CH(3)), 8,10 (s, 1H, CH(4))

10,17<smiles>COc1ccc2cc(C(C)=O)c(=O)oc2c1</smiles>

3-Acetil-7-metoxi-2Hcromen-2-ona

Dietilmalonato<smiles>CCOC(=O)c1cc2ccc(OC)cc2oc1=O</smiles>
Etil-7-metoxi-2-oxo-2Hcromeno-3-carboxilato
2,41 (s, 3H, $\left.\mathrm{CH}_{3}(6)\right), 3,70$ (s, 3H, $\left.\mathrm{CH}_{3}(5)\right)$, 6,54 (m, 2H, CH(1-2)), 7,06 (d, 1H, CH(3)),

10,48 8,42 (s, 1H, CH(4))

Tabla 8.6.- Tiempos de retención de reactantes y productos y ${ }^{1} \mathrm{H} \mathrm{RMN}$ del producto obtenidos. Programa de temperaturas del análisis por GC: $80^{\circ} \mathrm{C}(2 \mathrm{~min})-20^{\circ} \mathrm{C} / \mathrm{min}-280^{\circ} \mathrm{C}(2$ $\min )$.

\subsubsection{Reacción de Acetalización}

\section{A.- Procedimiento de reacción}

De forma general, en un matraz de base redonda de $10 \mathrm{~mL}$ y dos bocas se pesó el catalizador $(0,84 \mathrm{mmol})$ en atmósfera inerte. Los 2,73 mL de trietoximetano ( $25 \mathrm{mmol})$ y el 1,05 $\mathrm{mL}$ de benzaldehido $(10 \mathrm{mmol})$ se introdujeron en el matraz con jeringa de plástico. La mezcla se calentó a $130^{\circ} \mathrm{C}$ y se mantuvo con agitación vigorosa durante seis horas, tiempo durante el cual se tomaron muestras que una vez extraídas con éter dietílico, se analizaron por cromatografía de gases. 


\section{B.- Identificación de productos}

La reacción de acetalización se llevó a cabo en presencia de catalizadores tipo líquido iónico basados en estructuras moleculares diamínicas. El producto resultante de esta reacción así como sus características espectroscópicas, se presentan a continuación en la tabla resumen.

Características espectroscópicas del producto de la acetalización

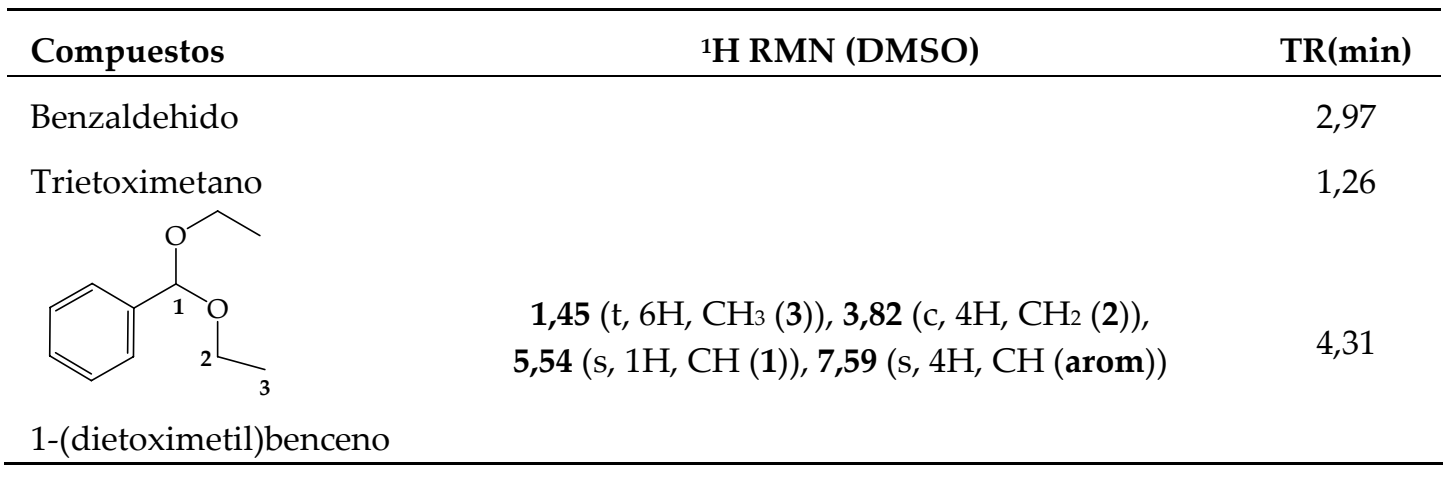

Tabla 8.7.- Tiempos de retención de reactantes y productos y ${ }^{1} \mathrm{H}$ RMN del producto de interés. Programa de temperaturas del análisis por GC: $80^{\circ} \mathrm{C}(2 \mathrm{~min})-20^{\circ} \mathrm{C} / \mathrm{min}-280^{\circ} \mathrm{C}(2$ $\min )$.

\subsubsection{Reacción de Claisen-Schmidt. Síntesis de chalconas}

A.- Procedimiento de reacción

De forma general, la condensación aldólica se realizó en un matraz de base redonda de $25 \mathrm{~mL}$ y dos bocas en el que se pesó, bajo atmósfera inerte, el catalizador $(1 \mathrm{mmol})$. En el matraz se introdujeron con jeringa de plástico $3 \mathrm{~mL}$ de acetofenona (28 mmol) y una vez alcanzada la temperatura de reacción, se introdujo también con jeringa de plástico, el aldehído ( $32 \mathrm{mmol}$ ). La reacción se llevó a cabo bajo atmósfera inerte durante 6 horas y se controló con la extracción periódica de muestras, que previo análisis se extrajeron con éter dietílico y a las que se añadió un patrón externo.

Acabada la reacción, la separación de reactantes y catalizador fue vía extracción con éter dietílico. La fase líquido iónico se disolvió en diclorometano y se secó con sulfato magnésico, se filtró en embudo cónico, se evaporó el disolvente y finalmente se secó a vacío $(4 \mathrm{mmHg})$ durante dos horas a $40^{\circ} \mathrm{C}$. Para experimentos en los que el catalizador se utilizó en varios ciclos seguidos, se aumentaron las cantidades de reactantes y catalizador empleadas manteniendo siempre las 
proporciones, con el fin de que las pérdidas de catalizador durante los procesos de purificación no afectaran al desarrollo de la propia reacción.

\begin{tabular}{lcc}
\hline Acetofenona & Aldehído & Catalizador \\
\hline Acetofenona & Benzaldehído & $1 \mathrm{mmol}$ \\
$(3,36 \mathrm{~g}, 28 \mathrm{mmol})$ & $(3,4 \mathrm{~mL}, 32 \mathrm{mmol})$ & \\
Acetofenona & 4-Nitrobenzaldehído & $1 \mathrm{mmol}$ \\
$(3,36 \mathrm{~g}, 28 \mathrm{mmol})$ & $(4,83 \mathrm{~g}, 32 \mathrm{mmol})$ & \\
Acetofenona & 4 -Clorobenzaldehído & $1 \mathrm{mmol}$ \\
$(3,36 \mathrm{~g}, 28 \mathrm{mmol})$ & $(4,83 \mathrm{~g}, 32 \mathrm{mmol})$ & \\
Acetofenona & 4-Metoxibenzaldehído & $1 \mathrm{mmol}$ \\
$(3,36 \mathrm{~g}, 28 \mathrm{mmol})$ & $(4,83 \mathrm{~g}, 32 \mathrm{mmol})$ & \\
\hline
\end{tabular}

Tabla 8.8.- Proporciones de reactantes para la condensación aldólica.

\section{B.- Identificación de productos}

La condensación de Claisen-Schmidt para la síntesis de chalconas, se llevó a cabo en presencia de catalizadores tipo líquido iónico basados en estructuras moleculares diamínicas. Los productos resultantes de estas reacciones así como sus características espectroscópicas, se presentan a continuación en la tabla resumen.

Características espectroscópicas de las chalconas

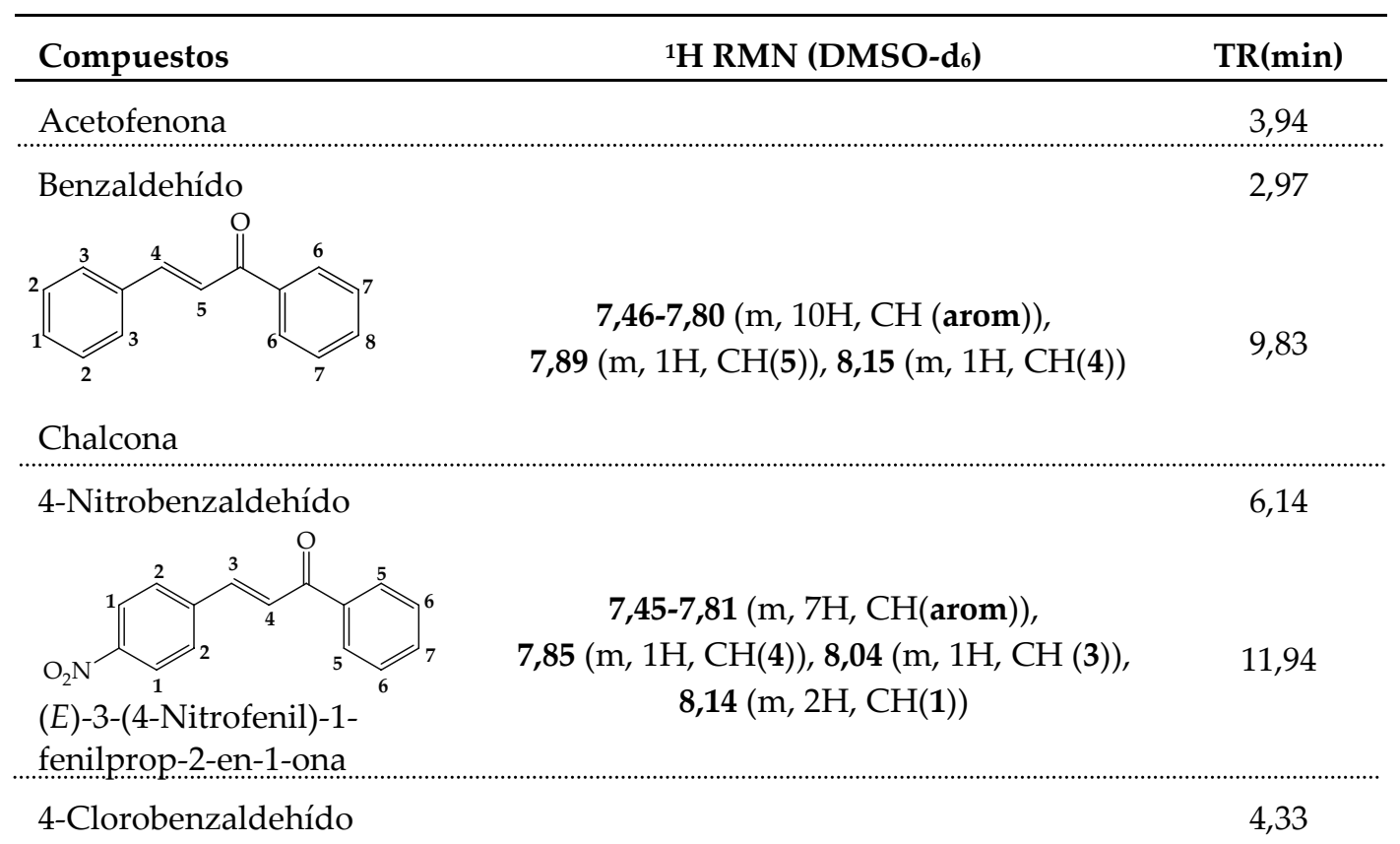


<smiles>O=C(/C=C/c1ccc(Cl)cc1)c1ccccc1</smiles>

(E)-3-(4-Clorofenil)-1-

fenilprop-2-en-1-ona

4-Metoxibenzaldehído<smiles>COc1ccc(/C=C/C(=O)c2ccccc2)cc1</smiles>

(E)-3-(4-Nitrofenil)-1fenilprop-2-en-1-ona
7,22 (m, 2H, CH(1)), 7,24 (m, 2H, CH (2)),

7,56 (m, 1H, CH(4)), 7,45-7,81 (m, 5H, CH

(arom)), 7,90 (m, 1H, CH (3))

3,73 (s, 3H, $\left.\mathrm{CH}_{3}(8)\right)$, 6,72 (dd, 2H, $\left.\mathrm{CH}(\mathbf{1})\right)$,

7,19 (dd, 2H, CH (2)), 7,45-7,54 (m, 3H, CH

(arom)), 7,56 (m, 1H, CH (4)), 7,90 (s, 1H,

$\mathrm{CH}(3))$

Tabla 8.9.- Tiempos de retención de reactantes y productos y ${ }^{1} \mathrm{H} \mathrm{RMN}$ del producto de interés. Programa de temperaturas del análisis por GC: $80^{\circ} \mathrm{C}(2 \mathrm{~min})-20^{\circ} \mathrm{C} / \mathrm{min}-280^{\circ} \mathrm{C}(8$ $\min )$.

\subsubsection{Adición de Michael}

\section{A.- Procedimiento de reacción}

De forma general, la reacción de adición de Michael se realizó en un matraz de base redonda de $25 \mathrm{~mL}$ y dos bocas en el que se pesó, bajo atmósfera inerte, el catalizador. En el matraz se introdujo en primer lugar el compuesto que actuó de nucleófilo y una vez alcanzada la temperatura de reacción, se introdujo con jeringa de plástico, el aceptor de Michael (las cantidades de reactantes y catalizador, así como las condiciones de reacción se detallan a continuación en una tabla resumen). La reacción se llevó a cabo bajo atmósfera inerte y se controló con la extracción periódica de muestras, que previo análisis se extrajeron con éter dietílico y a las que se añadió un patrón externo.

\begin{tabular}{lccc}
\hline $\begin{array}{l}\text { Aceptor de Michael } \\
\text { Comp. } \boldsymbol{\alpha}, \boldsymbol{\beta} \text { - insaturado }\end{array}$ & Nucleófilo & $\mathbf{T}\left({ }^{\circ} \mathrm{C}\right)$ & Catalizador \\
\hline $\begin{array}{l}\text { Chalcona } \\
(5,8 \mathrm{~g}, 28 \mathrm{mmol})\end{array}$ & $\begin{array}{c}\text { Malononitrilo } \\
(1,8 \mathrm{~g}, 28 \mathrm{mmol})\end{array}$ & 80 & $2,8 \mathrm{mmol}$ \\
$\begin{array}{l}\text { Metilacrilato } \\
(0,086 \mathrm{~g}, 1 \mathrm{mmol})\end{array}$ & $\begin{array}{c}\text { Nitrometano } \\
(2 \mathrm{~mL}, 41 \mathrm{mmol})\end{array}$ & 60 & $0,74 \mathrm{mmol}$ \\
$\begin{array}{l}\text { Cicloenonas } \\
(2,8 \mathrm{mmol})\end{array}$ & $\begin{array}{c}\text { Benzotiol } \\
(0,112 \mathrm{~mL}, 2,8 \mathrm{mmol})\end{array}$ & 80 & $0,28 \mathrm{mmol}$ \\
\hline
\end{tabular}

Tabla 8.10.- Proporciones de reactantes y condiciones de reacción para la adición de Michael. 
B.- Identificación de productos

La reacción de adición de Michael en presencia de distintos sustratos, se llevó a cabo con catalizadores tipo líquido iónico basados en estructuras moleculares diamínicas. Los productos resultantes de estas reacciones así como sus características espectroscópicas, se presentan a continuación en la tabla resumen.

Características espectroscópicas de los compuestos de adición de Michael

\begin{tabular}{lcc}
\hline Compuestos & 1H RMN (DMSO-d6) & TR(min) \\
\hline Chalcona & 9,83 \\
Malononitrilo & 1,92
\end{tabular}<smiles>Cc1ccccc1C(C)C(C(=O)c1ccccc1)C(C)C(C)C</smiles>

2-(1-Oxo-1,3-difenilpropan-2-

il)malononitrilo (Michael)<smiles>N#CC(C#N)=C(C=Cc1ccccc1)c1ccccc1</smiles>

2-((E)-1,3-

difenilalilodieno)malononitrilo

(Knoevenagel)

Metil Metacrilato

6,54 (d, 1H, CH(4)), 6,92 (d, 1H, CH(5)),

7,35-7,10 (m, 10H, CH(aromáticos))
2,52 (c, $\left.1 \mathrm{H}, \mathrm{CH}_{2}(4)\right), 2,83$ (c, $\left.1 \mathrm{H}, \mathrm{CH}_{2}(4)\right)$,

3,9 (c, 1H, CH(5)), 4,00 (d, 1H, CH(9)),

7,20-7,08 (m, 5H, CH $(3,2,1))$,

7,45-7,37 (m, 3H, $\mathrm{CH}(7,8))$,

11,23

$8,01(\mathrm{~d}, 2 \mathrm{H}, \mathrm{CH}(6))$,

Nitrometano<smiles>COC(=O)C(C)CCC(=O)N=O</smiles>

1,21 (d, 3H, $\left.\mathrm{CH}_{3}(\mathbf{4})\right), \mathbf{2 , 2 0}\left(\mathrm{c}, 2 \mathrm{H}, \mathrm{CH}_{2}(\mathbf{2})\right)$, 2,50 (q, $1 \mathrm{H}, \mathrm{CH}(3)), 3,60$ (s, 3H, $\left.\mathrm{CH}_{3}(5)\right)$,

$4,40\left(\mathrm{t}, 2 \mathrm{H}, \mathrm{CH}_{2}(\mathbf{1})\right)$,

Metil 2-metil-4-nitrobutanoato

2-Ciclopentenona

Benzotiol<smiles>O=C1CCC(Sc2ccccc2)C1</smiles>

3-(feniltio)ciclopentanona

2-Ciclohexenona 
Benzotiol<smiles>O=C1CCCC(Sc2ccccc2)C1</smiles>

3-(feniltio)ciclohexanona

Dodecano (Patron)
1,75-1,80 (m, 2H, $\left.\mathrm{CH}_{2}(3)\right), \mathbf{1 , 9 7 - 2 , 2 6}(\mathrm{m}, 2 \mathrm{H}$, $\left.\mathrm{CH}_{2}(2)\right), 2,28-2,39\left(\mathrm{~m}, 2 \mathrm{H}, \mathrm{CH}_{2}(4)\right), 2,42-2,64$ (c, $\left.2 \mathrm{H}, \mathrm{CH}_{2}(5)\right), 2,90(\mathrm{q}, 1 \mathrm{H}, \mathrm{CH}(\mathbf{1})), 7,00(\mathrm{~m}$, $1 \mathrm{H}, \mathrm{CH}(8)), 7,15-7,20(\mathrm{~m}, 4 \mathrm{H}, \mathrm{CH}(6-7))$

Tabla 8.11.- Tiempos de retención de reactantes y productos y ${ }^{1} \mathrm{H}$ RMN del producto de interés. Programa de temperaturas del análisis por GC: $80^{\circ} \mathrm{C}(2 \mathrm{~min})-20^{\circ} \mathrm{C} / \mathrm{min}-280^{\circ} \mathrm{C}(8 \mathrm{~min})$.

\subsubsection{Proceso multietapa Henry-Michael}

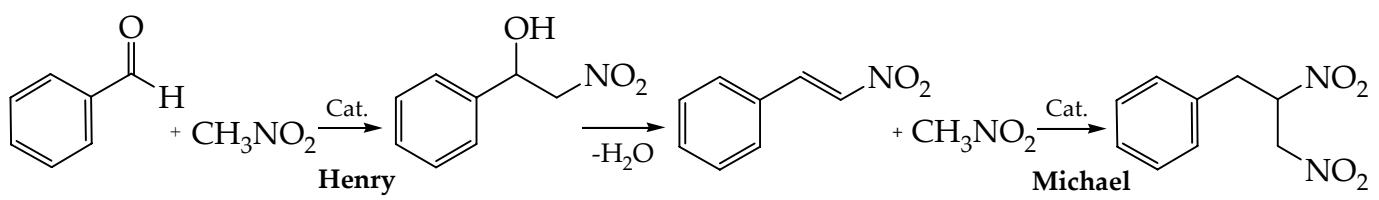

Esquema 8.1.- Esquema del proceso multietapa Henry-Michael entre benzaldehido y nitrometano.

\section{A.- Procedimiento de reacción}

De forma general, el proceso multietapa Henry-Michael se llevó a cabo en un matraz de base redonda de $10 \mathrm{~mL}$ equipado con dos bocas. El catalizador $(1 \mathrm{mmol})$ se pesó directamente en el matraz intentado mantener en todo momento la atmósfera inerte. $2 \mathrm{~mL}$ de nitrometano (37 mmol) se introdujeron al matraz, que se dispuso dentro del baño de silicona a $50^{\circ} \mathrm{C}$, conectado a un refrigerante y con agitación vigorosa. Alcanzada la temperatura de reacción se introdujo el aldehido correspondiente. El curso de la reacción, que duró 4 horas, se siguió tomando muestras periódicas que se extrajeron con éter dietílico, se les añadió un patrón externo y se analizaron por cromatografía de gases.

\begin{tabular}{lcc}
\hline \multicolumn{1}{c}{ Aldehído } & Nitrometano & Catalizador \\
\hline Benzaldehído & Nitrometano & $1 \mathrm{mmol}$ \\
$(3,4 \mathrm{~g}, 2 \mathrm{mmol})$ & $(2 \mathrm{~mL}, 37 \mathrm{mmol})$ & \\
4-Nitrobenzaldehído & Nitrometano & $1 \mathrm{mmol}$ \\
$(0,302 \mathrm{~g}, 2 \mathrm{mmol})$ & $(2 \mathrm{~mL}, 37 \mathrm{mmol})$ & \\
\hline
\end{tabular}




\begin{tabular}{lcc}
\hline 4-Clorobenzaldehído & Nitrometano & $1 \mathrm{mmol}$ \\
$(0,281 \mathrm{~g}, 2 \mathrm{mmol})$ & $(2 \mathrm{~mL}, 37 \mathrm{mmol})$ & \\
4-Metoxibenzaldehído & Nitrometano & $1 \mathrm{mmol}$ \\
$(0,240 \mathrm{~g}, 2 \mathrm{mmol})$ & $(2 \mathrm{~mL}, 37 \mathrm{mmol})$ & \\
\hline
\end{tabular}

Tabla 8.12.- Proporciones de reactantes y catalizador para el proceso multietapa HenryMichael.

B.- Identificación de productos

El proceso multietapa de Henry-Michael, en presencia de distintos sustratos, se llevó a cabo con catalizadores tipo líquido iónico basados en estructuras moleculares diamínicas. Los productos resultantes de estas reacciones así como sus características espectroscópicas, se presentan a continuación en la tabla resumen.

Características espectroscópicas de los productos obtenidos en los procesos de acoplamiento Henry-Michael

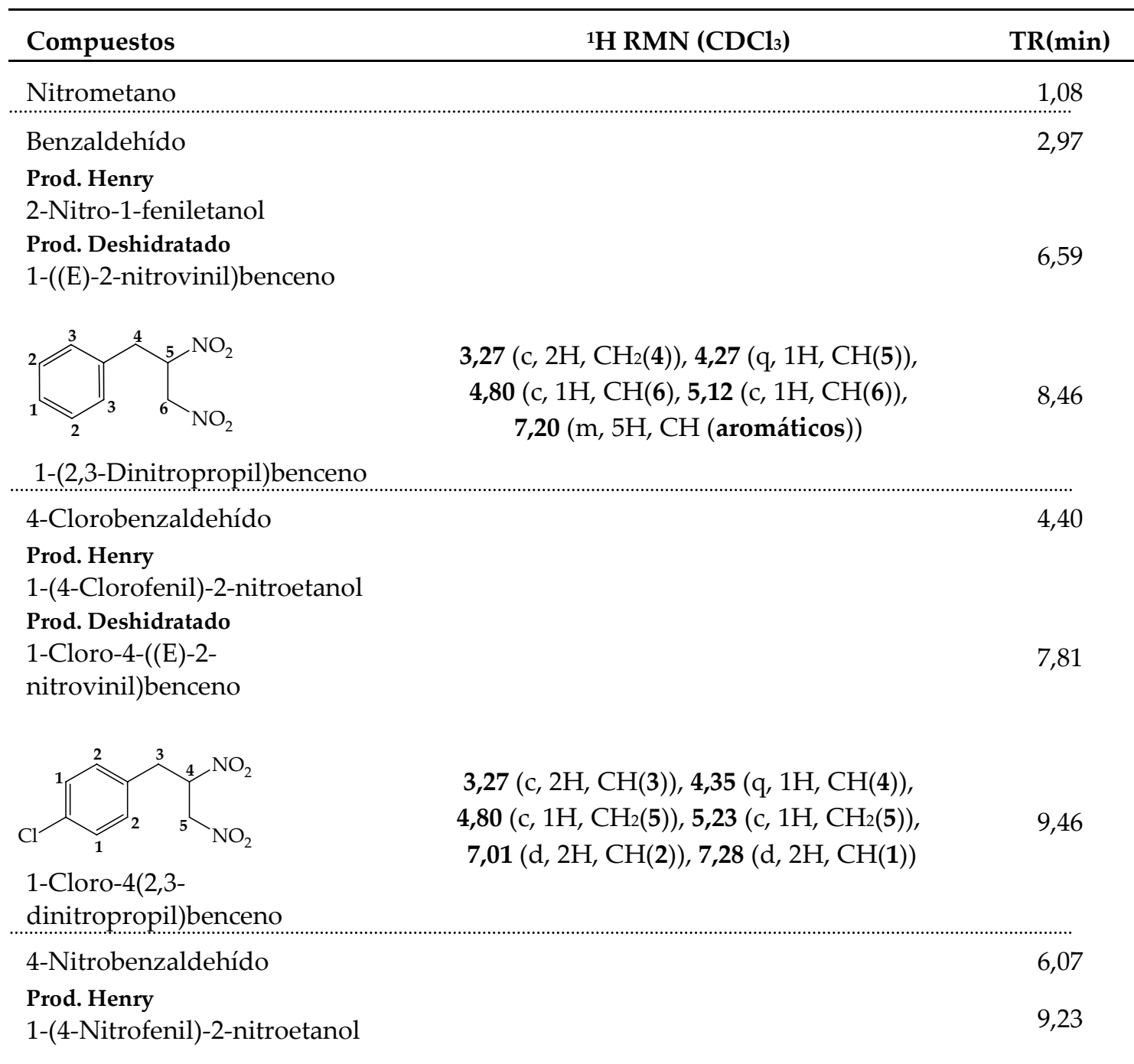


Prod. Deshidratado

1-Nitro-4-((E)-2-

nitrovinil)benceno<smiles>O=[N+]([O-])CC(Cc1ccc([N+](=O)[O-])cc1)[N+](=O)[O-]</smiles>

3,54 (c, 2H, $\left.\mathrm{CH}_{2}(3)\right), 4,35$ (q, 1H, $\left.\mathrm{CH}(4)\right)$,

4,92 (c, 1H, $\left.\mathrm{CH}_{2}(5)\right), 5,21$ (c, $1 \mathrm{H}_{1} \mathrm{CH}_{2}(5)$ ),

10,10

1-Nitro-4(2,3-

7,42 (d, 2H, CH(1)), 8,21 (d, 2H, CH(2))

4-Metoxibenzaldehído

1-(4-Metoxifenil)-2-

nitroetanol

Prod. Deshidratado

1-Metoxi-4-((E)-2-

nitrovinil)benceno<smiles>COc1ccc(CC(C[N+](=O)[O-])[N+](=O)[O-])cc1</smiles>

1-Metoxi-4(2,3-
3,27 (c, 2H, $\left.\mathrm{CH}_{2}(3)\right), 3,73$ (c, 3H, $\left.\mathrm{CH}_{3}(6)\right)$,

4,22 (q, 1H, CH(4)), 4,80 (c, 1H, $\left.\mathrm{CH}_{2}(5)\right)$,

5,01 (c, 1H, $\left.\mathrm{CH}_{2}(5)\right)$, 6,62 (d, 2H, $\left.\mathrm{CH}(\mathbf{1})\right)$,

$7,01(\mathrm{~d}, 2 \mathrm{H}, \mathrm{CH}(2))$

dinitropropil)benceno

Dodecano (Patrón)

Tabla 8.13.- Tiempos de retención de reactantes y productos y ${ }^{1} \mathrm{H}$ RMN del producto de interés. Programa de temperaturas del análisis por GC: $80^{\circ} \mathrm{C}(2 \mathrm{~min})-20^{\circ} \mathrm{C} / \mathrm{min}-280^{\circ} \mathrm{C}(8 \mathrm{~min})$. 
Anexos 



\section{ANEXO I: Índice de Figuras}

Figura 1.1.- Comparativa de estados físicos. Rango de temperatura de distintos compuestos 10

Figura 1.2.- Evolución del número de publicaciones sobre líquidos iónicos en los últimos doce años .14

Figura 1.3.- Reparto de las aplicaciones de los líquidos iónicos en los distintos ámbitos de la química 14

Figura 1.4.- Algunos de los cationes más empleados en la formación de líquidos iónicos .15

Figura 1.5.- Algunos de los aniones más empleados en la formación de líquidos iónicos .15

Figura 1.6.- Diagrama de flujo simplificado de síntesis de líquidos iónicos a partir de una sal de amonio

Figura 1.7.- Estructura del miconazol

Figura 1.8.- Esquema de obtención de cationes funcionarizados a partir de la amina 1-(3-aminopropil)imidazolio

Figura 1.9.- Ejemplos de cationes imidazolio funcionarizados y su potencial aplicación

Figura 1.10.- Ejemplos de aniones fucionalizados y su potencial aplicación

Figura 1.11.- De izq. a dcha.: [Bmim]PF, [Bmim]BF4, AMOENGTm100, [Mpim]I .28

Figura 1.12.- A la izq. [Bmim] $\mathrm{PF}_{6}$, a la dcha. [Mbpy] $\mathrm{PF}_{6}$ .28

Figura 3.1.- Estructuras y nombres abreviados de los líquidos iónicos comerciales empleados como medio de reacción y catalizador en la transposición de Beckmann de la ciclododecanona oxima. BmimPF6: Hexafluorofosfato de 1-butil-3-metilimidazolio; BmimBF4: Tetrafluoroborato de 1-butil-3metilimidazolio; BmpyPF6: Hexafluorofosfato 1-butil-4-metilpiridinio; BmmimPF6: Hexafluorofosfato 1-butil-2,3-dimetilimidazolio

Figura 3.2.- Espectros de RMN-MAS del ${ }^{15} \mathrm{~N}$ de la mezcla de reacción en diferentes estapas de la misma. El pico a -45 corresponde a la señal de la ciclododecanona oxima mientras que el que se aprecia a -258 corresponde a la de la $\omega$-laurolactama

Figura 3.3.- Espectro de RMN-MAS del ${ }^{19} \mathrm{~F}$ de la mezcla de reacción calentada a $50^{\circ} \mathrm{C}$ durante 20 minutos. Se puede apreciar tanto el doblete correspondiente al anión $\mathrm{PF}_{6}{ }^{-}$, como el del producto de hidrólisis $\left[\mathrm{PO}_{2} \mathrm{~F}_{2}\right]^{-}$

Figura 3.4.- Espectro de RMN-MAS del ${ }^{31} \mathrm{P}$ de la mezcla de reacción calentada a $50^{\circ} \mathrm{C}$ durante 20 minutos. Se pueden apreciar las señales correspondientes al producto de hidrólisis $\left[\mathrm{PO}_{2} \mathrm{~F}_{2}\right]^{-}$y el septuplete que se corresponde con el anión $\left[\mathrm{PF}_{6}\right]^{-}$ 
Figura 4.0.- Las imágenes muestran (de izquierda a derecha) las estructuras determinadas por difracción de rayos $\mathrm{X}$ del POM $\left(\mathrm{H}_{5} \mathrm{PO}_{40} \mathrm{~V}_{2} \mathrm{Mo10}\right)$. El POM rodeado de los cuatro cationes imidazolio que sustituyen a los protones de la estructura original del POM. Y una vista general de la red cristalina que forma la estructura secundaria ([bmim $\left.] 4 \mathrm{HPO}_{40} \mathrm{~V}_{2} \mathrm{Mo} 10\right)$

Figura 4.1.- Imagen del material POM-IL-Pd tomada por microscopía electrónica de transmisión (HAADF-STEM)

Figura 4.2.- (Derecha) detalles de alta resolución de los agregados de aproximadamente $20 \mathrm{~nm}$, compuesto por pequeñas nanopartículas. (Izquierda) perfil de alturas a lo largo de la línea recta que se muestra en la imagen de la derecha, en el que se puede ver claramente que el tamaño de las nanopartículas es bastante uniforme, con un diámetro comprendido entre 2-3 nm 91

Figura 4.3.- Imágenes (HAADF-STEM) de la muestra PMO-IL-Pd, con las correspondientes medidas XEDS en el punto indicado: (izquierda) sobre una superficie desnuda del soporte y (derecha) en uno de los agregados de la zona decorada del soporte. Las principales cumbres de P, Mo, V y Pd están señaladas para mayor claridad. Las líneas verdes corresponden al paladio

Figura 4.4.- Imágenes de microscopía electrónica de transferencia de alta resolución (HRTEM) de la muestra POM-IL-Pd. El recuadro en la parte inferior corresponde a la imagen de difracción de electrones a lo largo del eje [221] de la nanopartícula señalada en la imagen TEM . .93

Figura 4.5.- a) Espectros XANES en las proximidades del umbral $\mathrm{K}$ del Pd de la muestra de POM-IL$\mathrm{Pd}(-\bullet-)$ y de la muestra de PdO de referencia (línea continua). b) Fase no corregida de la transformada de Fourier $k^{3}$-ponderada, de los espectros EXAFS de las dos muestras contenedoras de Pd. c) Transformada de Fourier en el espacio $R$ de la señal experimental $k^{3}$ ponderada para la muestra de POM-IL-Pd y su mejor ajuste (línea continua). Se muestra tanto el módulo como la parte imaginaria de las transformadas de Fourier

Figura 4.6.- En el gráfico se presentan la relación funcional entre el número de coordinación calculado, de la segunda $(-\Delta-)$ y la tercera esfera $(-\square-)$ frente al tamaño de las partículas (para partículas de forma esférica $\mathrm{PdO}$ ). líneas gruesas representan los valores obtenidos para los ajustes de la segunda y la tercera esfera de la muestra de POM-IL-Pd . .98

Figura 4.7.- a) Espectros XANES en el borde Pd K de las muestras (de abajo hacia arriba): PdO, POMIL-Pd, POM-Pd, POM-IL-Pdusado y Pdmetálico. b) Fase no corregida de la transformada de Fourier $k^{3}-$ ponderada, de los espectros EXAFS de las mismas muestras. Se reportan tanto el módulo como la parte imaginaria de las transformadas de Fourier .100

Figura 4.8.- Gráfica de tiempo frente a conversión de la reacción de Heck entre yodobenceno (3 $\mathrm{mmol})$ y estireno $(3,9 \mathrm{mmol})$ en $\mathrm{DMF}$ a $100^{\circ} \mathrm{C}$ en presencia de diferentes catalizadores: ( $\square$ ) POM-IL$\mathrm{Pd} ;(\Delta)$ POM-Pd; (o) Acetato de paladio; $\left(^{*}\right)$ POM-IL .103

Figura 4.9.- Gráficas de tiempo frente a rendimiento de la reacción de Heck para el yodobenceno (3 mmol) y el estireno $(3,9 \mathrm{mmol})$, con trietilamina como base $(3,6 \mathrm{mmol})$ y POM-IL-Pd $(0,01 \%$ en peso de Pd). La reacción a) se llevó a cabo en $\mathrm{DMF}$ a $100^{\circ} \mathrm{C}$, tras $10 \mathrm{~min}$ de reacción, el catalizador se filtró en caliente y seguidamente la reacción se continuó en las mismas condiciones (línea contínua). La reacción b) se llevó a cabo en Tolueno a $110^{\circ} \mathrm{C}$, tras $30 \mathrm{~min}$ de reacción, el catalizador se filtró en caliente y seguidamente la reacción se continuó en las mismas condiciones (línea contínua). La línea 
discontínua en ambos casos representa la cinética de la reacción si no se hubiera retirando el catalizador

Figura 4.10.- Rendimientos a 1 hora de reacción de Heck entre yoadobenceno $(3 \mathrm{mmol})$ y estireno $(3,9$ mmol) en DMF a $140^{\circ} \mathrm{C}$, en presencia de POM-IL-Pd y POM-Pd respectivamente.(1) Catalizador fresco. (2-5) Catalizador reusado 106

Figura 4.11.- Imágenes BSE SEM de la muestra fresca y la usada así como sus correspondientes análisis XEDS de las zonas indicadas con flechas. En la muestra fresca se aprecia una distribución homogénea de Mo y V provenientes de las unidades de POM y de Pd de las nanopartículas. Por el contrario, la muestra reusada contiene regiones ricas en $\mathrm{Pd}$ (que se muestran como partículas blancas en la imagen de BSE) y regiones en las que Pd es inexistente (zonas más oscuras en la imagen de BSE), según lo confirmado a partir de los análisis XEDS 107

Figura 5.1.- Ejemplo de alguno de los cationes empleados para la síntesis de líquidos iónicos con acidez Brønsted: (de izda. a dcha.) Sal de 1-alquilimidazolio, lactama N-protonada y piridina Nprotonada

Figura 5.2.- Estructura básica de un catión imidazolio con el protón correspondiente al $\mathrm{C}_{2}$ marcado en negrita 112

Figura 5.3.- Ejemplo de tres aniónes tipo carboxilato empleados en la síntesis de líquidos iónicos básicos. (de izq. a dcha.) formiato, un alquilato genérico y lactato

Figura 5.4.- Ejemplo de líquido iónico con centro básico en el catión. Bis(trifuorometanosulfonil)amidato1-alquil-4-aza-1-azonio-biciyclo[2.2.2]octano .....................113

Figura 5.5.- Gem-diamina esponja de protones 114

Figura 5.6.- Ejemplos gráficos de cooperatividad de los grupos catalíticos A y B sobre los reactivos $\mathrm{R}_{1}$ y $R_{2}$. i) Activación dual: A activa $R_{1}$ y $B$ activa $R_{2}$. ii) Activación secuencial: A activa $R_{2} y$ seguidamente $B$ actúa sobre $R_{2}$ activado. iii) Autoactivación: A activa $B$ que a su vez activa $R_{2}$. vi) Estabilización múltiple del estado de transición $\left(R_{1}-R_{2}\right)^{*}$

Figura 5.7.- Esquema de la estructura de algunos líquidos iónicos gem-diaminas y su precursor Diamina-A (Dipiperidino metano). [Diamina-A]BF4 (Tetrafluoroborato de 1-Piperidina-1-metilpiperidinio), [Diamina-B]BF4 (Tetrafluoroborato de 1-Piperidina-1-etil-piperidinio) y $[\mathrm{N}-$ metilpiperidinio] $\mathrm{BF}_{4}$ (Tetrafluoroborato de N-Metilpiperidinio) 117

Figura 5.8.- Representación de la conversión del metileno activo en la condensación de Knoevenagel entre el benzaldehído $(32 \mathrm{mmol})$ y diferentes compuestos metilenos activos $(28 \mathrm{mmol})$ en presencia de [diamina-A]BF $4(0,28 \mathrm{mmol}):(\mathrm{x})$ malononitrilo a $25^{\circ} \mathrm{C} ;(\diamond)$ Cianoacetato de etilo a $25^{\circ} \mathrm{C}$; (口) Acetoacetato de etilo a $60^{\circ} \mathrm{C}$; (o) Malonato de dietilo a $80^{\circ} \mathrm{C}$

Figura 5.9.- Representación de la conversión del malononitrilo en la condensación de Knoevenagel entre el benzaldehído (32 mmol) y el malononitrilo $(28 \mathrm{mmol})$ en presencia de $(0,28 \mathrm{mmol})$ de (o) [Nmetilpiperidina] $\mathrm{BF}_{4},(\diamond)$ diamina- $\mathrm{A},(\square)$ [diamina- $\left.\mathrm{A}\right] \mathrm{BF}_{4}$ y $(\Delta)$ [diamina-B] $\mathrm{BF}_{4}$ 
Figura 5.10.- Geometría optimizada para el complejo de co-adsorción del benzaldehído y el malononitrilo sobre la [diamina-A]BF4. Código de colores: $\mathrm{O}$ rojo, $\mathrm{C}$ naranja, $\mathrm{N}$ azul, $\mathrm{H}$ blanco, $\mathrm{B}$ rosa, F amarillo .124

Figura 5.11.- a) Malononitrilo adsorbido. b) Estado de transición para la desprotonación del malononitrilo. c) Intermedio carbaniónico del metileno adsorbido sobre la [diamina-A]BF4 (izquierda) y [diamina-B]BF4 (derecha). Código de colores: $\mathrm{C}$ naranja, $\mathrm{N}$ azul, $\mathrm{H}$ blanco, $\mathrm{B}$ rosa, $\mathrm{F}$ amarillo

Figura 5.12.- .- Perfil de energías calculado para la condensación de Knoevenagel del benzaldehído y el malononitrilo catalizada por la [diamina-A]BF4 (línea continua) y [diamina-B]BF (línea discontinua)

Figura 5.13.- a) Co-adsorción del benzaldehído y el intermedio carbaniónico del metileno. b) Estado de transición en la formación del enlace C-C. c) Alcohol intermedio de la condensación sobre la [diamina-A]BF4 (izquierda) y [diamina-B]BF4 (derecha). Código de colores: O rojo, $\mathrm{C}$ naranja, $\mathrm{N}$ azul, $\mathrm{H}$ blanco, B rosa, $\mathrm{F}$ amarillo

Figura 5.14.- Representación del $\ln [\mathrm{A}]$ y $1 /[\mathrm{A}]$ frente al tiempo, para la condensación de Knoevenagel entre el malononitrilo y el benzaldehído catalizada por la [diamina-A]BF4 (izquierda) y la [diamina$\mathrm{B}_{\mathrm{BF}} 4$ (derecha) a $25^{\circ} \mathrm{C}$. La A representa la concentración $(\mathrm{mmol} / \mathrm{mL})$ de malononitrilo para la [diamina-A]BF 4 y la concentración $(\mathrm{mmol} / \mathrm{mL})$ de benzaldehído para la [diamina-B]BF 4

Figura 5.15.- Representación de la constante de la velocidad frente a la inversa de la temperatura $(1 / \mathrm{K})$, para la condensación de Knoevenagel entre el malononitrilo y el benzaldehído catalizada por la [diamina-A]BF4 $(\downarrow)$ y la [diamina-B]BF4 considerándola reacción de primer orden $(\boldsymbol{\square})$ o de segundo orden $(\mathbf{\Delta})$ 136

Figura 6.1.- Estructura de la 2-Fenil- $\gamma$-cromona y estructora general de flavonoides y chalconas .151

Figura 6.2.- Estructura del (1) Tetrafluoroborato de 1-piperidina-1-metil-piperidinio, (2) Tetrafluoroborato de 1-piperidina-1-etil-piperidinio, (3) Tetrafluoroborato de 1-piperidina-1-propilpiperidinio, (4) Dipiperidinometano, (5) Piperidina, (6) N-Metilpiperidina, (7) Tetrafluoroborato de N-metil-piperidinio

Figura 6.3.- Conversión de la acetofenona para dar trans-chalcona mediante la condensación de Claisen-Schmidt con benzaldehído a $130^{\circ} \mathrm{C}$ y en presencia de [diamina-A]BF4 (1 mmol) (), [metilpiperidinio]BF4 $(1 \mathrm{mmol})(\Delta)$, piperidina $(1 \mathrm{mmol})(\mathrm{o})$, amina-A $(1 \mathrm{mmol})(\diamond)$ y metilpiperidina $(1 \mathrm{mmol})(\mathrm{x})$ .154

Figura 6.4.- Conversión de la acetofenona para dar trans-chalcona mediante la condensación de Claisen-Schmidt con benzaldehído a $130^{\circ} \mathrm{C}$ y en presencia de [diamina-A]BF $4(\square)$, [diamina-B]BF4 (o), $\mathrm{y}[$ diamina-C]BF $4(\mathrm{x})$ 155

Figura 6.5.- Representación de las conversiones y selectividades a chalcona obtenidas por el catalizador [diamina-A]BF 4 tras sucesivos ciclos de uso y reciclado 
Figura 6.6.- Perfil de energías calculadas para la condensación de Claisen-Schmidt entre la acetofenona y el benzaldehído catalizada por [diamina-A]BF4 (línea continua) y [diamina-B]BF4 (línea discontinua) 158

Figura 6.7.- Geometrías optimizadas de las estructuras involucradas en el mecanismo de reacción de la condensación de Claisen-Schmidt entre la acetofenona y el benzaldehído, catalizada por la [diamina-A]BF4. Las distancias se expresan en Å. Código de colores: O rojo, C naranja, N verde, B morado, $\mathrm{F}$ amarillo, $\mathrm{H}$ blanco

Figura 6.8.- Geometría optimizada para la acetofenona absorbida sobre dos conformaciones diferentes del catalizador [diamina-B]BF. Las distancias marcadas en las imágenes están en $\AA$. Código de colores: $\mathrm{O}$ rojo, $\mathrm{C}$ naranja, $\mathrm{N}$ verde, $\mathrm{B}$ morado, $\mathrm{F}$ amarillo, $\mathrm{H}$ blanco 161

Figura 6.9.- Geometría optimizada y estabilidad relativa de los conformeros más estables obtenidos para los catalizadores [diamina- $\mathrm{A}_{\mathrm{BF}}$ y [diamina-B]BF 4 . Las distancias se miden en $\AA$. Código de colores: $\mathrm{O}$ rojo, $\mathrm{C}$ naranja, B morado, $\mathrm{F}$ amarillo, $\mathrm{H}$ blanco

Figura 7.1.- Cinética de la reacción en one-pot de Henry-Michael. Se representan los rendimientos al producto final (3) conseguidoa con: [diamina-A]BF4 ( $\square)$, diamina-A (o), piperidina $(\Delta)$ y metilpiperidina $(\mathrm{x})$

Figura 8.1.- [Diamina-A]BF 4 181

Figura 8.2.- [Diamina-B] $\mathrm{BF}_{4}$ 201

Figura 8.3.- [Metilpiperidina]BF 202

Figura 8.4.- [Diamina-A]Cl .203

Figura 8.5.- [Diamina-A $] \mathrm{N}\left(\mathrm{CF}_{3} \mathrm{SO}_{2}\right)_{2}$ 204

Figura 8.6.- [Diamina-C]BF4 205 



\section{ANEXO II: Índice de Tablas}

Tabla 1.1.- Comparativa entre Química Fina y a gran escala ..........................................6

Tabla 1.2.- Factor E de las diversas industrias químicas ..........................................

Tabla 1.3.- Temperaturas de fusión para distintas sales de cloro ....................................29

Tabla 1.4.- Temperaturas de Fusión de distintos LI con catión [Emim] ..................................29

Tabla 1.5.- Densidad de algunas sales binarias. Temperatura de medida: $298 \mathrm{~K}$.........................31

Tabla 1.6.- Miscibilidad de varios disolventes en $\left[\mathrm{Bmim}_{\mathrm{P}} \mathrm{PF}_{6},[\mathrm{Bmim}] \mathrm{Cl}-\mathrm{AlCl}_{3}\right.$ y $[\mathrm{Bmim}] \mathrm{Cl}-\mathrm{Al}_{2} \mathrm{Cl}_{6}$.

M: Completamente miscible, R: Reactivos, I: Completamente inmiscible .............................33

Tabla 1.7.- Aplicaciones industriales publicadas $^{92}$ de Líquidos iónicos ..............................35

Tabla 1.8.- Hidrogenación de 1-Penteno con “Complejo Osborn” como catalizador ......................44

Tabla 1.9.- Reacción de Diels-Alder entre el ciclopentadieno y el etilacrilato ..........................51

Tabla 1.10.- Productos obtenidos en la reacción de cloruros de alquilo con benceno en medio

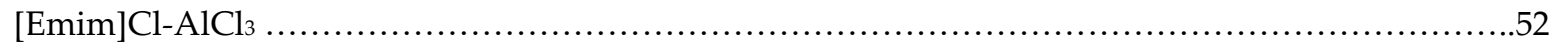

Tabla 3.1.- Algunos de los catalizadores heterogéneos más importantes empleados en la transposición de Beckmann de la ciclododecanona oxima de fase gas. a) WHSV: Weight Hourly Space Velocity (Velocidad espacial)

Tabla 3.2.- Resultados de la transposición de Beckmann de la ciclododecanona oxima en presencia de diferentes líquidos iónicos. Las reacciones se realizaron a $130^{\circ} \mathrm{C}$ durante $2 \mathrm{~h}$, manteniendo una relación molar oxima/lactama $=0,14$. La conversión de la ciclododecanona oxima se determinó por cromatografía de gases a partir de la cantidad de oxima transformada en lactama. La selectividad también se determinó por cromatografía de gases a partir de la lactama generada 67

Tabla 3.3.- Conversión de la ciclododecanona oxima y selectividad a -laurolactama en la transposición de Beckmann a $130^{\circ} \mathrm{C}$ durante $2 \mathrm{~h}$. Los líquidos iónicos empleados en reacción contenían la cantidad de agua indicada en la tabla y determinada por el método de Karl-Fisher. La cantidad de HF se determinó al final de la reacción a partir de los datos de RMN .....................72

Tabla 3.4.- Resultados de la transposición de Beckmann de la ciclododecanona oxima en medio líquido iónico, a $130^{\circ} \mathrm{C}$ durante $2 \mathrm{~h}$ y con adición de un 2,3-3,0\% en peso de agua. La concentración de ácido fluorhídrico se determinó al final de la reacción. (n.d.: no detectado)

Tabla 3.5.- Resultados de la transposición de Beckmann de la ciclododecanona oxima en medio líquido iónico, a $130^{\circ} \mathrm{C}$ durante $2 \mathrm{~h}$. En la entrada $1 \mathrm{el} \mathrm{BmimPF} 6$ fue secado durante $12 \mathrm{~h} \mathrm{a} 75^{\circ} \mathrm{C}$. En las entradas 2 y 3 se adicionó una cantidad determinada de ácido fluorhídrico diluido en agua. El contenido en ácido fluorhídrico y agua se determinó antes y después de la reacción .74 
Tabla 3.6.- Resultados de la reacción de transposición de Beckmann de la ciclododecanona oxima en presencia de 1-Butil-3-metilimidazolio hexafluorofosfato (relación molar oxima/líquido iónico = 0,14), a diferentes temperaturas de reacción durante 2 horas (excepto en el caso de la reacción a $150^{\circ} \mathrm{C}$, que duró 1,5 horas)

Tabla 3.7.- Resultados de la reacción de transposición de Beckmann de la ciclododecanona oxima $(0,260-7,8 \mathrm{~g})$ en presencia de 1-Butil-3-metilimidazolio hexafluorofosfato $(2,6 \mathrm{~g})$ con diferentes relaciones entre oxima y líquido iónico. El porcentaje de oxima detallado en la tabla está en relación con la cantidad inicial del líquido iónico empleado. La temperatura de reacción fue de $130^{\circ} \mathrm{C}$ . .77

Tabla 3.8.- Resultados del estudio de reuso del hexafluorofosfato de 1-butil-3-metilimidazolio (2,6 g) para la reacción de transposición de Beckmann de la ciclododecanona oxima $(0,260 \mathrm{~g})$ a $130^{\circ} \mathrm{C}$. Tiempo de reacción 2 horas. Las cantidades de oxima, tras el primer uso se fueron adecuando según la cantidad de líquido iónico obtenido tras el proceso de extracción

Tabla 4.1.- Análisis de los espectros EXAFS de la muestra de referencia PdO y la muestras POM-ILPd. Los valores entre paréntesis en la primera columna corresponden a las distancias publicadas para la estructura de $\mathrm{PdO}$ resuelto por difracción de rayos $\mathrm{X}$. $\mathrm{R}$ representa el radio medio de cada esfera de coordinación. $\mathrm{N}$ representa en número de coordinación. D-W es el factor de Debye-Waller que informa de la atenuación de la dispersión de los rayos $\mathrm{X}$ al encontrarse con los distintos elementos que conforman la estructura de la materia en estudio

Tabla 4.2.- Resultados de la reacción de Heck de yodobenceno o bromobenceno ( $3 \mathrm{mmol}$ ) con estireno o acrilato de metilo $(3,9 \mathrm{mmol})$ y trietilamina $(3,6 \mathrm{mmol})$ en $0,5 \mathrm{~mL}$ de DMF como disolvente y en presencia del $0,01 \%$ en peso de paladio. Las reacciones se realizaron a $100^{\circ} \mathrm{C}$ durante 2 horas .......102

Tabla 4.3.- Resultados de la reacción de Heck de yodobenceno ( $3 \mathrm{mmol})$ con el estireno $(3.9 \mathrm{mmol})$ y trietilamina $(3,6 \mathrm{mmol})$ en $0,5 \mathrm{ml}$ de disolvente, en presencia del $0,01 \%$ en peso de paladio (en la cantidad correspondiente de catalizador). Las reacciones se desarrollaron durante $2 \mathrm{~h}$

Tabla 5.1.- Resultados obtenidos para la condensación de Knoevenagel de diferentes sustratos, a temperatura ambiente y empleando como catalizador la [diamina-A]BF4. Condiciones de reacción: [diamina-A]BF4 4 (20 mol\%), compuesto metileno acitovo (5 mmol), aldehído o cetona (5 mmol), temperatura ambiente, atmósfera inerte. Rendimientos calculados por cromatografía de gases ......121

Tabla 5.2.- Propiedades de las sales orgánicas [diamina-A]BF 4 , [diamina-B]BF 4 , $[\mathrm{N}-$ metilpiperidina]BF4. [a] Las temperaturas de descomposición se determinaron por análisis termogravimétrico en flujo de nitrógeno y con una rampa de termepratura de $10^{\circ} \mathrm{C}$ por minuto. ${ }^{[b]} \mathrm{La}$ densidad se calculó a $30^{\circ} \mathrm{C}$. [c] Estado físico de las sales a $20^{\circ} \mathrm{C}$. [d] Conductividad iónica calculada en disolución acuosa al $10^{-3} \mathrm{M}$ y a $20^{\circ} \mathrm{C}$. [e] No se ha determinado

Tabla 5.3.- Energías de adsorción y activación y entalpía de reacción ( $\mathrm{kcal} / \mathrm{mol})$ calculadas para los dos pasos del mecanismo de reacción catalizada por [diamina-A]BF 4 y [diamina-B]BF 4

Tabla 5.4.- Rendimientos (\%) de la condensación de Knoevenagel a los cinco minutos de reacción entre el malononitrilo y el benzaldehído a diferentes temperaturas 
Tabla 5.5.- Energías de activación $(\mathrm{kcal} / \mathrm{mol})$ calculadas y obtenidas experimentalmente, para los dos pasos que entraña el mecanismo de la condensación de Knoevenagel entre el malononitrilo y el benzaldehído, catalizadas por la [diamina-A]BF4 y la [diamina-B]BF4

Tabla 5.6.- Resultados de la condensación de Knoevenagel para la obtención de cumarinas en presencia de diferentes catalizadores. Condiciones de reacción: Aldehído (32 mmol), Compuesto del metileno $(28 \mathrm{mmol})$, catalizador $(0,28 \mathrm{mmol}), \mathrm{T}=100^{\circ} \mathrm{C}$, atmósfera inerte; $\mathrm{El}$ rendimiento de la reacción determinó por cromatografía de gases a partir de la cantidad inicial de compuesto metilénico. La selectividad en todos los casos fue del $100 \%$

Tabla 5.7.- Resultados de la síntesis de iminocumarinas a partir de la condensación de Knoevenagel entre el salicilaldehído y el malononitrilo en presencia de diferentes catalizadores. Condiciones de reacción: Salicilaldehído (32 mmol), malononitrilo $(28 \mathrm{mmol})$, catalizador $(0,28 \mathrm{mmol})$, etanol $(10 \mathrm{~mL})$, temperatura ambiente y atmósfera inerte; el rendimiento se calculó por cromatografía de gases y atendiendo a la cantidad inicial de malononitrilo; la selectividaden todos los casos fue del $100 \%$

Tabla 6. 1.- Resultados de la condensación de Claisen-Schmidt entre la acetofenona y derivados del benzaldehído en presencia de catalizadores mono y bifuncionales. Condiciones de reacción: benzaldehído $(32 \mathrm{mmol})$, acetofenona $(28 \mathrm{mmol})$, catalizador $(1 \mathrm{mmol}), \mathrm{T}=130^{\circ} \mathrm{C}$, tiempo $=6 \mathrm{~h}$. [a]Cantidad de catalizador empleado: $2 \mathrm{mmol}$. ${ }^{[b]}$ Determinado mediante cromatografía de gases a partir de la acetofenona convertida

Tabla 6.2.- Resultados de la condensación de Claisen-Schmidt entre la acetofenona y el benzaldehído en presencia de catalizadores del tipo [diamina-A] con diferentes aniones. Condiciones de reacción: benzaldehído ( $32 \mathrm{mmol})$, acetofenona $(28 \mathrm{mmol})$, catalizador $(1 \mathrm{mmol}), \mathrm{T}=130^{\circ} \mathrm{C}$, tiempo $=6 \mathrm{~h}$. [a]Determinado mediante cromatografía de gases a partir de la acetofenona convertida 156

Tabla 6.3.- Energías de adsorción y activación y entalpías de reacción calculadas para la primera etapa de la reacción detallada en la Figura 6.5

Tabla 7.1.- Adición de Michael sobre chalconas empleando diferentes catalizadores. Condiciones de reacción: Compuesto carbonílico $\alpha, \beta$-insaturado $(2,8 \mathrm{mmol})$, nucleófilo $(2,8 \mathrm{mmol})$, catalizador $(0,28$ $\mathrm{mmol}), \mathrm{T}=80^{\circ} \mathrm{C}$

Tabla 7.2.- Adición de Michael sobre distintas cicloenonas empleando diferentes catalizadores. Condiciones de reacción: Compuesto carbonílico $\alpha, \beta$-insaturado (aceptor) $(2,8 \mathrm{mmol})$, nucleófilo $(2,8$ $\mathrm{mmol})$, catalizador $(0,28 \mathrm{mmol}), \mathrm{T}=80^{\circ} \mathrm{C}$, tiempo de reacción 2 horas. 176

Tabla 7.3.- Adición de Michael sobre metil metacrilato con diferentes catalizadores. Condiciones de reacción: Compuesto carbonílico $\alpha, \beta$-insaturado (aceptor) $(1 \mathrm{mmol})$, nucleófilo $(1 \mathrm{mmol})$, catalizador $(0,1 \mathrm{mmol})$ .177

Tabla 7.4.- Resultados del proceso multietapa entre el benzaldehído y el nitrometano. Condiciones de reacción: benzaldehído $(2 \mathrm{mmol})$, nitrometano $(37 \mathrm{mmol})$, Catalizador $(1 \mathrm{mmol}), \mathrm{T}=50^{\circ} \mathrm{C}$, tiempo de reacción: 2 horas. La conversión se calculó por cromatografía de gases a partir de la cantidad inicial de benzaldehído. El rendimiento se calculó también por cromatografía de gases y a partir de los productos de reacción generados. ${ }^{[a] L a s ~ c o n d i c i o n e s ~ d e ~ r e a c c i o ́ n ~ c o n ~ a l u ́ m i n a ~ b a ́ s i c a ~ f u e r o n: ~}$ 
benzaldehído ( $2 \mathrm{mmol})$, nitrometano $(37 \mathrm{mmol}), \mathrm{Al}_{2} \mathrm{O}_{3}(1 \mathrm{~g}), \mathrm{T}=100^{\circ} \mathrm{C}$, tiempo de reacción: 4 horas

Tabla 7.5.- Resultados del proceso multietapa entre benzaldehídos 4-sustituídos y el nitrometano. Condiciones de reacción: benzaldehído $(2 \mathrm{mmol})$, nitrometano $(37 \mathrm{mmol})$, Catalizador $(1 \mathrm{mmol}), \mathrm{T}=$ $50^{\circ} \mathrm{C}$, tiempo de reacción: 4 horas. La conversión se calculó por cromatografía de gases a partir de la cantidad inicial de benzaldehído. El rendimiento se calculó también por cromatografía de gases y a partir de los productos de reacción generados

Tabla 8.1.- Tiempos de retención de reactantes y productos y ${ }^{1} \mathrm{H}$ RMN del producto de interés y de uno de los líquidos iónicos empleados como medio de reacción. Programa de temperaturas del análisis por GC: $80^{\circ} \mathrm{C}(2 \mathrm{~min})-20^{\circ} \mathrm{C} / \mathrm{min}-280^{\circ} \mathrm{C}(2 \mathrm{~min})$ .206

Tabla 8.2.- Tiempos de retención de reactantes y productos y ${ }^{1} \mathrm{H}$ RMN del producto de interés. Programa de temperaturas del análisis por GC: $80^{\circ} \mathrm{C}(2 \mathrm{~min})-20^{\circ} \mathrm{C} / \mathrm{min}-280^{\circ} \mathrm{C}(8 \mathrm{~min})$ 208

Tabla 8.3.- Condiciones de reacción y proporciones de reactantes para la reacción de Knoevenagel

Tabla 8.4.- Tiempos de retención de reactantes y productos y ${ }^{1} \mathrm{H}$ RMN de los productos obtenidos. Programa de temperaturas del análisis por GC: $80^{\circ} \mathrm{C}(2 \mathrm{~min})-20^{\circ} \mathrm{C} / \mathrm{min}-280^{\circ} \mathrm{C}(2 \mathrm{~min})$ 210

Tabla 8.5.- Condiciones de reacción y proporciones de reactantes para la síntesis de cumarinas e iminocumarinas

Tabla 8.6.- Tiempos de retención de reactantes y productos y ${ }^{1} \mathrm{H}$ RMN del producto obtenidos. Programa de temperaturas del análisis por GC: $80^{\circ} \mathrm{C}(2 \mathrm{~min})-20^{\circ} \mathrm{C} / \mathrm{min}-280^{\circ} \mathrm{C}(2 \mathrm{~min})$

Tabla 8.7.- Tiempos de retención de reactantes y productos y ${ }^{1} \mathrm{H}$ RMN del producto de interés. Programa de temperaturas del análisis por GC: $80^{\circ} \mathrm{C}(2 \mathrm{~min})-20^{\circ} \mathrm{C} / \mathrm{min}-280^{\circ} \mathrm{C}(2 \mathrm{~min})$

Tabla 8.8.- Proporciones de reactantes para la condensación aldólica .214

Tabla 8.9.- Tiempos de retención de reactantes y productos y ${ }^{1} \mathrm{H}$ RMN del producto de interés. Programa de temperaturas del análisis por GC: $80^{\circ} \mathrm{C}(2 \mathrm{~min})-20^{\circ} \mathrm{C} / \mathrm{min}-280^{\circ} \mathrm{C}(8 \mathrm{~min})$

Tabla 8.10.- Proporciones de reactantes y condiciones de reacción para la adición de Michael .216

Tabla 8.11.- Tiempos de retención de reactantes y productos y ${ }^{1} \mathrm{H}$ RMN del producto de interés. Programa de temperaturas del análisis por GC: $80^{\circ} \mathrm{C}(2 \mathrm{~min})-20^{\circ} \mathrm{C} / \mathrm{min}-280^{\circ} \mathrm{C}(8 \mathrm{~min})$ .216

Tabla 8.12.- Proporciones de reactantes y catalizador para el proceso multietapa Henry-Michael

Tabla 8.13.- Tiempos de retención de reactantes y productos y ${ }^{1} \mathrm{H}$ RMN del producto de interés. Programa de temperaturas del análisis por GC: $80^{\circ} \mathrm{C}(2 \mathrm{~min})-20^{\circ} \mathrm{C} / \mathrm{min}-280^{\circ} \mathrm{C}(8 \mathrm{~min})$ $217-219$ 


\section{Anexo III: Índice de Esquemas}

Esquema 1.1.- Reacción básica de alquilación .16

Esquema 1.2.- Reacción general de formación de líquidos iónicos a partir de sales de plata .19

Esquema 1.3.- Reacción general de síntesis de TSILs, donde $\mathrm{R}$ y $\mathrm{R}^{\prime}$ representan diferentes grupos funcionales

Esquema 1.4.- Hidrogenación del 1-Penteno .44

Esquema 1.5.- Hidrogenación del Ácido 2-Arilacrílico al Ácido (S)-2-Fenilpropiónico con el complejo quiral $\left[\mathrm{RuCl}_{2}(\mathrm{~S})-\mathrm{BINAP}\right]_{2} \mathrm{NEt}_{3}$ como catalizador en $[\mathrm{Bmim}] \mathrm{BF} 4$ .45

Esquema 1.6.- Epoxidación asimétrica de Jacobsen-Katsuki del 2,2-dimetilcromeno con un complejo de manganeso (catalizador de Jacobsen) en medio [Bmim] $\mathrm{PF}_{6}$

.46

Esquema 1.7.- Reacción de Heck entre el Yodobenceno y el Etilacrilato con Acetato de Paladio como catalizador y $\left[\mathrm{Bmim}^{\mathrm{P}} \mathrm{PF}_{6}\right.$ como medio de reacción

Esquema 1.8.- Reacción de Suzuki entre un haluro de arilo y el Ácido Fenilborónico con Tetratrifenilfosfina de Paladio como catalizador y $[\mathrm{Bmim}] \mathrm{BF}_{4}$ como medio de reacción .47

Esquema 1.9.- Reacción de Stille catalizada por un complejo de paladio entre yodoenonas y vinil o arilestanadatos en medio [Bmim] $\mathrm{BF}_{4}$

Esquema 1.10.- Adición de Michael entre etilacrilato y dipropilamina en disolución acuosa de $[\mathrm{Bmim}] \mathrm{BF}_{4}$ 48

Esquema 1.11.- Reacción de Baylis-Hillman entre metilacrilato y benzaldehído en medio [Bmim] $\mathrm{PF}_{6}$

Esquema 1.12.- Reacción de Mannich entre 4H-isocromeno-1,3-diona, un aldehido y una amina en medio $\left[\mathrm{Bmim}_{\mathrm{P}} \mathrm{PF}_{6} \mathrm{o}[\mathrm{Bmim}] \mathrm{BF}_{4}\right.$ sin empleo de catalizadores heterogéneos

Esquema 1.13.- Síntesis de 1,1-diciano-2-fenileteno mediante reacción de Knoevenagel entre el propano-1,3-dinitrilo y el benzaldehido en medio [Hmim] $\mathrm{PF}_{6}$ y con glicina como base . .50

Esquema 1.14.- Reacción de Diels-Alder entre el ciclopentadieno y el etilacrilato. .51

Esquema 1.15.- Reacción de Friedel-Crafts. Alquilación del benceno con cloruro de metilo .52

Esquema 3. 1.- Esquema simplificado de reacción entre la $\varepsilon$-caprolactama y el ácido sulfúrico a escala industrial

Esquema 3.2.- .- Mecanismo de reacción de la transposición de Beckmann para la ciclododecanona oxima 
Esquema 4.1.- Esquema de reacción general para reacciones de cross-coupling utilizando distintos agentes nucleofílicos: (1) Organometálicos, (2) Insaturaciones y (3) Aminas ..........................87

Esquema 4.2.- Ciclo general de reacciones de acoplamiento C-C sobre un catalizador de paladio (Pd)

Esquema 4.3.- Ciclo de reacción para acoplamiento de Heck sobre un catalizador de paladio (Pd)

Esquema 4.4.- Esquema de reacción de acoplamiento C-C tipo Heck entre el estireno (2) o el acrilato de metilo (4) y un halobenceno (1)

Esquema 5.1.- Mecanismo general de la reacción de Knoevenagel entre un compuesto metileno activo y otro con un grupo carbonilo 118

Esquema 5.2.- Condensación de Knoevenagel entre el benzaldehído y distintos compuestos metileno activos $\left(X=\mathrm{CN}, \mathrm{CH}_{3}, \mathrm{COOCH}_{2} \mathrm{CH}_{3} ; \mathrm{Y}=\mathrm{CN}, \mathrm{COOCH}_{2} \mathrm{CH}_{3}\right)$

Esquema 5.3.- Propuesta de mecanismo bifuncional ácido-base para la condensación de Knoevenagel mostrada en el Esquema 5.2

Esquema 5.4.- Representación esquemática de la síntesis de derivados de cumarinas e iminocumarinas en presencia de [diamina-A]BF4 como catalizador .

Esquema 6.1.- Mecanismo generalmente aceptado de la condensación de Claisen-Schmidt de una cetona con un aldehído

Esquema 6.2.- Representación esquemática de la síntesis de la hexosa D-fructosa-1,6-bifosfato (FBP) mediante la condensación aldólica de la dihidroxiacetonafosfato (DHAP) y el D-gliceraldehído-3fosfato (GAP) catalizada por el enzima D-Fructosa-1,6-bifosfato aldolasa (FBPA) ... .165

Esquema 6.3.- Primera parte de los mecanismos de condensación catalizados por la aldolasa clase II y la [diamina-A]BF4 .166

Esquema 6.4.- Segunda parte de los mecanismos de condensación catalizados por la aldolasa clase II y la [diamina-A]BF4

Esquema 7.1.- Mecanismo de reacción general de la adición de Michael entre un nucleófilo y un compuesto carbonílico $\alpha, \beta$-insaturado

Esquema 7.2.- Esquema básico de condensación de Henry entre el benzaldehído y el nitrometano para dar como producto directo de la condensación el hidroxi-1-nitrometilbenceno (nitroalcohol) y el producto de su deshidratación el 1-(E)-2-nitrovinilbenceno (nitroalqueno) .179

Esquema 7.3.- Mecanismo general de la reacción de Henry entre un nitroalcano y un compuesto carbonílico. El compuesto final del mecanismo es un nitroalqueno formado por deshidratación del nitroalcohol 179 
Esquema 7.4.- Esquema del proceso multietapa para la síntesis del 2-Nitro-1-nitrometilbenceno 180

Esquema 8.1.- Esquema del proceso multietapa Henry-Michael entre benzaldehido y Nitrometano .217 

Anexo IV: Abreviaturas, acrónimos y aclaraciones

AAB: Atomic Absorption Background (Espectroscipía de absorción atómica).

AEPS: 3-[2-(2-aminoetilamino)etilamino]propilsiloxano.

Arom: Aromático.

BINAP: 2,2'-bis(difenilfosfino)-1,1'-binaftil.

[B]-MFI: Silicalita dopada con Boro.

Bmim: 1-Butil-3-metilimidazolio.

Bmmim: 1-Butil-2,3-dimetilimidazolio.

Bmpy: 1-Butil-4-metilpiridinio.

br: broad (banda ancha).

BSE-SEM: Backscattered electron mode of scanning electron microscopy (Microscopía electrónica de barrido en modo de electrones retrodispersados). c: cuadruplete.

Dabco: 1,4-diazabiciclo[2.2.2]octano.

DFT: Density Functional Theory (Teoría del funcional de la densidad).

DHAP: Dihidroxiacetonafosfato.

Diamina-A: Dipiperidino metano.

[Diamina-A]BF: Tetrafluoroborato de 1-Piperidina-1-metil-piperidinio.

[Diamina-B]BF4: Tetrafluoroborato de 1-Piperidina-1-etil-piperidinio.

[Diamina-C]BF4: Tetrafluoroborato de 1-Piperidina-1-propil-piperidinio.

DMF: Dimetilformamida.

DMAN: 1,8-bis(dimetilamino)naftaleno.

DMSO: Dimetilsulfóxido.

ED: Energetic Dispersion (Dispersión energética).

EXAFS: Extended X-ray Absorption Fine Structure (Absorción de rayos-X extendida a toda la estructura).

Emim: 1-Etil-3-metilimidazolio.

FBP: D-fructosa-1,6-bifosfato.

FBPA: D-fructosa-1,6-bifosfato aldolasa.

Filtro de membrana de nailon: Filtros semejantes a los de celulosa para separar una fase líquida de otra sólida, empleando un embudo Buchner y a vacío, pero con tamaño de poro mucho más pequeño y de más fácil manejo. Especialmente indicado para productos sólidos muy finos y escasos.

FP6: Sixth Framework Program for Research and Technological Development (Sexto programa marco de investigación y desarrollo tecnológico).

FT-IR: Fourier Transform-Infrared spectroscopy (Espectroscopía Infraroja por transformada de Fourier).

GAP: D-Gliceraldehído-3-fosfato. 
GC-MS: Gas Cromatography-Mass Spectrometer (Cromatógrafo de gases acoplado a un espectrómetro de masas).

Glu18z: Resíduo de aminoácido localizado en el enzima FBPA.

HAADF-STEM: high angle annular dark field scanning transmission electron microscopy. (Microscopía electrónica de transmisión de campo oscuro poralto ángulo anular).

Hmim: 1-Hexil-3-meilimidazolio.

HRTEM: High Resolution Transmission Electron Microscopy (Microscopía electrónica de transmisión de alta resolución).

ICP-OES: Inductively Coupled Plasma-Optical Emision Spectrometer

(Espectrómetro de emisión óptica por acoplamiento inductivo de plasma).

INCA: Consorcio Italiano Interuniversitario "Química para el Ambiente".

ITQ-2: Primer miembro de la clase de zeolitas deslaminadas.

m: Multiplete.

MCM-41: Mobil Composition of Matter $n^{\circ}$ 41. Tamiz molecular mesoporoso.

md: Medium (intensidad media)

Mmim: 1-Metil-3-metilimidazolio.

Mpim: 1-Metil-3-propilimidazolio.

MS-FAB: Mass spectroscopy-Fast Atom Bombardment (Espectroscopía de masas por bombardeo con átomos rápidos).

[N-metilpiperidinio]BF4: Tetrafluoroborato de N-Metilpiperidinio.

$\mathrm{Ntf}_{2}$ : Bis(trifluorometilsulfonil)imida.

PEG 4000: Polietilenglicol 4000.

POM: Polioxometalato.

ppm: Partes por millón.

q: Quintuplete.

RMN: Resonancia Magnética Nuclear.

RMN-MAS: Resonancia Magnética Nuclear- Giro del Ángulo Mágico.

RSC: Royal Society of Chemistry.

s: Singulete.

Salen: 2,2'-Etilenbis(nitrilometiliden)difenilo.

$\mathrm{scCO}_{2}$ : Dióxido de carbono supercrítico.

SAPOs: Silicoaluminofosfatos.

SEM: Scanning Electron Microscopy (Microscopía electrónica de barrido).

st: Strong (intensa).

STEM: Scanning Transmisión Electron Microscopy (Barrido de microscopía electrónica de transmisión).

t: Triplete. 
TEM: Transmission Electron Microscopy (Microscopía electrónica de transmisión).

TEOF: Trietilortoformiato.

TGA: Thermogravimetric Analysis (Análisis termogravimétrico).

TOF: Turnover Frequency (Frecuencia de transformación).

TON: Turnover Number (Número de transformaciones).

TSIL: Task Specific Ionic Liquid (Líquido iónico con tarea específica).

UE: Unión Europea.

US: United States (Estados Unidos).

USY: Ultra Stable Y zeolitas.

UV-VIS: Ultravioleta-Visible.

vst: Very Strong (muy intensa).

vwk: Very weak (muy débil).

WCED: World Commision for Enviromental Development (Comisión Mundial para el Desarrollo Sostenible).

wk: Weak (débil).

WHSV: Weight Hourly Space Velocity (Velocidad espacial en peso).

XANES: X-Ray absorption Near Edge Structur (Absorción de rayos $X$ en las cercanías de la estructura perimetral).

XEDS: X-Ray Energy Dispersive Spectroscopy (Espectroscopía de rayos- $X$ de energía dispersa).

ZSM-5: Zeolite Socony Mobil nº5. 

Anexo V: Cálculos

Los cálculos de la conversión, la selectividad y el rendimiento a un tiempo de reacción específico se llevaron a cabo según las definiciones clásicas:

$$
\begin{aligned}
& \left.\propto \quad \% \text { Conversión }(\mathrm{t})=\left[\mathrm{nR}_{\mathrm{R}}(0)-\mathrm{nR}_{\mathrm{R}}(\mathrm{t})\right) / \mathrm{nR}_{\mathrm{R}}(0)\right] \times 100 \\
& \propto \quad \% \text { SelectividadP }(\mathrm{t})=\left[\mathrm{nP}_{\mathrm{P}}(\mathrm{t}) /\left(\mathrm{n}_{\mathrm{R}}(0)-\mathrm{nR}_{\mathrm{R}}(\mathrm{t})\right)\right] \times 100 \\
& \propto \quad \% \text { Rendimiento }(\mathrm{t})=[\% \text { Conversión } \times \% \text { Selectividad }] \times 100
\end{aligned}
$$

donde nR representa el número de moles de reactivo limitante y np el número de moles de producto generado.

Los términos TON (Turnover number) y TOF (Turnover Frequency) provienen de la terminología empleada en enzimología y se utilizan para determinar la eficacia de un catalizador.

$$
\propto \quad \mathrm{TON}=\mathrm{nP} / \mathrm{nMet}
$$

Donde np continúa siendo el número de moles de producto obtenido y nMet representa el número de moles de metal, utilizados en la reacción y calculados a partir del contenido en metal del catalizador determinado por análisis químico, y la cantidad de catalizador introducida en el matraz de reacción. La determinación de los niveles de TOF para cada catalizador se realizó a partir de las medidas de velocidades iniciales de la reacción (moles de producto - $\left.\mathrm{mmols} \mathrm{Pd}^{-1} \cdot \mathrm{min}^{-1}\right)$, de acuerdo con la fórmula:

$$
\text { TOF }=\mathrm{r}(0) / \mathrm{n} \text { Met }
$$

así, $r(0)$ representa la velocidad inicial de reacción, calculada a partir de la pendiente de la representación conversión vs. tiempo, siempre y cuando que las conversiones obtenidas sean menores del $15 \%$. 



\section{RESUMEN}

La degradación ambiental se ha convertido en un importante problema al que deben enfrentarse la ciencia y la tecnología. Los temas tratados en este trabajo, pretenden aunar, con la introducción de los líquidos iónicos en distintos procesos, la preocupación por el medio ambiente y las inquietudes constantes del progreso.

Es por esto que lo largo de esta tesis se han desarrollado nuevos sistemas catalíticos basados en líquidos iónicos, que seguidamente se han aplicado a procesos químicos de interés:

- Se ha realizado un estudio de la transposición de Beckmann de oximas cíclicas para la obtención de los monómeros que posteriormente conformarán las fibras de nailon, empleando para ello líquidos iónicos como catalizadores y medios de reacción y estudiando mediante técnicas de resonancia magnética nuclear, el mecanismo que se lleva a cabo en este proceso.

- Por otra parte se ha preparado y caracterizado completamente un material híbrido orgánico-inorgánico-metal, mediante el intercambio parcial de los protones de un polioxometalato con la unidad catiónica de un líquido iónico y $\mathrm{Pd}^{2+}$. Este material, como catalizador heterogeneo permite llevar a cabo la reacción de Heck de acoplamiento C-C.

- Finalmente se han desarrollado organocatalizadores con características de líquido iónico, que poseen también bifuncionalidad ácido-base, con capacidad para emular la actividad de determinados sistemas enzimáticos. Estos nuevos catalizadores se han aplicado en reacciones de formación de enlaces C-C como Knoevenagel, Claisen-Schmidt, Adición de Michael y Henry. 


\section{RESUM}

La degradació ambiental s'ha convertit en un important problema a què $s^{\prime}$ han d'enfrontar la ciència i la tecnologia. Els temes tractats en aquest treball, pretenen unir, amb la introducció dels líquids iònics en diferents processos, la preocupació pel medi ambient i les inquietuds constants del progrés.

És per això que al llarg d'aquesta tesi s'han desenvolupat nous sistemes catalítics basats en líquids iònics, que tot seguit s'han aplicat a processos químics d'interès:

- S'ha realitzat un estudi de la transposició de Beckmann de oximes cícliques per a l'obtenció dels monòmers que posteriorment conformaran les fibres de niló, utilitzant líquids iònics com a catalitzadors i mitjans de reacció i estudiant mitjançant tècniques de ressonància magnètica nuclear, el mecanisme que es porta a terme en aquest procés.

- D'altra banda s'ha preparat i caracteritzat completament un material híbrid orgànic-inorgànic-metall, per mitjà del intercanvi parcial dels protons d'un polioxometalat amb la unitat catiònica d'un líquid iònic i $\mathrm{Pd}^{2+}$. Aquest material, com a catalitzador heterogeni permet dur a terme la reacció de Heck d'acoblament C-C.

- Finalment s'han desenvolupat organocatalizadors amb característiques de líquid iònic, que tenen també bifuncionalitat àcid-base, amb capacitat per a emular l'activitat de determinats sistemes enzimàtics. Aquests nous catalitzadors s'han aplicat en reaccions de formació d'enllaços C-C com Knoevenagel, ClaisenSchmidt, Addició de Michael i Henry. 


\section{ABSTRACT}

Environmental degradation has become an important issue to be faced by the science and technology. The topics discussed in this paper, aims to join, with the introduction of ionic liquids in various processes, concern for the environment and the constant concerns of progress.

That is why throughout this thesis we have developed new catalytic systems based on ionic liquids, which are then applied to chemical processes of interest:

- It has been studied the Beckmann rearrangement of oximes to obtain cyclic monomers which subsequently will form nylon fibers, employing ionic liquids as catalysts and reaction media and studing by nuclear magnetic resonance techniques the mechanism that takes place in this process.

- On the other hand has been prepared and fully characterized a hybrid organic-inorganic-metal material, through partial exchange of protons of polyoxometalates with cationic unit of an ionic liquid and $\mathrm{Pd}^{2+}$. This material generates nanoparticles which acts as heterogeneous catalyst and allows conducting the Heck coupling reaction of $\mathrm{C}-\mathrm{C}$.

- Finally new organocatalysts have been developed with characteristics of ionic liquid, which also have acid-base bifunctional activity and are able to emulate the activity of certain enzyme systems. These catalysts have been applied in reactions of C-C bonds formation as Knoevenagel, Claisen-Schmidt, Michael Adition and Henry. 


